\begin{abstract}
UNIVERSIDADE DE SÃO PAULO
ESCOLA DE ENGENHARIA DE SÃO CARLOS

PROGRAMA DE PÓS-GRADUAÇÃO EM CIÊNCIAS DA ENGENHARIA AMBIENTAL
\end{abstract}

FRANCIANE MENDONÇA DOS SANTOS

MODELAGEM CONCENTRADA E SEMI-DISTRIBUÍDA PARA SIMULAÇÃO DE VAZÃO, PRODUÇÃO DE SEDIMENTOS E DE CONTAMINANTES EM BACIAS HIDROGRÁFICAS DO INTERIOR DE SÃO PAULO 



\author{
UNIVERSIDADE DE SÃO PAULO \\ ESCOLA DE ENGENHARIA DE SÃO CARLOS \\ PROGRAMA DE PÓS-GRADUAÇÃO EM CIÊNCIAS DA ENGENHARIA AMBIENTAL
}

FRANCIANE MENDONÇA DOS SANTOS

\title{
MODELAGEM CONCENTRADA E SEMI-DISTRIBUÍDA PARA SIMULAÇÃO DE VAZÃO, PRODUÇÃO DE SEDIMENTOS E DE CONTAMINANTES EM BACIAS HIDROGRÁFICAS DO INTERIOR DE SÃO PAULO
}

(Versão Corrigida)

\begin{abstract}
Tese apresentada à Escola de Engenharia de São Carlos, da Universidade de São Paulo, como parte dos requisitos para obtenção do título de doutor em Ciências da Engenharia Ambiental.

Orientador (USP): Prof. Dr. Frederico Fábio Mauad

Coorientador (IST-Lisboa): Prof. Dr. Rodrigo de Almada Cardoso Proença de Oliveira
\end{abstract}


AUTORIZO A REPRODUÇÃO E DIVULGAÇÃO TOTAL OU PARCIAL DESTE TRABALHO, POR QUALQUER MEIO CONVENCIONAL OU ELETRÔNICO, PARA FINS DE ESTUDO E PESQUISA, DESDE QUE CITADA A FONTE.

Ficha catalográfica elaborada pela Biblioteca Prof. Dr. Sérgio Rodrigues Fontes da EESC/USP

S237m

Santos, Franciane Mendonça dos

Modelagem concentrada e semi-distribuída para simulação de vazão, produção de sedimentos e de contaminantes em bacias hidrográficas do interior de São Paulo / Franciane Mendonça dos Santos; orientador Frederico Fábio Mauad; coorientador Rodrigo de Almada Cardoso Proença de Oliveira. -- São Carlos, 2018.

Tese (Doutorado) - Programa de Pós-Graduação e Área de Concentração em Ciências da Engenharia ambiental -- Escola de Engenharia de São Carlos da Universidade de São Paulo, 2018.

1. SWAT. 2. SCS-CN. 3. Modelo hidrológico concentrado. 4. Modelo hidrológico seni-distribuído. 5. Vazão.

6. Produção de sedimento. 7. Qualidade da água. I. Titulo.

Elaborado por Elena Luzia Palloni - CRB 4464 


\section{FOLHA DE JULGAMENTO}

\section{Candidata: Engenheira FRANCIANE MENDONÇA DOS SANTOS.}

Título da tese: "Modelagem concentrada e semi-distribuída para simulação de vazão, produção de sedimentos e de contaminantes em bacias hidrográficas do interior de São Paulo".

Data da defesa: 11/09/2018.

\section{Comissão Julgadora:}

Prof. Associado Frederico Fabio Mauad (Orientador)

(Escola de Engenharia de São Carlos/EESC)

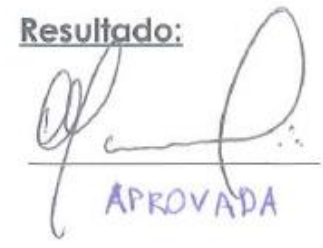

Prof. Dr. Rodrigo de Almada Cardoso Proença de Oliveira (Universidade de Lisboa)

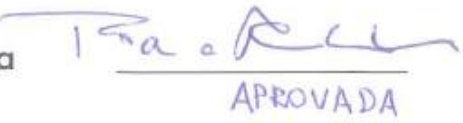

Prof. Dr. José Augusło de Lollo

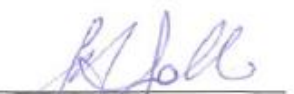

(Universidade Estadual Paulista "Júlio de Mesquita Filho"/UNESP - llha Solfeira) AP kOV A DA

Profa. Dra. Liliane Lazzari Albertin

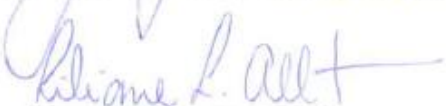

(Universidade Estadual Paulista "Júlio de Mesquita Filho"/UNESP - Itha Solteira)

APROV ADA

Coordenador do Programa de Pós-Graduação em Ciências da Engenharia Ambiental:

Prof. Associado Frederico Fabio Mavad

Presidente da Comissão de Pós-Graduação:

Prof. Associado Luís Fernando Costa Alberto 

Dedico este trabalho a Deus que me permitiu chegar até aqui e a minha família que acreditou comigo na concretização de mais um sonho. 



\section{AGRADECIMENTOS}

Agradeço a Deus, Nossa senhora Aparecida, Nossa Senhora de Fátima, São José e São Judas Tadeu. Me apego em todas as minhas orações, peço a intercessão, agradeço, divido minhas alegrias, minhas dificuldades e sempre sou atendida. Obrigada por sempre me guardarem, me protegerem e nunca me faltarem.

Agradeço a minha família, a minha mãe que eu amo tanto, um exemplo de mulher, uma nordestina cheia de força e de coragem, que sempre me incentivou a nunca desistir. Minha maior incentivadora, que me faz sempre ser o melhor que posso ser. Ao meu pai, meu muito obrigada por ser essa pessoa cheia de força, de sonhos, e de amor. Aos dois, obrigada por me fazerem ser quem sou hoje, com certeza essa conquista é de vocês.

A minha irmã, que privilégio ser irmã de uma pessoa tão maravilhosa, como ela mesmo disse, ela é a percursora de tudo isso, que veio primeiro, que deixou tudo preparado para minha chegada, que me esperou de bracinhos abertos para me abraçar, me cuidar, me amar, e dividir comigo os melhores momentos dessa vida. Obrigada por sonhar comigo, e realizar. Eu te amo. Vamos seguir realizando muitos sonhos.

Ao amor da minha vida, João Paulo. Obrigada ser esse homem parceiro, cuidadoso, amoroso que você é. Que sorte a minha ter você na minha vida. Que possamos realizar muitos sonhos juntos, minha vida ficou mais colorida quando você chegou.

Ao Prof. Fred, muito obrigada por ter acreditado no meu trabalho e me ajudado sempre ao longo dessa caminhada.

Ao Prof. Rodrigo por ter me recebido no IST, por ter dedicado seu tempo e energia para me orientar na elaboração dessa tese. Obrigada pela generosidade, pela confiança e por ter me permitido viver essa experiência incrível de morar em Portugal. Meu muito obrigada.

Ao Prof. Lollo, meu orientador de mestrado, uma pessoa cheia de luz e a Prof ${ }^{a}$ Liliane que participou da minha banca. Muito obrigada pela disponibilidade.

São tantos lugares que morei para chegar até o doutorado. Presidente Prudente, Ilha Solteira, São Carlos, Lisboa. São tantas pessoas especiais que Deus colocou no meu caminho, eu só tenho que agradecer.

As minhas amigas Natália e Karime, que de uma fila de matrícula e de uma casa caindo aos pedaços nasceu tanto amor e cumplicidade, com elas dividi o pão amassado com uma bolsa de 200 reais, e foram os anos de graduação mais incríveis da vida. A minha amiga Bianca, que em Ilha Solteira dividiu comigo sua família, para que os dias de mestrado longe da minha família fossem cheios de amor.

A Carlinha amiga que conheci na missa, em Presidente Prudente, e que me recebeu em São Carlos para o doutorado, com um sorriso largo e um quarto preparado para minha aventura.

A minha nordestina amada Schayanna, que pessoa incrível, que coração lindo. Muito obrigada por dividir tantos dias São Carlenses comigo. A amiga Melissa, que no final da sua Medicina, morou comigo e me ensinou um pouco de todo amor que tem por sua profissão.

A querida Juliana, essa amiga que o doutorado me deu, de um coração gigante cheio de amor que aceitou dividir comigo uma viagem incrível e dias que eu vou guardar para sempre na minha memória e no meu coração. Muito obrigada Ju. 
A Francisca, uma Portuguesa super especial, uma amiga que o intercâmbio me deu. Muito obrigada por me receber na sua casa e por fazer meus dias em Lisboa mais felizes.

A minha amiga Dudene e toda sua família pelo acolhimento em Lisboa e por me incentivar com sua força e história de vida. Muito obrigada.

As minhas biólogas preferidas, Mariana e Marina, pela amizade, pelo carinho, pelos ouvidos emprestados. Muito obrigada. Também a minha colombiana, Heidi, uma menina doce que eu tive o prazer de conhecer nessa pesquisa, muito obrigada.

Aos amigos que me acompanharam nesse doutorado e que dividiram comigo tantos momentos: Joyce, Dalva, Bruno, Jamil, Natália P., Rafael, Lis, Tainá e Renato, e ao Técnico do Laboratório Miro. Meu muito obrigada a todos.

Enfim agradeço ao CNPq pela bolsa de doutorado concedida, e ao Erasmus Smart2 pela bolsa de intercâmbio. 
"Naquele dia, ao anoitecer, Jesus disse aos seus discípulos: "Vamos para a outra margem".

Deixando a multidão, eles o levaram no barco, assim como estava.

Outros barcos também o acompanhavam.

Levantou-se um forte vendaval, e as ondas se lançavam sobre o barco, de forma que este ia se enchendo de água. Jesus estava na popa, dormindo sobre um travesseiro.

Os discípulos o acordaram e disseram-lhe: "Mestre, não te importas que estejamos perecendo?".

Ele se levantou e repreendeu o vento e o mar: "Silêncio! Cala-te!".

$\mathrm{O}$ vento parou, e fez-se completa calmaria.

Jesus disse-lhes então: "Por que sois tão medrosos? Ainda não tendes fé?".

Eles sentiram grande temor, e comentavam uns com os outros: mar?"

"Quem é este a quem obedecem até o vento e o

Marcos 4, Bíblia Sagrada. 



\title{
RESUMO
}

\author{
SANTOS, F.M. Modelagem concentrada e semi-distribuída para simulação de vazão, \\ produção de sedimentos e de contaminantes em bacias hidrográficas do interior de São \\ Paulo. 2018. 192 f. Tese (Doutorado) - Escola de Engenharia de São Carlos, Universidade \\ de São Paulo, São Carlos, 2018.
}

A escassez de dados hidrológicos no Brasil é um problema recorrente em muitas regiões, principalmente em se tratando de dados hidrométricos, produção de sedimentos e qualidade da água. A pesquisa por modelos de bacias hidrográficas tem aumentado nas últimas décadas, porém, a estimativa de dados hidrossedimentológicos a partir de modelos mais sofisticados demanda de grande número de variáveis, que devem ser ajustadas para cada sistema natural, o que dificulta a sua aplicação. $\mathrm{O}$ objetivo principal desta tese foi avaliar diferentes ferramentas de modelagem utilizadas para a estimativa da vazão, produção de sedimentos e qualidade da água e, em particular, comparar os resultados obtidos de um modelo hidrológico físico semi-distribuído, o Soil Water Assessment Tool (SWAT) com os resultados obtidos a partir de modelos hidrológicos concentrados, com base na metodologia do número da curva de escoamento do Soil Conservation Service (SCS-CN) e no modelo Generalized Watershed Loading Function (GWLF). Buscou-se avaliar e apresentar em quais condições o uso de cada modelo deve ser recomendado, ou seja, quando o esforço necessário para executar o modelo semi-distribuído leva a melhores resultados efetivos. Em relação à simulação da vazão, os resultados dos dois modelos foram altamente influenciados pelos dados de precipitação, indicando que existem, possivelmente, falhas ou erros de medição que poderiam ter influenciado negativamente os resultados. Portanto, foi proposto aplicar o modelo semi-distribuído com dados de precipitação interpolados (DPI) de alta resolução para verificar a eficiência de seus resultados em comparação com os resultados obtidos com a utilização dos dados de precipitação observados (DPO). Para simulação da produção de sedimentos, e das concentrações de nitrogênio e fósforo, o SWAT realiza uma simulação hidrológica mais detalhada, portanto, fornece resultados ligeiramente melhores para parâmetros de qualidade da água. $\mathrm{O}$ uso do modelo semi-distribuído também foi ampliado para simular uma bacia hidrográfica sob a influência do reservatório, a fim de verificar a potencialidade do modelo para esse propósito. Os modelos também foram aplicados para identificar quais os impactos potenciais das mudanças no uso do solo previstas e em andamento. Os cenários estudados foram: I cenário atual, II - cenário tendencial, com o aumento da mancha urbana e substituição do solo exposto e de parte da mata nativa por uso agrícola; III - cenário desejável, complementa o crescimento urbano tendencial com aumento de áreas de reflorestamento. As metodologias foram aplicadas em duas bacias hidrográficas localizadas no Sudeste do Brasil. A primeira é a bacia do rio Jacaré-Guaçu, incluída na Unidade de Gerenciamento de Recursos Hídricos 13 (UGRHI-13), a montante da confluência do rio das Cruzes, com uma área de $1934 \mathrm{~km}^{2}$. O segundo caso de estudo, é a bacia do rio Atibaia, inserida na UGRHI-5, tem uma área de $2817,88 \mathrm{~km}^{2}$ e abrange municípios dos estados de São Paulo e Minas Gerais. Como principal conclusão, o desempenho do modelo semi-distribuído para estimar a produção de sedimentos, e as concentrações de nitrogênio e fósforo foi ligeiramente melhor do que as simulações do modelo concentrado SCS-CN e GWLF, mas essa vantagem pode não compensar o esforço adicional de calibrá-lo e validá-lo.

Palavras-chave: SWAT. SCS-CN. GWLF. Modelo hidrológico concentrado. Modelo hidrológico semi-distribuído. Vazão. Produção de sedimentos. Qualidade da água. 


\begin{abstract}
SANTOS, F.M. Parsimonious and physically-based models to evaluate streamflow, soil loss and pollution in watersheds in the interior of São Paulo. 2018. $192 \mathrm{f}$. Tese (Doutorado) - Escola de Engenharia de São Carlos, Universidade de São Paulo, São Carlos, 2018.
\end{abstract}

The lack of hydrological data in Brazil is a recurrent problem in many regions, especially in hydrometric data, sediment yield and water quality. The research by simplified models has increased in the last decades, however, the estimation of hydrossedimentological data from these more sophisticated models demands many variables, which must be adjusted for each natural system, which makes it difficult to apply. At times it is necessary to respond quickly without much precision in the results, in these situations, simpler models with few parameters can be the solution. The objective of this research is to evaluate different modelling tools used estimate streamflow, sediments yield and nutrients loads values, and namely to compare the results obtained from a physically-based distributed hydrological model (SWAT) with the results from a lumped hydrological, the Soil Conservation Service (SCS-CN) and the Generalized Watershed Loading Function (GWLF) model. Both models use the curve number $(\mathrm{CN})$ concept, determined from land use, soil hydrologic group and antecedent soil moisture conditions and were run with a daily time step. We are particularly interested in understanding under which conditions the use of each model is to be recommended, namely when does the addition effort required to run the distributed model leads to effective better results. The input variables and parameters of the lumped model are assumed constant throughout the watershed, while the SWAT model performs the hydrological analysis at a small unit level, designated as hydrological response units (HRUs), and integrates the results at a sub-basin level. In relation to the flow simulation, the results of the two models were highly influenced by the rainfall data, indicating that, possibly, faults or measurement errors could have negatively influenced the results. Therefore, it was proposed to apply the distributed model with high-resolution grids of daily precipitation to verify the efficiency of its results when compared to rainfall data. For simulation of sediment, nitrogen and phosphorus, SWAT performs a more detailed simulation and thus provides slightly better results. The use of the SWAT was also extended to simulate the influence of reservoir, in order to verify the potentiality of the model, in relation to the simulation. The models also were used to identify which are potential impacts of the ongoing land use changes. The scenarios were: I - Current scenario, II trend scenario, with the increase of urban land and replacement of the exposed soil and part of the native forest by agricultural use; III - desirable scenario complements the trend urban growth with the replacement of exposed soil and part of the agricultural use by reforestation. The methodologies were applied on two watersheds located in the Southeast of Brazil. The first one is the Jacaré-Guaçu river basin, included in the Water Resources Management Unit 13 (UGRHI-13), upstream of Cruzes river confluence, with an area of $1934 \mathrm{~km}^{2}$. The second watershed is the Atibaia River Basin, a part of Water Resources Management Unit 5 (UGRHI-5). It has an area of $2817.88 \mathrm{~km}^{2}$ and covers municipalities of the states of São Paulo and Minas Gerais.

Key-words: SWAT. GWLF. Parsimonious lumped hydrological model. Distributed hydrological model. 


\section{LISTA DE FIGURAS}

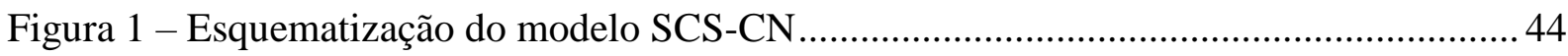

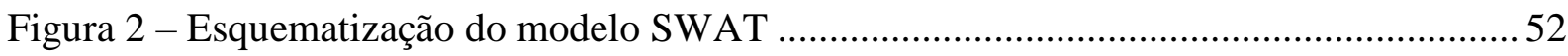

Figura 3 - Efeito combinado do grau de declive e do comprimento da encosta nas perdas de

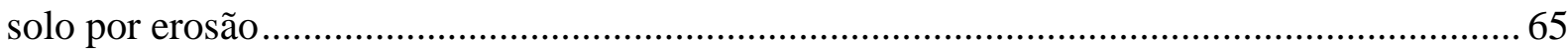

Figura 4 - Representação do ciclo do nitrogênio .............................................................. 77

Figura 5 - Representação do particionamento do nitrogênio pelo modelo SWAT.................. 77

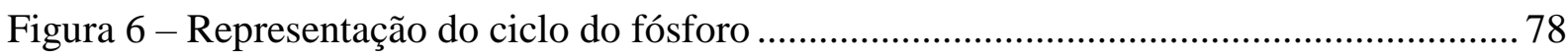

Figura 7 - Representação do particionamento do fósforo pelo modelo SWAT....................... 78

Figura 8 - Localização da bacia hidrográfica do rio Jacaré-Guaçu ....................................... 95

Figura 9 - Mapa altimétrico da bacia hidrográfica do rio Jacaré-Guaçu ................................ 96

Figura 10 - Localização das estações pluviométricas, fluviométricas e de qualidade da água

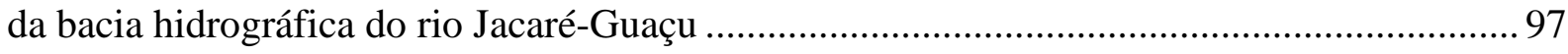

Figura 11 - Localização dos DPI para bacia hidrográfica do rio Jacaré-Guaçu ...................... 97

Figura 12 - Precipitações e temperaturas médias da bacia hidrográfica do rio Jacaré-Guaçu. 98

Figura 13 - Mapa de Isoietas $(\mathrm{mm})$ da bacia do rio Jacaré-Guaçu ........................................ 98

Figura 14 - Mapa de solos da bacia hidrográfica do rio Jacaré-Guaçu ................................. 100

Figura 15 - Mapa de uso e ocupação do solo da bacia hidrográfica do rio Jacaré-Guaçu ..... 101

Figura 16 - Localização da bacia hidrográfica do rio Atibaia ............................................... 102

Figura 17 - Mapa altimétrico da bacia hidrográfica do rio Atibaia ....................................... 103

Figura 18 - Localização das estações pluviométricas, fluviométricas e de qualidade da água

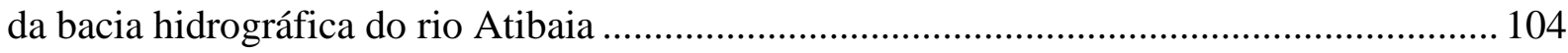

Figura 19 - Localização dos DPI para bacia hidrográfica do rio Atibaia ............................. 104

Figura 20 - Precipitações e temperaturas médias da bacia hidrográfica do rio Atibaia......... 105

Figura 21 - Mapa de Isoietas $(\mathrm{mm})$ da bacia hidrográfica do rio Atibaia ............................... 105

Figura 22 - Mapa de solos da bacia hidrográfica do rio Atibaia............................................ 106

Figura 23 - Mapa de uso e ocupação do solo da bacia hidrográfica do rio Atibaia ................ 107

Figura 24 - Comparação da simulação da vazão diária para estação 62760005 da hidrográfica

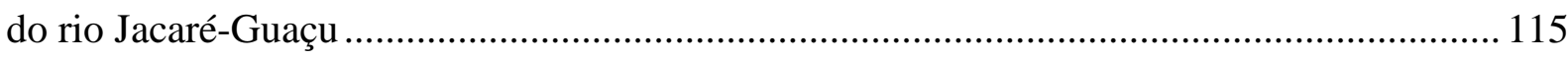

Figura 25 - Comparação da simulação da vazão mensal para estação 62760005 da

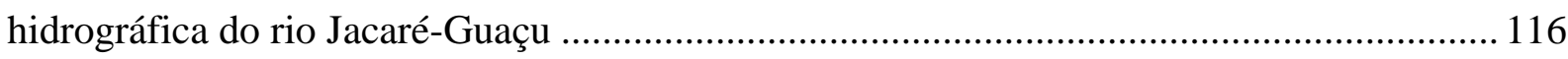
Figura 26 - Comparação da simulação da vazão diária para estação 62767500 da hidrográfica do rio Jacaré-Guaçu 
Figura 27 - Comparação da simulação da vazão mensal para estação 62767500 da hidrográfica do rio Jacaré-Guaçu

Figura 28 - Comparação da simulação da vazão diária para estação 62772500 da hidrográfica do rio Jacaré-Guaçu

Figura 29 - Comparação da simulação da vazão mensal para estação 62772500 da hidrográfica do rio Jacaré-Guaçu

Figura 30 - Comparação da simulação da vazão diária para estação 3006 da hidrográfica do rio Atibaia

Figura 31 - Comparação da simulação da vazão mensal para estação 3006 da hidrográfica do rio Atibaia

Figura 32 - Comparação da simulação da vazão diária para estação 3007 da hidrográfica do rio Atibaia

Figura 33 - Comparação da simulação da vazão mensal para estação 3007 da hidrográfica do rio Atibaia

Figura 34 - Comparação da simulação da vazão diária para estação 3003 da hidrográfica do rio Atibaia

Figura 35 - Comparação da simulação da vazão mensal para estação 3003 da hidrográfica do rio Atibaia.

Figura 36 - Comparação da simulação da vazão diária para estação 4009 da hidrográfica do rio Atibaia

Figura 37 - Comparação da simulação da vazão mensal para estação 4009 da hidrográfica do rio Atibaia

Figura 38 - Gráfico de dispersão dos dados diários e mensais simulados pelos modelos para estação 62760005 da Bacia hidrográfica do rio Jacaré-Guaçu

Figura 39 - Gráfico de dispersão dos dados diários e mensais simulados pelos modelos para estação 62767500 da bacia hidrográfica do rio Jacaré-Guaçu

Figura 40 - Gráfico de dispersão dos dados diários e mensais simulados pelos modelos para estação 62772500 da bacia hidrográfica do rio Jacaré-Guaçu

Figura 41 - Gráfico de dispersão dos dados diários e mensais simulados pelos modelos para estação

Figura 42 - Gráfico de dispersão dos dados diários e mensais simulados pelos modelos para estação 3007 da bacia hidrográfica do rio Atibaia

Figura 43 - Gráfico de dispersão dos dados diários e mensais simulados pelos modelos para estação 
Figura 44 - Gráfico de dispersão dos dados diários e mensais simulados pelos modelos para estação 4009 da bacia hidrográfica do rio Atibaia

Figura 45 - Desempenho dos modelos para estimativa produção de sedimentos para estação 62776400 da bacia hidrográfica do rio Jacaré-Guaçu .....

Figura 46 - Desempenho dos modelos para estimativa produção de sedimentos para estação 2605 da bacia hidrográfica do rio Atibaia

Figura 47 - Desempenho dos modelos para estimativa produção de sedimentos para estação 62691200 da bacia hidrográfica do rio Atibaia

Figura 48 - Desempenho dos modelos para estimativa da carga de nitrogênio para estação 62776400 da bacia hidrográfica do rio Jacaré-Guaçu

Figura 49 - Desempenho dos modelos para estimativa da carga de nitrogênio para estação 129 Figura 50 - Desempenho dos modelos para estimativa da carga de nitrogênio para estação 62691200 da bacia hidrográfica do rio Atibaia

Figura 51 - Desempenho dos modelos para estimativa da carga de fósforo para estação 62776400 da bacia hidrográfica do rio Jacaré-Guaçu

Figura 52 - Desempenho dos modelos para estimativa da carga de fósforo para estação 2605 da bacia hidrográfica do rio Atibaia

Figura 53 - Desempenho dos modelos para estimativa da carga de fósforo para estação 62691200 da bacia hidrográfica do rio Atibaia

Figura 54 - Comparação da vazão diário e mensal observada e simulada para a estação 62693100 da bacia hidrográfica do rio Atibaia

Figura 55 - Simulação da produção de sedimentos e cargas de nitrogênio e fósforo para a estação 62693100 da bacia hidrográfica do rio Atibaia

Figura 56 - Relação entre dados observados a jusante e a montante e simulados a jusante e a montante 138

Figura 57 - Relação entre dados simulados a jusante e a montante para todo o período de simulação (2009-2016)

Figura 58 - Gráficos de dispersão dos dados de precipitação observados e interpolados para a bacia hidrográfica do rio Jacaré-Guaçu .

Figura 59 - Gráficos de dispersão dos dados de precipitação observados e interpolados para a bacia hidrográfica do rio Atibaia.

Figura 60 - Comparação da simulação da vazão diária e mensal para estação 62760005 da bacia hidrográfica do rio Jacaré-Guaçu ..... 
Figura 61 - Comparação da simulação da vazão diária e mensal para estação 62767500 da bacia hidrográfica do rio Jacaré-Guaçu ....

Figura 62 - Comparação da simulação da vazão diária e mensal para estação 62772500 da bacia hidrográfica do rio Jacaré-Guaçu .....

Figura 63 - Comparação da simulação da vazão diária e mensal para estação 3006 da bacia hidrográfica do rio Atibaia

Figura 64 - Comparação da simulação da vazão diária e mensal para estação 3007 da bacia hidrográfica do rio Atibaia

Figura 65 - Comparação da simulação da vazão diária e mensal para estação 3003 da bacia hidrográfica do rio Atibaia

Figura 66 - Comparação da simulação da vazão diária e mensal para estação 4009 da bacia hidrográfica do rio Atibaia 146

Figura 67 - Cenários para a bacia hidrográfica do rio Jacaré-Guaçu

Figura 68 - Cenários para a bacia hidrográfica do rio Atibaia. 150

Figura 69 - Simulação dos cenários de vazão pelos modelos SWAT e SCS-CN para cada subbacia 62760005 da bacia hidrográfica do rio Jacaré-Guaçu.....

Figura 70 - Simulação dos cenários de vazão pelos modelos SWAT e SCS-CN para cada subbacia 62767500 da bacia hidrográfica do rio Jacaré-Guaçu. 155

Figura 71 - Simulação dos cenários de vazão pelos modelos SWAT e SCS-CN para cada subbacia 62772500 da bacia hidrográfica do rio Jacaré-Guaçu 156

Figura 72 - Simulação dos cenários de vazão pelos modelos SWAT e SCS-CN para sub-bacia 3006 da bacia hidrográfica do rio Atibaia 156 Figura 73 - Simulação dos cenários de vazão pelos modelos SWAT e SCS-CN para sub-bacia 3007 da bacia hidrográfica do rio Atibaia 157

Figura 74 - Simulação dos cenários de vazão pelos modelos SWAT e SCS-CN para sub-bacia 3003 da bacia hidrográfica do rio Atibaia

Figura 75 - Simulação dos cenários de vazão pelos modelos SWAT e SCS-CN para sub-bacia 4009 da bacia hidrográfica do rio Atibaia 158 Figura 76 - Porcentagem de variação da média mensal da vazão em relação ao cenário atual, calculada pelos modelos SWAT e SCS-CN para a sub-bacia 62760005 da bacia hidrográfica do rio Jacaré-Guaçu

Figura 77 - Porcentagem de variação da média mensal da vazão em relação ao cenário atual, calculada pelos modelos SWAT e SCS-CN para a sub-bacia 62767500 da bacia hidrográfica do rio Jacaré-Guaçu 
Figura 78 - Porcentagem de variação da média mensal da vazão em relação ao cenário atual, calculada pelos modelos SWAT e SCS-CN para a sub-bacia 62772500 da bacia hidrográfica do rio Jacaré-Guaçu

Figura 79 - Porcentagem de variação da média mensal da vazão em relação ao cenário atual, calculada pelos modelos SWAT e SCS-CN para a sub-bacia 3006 da bacia hidrográfica do rio Atibaia 160

Figura 80 - Porcentagem de variação da média mensal da vazão em relação ao cenário atual, calculada pelos modelos SWAT e SCS-CN para a sub-bacia 3007 da bacia hidrográfica do rio Atibaia

Figura 81 - Porcentagem de variação da média mensal da vazão em relação ao cenário atual, calculada pelos modelos SWAT e SCS-CN para a sub-bacia 3003 da bacia hidrográfica do rio Atibaia 161

Figura 82 - Porcentagem de variação da média mensal da vazão em relação ao cenário atual, calculada pelos modelos SWAT e SCS-CN para a sub-bacia 4009 da bacia hidrográfica do rio Atibaia

Figura 83 - Gráficos da curva de duração média (curva de permanência) da vazão diária, calculada pelos modelos SWAT e SCS-CN para as sub-bacias da bacia hidrográfica do rio Jacaré-Guaçu 164

Figura 84 - Gráficos da curva de duração média (curva de permanência) da vazão diária, calculada pelos modelos SWAT e SCS-CN para as sub-bacias da bacia hidrográfica do rio Atibaia

Figura 85 - Simulação da produção de sedimentos pelos modelos SWAT e GWLF para cada cenário da bacia hidrográfica do rio Jacaré-Guaçu

Figura 86 - Simulação da produção de sedimentos pelos modelos SWAT e GWLF para cada cenário da bacia hidrográfica do rio Atibaia 167 Figura 87 - Porcentagem de variação da média mensal da produção de sedimentos em relação ao cenário atual, calculada pelos modelos SWAT e GWLF para a bacia hidrográfica do rio Jacaré-Guaçu

Figura 88 - Porcentagem de variação da média mensal da produção de sedimentos em relação ao cenário atual, calculada pelos modelos SWAT e GWLF para a bacia hidrográfica do rio Atibaia 168

Figura 89 - Simulação da carga de nitrogênio pelos modelos SWAT e GWLF para cada cenário da bacia hidrográfica rio Jacaré-Guaçu 
Figura 90 - Simulação da carga de nitrogênio pelos modelos SWAT e GWLF para cada cenário da bacia hidrográfica rio Atibaia

Figura 91 - Simulação da carga de fósforo pelos modelos SWAT e GWLF para cada cenário da bacia hidrográfica rio Jacaré-Guaçu

Figura 92 - Simulação da carga de fósforo pelos modelos SWAT e GWLF para cada cenário171 Figura 93 - Porcentagem de variação da média mensal da carga de nitrogênio em relação ao cenário atual, calculada pelos modelos SWAT e GWLF para a bacia hidrográfica do rio Jacaré-Guaçu

Figura 94 - Porcentagem de variação da média mensal da carga de nitrogênio em relação ao cenário atual, calculada pelos modelos SWAT e GWLF para a bacia hidrográfica do rio Atibaia 172

Figura 95 - Porcentagem de variação da média mensal da carga de fósforo em relação ao cenário atual, calculada pelos modelos SWAT e GWLF para a bacia hidrográfica do rio Jacaré-Guaçu 173

Figura 96 - Porcentagem de variação da média mensal da carga de fósforo em relação ao cenário atual, calculada pelos modelos SWAT e GWLF para a bacia hidrográfica do rio Atibaia 


\section{LISTA DE TABELAS}

Tabela 1 - Limites das condições de humidade antecedentes para o período de dormência e o período de crescimento das plantas 45

Tabela 2 - Classificação da erosividade das chuvas de acordo com o fator R.

Tabela 3 - Equações desenvolvidas para determinar os valores de erosividade para áreas do território brasileiro e seus respectivos autores

Tabela 4 - Código de permeabilidade das classes texturais dos horizontes de solo 62

Tabela 5 - Valores do fator erodibilidade (K)

Tabela 6 - Valores do fator $\mathrm{C}$ reportados para diferentes de culturas.

Tabela 7 - Valores do fator P referentes a diferentes práticas conservacionistas

Tabela 8 - Fator P em função da declividade. 68

Tabela 9 - Contaminantes dissolvidos em áreas rurais 75

Tabela 10 - Parâmetros dos solos requeridos pelo SWAT 93

Tabela 11 - Dados relativos ao reservatório de Salto Grande 94

Tabela 12 - Valores originais e calibrados dos parâmetros do modelo SWAT

Tabela 13 - Valores originais e calibrados dos parâmetros dos modelos SCS-CN e GWLF 112 Tabela 14 - Desempenho dos modelos SWAT e SCS-CN em reproduzir as vazões diárias e mensais

Tabela 15 - Desempenho dos modelos SWAT e GWLF na reprodução da qualidade da água131 Tabela 16 - Valores originais e calibrados dos parâmetros do modelo SWAT para simular a vazão do reservatório, a produção de sedimentos, e a concentração dos contaminantes

Tabela 17 - Valores do indicador de desempenho do modelo para a estação 62693100....... 135 Tabela 18 - Valores do indicador de desempenho do modelo para simulação da concentração dos contaminantes 136

Tabela 19 - Parâmetros do modelo SWAT calibrados com os DPI 142 Tabela 20 - Desempenho do modelo SWAT em reproduzir as vazões diárias e mensais a partir dos DPI

Tabela 21 - Classes de uso e ocupação do solo e respectivas áreas para cada cenário da bacia hidrográfica do rio Jacaré-Guaçu

Tabela 22 - Classes de uso e ocupação do solo e respectivas áreas para cada cenário da bacia hidrográfica do rio Atibaia

Tabela 23 - Valores de CN atribuídos para cada cenário 152

Tabela 24 - Número de HRU determinadas para cada cenário. 
Tabela 24 - Gráfico de variação da média diária da vazão para os cenários II e III. 163

Tabela 26 - Valores médios diários das variáveis hidrológicas geradas pelo modelo SWAT para as bacias hidrográficas dos casos de estudo. 


\section{LISTA DE QUADROS}

Quadro 1 - Trabalhos desenvolvidos a partir do modelo SWAT e finalidades das pesquisas. 42

Quadro 2 - Estimativa dos valores de $\mathrm{CN}$ para áreas rurais 48

Quadro 3 - Estimativa dos valores de CN para bacias urbanas e suburbanas ........................ 49

Quadro 4 - Grupos hidrológicos de solo - tipos de solo e condições de uso............................ 49

Quadro 5 - Analogia entre o uso do solo na bacia e o banco de dados do SWAT .................. 93

Quadro 6 - Tipos de solo e suas classificações .................................................................... 99 



\section{SUMÁRIO}

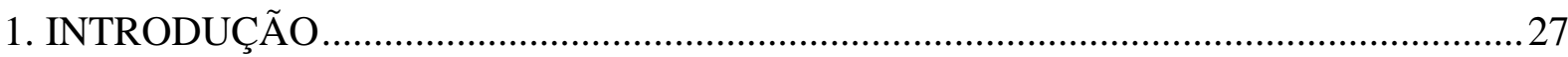

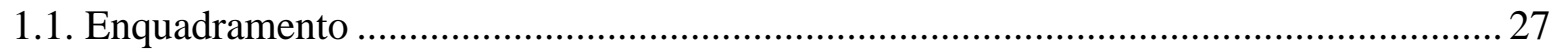

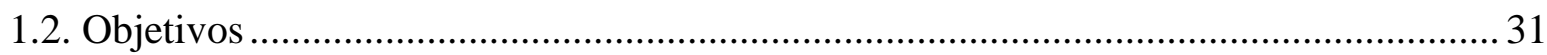

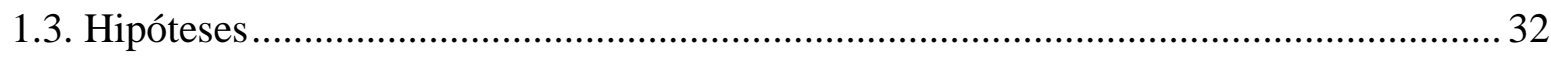

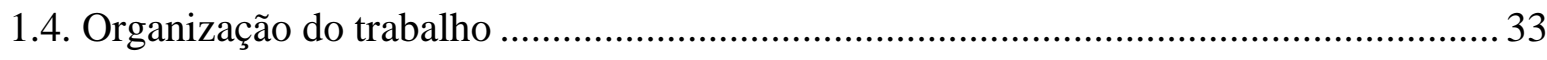

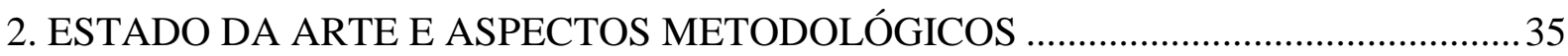

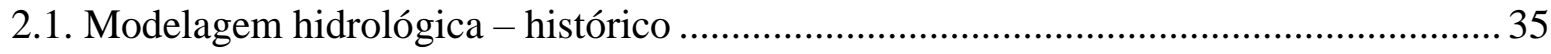

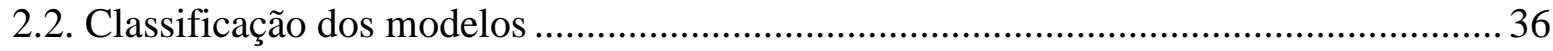

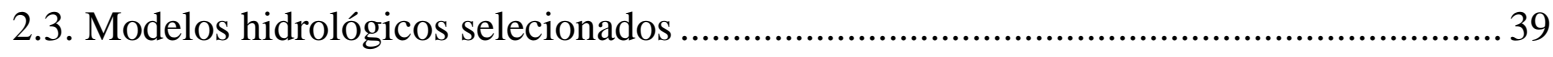

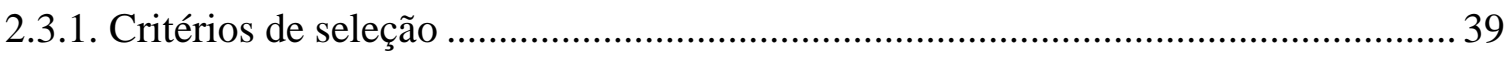

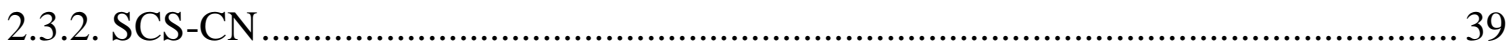

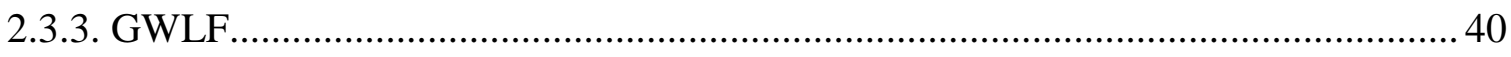

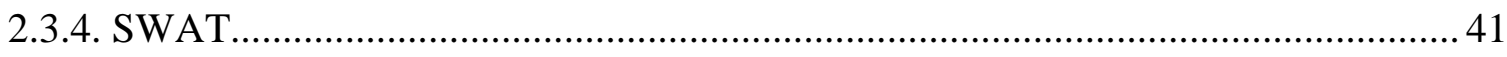

2.4. Transformação de precipitação em escoamento ............................................................ 43

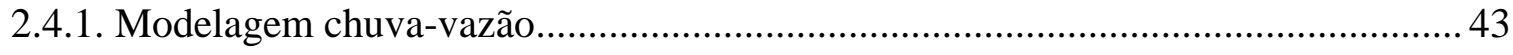

2.4.2. SCS-CN

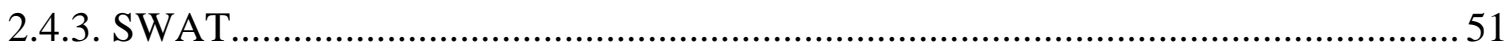

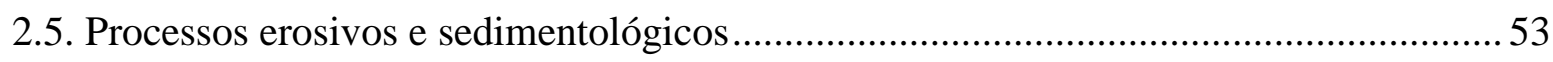

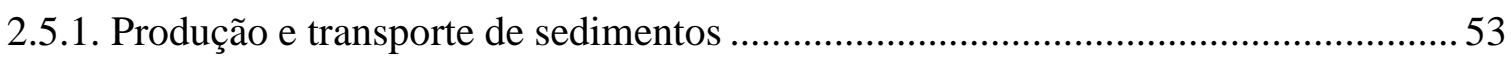

2.5.3. Equação Universal de Perda de Solos - EUPS ..................................................... 56

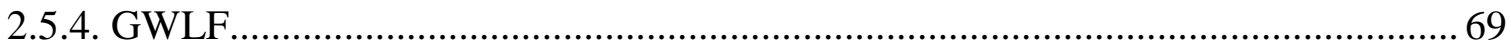

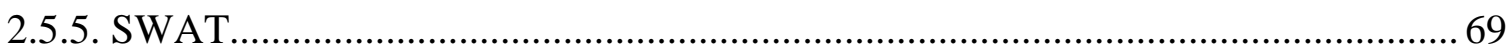

2.6. Transporte e transformação de contaminantes......................................................... 71

2.6.1. Qualidade da água em bacias hidrográficas ........................................................ 71

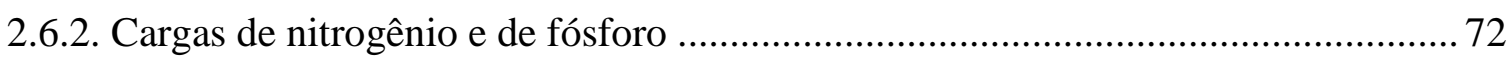

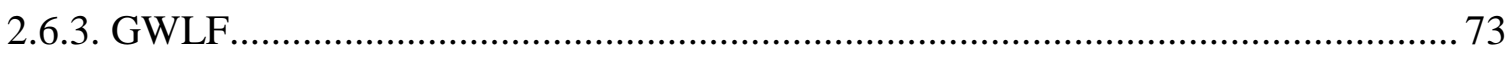

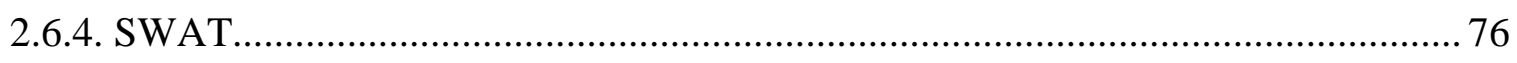

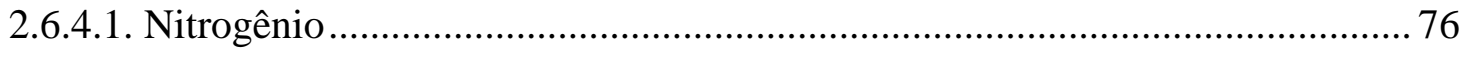

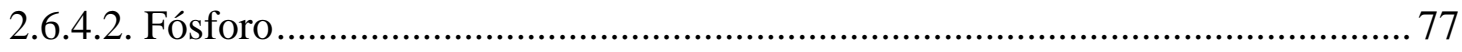

2.7. Propagação de sedimentos e contaminantes por reservatórios …................................... 79

2.7.1. Simulação hidrológica de reservatórios ................................................................ 79

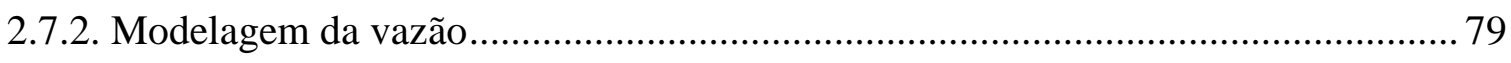

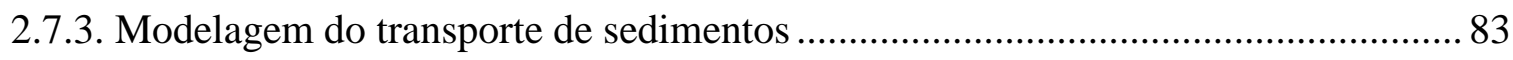


2.7.4. Modelagem da concentração de contaminantes .84

2.8. Mudanças no uso do solo e reflexos nos recursos hídricos ......................................... 86

2.8.1. A importância da modelagem matemática ........................................................... 86

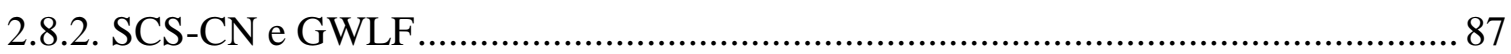

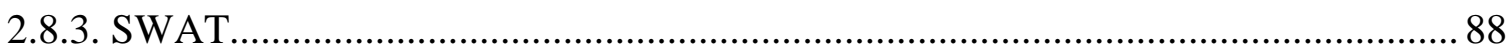

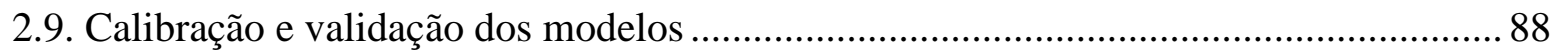

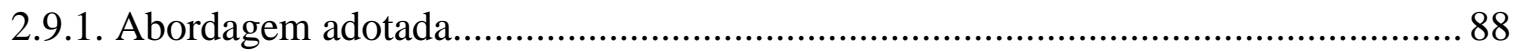

2.9.2. Indicadores de avaliação de desempenho dos modelos ....................................... 90

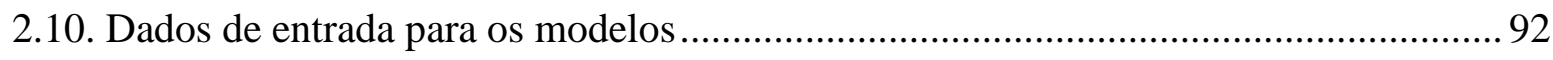

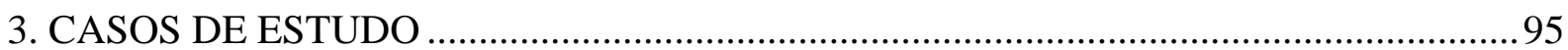

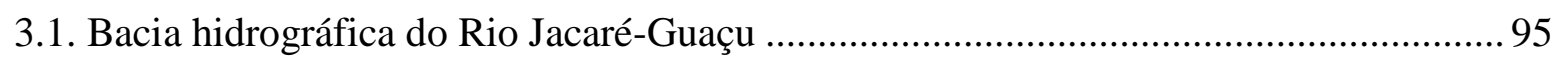

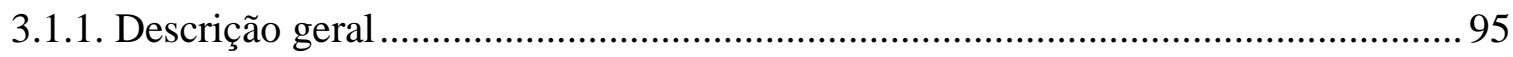

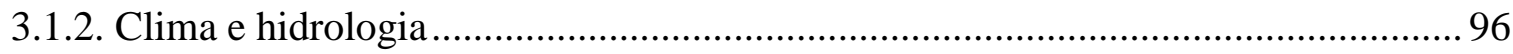

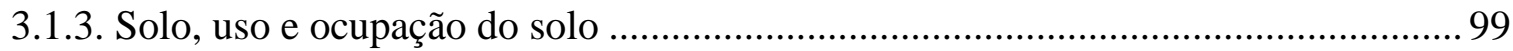

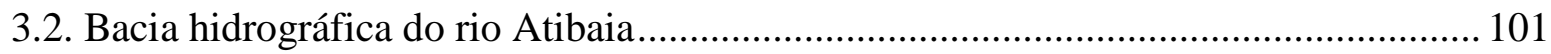

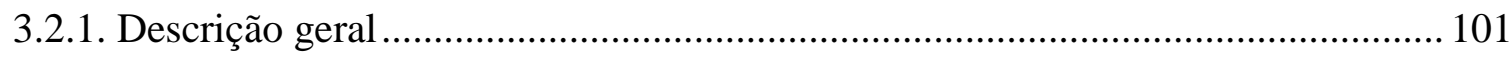

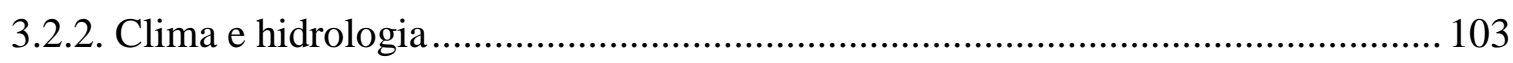

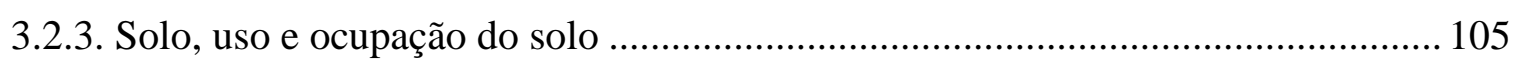

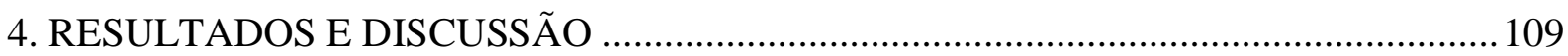

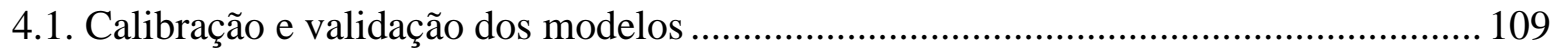

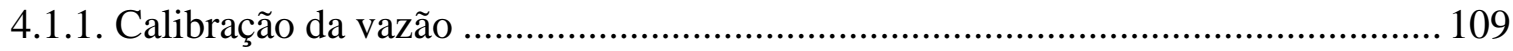

4.1.2. Calibração da produção de sedimentos ................................................................... 113

4.1.3. Calibração da concentração de contaminantes.................................................... 114

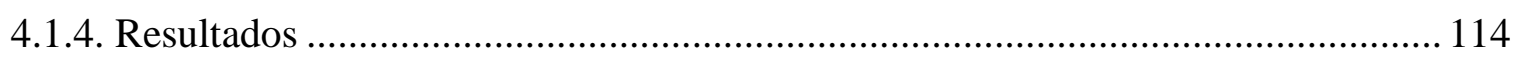

4.2. Simulação hidrológica sob influência de um reservatório - Modelagem SWAT ........ 133

4.3. Influência da descrição da precipitação no desempenho dos modelos ........................ 140

4.4. Avaliação de cenários de uso e de ocupação de solo .................................................... 148

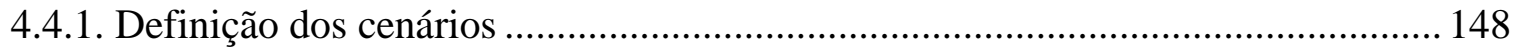

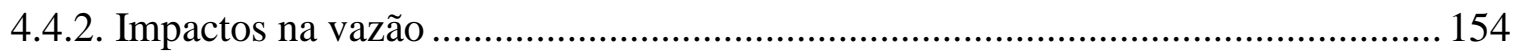

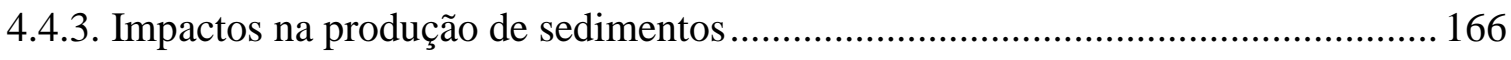

4.4.4. Impactos na concentração de contaminantes ...................................................... 169

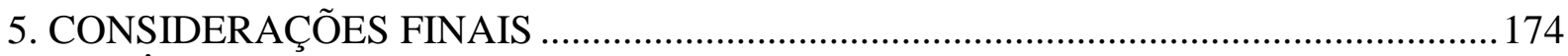

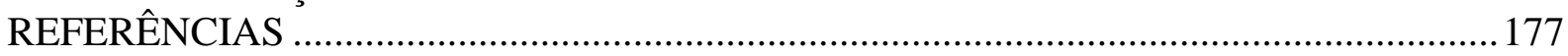




\section{INTRODUÇÃO}

\subsection{Enquadramento}

Compreender e avaliar os processos naturais que ocorrem em uma bacia hidrográfica são desafios contínuos para cientistas e engenheiros que procuram soluções para problemas detectados. Essa procura é muitas vezes condicionada com importantes lacunas de dados em resultado de redes de monitoramento ${ }^{1}$ incipientes ou mesmo inexistentes. Devido ao seu custo, os esforços de monitoramento de bacias hidrográficas são difíceis de manter de forma contínua e por um prazo longo, especialmente aqueles em que é difícil automatizar a medição, como é o caso da produção e transporte de sedimentos e alguns parâmetros da qualidade de água.

A abrangência espacial das redes de monitoramento não é uniforme e existem áreas que não são objeto de monitoramento. Países em desenvolvimento, como o Brasil, têm projetos e programas focados nas regiões mais densamente povoadas ou próximas ou nos locais de captação de água para abastecimento de áreas urbanas com grande densidade populacional.

No Brasil, a Agência Nacional de Águas (ANA) mantém a rede hidrometeorológica nacional, com mais de 4 mil estações, que monitoram o volume de chuvas, o nível e a vazão dos rios, a quantidade de sedimentos, a evaporação e a qualidade das águas.

No que respeita à qualidade de água, a ANA lançou em 2013 a RNQA (Rede Nacional de Monitoramento de Qualidade da Água), numa parceria estratégica com os operadores das redes estaduais de monitoramento. Apesar deste avanço, apenas 17 das 27 unidades de federação possuem redes de monitoramento de qualidade das águas. Em nível estadual, constam 2.400 pontos de monitoramento da qualidade da água, o que representa uma densidade de 0,26 ponto/1.000 $\mathrm{km}^{2}$ para o país. É considerada uma densidade baixa para uma rede nacional, quando comparada com as de outros países que possuem densidades maiores, como a Espanha $\left(2,55\right.$ pontos $\left./ 1.000 \mathrm{~km}^{2}\right)$, França $(1,96$ ponto/1.000 km²) e Canadá $(0,8$ ponto/1.000 km²) (ANA, 2015). Ainda de acordo com ANA (2015), existem 1.340 pontos em todo o país, nos quais são feitas análises de apenas quatro parâmetros básicos ( $\mathrm{pH}$, oxigênio dissolvido, condutividade e temperatura). Destas redes estaduais, somente oito apresentam

\footnotetext{
${ }^{1}$ Monitorização em português europeu.
} 
dados de monitoramento suficientes para a análise de tendência do Índice de Qualidade da Água (IQA), o qual determina a qualidade da água nos seus cursos naturais (ANA, 2013).

O uso de modelos matemáticos para simular processos hidrológicos, incluindo a qualidade da água, é uma solução possível para extrapolar conclusões a partir dos dados existentes e superar os problemas decorrentes da monitorização insuficiente.

Como alternativa aos modelos hidrológicos, muitos autores propuseram técnicas empíricas para modelar o processo precipitação-escoamento, como redes neurais ${ }^{2}$ artificiais e programação genética, entre outras (CHAU; WU, 2010; CHEN et al., 2017; KISI; OZKAN; AKAY, 2012). Estas técnicas estabelecem relações entre os dados de entrada e de saída do problema, sem procurar explicar os fenómenos que conduzem a essa transformação. Embora úteis em muitos casos, a informação recolhida pela sua aplicação é menor, quando comparada com os modelos de base conceitual ou física. Por essa razão, a presente investigação foca-se nos modelos hidrológicos de base conceitual ou física.

Historicamente, diferentes tipos de modelos hidrológicos foram aplicados separadamente para estimar a vazão, determinar as cargas de sedimentos e derivar concentrações de poluentes em córregos e outros corpos d'água. Os modelos de bacia hidrográfica incluem esses componentes de modelagem ${ }^{3}$ em um único código de computador e são capazes de calcular a vazão ${ }^{4}$ e as suas cargas de sedimentos e poluentes associadas, a partir de dados meteorológicos e dados de uso e ocupação do solo. A capacidade de simulação integrada de vários tipos de processos popularizou os modelos de bacia hidrográfica.

As entidades responsáveis pela gestão da água podem utilizar os modelos de bacias hidrográficas para avaliar os impactos de alterações da ocupação e uso do solo e das práticas de conservação do solo na vazão e na qualidade da água. Estes modelos podem ainda servir para estimar os impactos das alterações climáticas nos processos hidrológicos que ocorrem numa bacia hidrográfica.

No Brasil, as mudanças no uso e ocupação do solo, o desmatamento, as emissões de gases de efeito estufa e as mudanças climáticas estão intimamente interligadas. Estudos recentes mostram que essa relação vem mudando desde meados da década de 2000, com o crescimento da agricultura brasileira (LAPOLA et al., 2014). Mudanças no regime

\footnotetext{
${ }^{2}$ Neuronais em português europeu.

${ }^{3}$ Modelação em português europeu.

${ }^{4}$ Escoamento em português europeu.
} 
hidrológico e na qualidade da água decorrentes da expansão da cana-de-açúcar e cultivo da soja e a substituição da floresta por áreas de pastagem têm sido objeto de estudo de várias pesquisas (BLAINSKI et al., 2011, DEMANBORO; LAURENTIS; BETTINE, 2013, RODRIGUES et al., 2015).

A capacidade de previsão de um modelo matemático depende da sua estrutura, da disponibilidade e qualidade dos dados de entrada, bem como dos valores atribuídos aos parâmetros do modelo e que têm de ser estimados.

Os modelos distribuídos de bacias hidrográfica descrevem os processos hidrológicos que ocorrem na bacia com equações de base física e têm o potencial de reproduzir os fluxos de água e de contaminantes que variam no espaço-tempo para diferentes condições climáticas e ambientes hidrológicos. Este potencial tem um forte apelo para os gestores de recursos hídricos que precisam antever as condições futuras e tomar decisões para diferentes cenários.

Inicialmente, a utilização de modelos distribuídos era trabalhosa e morosa, mas o aumento do poder computacional e o advento dos sistemas de informação geográfica facilitaram o uso desses modelos e permitiram o recurso a modelos cada vez mais complexos. No entanto, esses modelos complexos de bacias hidrográficas requerem um grande conjunto de dados e parâmetros para caracterizar a bacia hidrográfica e seus processos hidrológicos, o que torna a coleta de dados e a calibração dos modelos um procedimento complicado, propenso a falhas ou até erros, quando realizado por usuários não experientes (FATICHI et al., 2016; GUPTA; WAGENER; LIU, 2008).

Vários autores questionaram essa abordagem e mostraram que modelos mais simples podem explicar grande parte da variância do escoamento e são quase tão precisos quanto os modelos mais complexos. Acresce que modelos simples e complexos têm ambos um desempenho fraco em determinados casos (AJAMI et al., 2004; MICHAUD; SOROOSHIAN, 1994; NAEF, 1981).

$\mathrm{Na}$ escolha de um modelo para um caso específico, a decisão é condicionada pela disponibilidade de dados e pela capacidade do modelo de simular o problema em análise. Essa decisão, dever ainda orientar-se pelo princípio de Ochham, do século XIII, que afirma que qualquer complexidade desnecessária deve ser evitada (YOUNG; PARKINSON; LIES, 1996).

Fatichi et al. (2016) discutem a necessidade de equilibrar parcimônia e complexidade ao selecionar um modelo hidrológico. Gupta; Wagener; Liu (2008) apontaram que a calibração e validação de modelos complexos de bacias com muitos parâmetros requer um 
conjunto de dados onde uma quantidade suficiente de informações pode ser recuperada para identificar os valores apropriados a serem atribuídos a cada parâmetro do modelo.

Neste contexto, esta tese tem como objetivo principal comparar os resultados de dois tipos de modelo de bacia hidrográfica, ambos conceituais ${ }^{5}$ ou fisicamente baseados. Concentramo-nos em modelos hidrológicos conceituais e baseados fisicamente porque estas ferramentas fornecem uma caracterização completa dos principais fluxos de água que ocorrem na bacia e de outros processos hidrológicos associados, como a produção e o transporte de sedimentos e de contaminantes (os contaminantes considerados nesta pesquisa são o nitrogênio ${ }^{6}$ e o fósforo).

Comparam-se os resultados de um modelo semi-distribuído, o Soil Water Assessment Tool (SWAT) (ARNOLD et al., 1998; ARNOLD; FOHRER, 2005) com os resultados obtidos a partir de modelos concentrados ${ }^{7}$, nomeadamente os baseados na metodologia do Soil Conservation Service (SCS-CN), como é o caso do modelo Generalized Watershed Loading Function (GWLF) (HAITH; SHOEMAKER, 1987). O SWAT possui mais de 2100 referências em revistas científicas (FRANCESCONI et al., 2016) e nos últimos tempos, tornou-se muito popular devido às suas capacidades de simulação, grande comunidade de usuários e disponibilidade de suporte. O método SCS-CN é o produto de mais de 20 anos de estudos envolvendo relações de precipitação-vazão de pequenas bacias hidrográficas rurais nos EUA (NEITSCH et al., 2009). Originalmente desenvolvido para calcular o escoamento de eventos de precipitação simples e curtos, o método também foi adaptado para uma simulação contínua da transformação de precipitação em vazão. O GWLF é um modelo concentrado que utiliza o método do SCS-CN para estimar a vazão, para depois calcular a produção de sedimentos e as cargas de nitrogênio e de fósforo geradas numa bacia hidrográfica.

Muitos estudos compararam os resultados de diferentes modelos hidrológicos (e.g. HUANG; HONG, 2010; LI et al., 2010), mas poucos com o objetivo de justapor o desempenho de modelos mais simples a modelos mais completos e detalhados, como o SWAT. A popularidade obtida pelo SWAT e o esforço necessário para aplicá-lo justificam essa pesquisa. Pretende-se avaliar se os objetivos alcançados por este modelo podem ser alcançados de forma mais simples e fácil de entender e aplicar por modelos mais simples. A

\footnotetext{
${ }^{5}$ Conceptuais em português europeu

${ }^{6}$ Azoto em português europeu.

${ }^{7}$ Agregados em português europeu.
} 
simplicidade de tais modelos é uma clara vantagem em muitas partes do mundo onde a disponibilidade de dados e o conhecimento pormenorizado da hidrologia de uma região limitam o uso de modelos mais complexos.

Para suportar a nossa análise são utilizados dois casos de estudo. O primeiro caso de estudo consiste na bacia do rio Jacaré-Guaçu que está inserida na Unidade de Gerenciamento ${ }^{8}$ de Recursos Hídricos 13 (UGRHI-13) denominada Tietê-Jacaré, e possui uma área de drenagem de $11.779 \mathrm{~km}^{2}$. O segundo caso de estudo é referente a bacia do rio Atibaia que está inserida na Unidade de Gerenciamento de Recursos Hídricos 5 (UGRHI-5) denominada PCJ Piracicaba, Capivarí e Jundiai, e possui uma área de drenagem de $2.818 \mathrm{~km}^{2}$ na qual estão inseridos, total ou parcialmente, municípios dos estados de São Paulo e Minas Gerais.

Deste modo, esta tese vem contribuir com os estudos realizados nestas bacias hidrográficas a partir da geração de informações relativas ao processo modelagem hidrológica de precipitação-vazão, produção de sedimentos e qualidade da água, que complementará futuros estudos, além de poder ser utilizado como suporte para trabalhos em bacias hidrográficas com características semelhantes à estas, e áreas com ausência de dados hidrológicos.

\subsection{Objetivos}

O objetivo principal deste trabalho foi verificar as condições em que modelos mais simples (e concentrados) podem ser empregues como alternativa a modelos mais complexos, quer para estimar a vazão quer para avaliar as cargas de sedimentos e poluentes. Um aspecto particular deste objetivo é a verificação das condições em que uma descrição pormenorizada do regime de precipitação sobre uma bacia hidrográfica é essencial para um bom desempenho do modelo. Pretendeu-se ainda avaliar se ambos os tipos de modelos permitem quantificar os impactos das alterações do uso e ocupação do solo na vazão, produção de sedimentos e concentração de poluentes, como os nutrientes.

Para atender estes objetivos, a tese conta com os seguintes objetivos específicos:

1. Simular a vazão nos pontos monitorados de duas bacias hidrográficas e comparar com os resultados obtidos com um modelo hidrológico concentrado e um modelo hidrológico semi-distribuído para compreender em que condições o uso de cada modelo deve ser recomendado.

\footnotetext{
${ }^{8}$ Gestão em português europeu.
} 
2. Estimar a produção de sedimentos e as concentrações de contaminantes, nomeadamente de nitrogênio e de fósforo nas bacias, com os dois tipos de modelos e comparar com os resultados obtidos.

3. Estimar a vazão, a produção de sedimentos e a concentração dos contaminantes para um dos estudos de caso, em que seja possível verificar a modelagem semidistribuída sob a influência de um reservatório.

4. Avaliar a desempenho do modelo semi-distribuído para duas descrições da distribuição da precipitação, nomeadamente a decorrente da rede de monitoramento e uma outra grade $^{9}$ de precipitação obtida a partir de dados de precipitação interpolados (DPI) desenvolvido por Xavier; King; Scanlon, (2016).

5. Simular diferentes cenários de uso do solo e analisar os efeitos dessas mudanças no regime hidrológico, fazendo-se comparações com a classificação mais recente de uso do solo.

\subsection{Hipóteses}

A hipótese que norteia este trabalho é que os modelos hidrológicos mais simples oferecem, em diversas situações, uma estimativa confiável de variáveis hidrosedimentológicas, quando se trabalha em escala diária e mensal.

A modelagem com modelos semi-distribuídos, como o modelo SWAT, necessita de uma ampla gama de parâmetros, o que dificulta muitas vezes sua aplicação, principalmente em relação ao Brasil, onde há carência de dados em muitas regiões. O modelo concentrado demanda um reduzido número de parâmetros para sua calibração e validação, o que faz com que a modelagem seja realizada em menor período do tempo, principalmente quando aplicada em uma programação simplificada elaborada em Microsoft Excel.

Em relação aos dados de produção de sedimentos e de concentração de contaminantes, a hipótese é que o modelo concentrado permite a estimativa das variáveis, embora a modelagem tenha limitações, principalmente no tange a concentração dos contaminantes.

O modelo semi-distríbuído também foi utilizado para verificar sua aplicação na simulação de vazão e qualidade de água sob influência de um reservatório, localizado em um dos casos de estudo. A hipótese neste caso é de que o modelo é capaz de simular a vazão e a

\footnotetext{
${ }^{9}$ Grelha de cálculo em Português europeu.
} 
qualidade de água a jusante do reservatório com qualidade similar a simulação dos dados a montante.

A aplicação de uma nova grade de dados de precipitação interpolados (DPI) para a simulação da vazão a partir do modelo semi-distríbuido teve como hipótese que os erros possivelmente encontrados nas simulações com os dados de precipitação observados (DPO) poderiam ser estar relacionados com falhas ou erros de monitoramento. E deste modo, a utilização dos DPI tem como objetivo trazer uma solução para esta problemática.

Ainda com a proposta de verificar algumas das aplicações permitidas pelos modelos (SWAT e GWLF), elaborou-se a hipótese de que os modelos são capazes de simular a influência das mudanças no uso e ocupação do solo no regime hidrológico e na qualidade da água.

\subsection{Organização do trabalho}

Este trabalho está organizado em 5 capítulos.

O primeiro capítulo é constituído pelo enquadramento do trabalho e pela descrição dos objetivos e da hipótese da tese.

O segundo capítulo aborda os aspectos metodológicos do trabalho, apresentando o estado da arte decorrente da revisão bibliográfica realizada para o desenvolvimento deste trabalho. Esta revisão apresenta um breve historial da modelagem hidrológica e uma classificação dos vários modelos existentes, com destaque para os modelos de bacias hidrográficas que são os objetos deste estudo. Discute-se ainda as formulações matemáticas utilizadas para descrever a transformação da precipitação em escoamento, os processos erosivos e o transporte de sedimentos e de nutrientes. Abordam-se também os reflexos nos recursos hídricos resultantes de diferentes cenários de uso e ocupação do solo. É ainda apresentada a forma como o modelo SWAT simula alguns processos relacionados com a qualidade da água e a dinâmica escoamento e retenção de sedimentos e nutrientes em reservatórios. O capítulo termina com uma discussão sobre as fases de calibração e validação dos modelos, nomeadamente os passos que é necessário executar e os indicadores de avaliação de desempenho dos modelos empregues para avaliação do desempenho dos modelos.

O terceiro capítulo apresenta os casos de estudo e as principais características das bacias hidrográficas selecionadas, nomeadamente a localização, o clima, hidrologia, a geomorfologia, os solos e o uso e ocupação do solo. 
O quarto capítulo é relativo aos resultados e discussões. Apresenta a comparação dos modelos, a simulação hidrológica sob influência de um reservatório, a influência da precipitação na análise hidrológica e a avaliação dos cenários de uso e ocupação do solo para a região.

O quinto capítulo apresenta as considerações finais que este trabalho proporcionou. 


\section{ESTADO DA ARTE E ASPECTOS METODOLÓGICOS}

\subsection{Modelagem hidrológica - histórico}

Os modelos matemáticos são ferramentas amplamente utilizadas em todo o mundo na pesquisa e na gestão de recursos ambientais, incluído a água, porque nos permitem compreender os processos naturais e encontrar soluções para problemas. No domínio da hidrologia, estes modelos são essenciais no planejamento ${ }^{10}$ e gestão dos recursos hídricos e são rotineiramente utilizados para avaliar o comportamento hidrológico das bacias hidrográficas em várias aplicações, como a previsão de fluxos de água e de materiais em rios, a avaliação de disponibilidade de água e sua dependência de fatores externos, como o clima ou a mudança de uso do solo, e ainda o dimensionamento de obras e a operação de infraestruturas (FUKUNAGA et al., 2015).

A modelagem matemática no domínio da hidrologia surgiu há mais de um século, a partir do equacionamento de alguns processos hidrológicos. Por exemplo, por volta de 1822 Mulvany propôs o método racional para prever a vazão máxima decorrente de um evento de chuva (TODINI, 2007).

Na década de 1930 muitos avanços ocorreram quando as agências governamentais de países desenvolvidos começaram a desenvolver seus próprios programas de pesquisas hidrológicas. Sherman desenvolveu o hidrograma unitário (SHERMAN, 1932). Horton desenvolveu a teoria da infiltração (HORTON, 1933). McCarthy desenvolveu um modelo de escoamento em rios baseando-se no modelo Muskingum para o escoamento em reservatórios (MCCARTHY, 1938).

Nas décadas de 1940 e 1950 os primeiros modelos hidrológicos foram desenvolvidos, como o modelo de balanço hidrológico de Thorthwaite-Mather (THORNTHWAITE, 1948; THORNTHWAITE; MATTER, 1955, 1957).

A revolução digital década de 1960 tornou possível a integração de modelos de diferentes componentes do ciclo hidrológico e a simulação de praticamente toda a bacia hidrográfica. O Stanford Watershed Model-SWM (agora HSPF - Hydrological Simulation Program), proposto por Crawford e Linsley (1966), foi provavelmente a primeira tentativa de modelar virtualmente todo o ciclo hidrológico. Simultaneamente, foram desenvolvidos outros modelos com objetivos mais específicos e um pouco menos abrangentes, mas que ganharam

\footnotetext{
${ }^{10}$ Planeamento em português europeu
} 
popularidade, como são exemplo os modelos de divisores Dawdy e O'Donnell (1965) e o modelo HEC-1 (Hydrologic Engineering Center, 1968). Durante as décadas de 1970 e 1980, mais modelos matemáticos foram desenvolvidos não apenas para simulação da hidrologia de bacias hidrográficas, mas também para suas aplicações em outras áreas, como gestão ambiental e de ecossistemas (SINGH; WOOLHISER, 2002). Exemplos de tais modelos são QUAL2 (Enhanced Stream Quality Model) desenvolvido pela U.S. Environmental Protection Agency (EPA), CREAMS (Chemicals, Runoff, and Erosion from Agricultural Management Systems) model (USDA, 1983) e AGNPS (Agricultural Non-Point Source Pollution Model) (YOUNG et al., 1987)

Todos esses modelos foram melhorados significativamente, com as versões mais recentes a expandirem o âmbito de aplicação das versões originais e a aperfeiçoarem o rigor dos resultados. O SHE, por exemplo, foi estendido para incluir o transporte de sedimentos e é aplicável na escala de uma bacia hidrográfica (BATHHURST et al., 1995). O TOPMODEL foi estendido para conter processos mais baseados fisicamente e melhor estimativa de parâmetros. Esta evolução é ainda patente nas várias versões do QUAL2 (Enhanced Stream Quality Model) desenvolvido pela U.S. Environmental Protection Agency (EPA), no AGNPS (Agricultural Non-Point Source Pollution Model) (YOUNG et al., 1987), no EPIC (Environmental Policy Impact Calculator) (WILLIAMS; SHARPLEY, 1989) e no SWAT (Soil and Water Assessment Tool).

O desenvolvimento de novos modelos ou a melhoria de modelos desenvolvidos anteriormente continua até hoje. World Meteorological Organization - WMO (1975), Xu e Singh (1998), Van Griensven et al., (2006) e Kaleris e Langousis (2016), entre outros, apresentam uma visão geral dos modelos hidrológicos mais representativos, discutem seus pressupostos, limites e potencialidades e avaliam algumas de suas aplicações.

\subsection{Classificação dos modelos}

Os modelos hidrológicos podem ser agrupados em várias categorias com base nas abordagens de modelagem usadas. Os principais fatores que distinguem estes modelos incluem a sua estrutura ou base científica (empíricos, conceituais ou físicos), a sua representação espacial (concentrada ou distribuída), o âmbito temporal de simulação (contínuos ou de eventos) e a natureza dos algoritmos empregados (determinística ou estocástica) (EDSEL et al., 2011). 
No que respeita à sua estrutura, os modelos hidrológicos podem ser classificados como modelos empíricos ou físicos (também designados por conceituais). Os modelos empíricos são fundamentados em formulações matemáticas que tem como base observações locais de condições específicas, e por isso são considerados mais simples e pouco robustos. Estes modelos são baseados em relações entre variáveis obtidas a partir de dados observados num conjunto reduzido de bacias hidrográficas. Essas relações podem ser equações de regressão estatísticas, redes neuronais ou outras metodologias (CHAU; WU, 2010; CHEN et al., 2017; KISI; OZKAN; AKAY, 2012). Sendo exclusivamente baseados em relações derivadas de dados no terreno, apenas podem ser aplicados em condições para as quais o modelo foi formulado, como por exemplo, uma determinada bacia hidrográfica, condições climáticas específicas e gamas pré-definidas de usos e ocupações do solo.

Em contrapartida os modelos físicos procuram descrever os processos físicos de natureza hidrológica que ocorrem numa bacia hidrográfica. Traduzem esses processos num conjunto de conceitos e as principais equações diferenciais do sistema físico para representar os processos que ocorrem na natureza. Por regra, os modelos físicos são mais complexos e requerem um maior número de parâmetros para sua aplicação. Têm, no entanto, um âmbito de aplicação mais generalizado porque é potencialmente possível estimar os seus parâmetros para uma determinada bacia hidrográfica e aplicá-los a bacias hidrográficas que não possuem dados observados. Permitem ainda avaliar os impactos das mudanças das características das bacias através da alteração dos valores dos parâmetros, os quais podem ser avaliados através de medidas de campo (TUCCI, 1998).

Uma outra categorização distingue os modelos concentrados dos modelos semidistribuídos e distribuídos. A modelagem concentrada considera uma bacia hidrográfica como uma unidade única de características uniformes, em que os parâmetros e as variáveis das bacias hidrográficas são representados pelo valor médio ou mediano que assumem nessa unidade. Por regra, os modelos concentrados assumem um número reduzido de elementos conceituais para representar os processos de escoamento e de armazenamento de água na bacia.

Em comparação com os modelos concentrados, os modelos semi-distribuídos ou distribuídos assumem a variabilidade espacial das características das bacias hidrográficas, dos processos hidrológicos, dos dados de entrada e das condições de contorno (LI; WELLER; 
JORDAN, 2007). Nos modelos distribuídos, a bacia hidrográfica é dividida numa grade ${ }^{11}$ de células quadradas ou retangulares, enquanto nos modelos semi-distribuídos, a bacia é dividida em várias sub-bacias ou unidades de menor dimensão, em que se assume uniformidade espacial das suas características (MELONE et al., 2005). O grau de pormenor da heterogeneidade espacial considerada num modelo distribuído é tipicamente definido pelo modelador (MELONE et al., 2005).

A complexidade dos modelos hidrológicos surge quando se considera a distribuição espacial das variáveis de entrada e as características das bacias hidrográficas e se representam os processos hidrológicos que ocorrem na bacia hidrográfica com equações fisicamente baseadas com grande número de parâmetros. Em consequência, muitos modelos distribuídos e semi-distribuídos requerem um grande conjunto de dados e parâmetros para caracterizar a bacia hidrográfica e os seus processos hidrológicos, o que torna a coleta de dados e a calibração do modelo um procedimento moroso, propenso a falhar e muitas vezes inviável.

Os modelos podem também ser subdivididos em modelos baseados em eventos ou em processos contínuos. Modelos baseados em eventos simulam eventos individuais de precipitação, tipicamente eventos de cheias, focando-se no cálculo da infiltração e do escoamento superficial que ocorre durante e logo após o evento de precipitação. Os modelos de processos contínuos explicam explicitamente todos os componentes de escoamento, considerando a redistribuição da umidade do solo entre eventos de tempestade (MELONE et al., 2005).

Os modelos também podem ser categorizados como determinísticos ou estocásticos, dependendo das técnicas envolvidas no processo de modelagem. Os modelos determinísticos são modelos matemáticos em que os resultados são obtidos através de relações conhecidas entre estados e eventos. Nos modelos estocásticos, parte ou todos os dados de entrada e processo de transformação são representados por distribuições estatísticas que determinam uma gama de valores de saídas.

Embora a maioria dos modelos sejam determinísticos por natureza, os modelos estocásticos fornecem duas vantagens importantes. Primeiro, a sua estrutura conceitualmente simples torna possível descrever a heterogeneidade quando há detalhes espaciais ou temporais limitados. Segundo Melone et al. (2005) eles fornecem aos tomadores de decisão a capacidade de determinar a incerteza associada às previsões.

\footnotetext{
${ }^{11}$ Grelha em português europeu.
} 
Arnold et al. (1998) apresentaram seis características importantes de um bom modelo hidrológico: eficiência computacional; alto detalhamento ${ }^{12}$ espacial; dados de entrada disponíveis; representação contínua do tempo; capacidade de simular cenários de gestão do uso do solo; e a capacidade de fornecer resultados razoáveis.

\subsection{Modelos hidrológicos selecionados}

\subsubsection{Critérios de seleção}

A seleção dos modelos hidrológicos utilizados nesta investigação foi determinada pelo seu objetivo, concretamente a verificação que em muitas situações os modelos concentrados e mais simples podem ser utilizados em alternativa a modelos mais complexos semidistribuídos ou distribuídos.

Entre os modelos mais simples, selecionaram-se dois modelos hidrológicos concentrados que necessitam de um conjunto reduzido de dados de entrada e exigem um esforço moderado para os calibrar e validar. Para estimar a vazão recorreu-se ao método do Soil Conservation Service (SCS) e para estimar a produção de sedimentos e a concentração de contaminantes utilizou-se o GWLF, que inclui no seu cálculo o método do SCS.

Entre os modelos hidrológicos distribuídos optou-se pelo modelo SWAT que é amplamente utilizado no meio acadêmico. Trata-se de um modelo semi-distribuído que permite, entre outras funcionalidades, a simulação dos fluxos de água bem como a avaliação da produção de sedimentos e de cargas de contaminantes. Este modelo exige a atribuição de valores a muitos parâmetros o que dificulta a sua calibração e validação.

Apresenta-se de seguida o historial de desenvolvimento de cada modelo e uma descrição das formulações matemáticas adotadas para simular os processos hidrológicos que ocorrem numa bacia hidrográfica. O capítulo termina com uma discussão sobre a metodologia utilizada para calibrar e validar os modelos.

\subsection{2. $S C S-C N$}

O método desenvolvido pelo Serviço de Conservação do Solo (SCS) do Departamento de Agricultura dos EUA (USDA) (agora Natural Resources Conservation Service) é uma técnica amplamente utilizada para o cálculo do escoamento superficial em bacias hidrográficas (USDA-SCS, 1972). O método baseia-se num conceito denominado número da

\footnotetext{
12 Pormenorização em português europeu.
} 
curva de escoamento ou número de escoamento, com o símbolo $\mathrm{CN}$ (curve number) em inglês.

O método SCS-CN é baseado no fato de que o escoamento direto (após a infiltração inicial ocorrer) depende do uso e ocupação do solo, do tipo de solo e das condições de umidade antecedentes do solo. Várias tabelas de acompanhamento foram desenvolvidas em associação com equações empíricas (MOCKUS, 1964, 1972). O método do SCS-CN admite que, na sequência de um acontecimento pluvioso intenso, a razão entre a altura de precipitação retida na bacia hidrográfica após o início do escoamento superficial e a capacidade máxima de retenção de água na bacia é igual à razão entre a precipitação efetiva e o escoamento superficial potencial (PONCE, 1989).

Desde seu desenvolvimento inicial, em 1954, o método SCS-CN sofreu inúmeras melhorias, por exemplo, o método foi originalmente desenvolvido com dados regionais da região centro-oeste dos EUA e ao longo dos anos foi estendido para ser aplicado a outros países com adaptações feitas nas tabelas de CN (CRONSHEY, 1986; RALLISON, 1980). Os modelos STORM (USACE, 1977), GWLF (HAITH; SHOEMAKER, 1987) e SWAT (ARNOLD; FOHRER, 2005; ARNOLD et al., 1998,) são alguns dos exemplos de modelos hidrológicos contínuos que utilizam o método do SCS ou alguma variante deste método.

Durante este período, o método SCS-CN tornou-se uma das ferramentas mais conhecidas para o cálculo do escoamento devido à sua relativa facilidade de utilização e ao reduzido número de parâmetros. Além disso, outros fatores preponderantes para sua utilização é a relação direta entre os parâmetros do modelo e as características da bacia e a sua dependência por dados geralmente disponíveis (PONCE; HAWKINS, 1996). Ao calcular o escoamento superficial a partir das características do solo e do uso e cobertura da terra, este modelo permite suprir a carência de dados hidrológicos, existente em grande parte dos municípios brasileiros.

\subsubsection{GWLF}

O GWLF é um modelo concentrado, utilizado para estimar, em passo de cálculo mensal, a vazão, a produção de sedimentos e as concentrações de nitrogênio e de fósforo. Os parâmetros do modelo GWLF podem ser ajustados de acordo com as condições climáticas, as características do solo e os tipos de uso do solo de uma bacia hidrográfica. Este modelo foi aplicado em diversos lugares do mundo, por exemplo nos Estados Unidos da América (HAITH; MANDEL; WU, 1992; LEE et al., 2000; LI et al., 2010; NIRAULA et al., 2013; SCHNEIDERMAN et al., 2002; SWANEY; SHERMAN; HOWARTH, 1996; TU, 2009), na 
China (DU et al., 2014; HUANG; HONG, 2010) e em Porto Rico (WU; HALL; SCETENA, 2007).

O modelo recorre a dados de uso do solo, tipo de solo e informações climáticas diárias (precipitação e temperatura) para calcular o balanço hídrico. Os fluxos (vazão, escoamento superficial e subterrâneo) são calculados a partir da metodologia SCS-CN e a produção de sedimentos é calculada pela relação entre a Equação Universal de Perda de Solo (EUPS), (WISCHMEIER; SMITH, 1978), e a razão de entrega de sedimentos (SDR) (HAITH; MANDEL; WU, 1992). O balanço hídrico é calculado para zonas saturadas e zonas não saturadas. A infiltração nas zonas saturadas e não saturadas é igual ao excesso de água da chuva, menos o escoamento superficial e a evapotranspiração. A percolação ocorre quando a água da zona não saturada excede a capacidade do campo.

O modelo GWLF produz estimativas das cargas de nitrogênio e de fósforo em fases sólida e dissolvida. As cargas dos contaminantes em fase sólida são provenientes de fontes rurais e de fontes urbanas e as cargas de contaminantes em fase dissolvida são provenientes de fontes rurais, de fontes difusa e de águas subterrâneas.

\subsubsection{SWAT}

O SWAT é um modelo de domínio público, desenvolvido pelo Serviço de Pesquisa Agrícola (Agricultural Research Service - ARS) do Departamento de Agricultura dos Estados Unidos (United States Department of Agriculture - USDA) (ARNOLD; FOHRER, 2005; ARNOLD et al., 1998). É considerado como um dos modelos mais adequados atualmente para prever os impactos em longo prazo de medidas de gestão da terra e da água, produção de sedimentos e aporte de químicos agrícolas (perda de nutrientes) em bacias hidrográficas complexas com diferentes tipos de solos, uso do solo e condições de gestão.

Considerado um modelo semi-distribuído, está acoplado a uma interface de Sistemas de Informações Geográficas (SIG), que delimita bacias hidrográficas e redes de rios a partir do Modelo Digital de Terreno (MDT). No SWAT, as bacias hidrográficas são divididas em várias sub-bacias, que são subdivididas em HRUs, que consistem em áreas com uso homogêneo da terra, gestão e características do solo (GASSMAN et al., 2007).

O modelo calcula o balanço hídrico diário com base no tipo de solo, declividade, uso do solo e dados meteorológicos. Inclui um componente importante que trabalha com a qualidade da água, e esta aplicação possibilita ao modelo a capacidade para lidar com uma ampla variedade de problemas de gestão da qualidade da água, como a avaliação da qualidade da água, as perdas de sedimentos e melhores práticas de manejo na agricultura; o uso do solo 
e a mudança na gestão da terra; a avaliação do impacto das alterações climáticas, etc (GASSMAN et al., 2007). O SWAT emprega o conceito de número da curva de escoamento (CN) para a estimativa do escoamento superficial e a Equação Universal de Perda de Solo Modificada (MUSLE) para estimar a produção de sedimentos. O SWAT é um modelo computacionalmente eficiente para operar sobre médias a grandes bacias, sendo capaz de simular longos períodos (> 100 anos) de forma a computar os efeitos das alterações do uso e ocupação do solo (MACHADO, 2002).

O SWAT pode avaliar o efeito de diferentes combinações de solo e de cobertura do solo no escoamento superficial e na produção de sedimentos e de contaminantes (MISHRA; KAR; SINGH, 2007). Permite ainda identificar as áreas, onde os processos erosivos ou de contaminação ambiental sejam mais ativos e isolar o impacto de qualquer mudança de gestão da bacia hidrográfica na sua resposta hidrológica. Essa capacidade de resposta do modelo possibilita apoiar o processo de tomada de decisão e avaliar os impactos de decisões diferenciadas, dentro de uma mesma bacia hidrográfica (BAKER; MILLER, 2013).

Ao longo do tempo o SWAT tornou-se muito popular com mais de 2100 referências científicas desde 1998 (FRANCESCONI et al., 2016) (base de dados da literatura do SWAT para revistas examinadas pelo Center for Agricultural and Rural Development na Universidade de Estado de Iowa (www.card.iastate.edu/swat_articles). Muitos trabalhos foram elaborados em âmbito mundial a partir da utilização do modelo com diferentes objetivos de pesquisa. O Quadro 1 apresenta alguns destes trabalhos bem como as finalidades dos estudos.

Quadro 1 - Trabalhos desenvolvidos a partir do modelo SWAT e finalidades das pesquisas

\begin{tabular}{|l|l|}
\hline Autor (es) & Finalidades das pesquisas \\
\hline $\begin{array}{l}\text { Spruill et al., } \\
(2000)\end{array}$ & $\begin{array}{l}\text { Determinar a sensibilidade dos parâmetros ao modelar os fluxos diários e mensais em uma } \\
\text { pequena bacia hidrográfica central de Kentucky, EUA, ao longo de um período de dois anos. }\end{array}$ \\
\hline $\begin{array}{l}\text { Kirsch et al., } \\
(2002)\end{array}$ & $\begin{array}{l}\text { Quantificar fontes de fósforo em toda a bacia localizada nos EUA e quantificar os impactos } \\
\text { da aplicação de BMPs em toda a bacia. }\end{array}$ \\
\hline $\begin{array}{l}\text { Chu et al., } \\
(2004)\end{array}$ & $\begin{array}{l}\text { Calibrar e validar a capacidade do modelo na avaliação da poluição difusa para uma bacia } \\
\text { hidrográfica de 346ha na região fisiográfica do Piemonte, EUA. }\end{array}$ \\
\hline $\begin{array}{l}\text { Mishra; Kar; } \\
\text { Singh, (2007) }\end{array}$ & $\begin{array}{l}\text { Simular a vazão e a quantidade de sedimentos em uma bacia no nordeste da Índia com o } \\
\text { objetivo de auxiliar as tomadas de decisões e consequentemente o planejamento dos recursos } \\
\text { hídricos das bacias hidrográficas }\end{array}$ \\
\hline $\begin{array}{l}\text { Galván et al., } \\
(2009)\end{array}$ & $\begin{array}{l}\text { Estimar a carga de poluentes transportada do Rio Meca para o reservatório Sancho localizado } \\
\text { na Península Ibérica. }\end{array}$ \\
\hline $\begin{array}{l}\text { Baker } \\
\text { Miller, (2013) }\end{array}$ & $\begin{array}{l}\text { Determinar se as mudanças de cobertura da terra observadas dentro da bacia hidrográfica do } \\
\text { rio Njoro, Kenya poderiam ter uma relação causal com as alterações hidrológicas. }\end{array}$ \\
\hline $\begin{array}{l}\text { Bonumá } \\
\text { al., (2013) }\end{array}$ & $\begin{array}{l}\text { Avaliar a capacidade do modelo para simular de forma realista os fluxos de uma pequena } \\
\text { bacia hidrográfica no sul do Brasil. }\end{array}$ \\
\hline
\end{tabular}




\begin{tabular}{|l|l|}
\hline $\begin{array}{l}\text { Me et al. } \\
(2015)\end{array}$ & $\begin{array}{l}\text { Quantificar o desempenho do modelo na simulação de descarga e fluxos de sedimentos em } \\
\text { suspensão e nutrientes na bacia hidrográfica. }\end{array}$ \\
\hline $\begin{array}{l}\text { Bressiani et } \\
\text { al., (2015) }\end{array}$ & $\begin{array}{l}\text { Analisar como as previsões hidrológicas respondem a diferentes insumos climáticos com } \\
\text { diferentes resoluções para a bacia hidrográfica semi-árida do rio Jaguaribe no Nordeste do } \\
\text { Brasil. }\end{array}$ \\
\hline $\begin{array}{l}\text { Santos et al., } \\
(2016)\end{array}$ & $\begin{array}{l}\text { Aplicar o modelo a uma bacia hidrográfica de médio porte }\left(252 \mathrm{~km}^{2}\right) \text { no noroeste de Portugal } \\
\text { e desenvolver um conjunto de simulações para apoiar as opções de planejamento sob } \\
\text { diferentes tipos de coberturas do solo e futuras condições climáticas. }\end{array}$ \\
\hline $\begin{array}{l}\text { Rodriguez- } \\
\text { Blanco et al., } \\
(2016)\end{array}$ & $\begin{array}{l}\text { Examinar o desempenho do modelo na simulação da produção dos sedimentos em uma } \\
\text { pequena floresta e na captação da agricultura no noroeste da Espanha e determinar a } \\
\text { contribuição de diferentes usos da terra para a produção dos sedimentos. }\end{array}$ \\
\hline $\begin{array}{l}\text { Malagó et al. } \\
(2017)\end{array}$ & $\begin{array}{l}\text { Desenvolver uma estratégia robusta para a calibração e validação, inspirados em recentes } \\
\text { estudos, que abordam lacunas observadas em âmbito internacional, e aplicar a abordagem da } \\
\text { bacia do rio Danúbio. }\end{array}$ \\
\hline
\end{tabular}

Fonte: Próprio autor

Como um modelo semi-distribuído, uma das principais preocupações no seu uso é a dificuldade em trabalhar a grande quantidade de dados que descrevem a heterogeneidade dos sistemas naturais (Randall e Muleta, 2011; Machado e Vettorazzi, 2003). Nesse contexto a integração do modelo SWAT com SIG possibilita a obtenção, edição e análise dessas informações requeridas pelo modelo, além de permitir que os dados de saída possam ser exibidos em gráficos, tabelas e mapas. Nos EUA, os dados necessários são comumente disponíveis em alta resolução para que um modelo possa ser criado de forma relativamente rápida, já no Brasil existe uma grande dificuldade para obtenção de dados.

\subsection{Transformação de precipitação em escoamento}

\subsubsection{Modelagem chuva-vazão}

A modelagem chuva-vazão é realizada para melhorar o entendimento do comportamento dos fenômenos hidrológicos na bacia hidrográfica, analisar a consistência da curva-chave, preencher falhas nas séries hidrológicas, dimensionar obras hidráulicas, prever cheias e avaliar os efeitos resultantes da modificação do uso do solo, etc. (YAPO; GUPTA; SOROOSHIAN, 1996).

A modelagem chuva-vazão ocorre a partir das características físicas da bacia (área, declividade, tipo de cobertura vegetal, características dos solos e formação geológica, dentre outras características) e de conjuntos de registos de precipitação e de outros dados climáticos (radiação solar, evapotranspiração, velocidade do vento, temperatura, etc.).

Por regra, estes modelos assumem uma divisão da coluna litológica em três zonas: zona não saturada, zona saturada pouco profunda e zona saturada profunda (SOIL CONSERVATION SERVICE - SCS, 1972). O escoamento na foz da bacia hidrográfica é a 
soma do escoamento superficial e do escoamento subterrâneo proveniente da zona saturada pouco profunda que percola para a rede hidrográfica, considerando-se que a zona saturada profunda não contribui para o escoamento fluvial. Alguns modelos não admitem uma zona saturada profunda e nesses casos toda a precipitação que ocorre na bacia hidrográfica se transforma em evapotranspiração ou contribui com a vazão dos cursos de água.

Os resultados do modelo incluem a evapotranspiração real, os fluxos de água entre zonas litológicas e a vazão na rede hidrográfica, com intervalos de discretização que podem ser em nível de tempo horário, diário, mensal, etc.

Entre os modelos chuva-vazão mais amplamente utilizados e estudados, tanto em pequenas como em grandes bacias, incluem-se o SSARR (Streamflow Simulation and Reservoir Regulation Model), elaborado por Rockwood em 1958 (TUCCI, 1998), o modelo de Dawdy e O’Donnell (DAWDY; O’DONNEL, 1965), o modelo SWM (Stanford Watershed Model), (CRAWFORD; LINSLEY, 1966), o modelo SCS-CN e o modelo SWAT.

\subsubsection{SCS-CN}

A natureza concentrada do método SCS-CN utilizado neste estudo determina que as variáveis de entrada e as características das bacias hidrográficas são uniformizadas espacialmente e que a bacia hidrográfica funciona como um corpo único e unificado.

O perfil do solo é dividido em 3 camadas (figura 1). A zona superior não saturada e o aquífero superficial contribuem para o fluxo do rio no exutório da bacia hidrográfica, enquanto o aquífero profundo recebe percolação profunda da camada superior, mas não contribui para o fluxo total.

Figura 1 - Esquematização do modelo SCS-CN

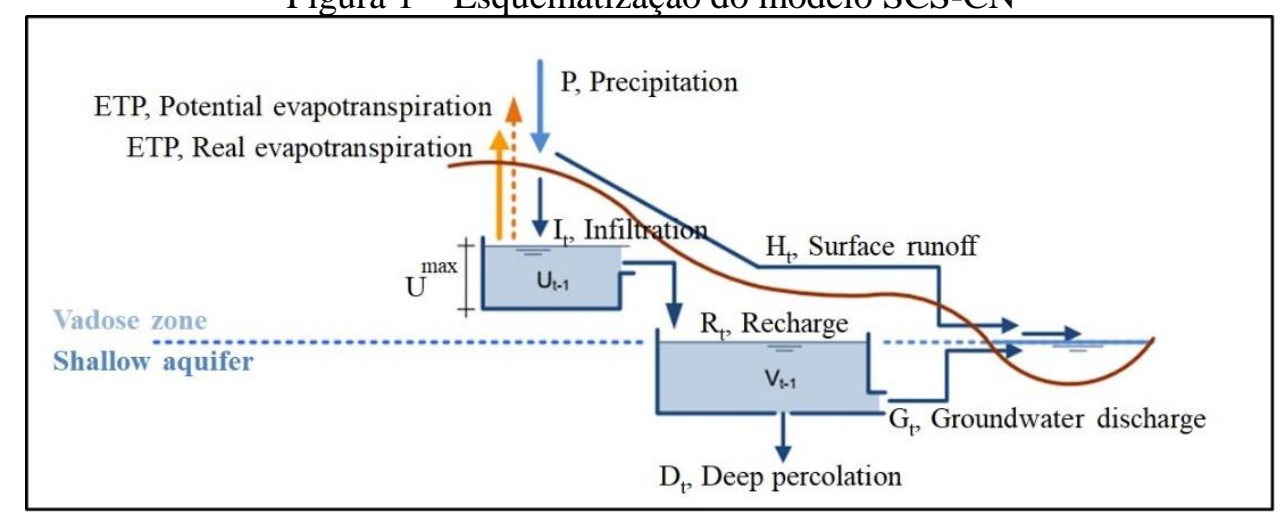

Fonte: Próprio autor

$\mathrm{O}$ escoamento superficial, $\mathrm{H}_{\mathrm{t}}$, é calculado a partir de dados de precipitação, levando em consideração a capacidade de armazenamento de água dentro da bacia, proporcionada pela 
intercetação da vegetação, a retenção em pequenas depressões do terreno e a retenção de água em movimento. A água que está presa ou retida eventualmente infiltra-se no chão depois de um certo tempo. A capacidade total de armazenamento superficial de água na bacia, em mm, é calculada a partir do número da curva de escoamento da bacia, $\mathrm{CN}$, um parâmetro que é calculado a partir de dados do solo, dados de uso do solo e de condições de umidade antecedente.

Na proposta original do SCS-CN, foram sugeridos três valores nominais de CN para três condições de umidade antecedentes da bacia hidrográfica (AM). Esta formulação pode ser expandida para considerar uma computação contínua das condições de umidade antecedentes e da evolução do $\mathrm{CN}$, e da capacidade de armazenamento de água, $L$, à medida que as condições mudam (HAWKINS et al., 1985).

As condições de humidade antecedentes em cada dia são definidas como a soma da precipitação diária ocorrida nos cinco dias anteriores ao início do evento de precipitação.

$$
A M_{t}=\sum_{i=t-5}^{t-1} P_{t}
$$

O valor de $\mathrm{CN}$ no dia $t$ é calculado pela equação 3 a partir dos três valores de referência originais de $\mathrm{CN}$ (equação 2) e as condições de humidade antecedentes. A tabela 1 apresenta os limites das condições de humidade antecedentes para o período de dormência e o período de crescimento das plantas (HJELMFELT; KRAMER; BURWELL, 1982).

$$
\left\{\begin{array}{l}
C N_{1}=\frac{C N}{2,281-0,01281 \cdot C N} \\
C N_{2}=C N \\
C N_{3}=\frac{C N}{0,427+0,00573 \cdot C N}
\end{array}\right.
$$

Tabela 1 - Limites das condições de humidade antecedentes para o período de dormência e o período de crescimento das plantas

\begin{tabular}{lcc}
\hline & $\begin{array}{c}\text { Período de } \\
\text { dormência das } \\
\text { plantas }\end{array}$ & $\begin{array}{c}\text { Período de } \\
\text { crescimento das } \\
\text { plantas }\end{array}$ \\
\hline $\mathrm{AM}_{1}$ & $13 \mathrm{~mm}$ & $36 \mathrm{~mm}$ \\
\hline $\mathrm{AM}_{2}$ & $28 \mathrm{~mm}$ & $53 \mathrm{~mm}$ \\
\hline
\end{tabular}

Fonte: USDA (1983) 


$$
C N_{t}= \begin{cases}\frac{C N_{2}-C N_{1}}{A M_{1}} \cdot A M_{t}-C N_{1} & A M_{t}<A M_{1} \\ \frac{C N_{3}-C N_{2}}{A M_{2}-A M_{1}} \cdot\left(A M_{t}-A M_{1}\right)+C N_{2} & A M_{1}<A M_{t}<A M_{2} \\ C N_{3} & A M_{t}>A M_{2}\end{cases}
$$

Finalmente, a capacidade de armazenamento de água na bacia, $L$, é calculada a partir de $\mathrm{CN}$ :

$$
L_{t}=\frac{2540}{C N_{t}}-25,4
$$

O método SCS-CN assume que apenas uma parte desta capacidade de armazenamento disponível é mobilizável em qualquer dia, ou seja, 20\%. O escoamento, $H_{t}$, em mm, pode então ser calculado por:

$$
H_{t}= \begin{cases}0 & P_{t} \leq 0,2 \cdot L_{t} \\ \frac{\left(P_{t}-0,2 \cdot L_{t}\right)^{2}}{P_{t}+0,8 \cdot L_{t}} & P_{t}>0,2 \cdot L_{t}\end{cases}
$$

À medida que a precipitação ocorre, a precipitação acumulada e o valor de CN aumentam e a capacidade de armazenamento diminui. Consequentemente, a percentagem de precipitação, $P_{t}$, que leva a escoamento superficial, também aumenta.

Conhecendo a precipitação, $P_{t}$ e o escoamento, $H_{t}$, é possível calcular a quantidade de água, que se infiltra e contribui para o armazenamento de água na zona insaturada da coluna litológica:

$$
I_{t}=P_{t}-H_{t}
$$

A zona não saturada do solo recebe água por infiltração, e perde água na atmosfera por evapotranspiração, $E T R_{t}$ e para o aquífero pouco profundo por recarga, $R_{t}$. A evapotranspiração é limitada pela evapotranspiração potencial e pela água disponível no solo. A recarga, $R_{t}$, ocorre quando a quantidade de água na zona saturada excede a capacidade do campo. A quantidade de água armazenada na zona não saturada, acima do ponto de murcha, no final do intervalo de tempo $t, U_{t}$, pode então ser calculada pelas seguintes equações:

$$
\begin{gathered}
\operatorname{ETR}_{t}=\min \left(\operatorname{ETP}_{t}, U_{t-1}+I_{t}-R_{t}\right) \\
R_{t}=\max \left(0, U_{t-1}+I_{t}-E T R_{t}-U^{\max }\right) \\
U_{t}=\min \left(U_{t-1}+I_{t}-E T R_{t}-R_{t} U^{\max }\right)
\end{gathered}
$$


onde $U^{\max }$ é a capacidade máxima de armazenamento, ou seja, a diferença entre a capacidade de campo e o ponto de murcha.

A evapotranspiração ocorre sempre que o teor de água do solo está acima do ponto de murcha, ou seja, sempre que $U_{t}$ é positivo. Como a quantidade de água do solo acima da capacidade do campo pode contribuir tanto para a recarga quanto para a evapotranspiração, é necessário determinar como este volume está dividido entre esses dois processos. Definindo $\delta$ como a porção deste volume que satisfaz a recarga e $X_{t}$ como o volume de água acima da capacidade do campo, recarregar $R_{t}$ pode ser calculado por:

$$
\begin{gathered}
\mathrm{X}_{\mathrm{t}}=\underset{\max \left(0, \mathrm{U}_{\mathrm{t}-1}+\mathrm{I}_{\mathrm{t}}-\mathrm{U}^{\text {máx }}\right)}{\mathrm{R}_{\mathrm{t}}=\delta \cdot \mathrm{X}_{\mathrm{t}}}
\end{gathered}
$$

A equação do balanço hídrico para a zona saturada rasa pode ser definida:

$$
\mathrm{V}_{\mathrm{t}}=\mathrm{V}_{\mathrm{t}-1}+\mathrm{R}_{\mathrm{t}}-\mathrm{G}_{\mathrm{t}}-\mathrm{D}_{\mathrm{t}}
$$

Com o $V_{t}$ sendo o volume armazenado no aquífero pouco profundo e $D_{t}$ a recarga para o aqüífero profundo ou percolação profunda. Supondo que a zona rasa se comporta como um reservatório linear, a perda de água para a rede hidrográfica, $G_{t}$, e a perda de água para a zona saturada, $D_{t}$, podem ser estimadas por:

$$
\begin{aligned}
& G_{t}=\alpha \cdot V_{t-1} \\
& D_{t}=\beta \cdot V_{t-1}
\end{aligned}
$$

Os parâmetros $\alpha$ e $\beta$ são as constantes de recessão do fluxo de água subterrânea e recarga profunda, respetivamente, e têm como unidade $\mathrm{mm} /$ dia. Finalmente, o fluxo total $\mathrm{T}_{\mathrm{t}}$, em mm/dia, ocorrendo na saída da bacia hidrográfica em um determinado intervalo de tempo, pode ser calculado por:

$$
\mathrm{T}_{\mathrm{t}}=\mathrm{H}_{\mathrm{t}}+\mathrm{G}_{\mathrm{t}}
$$

A partir da formulação supramencionada, verifica-se que o modelo tem os seguintes parâmetros como essenciais para suas simulações: número de escoamento, $\mathrm{CN}$; capacidade de campo $\mathrm{U}^{\text {máx}}$; constante de recessão do escoamento fluvial e de origem subterrânea, $\alpha$ e constante de recessão da recarga profunda, $\beta$. 
Dentre estes parâmetros, o número da curva de escoamento pode ser estimado a partir de dados relativos ao tipo de solo e uso e ocupação do solo, e de tabelas e gráficos propostos pela metodologia SCS-CN.

Os quadros 2, 3 e 4 permitem a estimativa desse parâmetro. Os quatro grupos hidrológicos de solo, A, B, C, e D, classificados de acordo com as taxas de infiltração mínima, identificados nas referidas tabelas, são representados através do quadro 3.

A capacidade de campo da bacia, $\mathrm{U}^{\text {máx }}$, pode ser estimada sabendo-se o tipo de solo da bacia bem como a altura do solo, estas informações podem ser obtidas a partir da carta de solo da região. A partir do cruzamento destes dados com as tabelas publicadas na bibliografia cujas apresentam valores referentes a capacidade de campo em $\mathrm{mm} / \mathrm{metro}$ de altura do solo, é possível determinar a $U^{\text {máx }}$.

Neste estudo a capacidade de campo das áreas de estudo foram estimadas a partir de dados de profundidade do solo e capacidade de campo, disponibilizados por Oliveira e Prado (1984) e Saxton e Rawls (2006).

Quadro 2 - Estimativa dos valores de CN para áreas rurais

\begin{tabular}{|c|c|c|c|c|c|}
\hline Uso do solo & Superfície & $\mathbf{A}$ & B & $\mathbf{C}$ & D \\
\hline \multirow{2}{*}{ Solo lavrado } & Com sulcos retilíneos & 77 & 86 & 91 & 94 \\
\hline & Em fileiras retas & 70 & 80 & 87 & 90 \\
\hline \multirow{3}{*}{ Plantações regulares } & Em curvas de níveis & 67 & 77 & 83 & 87 \\
\hline & Terraceamento em nível & 64 & 76 & 84 & 88 \\
\hline & Em fileiras retas & 64 & 76 & 84 & 88 \\
\hline \multirow{3}{*}{ Plantações de cereais } & Em curvas de níveis & 62 & 74 & 82 & 85 \\
\hline & Terraceamento em nível & 60 & 71 & 79 & 82 \\
\hline & Em fileiras retas & 62 & 75 & 83 & 87 \\
\hline \multirow{5}{*}{$\begin{array}{l}\text { Plantações } \\
\text { legumes } \\
\text { cultivados }\end{array}$} & Em curvas de níveis & 60 & 72 & 81 & 84 \\
\hline & Terraceamento em nível & 57 & 70 & 78 & 89 \\
\hline & Pobres & 68 & 79 & 86 & 89 \\
\hline & Normais & 49 & 69 & 79 & 94 \\
\hline & Boas & 39 & 61 & 74 & 80 \\
\hline \multirow{3}{*}{$\begin{array}{l}\text { Pastagem em curvas } \\
\text { de nível }\end{array}$} & Pobres & 47 & 67 & 81 & 88 \\
\hline & Normais & 25 & 59 & 75 & 83 \\
\hline & Boas & 6 & 35 & 70 & 79 \\
\hline \multirow{4}{*}{ Campos permanentes } & Normais & 30 & 58 & 71 & 78 \\
\hline & Esparsas, de baixa transpiração & 45 & 66 & 77 & 83 \\
\hline & Normais & 36 & 60 & 73 & 79 \\
\hline & Densas, de alta transpiração & 25 & 55 & 70 & 77 \\
\hline \multirow{3}{*}{$\begin{array}{l}\text { Chácaras estradas de } \\
\text { terra }\end{array}$} & Normais & 56 & 75 & 86 & 91 \\
\hline & Ruim & 72 & 82 & 87 & 89 \\
\hline & De superfície dura & 74 & 84 & 90 & 92 \\
\hline \multirow{4}{*}{ Floresta } & Muito esparsa, baixa transpiração & 56 & 75 & 86 & 91 \\
\hline & Esparsas & 46 & 68 & 78 & 84 \\
\hline & Densas, alta transpiração & 26 & 52 & 62 & 69 \\
\hline & Normais & 36 & 60 & 70 & 76 \\
\hline
\end{tabular}

Fonte: Adaptado de Tucci (1998) 
Quadro 3 - Estimativa dos valores de CN para bacias urbanas e suburbanas

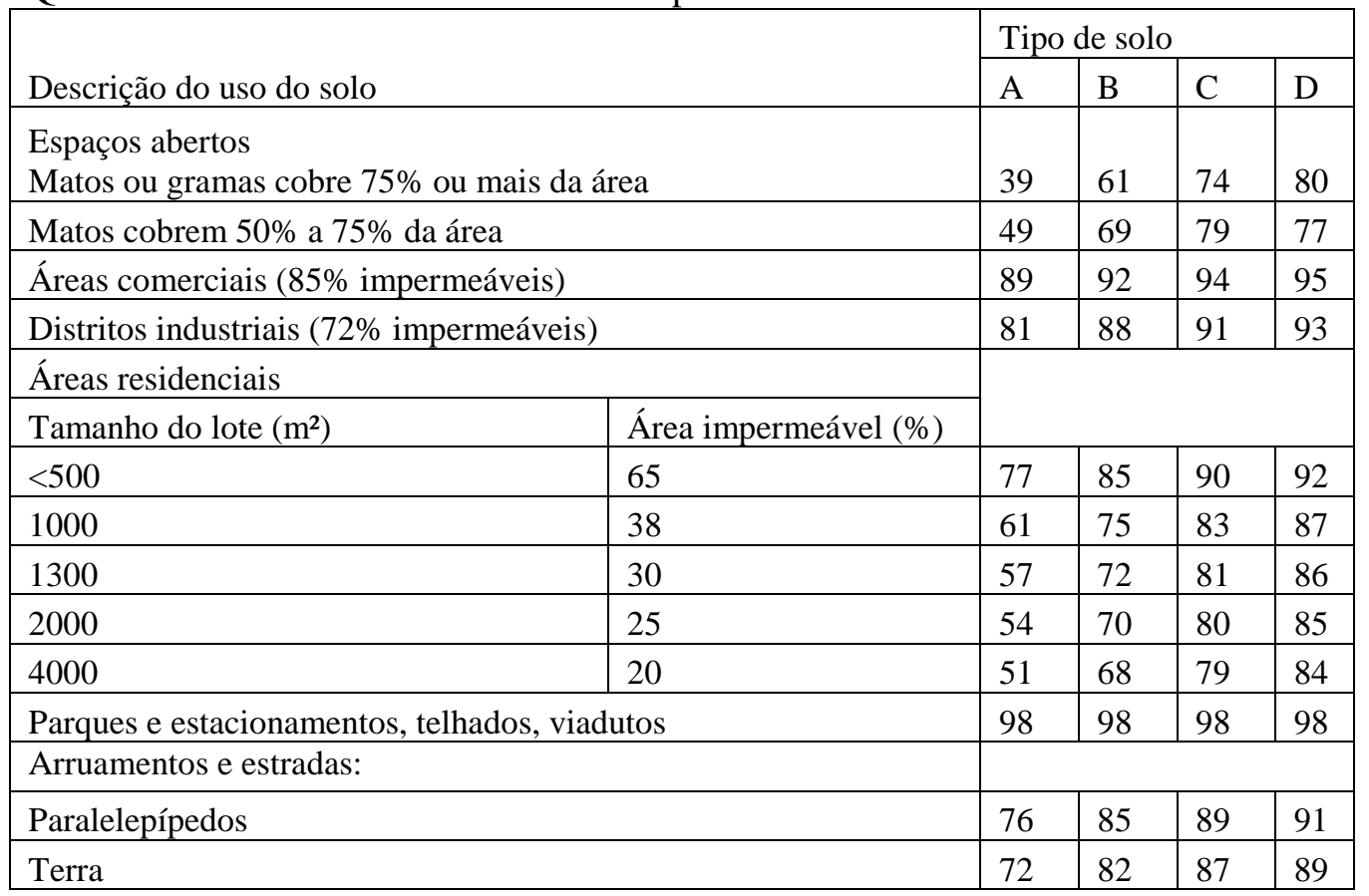

Fonte: Adaptado de Tucci (1998)

Quadro 4 - Grupos hidrológicos de solo - tipos de solo e condições de uso

\begin{tabular}{|c|l|}
\hline Grupos & Tipos de solo e condiçóes de uso \\
\hline A & $\begin{array}{l}\text { Solos arenosos com baixo teor de argila total, inferior a } 8 \% \text {, não havendo rocha nem camadas } \\
\text { argilosas, e nem mesmo densificadas até a profundidade de 1,5m. O teor de húmus é muito baixo } \\
\text { não atingindo 1\%. }\end{array}$ \\
\hline B & $\begin{array}{l}\text { Solos arenosos menos profundos que o Grupo A e com menos teor de argila total, porém ainda } \\
\text { inferior a 15\%. No caso de terras roxas, esse limite pode subir a 20\% graças a menor porosidade. } \\
\text { Os dois teores de húmus podem subir, respectivamente, a 1,2 e 1,5\%. Não pode haver pedras e nem } \\
\text { camadas argilosas até 1,5m, mas é, quase sempre, presente camada mais densificada que a camada } \\
\text { superficial. }\end{array}$ \\
\hline C & $\begin{array}{l}\text { Solos barrentos com teor total de argila de 20 a 30\%, mas sem camadas argilosas impermeáveis ou } \\
\text { contendo pedras até profundidade de 1,2m. No caso de terras roxas, esses dois limites máximos } \\
\text { podem ser de 40\% e 1,5m. Nota-se a cerca de 60cm de profundidade, camada mais densificada que } \\
\text { no Grupo B, mas ainda longe de condições de impermeabilidade. }\end{array}$ \\
\hline D & $\begin{array}{l}\text { Solos argilosos (30 a 40\% de argila total) e ainda com camada densificada a uns 50cm de } \\
\text { profundidade. Ou solos arenosos como o Grupo B, mas com a camada argilosa quase impermeável, } \\
\text { ou horizontes de seixos rolados. }\end{array}$ \\
\hline
\end{tabular}

Fonte: Adaptado de Tucci (1998) 
A estimativa da constante de recessão do escoamento fluvial de origem subterrânea, $\alpha$, pode ser realizada a partir da análise da curva de recessão do hidrograma. O decréscimo da vazão depois da ocorrência de picos de cheia de acordo com Hipólito e Vaz (2011), segue um padrão que pode ser expresso por uma função do tipo exponencial negativo representada pela equação:

$$
Q=Q_{0} \cdot e^{-\alpha t}
$$

em que $\mathrm{Q}$ representa a vazão $\mathrm{em} \mathrm{m}^{3} / \mathrm{s}$ após um período $\mathrm{t}$ (dias); $\mathrm{Q}_{0}$, a vazão $\mathrm{em} \mathrm{m}^{3} / \mathrm{s}$ no instante $t_{0}$ adotado como origem do decréscimo, e $\alpha$, a constante de recessão.

Uma vez que a partir de $t_{0}$ não ocorre precipitação e que a lei da recessão se manteria, então, o volume de água que escoa pela secção transversal é expresso pela seguinte equação:

$$
V_{0}=\int_{t_{0}}^{\infty} Q d t=\int_{t_{0}}^{\infty} Q_{0} e^{-\alpha\left(t-t_{0}\right)} d t=\frac{Q_{0}}{\alpha}
$$

E, a equação a seguir representa o volume a partir de qualquer instante $\mathrm{t}$ no decréscimo.

$$
V=-\frac{Q}{\alpha}
$$

A equação anterior, representa também o comportamento de um tipo de reservatório onde a vazão que escoa é proporcional ao volume de água que armazena, e que se designa por reservatório linear.

A constante de recessão numa dada secção de um curso de água, pode ser estimada com base em hidrogramas de cheia observados. De fato, a representação num gráfico semilogarítmico $(t, \ln Q)$ de cada hidrograma observado revela um andamento em forma de segmento de reta nos períodos com ausência de precipitação e afastados da ocorrência anterior de escoamento superficial, ou seja, em período de esgotamento dos aquíferos da bacia hidrográfica (HIPÓLITO, 1996).

Em relação a constante de recarga profunda, $\beta$, não existem técnicas para sua estimativa na literatura, no entanto, a abordagem mais conservadora é assumir que $\beta$ é nulo, ou seja, toda a precipitação existente na bacia é transformada em evapotranspiração ou vazão. Por outro lado, a constante também pode ser determinada por calibração. 
A formulação do modelo foi originalmente escrita em QuickBasic para MS-DOS. Neste trabalho a formulação do modelo foi transcrita para fórmulas no Microsoft Excel.

\subsubsection{SWAT}

A bacia hidrográfica no modelo SWAT é dividida em sub-bacias, cada uma subdividida em HRUs. As HRUs são áreas homogêneas, dentro da sub-bacia, que possuem uma combinação única de cobertura de terra, solo, declividade e práticas conservacionistas. Uma sub-bacia contém pelo menos uma HRU, um canal tributário e um canal principal (NEITSCH et al., 2009).

O modelo SWAT requer dados meteorológicos diários e atribui o mesmo indicador meteorológico a todas HRUs dentro de uma sub-bacia. O modelo escolhe automaticamente uma estação meteorológica para cada sub-bacia, com base na distância entre o centroide da sub-bacia e estação pluviométrica.

Para a delimitação das HRUs os mapas de uso e ocupação do solo, bem como o mapa com os tipos de solos são inseridos e a opção de criação de HRUs múltiplas foi selecionada neste trabalho, com intuito de obter áreas com combinações entre tipos de uso e ocupação do solo, tipos de solos e declividade das áreas.

O modelo SWAT requer dois tipos de dados de entrada: informações espaciais e dados tabulares. As informações espaciais contemplam o MDT, o mapa de uso e de ocupação dos solos e o mapa de tipos de solos, já os dados tabulares comtemplam as informações relativas a cada classe de uso e ocupação do solo e tipo de solo, dados meteorológicos, etc.

O processo de simulação no SWAT requer uma sequência de entrada de dados que são requisitados ao utilizador uma vez que se trabalhe na interface em ArcView GIS. Primeiramente a bacia hidrográfica é delimitada a partir do MDT disponibilizado, e em seguida são delimitados os cursos de água conforme a ordem de grandeza especificada pelo utilizador.

Esta investigação adotou a versão SWAT 2000 (DI LUZIO et al., 2002) que incorpora uma interface ArcView GIS para otimizar a entrada e a saída do modelo.

O balanço hídrico é a força motriz por trás de todos os cálculos no SWAT, incluindo o movimento de água, pesticidas, sedimentos e nutrientes. O cálculo dos fluxos de água e materiais através da bacia hidrográfica é separado em dois componentes principais. O primeiro considera a fase terrestre do ciclo hidrológico e calcula a quantidade de água, sedimentos, nutrientes e pesticidas que atinge o canal principal de cada sub-bacia. $\mathrm{O}$ segundo 
componente é a fase aquática que traça o movimento de água, sedimentos e contaminantes através da rede de canais para a saída da bacia hidrográfica (NEITSCH et al., 2009).

A fase terrestre é mostrada na figura 2, onde o perfil hidrológico é dividido em 3 camadas. A zona não saturada e o aquífero superficial contribuem para o fluxo total no canal, enquanto o aquífero profundo recebe percolação profunda da camada superior, mas não contribui para o fluxo na saída da bacia hidrográfica. A zona não saturada é subdividida em camadas, de acordo com os tipos de solo que ocorrem na área.

Figura 2 - Esquematização do modelo SWAT

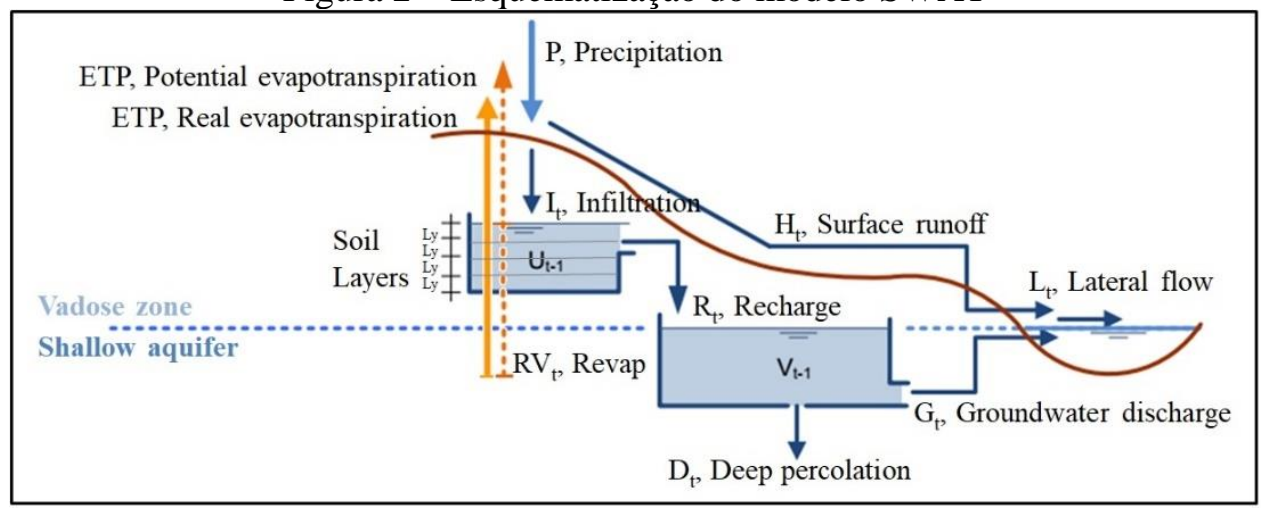

Fonte: Próprio autor

A precipitação no modelo SWAT é dividida em precipitação e neve. Como a última não ocorre na região de estudo, foi desconsiderada neste trabalho. No que respeita à evapotranspiração potencial estão disponíveis três opções para a estimar: métodos de PenmanMonteith, Priestley-Taylor e Hargreaves (NEITSCH et al., 2005). O método PenmanMonteith foi selecionado neste estudo, pois é considerado o método mais completo e preciso para estimar a evapotranspiração potencial.

A quantidade de água armazenada na zona não saturada no final do intervalo de tempo, $t$, pode ser calculada por um balanço hídrico aplicado a cada camada de solo. $\mathrm{O}$ balanço hídrico geral da zona não saturada é calculado por:

$$
U_{t+1}=U_{t}+P_{t}-E T R_{t}-H_{t}-L_{t}-R_{t}
$$

onde $U_{t+1}$ é a quantidade final de água na zona não saturada $(\mathrm{mm} / \mathrm{dia}), U_{t}$ é a quantidade inicial de água no solo na zona não saturada $\left(\mathrm{mm} /\right.$ day), $P_{t}$ é a precipitação $\left(\mathrm{mm} /\right.$ day), $E T R_{t}$ é a evapotranspiração ( $\mathrm{mm} /$ day) e $R_{t}$ é a recarga no aquífero superficial ( $\left.\mathrm{mm} / \mathrm{dia}\right)$.

$H_{t}$ é a quantidade de água proveniente do escoamento superficial $(\mathrm{mm} / \mathrm{dia})$ e é calculada usando uma versão modificada do número da curva SCS-CN (USDA-SCS, 1972). 
Alternativamente, o SWAT também pode estimá-lo usando o método de infiltração Green \& Ampt.

$L_{t}$ é o fluxo lateral (mm/dia) originário da zona não saturada. O SWAT incorpora um modelo de armazenamento cinemático para fluxo lateral, desenvolvido por Sloan et al. (1983), que simula o fluxo subterrâneo em uma seção transversal bidimensional ao longo de um caminho de fluxo abaixo de uma colina íngreme. O modelo baseia-se na equação de continuidade de massa, ou no balanço hídrico de massa, com todo o segmento de colinas utilizado como volume de controle (ARNOLD et al., 1998).

O SWAT divide a parte saturada do solo em duas zonas: um aquífero pouco profundo e não confinado, que contribui para o fluxo de córregos e um aquífero mais profundo e confinado, o que contribui para o fluxo a jusante da saída da bacia hidrográfica (ARNOLD et al. 2012). O balanço hídrico no aquífero pouco profundo pode ser calculado pela seguinte equação:

$$
V_{t+1}=V_{t}+R_{t}-G_{t}-R V_{t}
$$

onde $V_{t+1}$ é o teor final de água do solo no aquífero pouco profundo $(\mathrm{mm} / \mathrm{dia}), V_{t}$ é o teor inicial de água do solo no aquífero pouco profundo $(\mathrm{mm} / \mathrm{dia}), R_{t}$ é a recarga para o aquífero pouco profundo (mm/dia), Gt é a quantidade de retorno de água para o fluxo e $R V_{t}$ é a quantidade de água que é removida do aquífero pouco profundo via evapotranspiração, designada como revap ( $\mathrm{mm} / \mathrm{dia})$.

O fluxo total que atinge os fluxos da bacia hidrográfica pode ser calculado por:

$$
T_{t}=H_{t}+L_{t}+G_{t}
$$

\subsection{Processos erosivos e sedimentológicos}

\subsubsection{Produção e transporte de sedimentos}

A erosão do solo está entre as causas da diminuição da qualidade da água, devido à quantidade de sedimentos que são carregados e depositados nos cursos de água (MENESES et al., 2015). Os sedimentos são, provavelmente, o mais significativo de todos os poluentes em termos de sua concentração na água, seus impactos no uso da água e seus efeitos no transporte de outros poluentes. 
A produção de sedimentos numa bacia hidrográfica é difícil de ser estimada, uma vez que é resultado de uma complexa interação de vários processos hidrogeológicos (SINGH; MALIK; SINHA, 2005). Em ambientes naturais os sedimentos desagregados são provenientes do intemperismo de rochas associados com os fatores climáticos (características da precipitação e temperatura) e caraterísticas físicas da área, como pedologia e geomorfologia. Em ambientes rurais esses sedimentos são provenientes das atividades agrícolas que utilizam defensivos agrícolas como agrotóxicos, fertilizantes e resíduos derivados da criação intensiva de animais. Já em ambientes urbanos a composição dos sedimentos é mais complexa devido aos tipos de uso e ocupação serem os mais diversos contribuindo com a geração dos sedimentos (MINELLA et al., 2007).

Todos estes ambientes contribuem com sedimentos para os rios através de um processo natural que envolve erosão, remoção, transporte e deposição de material. Exemplos de sedimentos que podem ser transportados para a calha fluvial são os agrotóxicos, resíduos de construção civil, metais, resíduos industriais, efluentes industriais e domésticos, dentre outros.

A erosão e o transporte de sedimentos são fenômenos interligados e complexos que dependem dos processos erosivos que ocorrem nas vertentes da bacia e no leito e margens dos rios, onde tem origem o material erodido passível de ser transportado. Dependem ainda da energia do fluxo para transportar esse material. A combinação do fornecimento de material e da energia do fluxo para o transportar resulta em um fenômeno com grande variação no tempo e no espaço, que formas geomorfológicas e condiciona a evolução da paisagem (ADRIOLO et al., 2008).

$\mathrm{Na}$ descrição dos processos erosivos é importante distinguir dois contextos ou meios, com distintos agentes erosivos, ambos com poder para transformar paisagens e implementar novas dinâmicas naturais ao longo do tempo geológico (SILVA, 2012). Numa encosta ocorrem processos erosivos com origem pluvial quer podem reduzir a espessura do solo e diminuir a sua capacidade de retenção de água, gerando como consequência maiores escoamentos superficiais e, por vezes, maiores taxas de erosão do solo e, consequentemente, maior produção de sedimentos. Nos canais fluviais, a corrente de fluxo d'águas dos rios pode causar o transporte do material do leito e a destruição progressiva das áreas marginais por desmoronamento ou escorregamento, sobretudo na época de cheias, ocasionando a fragilidade do ambiente local e limitação para seu uso

A ação pluvioerosiva sobre a superfície das encostas depende da capacidade da precipitação pluviométrica de ocasionar os processos erosivos (erosividade), das 
características e condição do solo, do relevo, da cobertura vegetal e tipo de cultivo e, ainda da aplicação de práticas conservacionistas (SANTOS; GRIEBELER; OLIVEIRA, 2010).

O potencial erosivo da precipitação (i.e. erosividade) depende da energia cinética dos eventos de chuva que é função das características das gotas de chuva que variam em tempo e no espaço e da quantidade e intensidade da precipitação (CUNHA; GUERRA,1998).

A erodibilidade do solo é a capacidade do solo de resistir a processos erosivos e depende das suas características como a textura, a densidade aparente, a porosidade, o teor de matéria orgânica, o teor e estabilidade dos agregados e pH do solo (SILVA; SHULZ; CAMARGO, 2003). Depende ainda o estado de umidade do solo.

A erosão dos solos é também condicionada pelo relevo e pelas características das encostas, nomeadamente a sua declividade, comprimento e forma. As características da cobertura do solo também se constituem como um fator condicionante, uma vez que, uma superfície vegetada possui alta capacidade de retenção de água no solo, e proteção do solo contra os impactos das gotas de chuva, evitando a desagregação de suas partículas e consequentes processos erosivos (CUNHA; GUERRA, 1998).

A erosão nos canais fluviais ocorre através de diversos processos, como a suspensão, saltação e o rolamento, consoante a granulometria dos sedimentos (tamanho e forma) e as características do próprio fluxo, concretamente a turbulência e as forças hidrodinâmicas exercidas sobre as partículas. Por regra, a carga sólida de fundo formada por partículas de tamanhos maiores (areia, cascalho ou seixos rolados) saltam ou rolam ao longo do leito fluvial. Já a carga em suspensão é constituída por partículas finas (silte e argila) que se conservam suspensas na água enquanto a velocidade do fluxo conseguir movimentá-las (CUNHA, 2008).

A identificação das fontes de sedimentos pode fornecer um entendimento e uma avaliação do impacto do uso e manejo do solo nos processos hidrossedimentológicos, e assim contribuir para a qualidade ambiental da bacia hidrográfica e para a conservação e preservação dos recursos hídricos.

O conhecimento da relação entre a erosão do solo e a produção de sedimentos é importante para prever a produção de sedimentos e avaliar o impacto de determinados cenários de uso da terra na geração desses sedimentos (RODRÍGUEZ-BLANCO; TABOADA - CASTRO; TABOADA-CASTRO, 2013). O planejamento territorial em escala de bacia hidrográfica pode assegurar a aplicação das melhores práticas de uso e ocupação do solo para controlar os processos erosivos e a produção de sedimentos que atingem os cursos de água, e desta forma contribuir para a conservação da qualidade dos recursos naturais. 


\subsubsection{Equação Universal de Perda de Solos - EUPS}

A produção de sedimentos de uma bacia hidrográfica é definida como o fluxo total de sedimentos com origem na bacia hidrográfica e que é medido na sua secção de referência, durante um período especificado (VAN ROMPAEY et al., 2001). Pode ser expresso em termos absolutos (por exemplo, ton/ano) ou em termos específicos da área (por exemplo, ton/ha/ano).

Segundo Guimarães et al. (2011), o estudo da produção destes sedimentos pode ser realizado a partir de métodos diretos, ou seja, baseados na coleta do material erodido, em campos experimentais; ou métodos indiretos, por meio da aplicação de modelos matemáticos. Um dos métodos indiretos muito utilizado e pesquisado é a Equação Universal de Perda de Solo (EUPS ${ }^{13}$ ) muito utilizada em diversos modelos hidrossedimentológicos.

A EUPS permaneceu, por quase 40 anos, como o método mais prático para estimar o potencial de erosão do solo e estimar os efeitos de diferentes práticas conservacionistas na erosão do solo (LIM et al., 2005). Wischmeier e Smith $(1965,1978)$ coletou dados de erosão do solo de 8.000 comunidades de 36 regiões de 21 estados dos EUA e analisou e avaliou vários fatores determinantes para o processo de erosão do solo e desenvolveu a EUPS para avaliar a erosão do solo por água.

A equação prevê a taxa média anual de perda de solo a longo prazo com origem numa encosta, com base no padrão de precipitação, tipo de solo, topografia, sistema de cultivo e práticas conservacionistas. A sua formulação é a seguinte:

$$
P S=R \cdot K \cdot L \cdot S \cdot C \cdot P
$$

em que: PS: fator que corresponde à média de perda de solo devido à erosão hídrica por unidade de área e tempo (ton/ha/ano); $R$ : fator de erosividade da chuva, expressa a erosão potencial, ou poder erosivo da precipitação média anual da região (MJ.mm/ha.h); $K$ : fator de erodibilidade do solo que representa a capacidade do solo de sofrer erosão por uma determinada chuva; ton/h/MJ.mm); L: fator topográfico que expressa o comprimento do declive (m); $S$ : fator topográfico, que expressa a declividade do terreno ou o grau de declive (graus); $C$ : fator que expressa uso e manejo do solo e cultura (adimensional); $P$ : fator que representa as práticas conservacionistas (adimensional).

\footnotetext{
${ }^{13} \mathrm{O}$ acrónimo em inglês é USLE (Universal Soil Loss Equation).
} 
A EUPS fornece como resultado a média de longo período para uma área considerada homogênea, não sendo possível discretizar minuciosamente a variabilidade espacial da perda de solo e das áreas fontes de sedimentos, principalmente em áreas de relevo complexo, como as bacias hidrográficas. No entanto a utilização conjunta com um SIG permite a espacialização dos fatores que determinam a perda de solo e, consequentemente, realizar o cálculo independente da complexidade espacial dos fatores.

A EUPS foi desenvolvida inicialmente para estimar o total de perda de solo anual, não considerando a deposição dos sedimentos que ocorre em bacias hidrográficas nas zonas de menor declive ou com vegetação com capacidade para reter sedimentos. Por essa razão, a produção de sedimentos é geralmente menor do que as estimativas fornecidas pela equação. Assim, as estimativas da EUPS precisam ser afetadas por uma razão de entrega de sedimentos (SDR) para obter estimativas da quantidade de sedimentos que atinge a rede hidrográfica (KHANBILVARDI; ROGOWSKI, 1984).

Os valores da SDR podem ser influenciados por fatores como a fonte de sedimentos, textura, proximidade ao canal principal, densidade do canal, área da bacia, declividade, uso e ocupação do solo e relação entre chuva-escoamento. Em geral, quanto maior a área da bacia hidrográfica menor será o valor da SDR (OUYANG, 1997).

$\mathrm{Na}$ literatura são encontrados diversos métodos para a estimativa da SDR (RENFRO, 1975; ROEHL, 1962; USDA-SCS, 1972; VANONI, 1975; WILLIAMS; HAROLD, 1972), desenvolvidos com base em medições da razão de entrega de sedimentos em diversas regiões específicas e que dependem de vários fatores como a área de drenagem, a relação precipitação-escoamento e a declividade do terreno. Devido à natureza complexa retenção de sedimentos, é difícil identificar o melhor método, mas é consensual que a área é o principal fator que influencia o SDR (OUYANG, 1997).

Neste sentido, Vanoni et al. (1975) utilizou dados de 300 bacias hidrográficas ao redor do mundo para desenvolver uma função para estimativa de SDR com base na área de drenagem das bacias hidrográficas.

$$
S D R=0,3750 \cdot A^{-0,2382}
$$

onde A representa a área de drenagem em $\mathrm{km}^{2}$. O cálculo da produção de sedimentos que atinge a rede hidrográfica pode ser aprimorado através da multiplicação entre o resultado obtido pela aplicação da EUPS e o fator SDR.

A partir da EUPS, foram desenvolvidos outros modelos para estimativa da quantidade de material sólido erodido numa bacia hidrográfica em diferentes condições. 
A MUSLE $^{14}$ (Modified Universal Soil Loss Equation) (WILLIAMS, 1975) foi desenvolvida para estimar a produção de sedimentos oriunda de um evento isolado de chuva e contempla os mesmos fatores da EUPS, com exceção da erosividade das chuvas que é substituída por fatores que envolvem os processos hidrológicos na bacia. A MUSLE é representada pela seguinte equação:

$$
P S=a \cdot\left(H \cdot q_{\text {peak }} \cdot A\right)^{\beta} \cdot K \cdot L \cdot S \cdot C \cdot P
$$

em que $a$ e $\beta$ são coeficientes de regularização, definidos como originais por Williams (1975) como 89,6 e 0,56 respetivamente. O modelo SWAT utiliza o valor de 11,8 para o coeficiente $a$, definido por Sadeghi et al., (2007) e o valor original para $\beta$. $H$ é definido como a altura de escoamento superficial (mm), e $q_{\text {peak }}$ a vazão de pico do evento $\left(\mathrm{m}^{3} / \mathrm{s}\right)$.

A RUSLE ${ }^{15}$ (Revised Universal Soil Erosion Equation) (RENARD et al., 1991) utiliza a mesma equação empírica da EUPS, mas recorre a novos métodos para estimar os fatores da equação. Esses novos métodos permitem a inclusão de informações quantitativas sobre a variação sazonal do fator de erodibilidade do solo, declividade e relações entre manejo e cultura e seu efeito sobre a produção de material sólido.

Diversos modelos matemáticos utilizam a EUPS, ou as suas variantes, nas suas formulações para estimar a produção de material sólido. São exemplo o Water Erosion Prediction Project (WEPP) (FLANAGAN; NEARING, 1995), Soil Water Assessment Tool (SWAT) (ARNOLD; FOHRER, 2005; ARNOLD et al., 1998) e o European Soil Erosion Model (EUROSEM) (MORGAN et al., 1998).

A EUPS e as suas variantes foram desenvolvidas para climas temperados, não sendo clara a aplicabilidade às condições tropicais onde há ocorrência de alta pluviosidade e uma outra diversidade de cobertura vegetal e de características de solos. A sua aplicação só é viável no Brasil devido a estudos para determinação de parâmetros da EUPS em condições locais (BERTOLINI; LOMBARDI NETO, 1990). Lombardi-Neto e Bertolini (1975) foram os primeiros a aplicar a EUPS no Brasil, concretamente no Estado de São Paulo, onde

${ }^{14}$ Optou-se por utilizar o acrónimo em inglês, uma vez que não existe um acrónimo em português com aceitação generalizada.

15 Idem. Optou-se por utilizar o acrónimo em inglês, uma vez que não existe um acrónimo em português com aceitação generalizada. 
apresentou resultados satisfatórios. Desde então tem sido avaliada por vários autores quanto a sua aplicabilidade em características tropicais, dentre esses estão: Brito et al., (1998); Carvalho (1994); Marcomin (2002); Minella; Merten; Ruhoff (2010) e Souto (1998).

A seguir serão apresentados os fatores necessários para a aplicação da USLE, suas definições e métodos disponíveis na literatura para determinação.

\section{- Erosividade da chuva-Fator $R$}

O fator erosividade da chuva, $\mathrm{R}$, expressa à capacidade da chuva de provocar erosão em um solo desprotegido em uma determinada área. O seu cálculo é oriundo de um estudo detalhado das características das precipitações ao longo do ano que quantifica a energia disponível para o impacto das gotas de chuva e a taxa de arraste do solo resultante do escoamento superficial (WISCHMEIER; SMITH, 1978). Quando outros fatores, à exceção da chuva, são mantidos constantes, as perdas de solo ocasionadas pelas chuvas nos terrenos cultivados são diretamente proporcionais ao valor do produto de duas características de chuva: sua energia cinética total (do impacto das gotas sobre a superfície do solo) e sua intensidade máxima em trinta minutos (BERTOLINI; LOMBARDI NETO, 1990). Esse produto representa um termo de interação que mede o efeito de como a erosão por impacto, o salpico e a turbulência se combinam com a enxurrada para transportar as partículas de solo desprendidas.

Wischmeier; Smith, (1958) propôs uma metodologia para estimativa da capacidade erosiva da chuva que requer a utilização de registros pluviográficos. Através da leitura dos pluviogramas é possível a determinação da energia cinética e a intensidade máxima de precipitação em 30 minutos. De acordo com esta metodologia, o valor do índice de erosividade em trinta minutos para um evento pluvioso $j$ é calculado pela seguinte equação:

$$
\begin{array}{ll}
E_{j}=0,119+0,0873 \cdot \log _{10} I_{j}^{30} & \mathrm{I}<76 \mathrm{~mm} / \mathrm{h} \\
E_{j}=0,263 & \mathrm{I}>76 \mathrm{~mm} / \mathrm{h}
\end{array}
$$

em que: $E_{j}$ é a energia cinética da chuva $\left(\mathrm{MJ}\right.$ ha. $\left.\mathrm{mm}^{-1}\right), I$ é definido como intensidade de chuva em cada segmento com intensidade constante $\left(\mathrm{mm} \cdot \mathrm{h}^{-1}\right)$.

A soma dos índices de erosividade em 30 minutos constitui-se na erosividade da chuva para aquele período de análise, ou seja: 


$$
R_{i}=\sum_{j=1}^{m}\left(E I_{30}\right)_{j}
$$

Diversas pesquisas foram realizadas no sentido de estabelecer índices ou equações que possibilitem avaliações confiáveis da capacidade erosiva das chuvas utilizando registros pluviométricos.

Os resultados obtidos por Fournier (1960) comprovaram a possibilidade de estimativas satisfatórias para a erosividade com boas correlações com as perdas de solo. O autor concluiu que os parâmetros utilizados na estimativa da erosividade podem ser dependentes de condições locais como localização geográfica, topografia e tipo de medida. Em Campinas (SP), Lombardi e Moldenhauer (1980) analisaram 22 anos de registros de precipitação e encontraram um elevado coeficiente de correlação para regressão linear entre o índice mensal de erosão e o coeficiente chuva, com base na proposição de Fournier (1960):

$$
E_{j}=68,730 \cdot\left(\frac{p^{2}}{P}\right)^{0,841}
$$

onde, $E_{j}$ define-se como a média mensal do índice de erosão (MJ.mm/ha.h.ano); $p$ é precipitação média mensal (mm) e $P$ a precipitação média anual (mm).

De acordo com Lombardi e Moldenhauer (1980), o fator de erosividade anual, R, é a soma dos valores mensais do índice de erosão. Para este estudo, a equação foi adaptada para permitir o cálculo de R com um passo de tempo diário:

$$
R_{t}=\left(\frac{P_{t}^{d^{2}}}{\sum_{t \in m} P_{t}^{d^{2}}}\right) \cdot E_{m}
$$

A erosividade da chuva pode ser classificada de acordo com a tabela 2 adaptada de Foster, (1981).

Tabela 2 - Classificação da erosividade das chuvas de acordo com o fator $\mathrm{R}$

\begin{tabular}{l|l}
\hline Erosividade (MJ.mm/ha.h.ano) & Classificação \\
\hline $\mathrm{R} \leq 2452$ & Erosividade fraca \\
\hline $2452<\mathrm{R} \leq 4905$ & Erosividade moderada \\
\hline $4905<\mathrm{R} \leq 7357$ & Erosividade moderada a forte \\
\hline $7357<\mathrm{R} \leq 9810$ & Erosividade forte \\
\hline
\end{tabular}


Fonte: Próprio autor

\begin{tabular}{l|l}
\hline $\mathrm{R}>9810$ & Erosividade muito forte \\
\hline
\end{tabular}

Outros autores desenvolveram equações para determinar os valores de erosividade mensais/anuais para regiões do território brasileiro. A tabela 3 apresenta as equações e os seus respectivos autores.

Tabela 3 - Equações desenvolvidas para determinar os valores de erosividade para áreas do território brasileiro e seus respectivos autores

Fonte: Próprio autor

\begin{tabular}{cc|l}
\hline Equações & & Autor (es) \\
\hline$E_{j}=3,76 \cdot\left(\frac{p^{2}}{P}\right)+42,77$ & $(29)$ & Oliveira e Medina (1990) \\
\hline$E_{j}=36,849 \cdot\left(\frac{p^{2}}{P}\right)^{1,0852}$ & $(30)$ & Morais et al., (1991) \\
\hline$E_{j}=0,66 \cdot p+8,88$ & $(31)$ & Oliveira Jr., (1988) \\
\hline$E_{j}=0,13 \cdot\left(p^{1,24}\right)$ & $(32)$ & Leprun (1981) \\
\hline$E_{j}=12,592 \cdot\left(\frac{p^{2}}{P}\right)^{0,6030}$ & $(33)$ & Val et al., (1986) \\
\hline$E_{j}=68,73 \cdot\left(\frac{p^{2}}{P}\right)^{0,841}$ & $(34)$ & Rufino et al., (1993) \\
\hline
\end{tabular}

- Erodibilidade do Solo - Fator K

O significado de erodibilidade do solo é diferente de erosão do solo, uma vez que, a erosão de uma área qualquer pode ser mais influenciada pela precipitação, declividade do terreno, cobertura vegetal e manejo, do que pelas propriedades do solo (BERTOLINI; LOMBARDI NETO, 1990). No entanto, quando a declividade, a precipitação, a cobertura vegetal e as práticas de controle de erosão são as mesmas, alguns solos são mais facilmente erodidos que outros. Essa diferença, devida as propriedades inerentes ao solo, é referida como erodibilidade do solo.

As propriedades do solo que influenciam a erodibilidade pela água são aquelas que afetam a capacidade de infiltração e de armazenamento de água no solo e a capacidade de resistência à abrasão, fragmentação e transporte de sedimentos pela precipitação e escoamento superficial (SIMMS; WOODROFFE; JONES, 2003). Segundo Wischmeier e Smith (1978), o fator erodibilidade do solo, $K$, é o fator mais importante no diagnóstico da erosão e no planejamento do uso do solo.

Middleton (1930) foi um dos pioneiros a estudar a relação entre a erodibilidade do solo e as suas propriedades físicas, tendo identificado que os solos resistentes à erosão têm 
como características maior teor de partículas de argila, maior relação colóide/umidade equivalente, maior peso específico, menor limite de plasticidade, menor dispersão e menor taxa de erosão.

Um dos métodos amplamente utilizado para determinação da erodibilidade do solo foi proposto por Wischmeier; Johnson; Cross (1971) e tem como base os parâmetros textura, estrutura, classes de permeabilidade e porcentagem de matéria orgânica combinando-os graficamente em um nomograma com a seguinte formulação:

$$
K=\frac{2,1 \cdot M^{1,14} \cdot 10^{-4} \cdot(12-M o)+3,2 \cdot(c e-2)+2,5 \cdot(c p-3)}{759,3}
$$

em que: $K$ é o valor de perda de solo por unidade de erosividade da precipitação (ton.h.MJ$\left.{ }^{1} \cdot \mathrm{mm}^{-1} \cdot \mathrm{ano}^{-1}\right) ; M$ é a soma dos teores de silte (\%) e areia muito fina (\%) multiplicado por 100 , menos o teor de argila (\%); Mo é o teor de matéria orgânica (\%); ce é o código de classe de estrutura do solo (1 a 4), e $c p$ é o código de classe de permeabilidade do solo (1 a 6 ) apresentado na tabela 4.

Tabela 4 - Código de permeabilidade das classes texturais dos horizontes de solo

\begin{tabular}{l|l|l}
\hline Classe textural & $\begin{array}{l}\text { Classe de } \\
\text { permeabilidade }\end{array}$ & Permeabilidade \\
\hline Muito argilosa, Argilosa e Argilo-siltosa & 6 & Muito Lenta \\
\hline Franco-argilo-siltosa e Argilo-arenosa & 5 & Lenta \\
\hline Franco-argilo-arenosa e Franco-Argilosa & 4 & Lenta A Moderada \\
\hline Franca, Franco-siltosa e Siltosa & 3 & Moderada \\
\hline Areia-franca e Franco-arenosa & 2 & Moderada A Rápida \\
\hline Arenosa & 1 & Rápida \\
\hline
\end{tabular}

Fonte: Wischmeier; Johnson; Cross (1971)

Outros métodos para a estimativa de $K$ são citados na literatura e incluem Denardin (1990), Lima et al. (1990) e Roloff e Denardin (1994).

No Brasil, Bertolini e Lombardi Neto $(1990,1994)$ estabeleceram para vários solos do Estado de São Paulo os valores de $K$, medidos diretamente no campo, bem como sua tolerância a perdas de solos. O total de 66 perfis foram estudados para dois agrupamentos de solos que ocorrem no estado e foram analisados conforme o método de Middleton (1930) com modificações.

Outros trabalhos também realizaram a estimativa do fator $K$ para solos brasileiros, Mannigel et al. (2002), estudaram 25 perfis representativos de solos de acordo com a nova 
classificação (sistema brasileiro de classificação de solos de 1999), e utilizaram a expressão de Bouyoucos para a determinação indireta do fator de erodibilidade para os horizontes superficiais e subsuperficiais.

A tabela 5 apresenta alguns tipos de solo e os respectivos valores para o fator $\mathrm{K}$ estimados por Bertolini e Lombardi Neto (1990) e Mannigel et al. (2002), selecionados de acordo com a ocorrência nos casos de estudo deste trabalho.

Tabela 5 - Valores do fator erodibilidade $(\mathrm{K})$

\begin{tabular}{|c|c|c|}
\hline & $\begin{array}{ll}\text { Classe de solo } \\
\end{array}$ & $\boldsymbol{K}$ (t.ha.h/ha.MJ.mm) \\
\hline $\mathrm{AQ}$ & Neossolo quartzarênico - órtico típico a fraco & 0,1448 \\
\hline Or & Gleissolo háplico - distrófico típico a moderado, textura errática & 0,0044 \\
\hline LE-1 & $\begin{array}{l}\text { Latossolo vermelho - distrófico típico a moderado textura muito } \\
\text { argilosa }\end{array}$ & 0,0061 \\
\hline LRd & $\begin{array}{l}\text { Latossolo vermelho - distroférrico típico a moderado textura muito } \\
\text { argilosa }\end{array}$ & 0,0071 \\
\hline LV-2 e LV-5 & Latossolo vermelho - amarelo alumínico & 0,0223 \\
\hline LV-6 & Latossolo vermelho amarelo - distrófico a moderado textura argilosa & 0,0112 \\
\hline Li-3 & Neossolo litólico - eutrófico chernossólico & 0,0250 \\
\hline $\mathrm{PV}-2$ & $\begin{array}{l}\text { Luvissolo crômico - pálico planossólico a moderado textura } \\
\text { arenosa/média }\end{array}$ & 0,2466 \\
\hline PV-3 & $\begin{array}{l}\text { Nitossolo háplico - distrófico típico a moderado textura média / } \\
\text { argilosa }\end{array}$ & 0,0355 \\
\hline PV-4 e PV-5 & $\begin{array}{l}\text { Argissolo vermelho-amarelo - distrófico típico a moderado textura } \\
\text { média/argilosa }\end{array}$ & 0,0466 \\
\hline TE-2 & $\begin{array}{l}\text { Nitossolo vermelho - eutroférrico típico a moderado textura muito } \\
\text { argilosa }\end{array}$ & 0,0081 \\
\hline
\end{tabular}

Fonte: Bertolini e Lombardi Neto (1990) e Mannigel et al. (2002)

\section{- Fator topográfico - Fatores L e S}

O fator $L S$ combinado reflete o efeito da topografia na erosão do solo. Entre os seis fatores de entrada da EUPS, a combinação do comprimento (L) e da declividade da encosta (S) é um dos que tem a maior influência na perda de solo (MCCOOL; FOSTER; WEESIES, 1997). Um aumento no comprimento ou na inclinação da encosta produz velocidades de escoamento mais elevadas e consequentemente maior erosão (KOULI; SOUPIOS; VALLIANATOS, 2009).

O comprimento da encosta pode ser definido como a distância do ponto de origem do escoamento superficial até o ponto em que: a) o gradiente da inclinação diminui o suficiente para ocorrer a deposição; b) o fluxo é concentrado num canal definido (WISCHMEIER; SMITH, 1978). 
De acordo com a proposta de Wischmeier e Smith, (1978), o fator $L S$ é definido como a relação esperada de perdas de solo por unidade de área em um declive qualquer em relação a perdas de solos correspondentes de uma parcela unitária para o mesmo solo, de 25 metros de comprimento e $9 \%$ de declividade. De acordo com os autores, $L S$ pode ser calculado pela seguinte formulação:

$$
L S=\left(\frac{\lambda}{72,6}\right)^{m} \cdot\left(65,41 \cdot \sin ^{2} \theta+4,56 \cdot \sin \theta+0,065\right)
$$

onde: $\lambda$ é o comprimento da vertente $(\mathrm{m}) ; \theta$ é o ângulo da declividade e $\mathrm{m}$ é o coeficiente que varia com a declividade ou seja: 0,5 se a inclinação percentual for $5 \%$ ou mais, 0,4 em declives de 3,5 a 4,5\%, 0,3 em declives de 1 a $3 \%$ por cento e 0,2 em gradientes uniformes de menos de $1 \%$.

Esta equação não mensura o cálculo do fator $L S$ para vertentes com declividades irregulares. No entanto, Foster e Wischmeier (1974) desenvolveram uma técnica para avaliar o fator topográfico, para diferentes declividades ao longo da vertente:

$$
L S_{j}=\frac{S_{j} \cdot \lambda_{j}^{1.5}-S_{j} \cdot \lambda_{j-1}^{1.5}}{\lambda_{e} \cdot(72,6)^{0,5}}
$$

em que $S_{j}$ corresponde ao fator $\mathrm{S}$ calculado com base no ângulo de declividade do seguimento $j$ e $j$ ao comprimento da encosta medido do divisor de águas até a jusante do seguimento $j$; o termo $\lambda_{j}$ é a distância, em pés, do topo da inclinação para a extremidade inferior do segmento, $\mathrm{j} ; \lambda_{j-1}$ é o comprimento da inclinação acima do segmento $j$; e $\lambda_{e}$ é o comprimento total da inclinação.

A técnica também fornece um meio de avaliar os efeitos das diferenças na erodibilidade do solo que podem estar associadas a mudanças na inclinação da encosta. No entanto, não prevê deposição que pode ocorrer em uma inclinação

No Brasil, Bertolini (1959), determinou uma equação que permite calcular as perdas médias de solo para os diferentes graus de declive e comprimentos da encosta, para isso utilizou-se de determinações de perda de erosão obtidos nos principais tipos de solo do estado de São Paulo, numa média de 10 anos de observações, em talhões de diferentes comprimentos da encosta e diferentes graus de declive, com culturas anuais. 


$$
T=0,018 \cdot D^{1,18} \cdot C^{1,63}
$$

onde $T$ é considerada a perda de solo em $\mathrm{Kg}$ por unidade de largura, $D$ é o grau de declive em porcentagem, e $C$ o comprimento da encosta em metros.

$$
C=\frac{A}{4 L}
$$

sendo $A$ área de contribuição hídrica da microbacia $\left(\mathrm{m}^{2}\right)$ e $L$ o somatório do comprimento de todos os cursos de água da microbacia.

A figura 3 apresenta, em forma gráfica, a variação das perdas de solo, em kg por unidade de largura, pela combinação dos efeitos do grau de declive e do comprimento da encosta.

Figura 3 - Efeito combinado do grau de declive e do comprimento da encosta nas perdas de solo por erosão

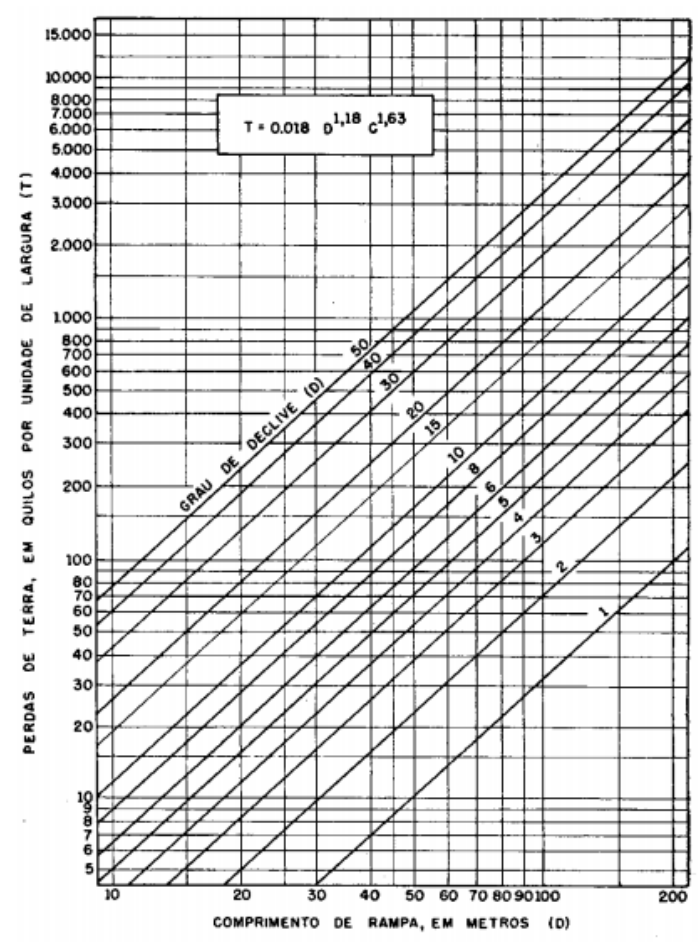

Fonte: Bertolini (1959)

Com as técnicas disponíveis dos SIGs e a facilidade de obtenção de modelos digitais de elevação (MDE), o comprimento da encosta $(L)$ e a declividade $(S)$ podem ser determinados com precisão e combinados para formar um único fator conhecido como o fator topográfico $L S$ a partir das feições geomorfológicas do relevo, que são determinantes em relação aos processos hidrológicos que ocorrem nas áreas de relevo complexo. A precisão com que esse fator pode ser estimado depende da resolução do MDE. 
A tecnologia dos SIGs prevê a construção e o manuseio relativamente viáveis dos MDEs que, em princípio, permitem o cálculo da área de contribuição de modo que a natureza complexa da topografia possa ser totalmente contabilizada.

Para isso, vários algoritmos foram propostos na literatura e algumas aplicações já foram feitas em estudos de erosão, por exemplo: Bork e Hensel, (1988), Desmet, (1993), Desmet e Govers, (1995), Moore e Burch, (1986), Moore e Nieber, (1989), Moore; Grayson; Ladson, (1991).

De acordo com Desmet e Govers (1995) o cálculo dos fatores $L$ e $S$ podem ser realizados a partir do conceito de área de contribuição. O cálculo automatizado do comprimento da encosta $(L)$ pode ser descrito pela equação a seguir:

$$
L_{i j}=\frac{\left(A_{i j-i n}+D^{2}\right)^{m+1}-\left(A_{i j-i n}\right)^{m+1}}{D^{m+2} \cdot X_{i j}{ }^{m} \cdot(22,13)^{m}}
$$

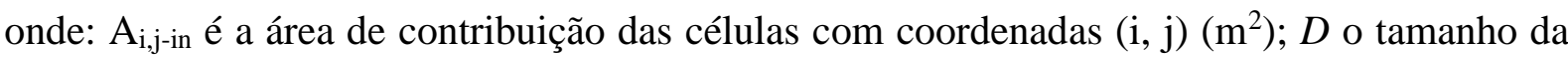
célula (m), ou seja, tamanho do pixel $(30 \mathrm{~m}) ; m$ o coeficiente em função da declividade para o grau de célula com coordenadas $(i, j) ; x$ o coeficiente em função do aspecto para grau de célula com coordenadas $(\mathrm{i}, \mathrm{j})$.

O coeficiente $m$ é obtido através das classes de declividade, ou seja: 0,5 se declividade é maior que 5\%; 0,4 para o intervalo de declividade entre $3 \%$ e 5\%; 0,3 para o intervalo de declividade entre $1 \%$ e $3 \%$; e 0,2 para declividades menores que $1 \%$.

A declividade por sua vez pode ser calculada pelo algoritmo descrito por Zevenbergen e Thorne (1987):

$$
S_{i j}=S_{x}^{2}+S_{y}^{2}
$$

onde $S_{\mathrm{x}}$ é o gradiente de direção x $(\mathrm{m} / \mathrm{m})$ e $S_{\mathrm{y}}$ o gradiente de direção y $(\mathrm{m} / \mathrm{m})$.

De acordo com o Kuhnle et al. (1996) o comprimento das encostas de colina nos lotes experimentais da EUPS variaram de $10,7 \mathrm{~m}$ a $91,4 \mathrm{~m}$. Assim, recomendou-se a utilização de comprimentos de declive inferior a $122 \mathrm{~m}$, uma vez que o escoamento terrestre é concentrado nos riachos em menos de $122 \mathrm{~m}$ em condições naturais.

Neste sentido, o método desenvolvido por Moore e Burch (1986) utiliza um limite superior de comprimento de declividade de $12 \mathrm{~m}$, com a seguinte formulação:

$$
L S=\left(\frac{A f}{22.13}\right)^{0.4} \cdot\left(\frac{\sin \theta}{0.0896}\right)^{1.3}
$$


onde: Af define-se como o fluxo acumulado que é calculado de acordo com o tamanho da célula do MDE; $\theta$ é o angulo da declividade calculado em graus.

- Cobertura do solo e práticas conservacionistas - Fator CP

Os fatores $C$ e $P$ medem o efeito combinado de todas as relações das variáveis de cobertura e manejo, ou seja, referem-se à participação antrópica no processo. $\mathrm{O}$ fator uso e manejo do solo, $C$, é a relação esperada entre as perdas de solo de um terreno cultivado em dadas condições e as perdas correspondentes de um terreno mantido continuamente descoberto e cultivado (BERTOLINI; LOMBARDI NETO, 1990). Este fator é usado para refletir o efeito das práticas de gestão nas taxas de erosão.

Através da EUPS é possível comparar os impactos relativos das opções de gestão, fazendo alterações no fator $C$. O fator $C$ é determinado usando subfatores para prever o uso da terra, cobertura do solo, rugosidade da superfície, e umidade do solo.

A EUPS foi desenvolvida para uso em campos agrícolas, no entanto, pode ser adaptada para uso em condições não agrícolas. Neste caso, o fator $C$ mede a proteção da superfície do solo ao impacto das gotas de chuva e o impacto do escoamento superficial de acordo com cobertura do solo. Os valores atribuídos a cada classe de uso e ocupação podem variar de solos bem protegidos para superfícies que produz maiores taxas de escoamento, deixando-o solo suscetível à erosão (SIMMS; WOODROFFE; JONES, 2003).

Os valores do fator $C$ podem variar de zero quando o solo se encontra bem protegido a 1,5 para uma superfície desprotegida, o que favorece o escoamento superficial e propicia elevada suscetibilidade do solo a erosão. A tabela 6 apresenta os valores de $C$ reportados para os tipos de culturas deste trabalho e determinados por diferentes fontes bibliográficas.

Tabela 6 - Valores do fator C reportados para diferentes de cultura
\begin{tabular}{l|l|lll}
\hline Tipo de uso do solo & $\boldsymbol{C}$ & Fonte & \\
\hline Pasto & 0,18 & Morgan, 1995 & \\
\hline Floresta & 0,01 & $\begin{array}{l}\text { Bertolini; Lombardi } \\
1993\end{array}$ & Neto, \\
\hline Área urbana & 0,2 & Morgan, 1995 & \\
\hline Solos expostos & 0,404 & $\begin{array}{l}\text { Bertolini; Lombardi } \\
1993\end{array}$ & Neto, \\
\hline Agricultura & 0,29 & $\begin{array}{l}\text { Bertolini; Lombardi } \\
1993\end{array}$ & Neto, \\
\hline & & $\begin{array}{l}\text { Bertolini; Lombardi } \\
1993\end{array}$ & Neto, \\
\hline
\end{tabular}

Fonte: Bertolini; Lombardi Neto (1993) e Morgan (1995) 
O fator de práticas conservacionistas, $P$, é a razão de perda de solo com uma prática específica de apoio para a perda de solo (SHI et al., 2004). Este fator é a relação entre a intensidade esperada de tais perdas, com determinada prática conservacionista e aquelas quando a cultura está plantada no sentido do declive (morro abaixo) (BERTOLINI; LOMBARDI NETO, 1990).

$\mathrm{O}$ uso da terra normalmente tem maior efeito sobre a perda de solo do que qualquer outro fator. Entre os principais fatores que afetam a perda de solo, o uso da terra é geralmente o único que pode ser modificado para controlar a perda de solo.

Uma diminuição na perda de solo ao longo do tempo demonstraria que as práticas de gestão que estão sendo utilizadas são ambientalmente favoráveis. Por outro lado, o aumento pode apontar para a necessidade de abordar as práticas de gestão e vulnerabilidade paisagem (JONES, 2001).

A tabela 7 apresenta de acordo com Bertolini e Lombardi Neto (1990) as práticas conservacionistas para algumas culturas anuais (plantio em contorno, terraceamento e alternância de capina).

Tabela 7 - Valores do fator P referentes a diferentes práticas conservacionistas

Fonte: Bertolini e Lombardi Neto (1990)

\begin{tabular}{l|l}
\hline Práticas conservacionistas & P \\
\hline Plantio morro abaixo & 1,00 \\
\hline Plantio em contorno & 0,5 \\
\hline Alternância de capinas+plantio em contorno & 0,4 \\
\hline Cordões de vegetação permanente & 0,2 \\
\hline Terraço & 0,1 \\
\hline
\end{tabular}

O fator P também pode ser tabelado em função das classes de declividade de acordo com Carvalho (1994), (tabela 8), uma vez que a eficiência das práticas de controle de erosão é relacionada com a declividade da área.

Fonte: Carvalho (1994)

Tabela 8 - Fator P em função da declividade

\begin{tabular}{l|l}
\hline Declividade (\%) & $\mathbf{P}$ \\
\hline $0-2$ & 0,60 \\
\hline $2-7$ & 0,50 \\
\hline $7-12$ & 0,60 \\
\hline $12-18$ & 0,80 \\
\hline $18-24$ & 0,90 \\
\hline
\end{tabular}




\subsubsection{GWLF}

Na aplicação da EUPS para o cálculo da produção de sedimentos pelo modelo GWLF, utilizaram-se os valores sugeridos nos estudos de Bertolni e Lombardi Neto (1990), Lombardi e Moldenhauer (1980), Mannigel et al. (2002) e Morgan (1995).

A produção de sedimentos, $S T_{t}$, pode ser calculada considerando-se separadamente a perda de solo e o seu subsequente transporte pelo escoamento (HAITH; MANDEL; WU, 1992). A média de perda de solo devido à erosão hídrica por unidade de área e de tempo, $t$, (ton/ha/dia), $\mathrm{PS}_{\mathrm{t}}$, é estimada pela EUPS:

$$
\mathrm{PS}_{\mathrm{t}}=\mathrm{R}_{\mathrm{t}} \cdot \mathrm{K}_{\mathrm{s}} \cdot \mathrm{L} \cdot \mathrm{S} \cdot \mathrm{C} \cdot \mathrm{P}
$$

em que $\mathrm{R}_{\mathrm{t}}$ é o fator de erosividade da chuva (MJ.mm/ha.h) no intervalo de tempo $t ; \mathrm{K}_{\mathrm{s}}$ é o fator de erodibilidade do solo do tipo $s$ (ton.h/MJ.mm), $L$ é o fator topográfico que expressa o comprimento do declive $(\mathrm{km}), S$ é o fator topográfico que expressa a declividade do terreno ou o grau de declive (adimensional), $C$ é o fator que expressa o uso e manejo do solo e cultura (adimensional) e $P$ é o fator que representa as práticas conservacionistas (adimensional).

A produção de sedimentos, $S T_{t}$ (ton), é o produto da perda de solo e da taxa de entrega de sedimento (SDR).

$$
\mathrm{ST}_{\mathrm{t}}=\mathrm{PS}_{\mathrm{t}} \cdot \mathrm{SDR}
$$

Kinnell (2004) define a SDR como a relação entre o aumento dos processos erosivos em um determinado ponto da bacia hidrográfica e o sedimento que é transportado a partir desse ponto. Segundo Ouyang e Bartholic, (1997), Vanoni (1975) usou os dados de 300 bacias hidrográficas em todo o mundo para desenvolver um modelo para estimar a SDR.

\subsubsection{SWAT}

A erosão e a produção de sedimentos de cada HRU são estimadas com base na MUSLE (WILLIAMS, 1975).

$$
S Y_{t}=11,8 \cdot\left(H_{t} \cdot T_{t}^{\text {peak }} \cdot A_{h r u}\right)^{0,56} \cdot K_{S} \cdot C \cdot P \cdot L \cdot S \cdot C F R G
$$

em que $S Y_{t}$ é a produção de sedimentos transportado pelo escoamento superficial para um determinado dia (ton), $H_{T}$ é o escoamento superficial $(\mathrm{mm}), T_{t}^{\text {peak }}$ é a vazão de pico $\left(\mathrm{m}^{3} / \mathrm{s}\right)$, $A_{h r u}$ é a área da HRU (ha), $K$ é o fator de erodibilidade da EUPS (0,013 ton $\mathrm{m}^{2} \mathrm{hr} /$ ton.cm), $C$ é o fator de cobertura do solo da EUPS, $P$ é o fator de práticas conservacionistas da EUPS, $L S$ é o fator topográfico da EUPS e CFRG é o fator de fragmentação grosseira. O CFRG pode ser calculado por: 


$$
C F R G=\mathrm{e}^{(-0,053 \cdot r o c k)}
$$

onde rock é a percentagem de partículas do solo com um diâmetro maior que $2 \mathrm{~mm}$ na primeira camada do solo (\%).

A produção total de sedimentos que atinge o rio, $S T_{t}$, é a soma dos sedimentos transportados pelo escoamento superficial, $S_{t}^{S}$, e pelo fluxo lateral e terrestre, $S_{t}^{L G}$ :

$$
S T_{t}=S_{t}^{S}+S_{t}^{L G}
$$

O sedimento transportado pelo escoamento superficial que atinge o canal principal é a diferença entre a produção total de sedimentos da bacia hidrográfica, calculada pela MUSLE para cada HRU, e o sedimento que fica retido na paisagem (áreas com coberturas vegetadas, lagos, etc).

O SWAT assume um intervalo de tempo entre a produção total de sedimentos da bacia hidrográfica, $S Y_{t}$, e o sedimento transportado pelo escoamento superficial que atinge o canal principal $S_{t}^{S}$ :

$$
S_{t}^{S}=\left(S Y_{t}+S Y_{t-1}\right) \cdot\left(1-e^{\left(- \text {surlag } / T^{c o n c}\right)}\right)
$$

onde $S_{t}^{S}$ é o sedimento que atinge o canal principal no dia t (ton), $S Y_{t-1}$ é o sedimento relativo ao dia anterior (ton), $S Y_{t}$ é a produção de sedimentos gerada em cada HRU em um determinado dia (ton), surlag é o coeficiente de atraso do escoamento superficial especificado pelo usuário, e $T^{\text {conc }}$ é o tempo de concentração para a HRU (hrs).

A expressão $\left(1-e^{\left(-\operatorname{surlag} / T^{c o n c}\right)}\right)$ na equação (37) representa a fração da produção de sedimento disponível que será possível entrar no canal principal no dia.

O modelo SWAT permite que o fluxo de águas laterais e subterrâneas contribuam com a produção de sedimento no canal principal. A quantidade de sedimento que é produzido pelo fluxo de águas laterais e subterrâneas é calculada:

$$
S_{t}^{L G}=\frac{\left(L_{t}+G_{t}\right) \cdot A_{h r u} \cdot S C}{1000}
$$

onde $S_{t}^{L G}$ é a quantidade de sedimentos no fluxo lateral e subterrâneo (ton), $L_{t}$ é o fluxo lateral para um determinado dia (mm), $G_{t}$ é o fluxo subterrâneo para um determinado dia (mm), $A_{h r u}$ 
é a área da HRU $\left(\mathrm{km}^{2}\right)$, e $S C$ é a concentração de sedimentos no fluxo de águas laterais e subterrâneas especificado pelo usuário (mg/L).

O sedimento é encaminhado através de canais usando uma modificação da equação de transporte de sedimentos de Bagnold (BAGNOLD, 1977). Esta equação calcula a capacidade de transporte de sedimentos em função da velocidade do fluxo. O modelo deposita ou erode o sedimento, dependendo da carga de sedimento que entra no canal e da capacidade do fluxo.

\subsection{Transporte e transformação de contaminantes}

\subsubsection{Qualidade da água em bacias hidrográficas}

O termo qualidade de água se refere às características químicas, físicas e biológicas, e conforme essas características são estipuladas diferentes finalidades para o uso da água. Segundo esta definição, para cada tipo de uso específico da água podem ter diferentes requisitos de qualidade e são estabelecidos limites máximos de impurezas que a mesma deve conter (MERTEN; MINELLA, 2002). A resolução do Conselho Nacional do Meio Ambiente (CONAMA) nº 357/2005 (BRASIL, 1986) estabelece valores que definem limites aceitáveis para os parâmetros, considerando os diferentes usos. Nesse sentido, a qualidade da água é um conceito relativo que depende diretamente do uso/finalidade a que se destina como, por exemplo: irrigação, abastecimento humano, pesca e lazer, etc.

Para verificar se os limites de determinado poluente se encontram em acordo com a legislação mencionada e evitar que problemas decorrentes dos poluentes venham a comprometer o aproveitamento múltiplo e integrado dos recursos hídricos é necessário um monitoramento que forneça uma estimativa representativa e confiável da qualidade das águas (SINGH; MALIK; SINHA, 2005). Este monitoramento pode ser realizado a partir de medidas quantitativas como determinações de variáveis físicas e químicas (na água, sedimentos e/ou organismos), e testes bioquímicos/biológicos, aspectos visuais (turbidez), odor, etc. (CHAPMAN,1996).

Os poluentes encontrados nos ecossistemas aquáticos naturais têm origem em fontes pontuais ou difusas. As fontes pontuais são facilmente identificadas e diagnosticadas, e compreendem, por exemplo, a descarga de efluentes a partir de indústrias e estações de tratamento de esgotos. Por este motivo, é possível estabelecer medidas de controle e, em alguns casos, punições aos responsáveis pelo descarte de efluentes que não se enquadram na legislação vigente. 
Ao contrário das fontes pontuais, as fontes difusas são aquelas que estão distribuídas no terreno em extensas áreas agrícolas e urbanas. Sendo de difícil identificação e determinação, em função das características de suas descargas, estas fontes constituem um grande desafio em estudos ambientais.

As cargas de poluentes advindas de fontes difusas são influenciadas diretamente por características naturais do meio, como o clima, a geomorfologia, a vegetação e as condições geoquímicas da sua bacia de drenagem e do aquífero que a alimenta, assim como por intervenções antrópicas, como desmatamento de áreas adjacentes aos corpos d’água, mudanças no uso do solo urbano e rural, lançamento de cargas poluentes nos ecossistemas aquáticos, e modificação no sistema fluvial (SHRESTHA; KAZAMA, 2007).

A presença da cobertura vegetal nas bacias hidrográficas, por exemplo, promove a proteção do solo contra a erosão, a lixiviação excessiva de nutrientes e outros processos que comprometem a qualidade da água. Por outro lado, as atividades antrópicas, como a remoção da vegetação para a expansão das áreas urbanas e industriais, podem modificar as caraterísticas físicas naturais da bacia e favorecer o lançamento de poluentes nos recursos hídricos.

A quantificação dos poluentes de origem pontual ou difusa nos cursos de água é de fundamental importância para a gestão dos recursos hídricos que objetive a conservação e o uso sustentável da água. Através da análise integrada entre os dados de qualidade da água e as características de uso e ocupação do solo em uma bacia hidrográfica, juntamente com a distribuição da população urbana e a disponibilidade de infra-estrutura urbana e industrial, torna-se possível definir relações de causa e efeito entre as condições de ocupação do solo nas bacias hidrográficas e a qualidade da água (ZIMMERMANN; GUIMARÃES; PERALTAZAMORA, 2008).

\subsubsection{Cargas de nitrogênio e de fósforo}

A determinação das variáveis químicas tem como objetivo determinar os teores qualitativos e quantitativos de substâncias, que, embora não sejam nocivas até determinados limites, devem ser conhecidas para avaliar a necessidade dos processos de tratamento, ou ainda, alertar sobre a viabilidade de uso da água para fins de abastecimento público. Dentre as variáveis podemos citar: o nitrogênio e o fósforo, que são simulados pelos modelos com base nos dados monitorados nas bacias hidrográficas estudadas neste trabalho.

O excesso de nitrogênio e fósforo utilizados nos fertilizantes são descarregados nos cursos de água quando ocorrem eventos de precipitação e práticas de irrigação, o que pode 
induzir o fenômeno de eutrofização e perdas de biodiversidade no ecossistema aquático. Portanto, o conhecimento das emissões de N e P é uma questão fundamental em relação à proteção de qualidade da água e práticas sustentáveis de gestão de bacias hidrográficas (DU et al., 2014; HUANG; HONG, et al., 2010).

As informações sobre as contribuições relativas de diferentes fontes de contaminantes podem contribuir para explicar os impactos das fontes de poluição, estabelecer programas de monitoramento e projetar medidas para reduzir a poluição das águas superficiais.

No Brasil, de acordo com limites regidos pela Resolução Conama 357 (BRASIL, 2005) para rios de Classe 2 a concentração de fósforo total não pode exceder o valor de 0,1mg/L. Para o nitrogênio, este limite é muito variável, e a legislação estabelece valores em termos de nitrato, nitrito. Os valores de nitrito e nitrato máximos devem ser 1 e 10mg/L, respectivamente.

O monitoramento destes padrões de qualidade é muito caro, demorado e espacialmente impraticável no nível da bacia hidrográfica. Portanto, a modelagem matemática tornou-se uma tecnologia primária para análise dos contaminantes e sua distribuição espacial.

Os modelos de bacias hidrográficas podem ser usados para prever os efeitos que as mudanças nas atividades agrícolas têm no escoamento, erosão do solo e transporte de nutrientes e são essenciais para analisar a poluição fontes não pontuais (CHU et al., 2004).

\subsubsection{GWLF}

O modelo GWLF assume que os contaminantes são transportados em fase sólida ou dissolvida, sendo os contaminantes em fase sólida oriundos de áreas rurais e urbanas e os contaminantes dissolvidos oriundos de fontes pontuais, rurais e águas subterrâneas.

A interação dos contaminantes nos cursos d'água não é contabiliza pelo modelo, sendo o cálculo da concentração dos contaminantes referente a produção dos contaminantes até a chegada na água.

Assume-se que todas as cargas de contaminantes provenientes de fontes pontuais e de águas subterrâneas encontram-se somente em fase dissolvida, e que as cargas de contaminantes provenientes de fontes urbanas se encontram somente em fase sólida.

Assim a carga total de nitrogênio $\left(N^{T}\right)$ e de fósforo $\left(P^{T}\right)$ pode ser calculada de acordo com as seguintes formulações:

$$
\mathrm{N}_{\mathrm{t}}^{\mathrm{D}}=\mathrm{N}_{\mathrm{t}}^{\mathrm{DP}}+\mathrm{N}_{\mathrm{t}}^{\mathrm{DR}}+\mathrm{N}_{\mathrm{t}}^{\mathrm{DG}} \quad \mathrm{P}_{\mathrm{t}}^{\mathrm{D}}=\mathrm{P}_{\mathrm{t}}^{\mathrm{DP}}+\mathrm{P}_{\mathrm{t}}^{\mathrm{DR}}+\mathrm{P}_{\mathrm{t}}^{\mathrm{DG}}
$$




$$
\mathrm{N}_{\mathrm{t}}^{\mathrm{S}}=\mathrm{N}_{\mathrm{t}}^{\mathrm{SR}}+\mathrm{N}_{\mathrm{t}}^{\mathrm{SU}} \quad \mathrm{P}_{\mathrm{t}}^{\mathrm{S}}=\mathrm{P}_{\mathrm{t}}^{\mathrm{SR}}+\mathrm{P}_{\mathrm{t}}^{\mathrm{SU}}
$$

Nessas equações, $\mathrm{N}_{\mathrm{t}}^{\mathrm{D}}$ e $\mathrm{N}_{\mathrm{t}}^{\mathrm{S}}$ são as cargas de nitrogênio dissolvido e em fase sólida respetivamente, $\mathrm{P}_{\mathrm{t}}^{\mathrm{D}}$ e $\mathrm{P}_{\mathrm{t}}^{\mathrm{S}}$ são as cargas de fósforo dissolvido e em fase sólida respetivamente, os expoentes $D P, D R$ e $D G$ são relativos as cargas de contaminantes dissolvidos provenientes de fontes pontuais, áreas rurais e águas subterrâneas respetivamente, e $S R$ e $S U$ dizem respeito as cargas de contaminantes em fase sólida provenientes de áreas rurais e áreas urbanas, respectivamente.

As equações apresentadas subsequentemente para o cálculo das cargas de nitrogênio são aplicadas da mesma forma para o cálculo das cargas de fósforo.

A carga de contaminantes provenientes de fontes pontuais, $\mathrm{N}_{\mathrm{t}}^{\mathrm{DP}}(\mathrm{mg} / \mathrm{L})$, pode ser calculada de acordo com a equação 52.

$$
\mathrm{N}_{\mathrm{t}}^{\mathrm{DP}}=\frac{\mathrm{t}^{\mathrm{c}} \cdot \mathrm{Pop} \cdot \mathrm{NC}^{\mathrm{DP}} \cdot\left(1-\mathrm{r} 1^{\mathrm{N}}\right)+\left(1-\mathrm{t}^{\mathrm{c}}\right) \cdot \mathrm{Pop} \cdot \mathrm{NC}^{\mathrm{DP}} \cdot\left(1-\mathrm{r} 2^{\mathrm{N}}\right)}{T_{t}}
$$

em que Pop é a população estimada da área de estudo (hab), $\mathrm{t}^{\mathrm{c}}$ é percentagem da população que possui sistema de tratamento de esgoto, $\mathrm{NC}^{\mathrm{DP}}$ é a carga per capita de nitrogênio nos efluentes de fontes pontuais ( $\mathrm{mg} / \mathrm{hab}$.dia), $\mathrm{r} 1^{\mathrm{N}}$ é a taxa de remoção de nitrogênio pelo sistema de tratamento de esgoto, $r 2^{\mathrm{N}}$ é a taxa de remoção de nitrogênio provenientes de áreas sem sistema de tratamento de esgoto e $\mathrm{T}_{\mathrm{t}}$, é o fluxo total em $\mathrm{mm} / \mathrm{dia}$

A carga de contaminantes dissolvidos provenientes de área rural, $\mathrm{N}_{\mathrm{t}}^{\mathrm{DR}}(\mathrm{mg})$, pode ser calculada a partir da seguinte formulação:

$$
\mathrm{N}_{\mathrm{t}}^{\mathrm{DR}}=\sum_{\mathrm{k}} \mathrm{NC}_{\mathrm{k}}^{\mathrm{DR}} \cdot \mathrm{H}_{\mathrm{kt}} \cdot \mathrm{A}_{\mathrm{k}}
$$

em que $\mathrm{NC}_{\mathrm{k}}^{\mathrm{DR}}$ é a concentração de contaminantes dissolvidos $(\mathrm{mg} / \mathrm{L})$ provenientes de áreas rurais dependente do tipo de uso da área, $k, \mathrm{H}_{\mathrm{kt}}$ é o escoamento superficial (mm) relacionado com o tipo de uso, $k$, no dia $\mathrm{t}, \mathrm{A}_{\mathrm{k}}$ é a área $\left(\mathrm{m}^{2}\right)$ de $k$.

As concentrações médias de fluxo de contaminantes dissolvidos provenientes de áreas rurais são apresentadas na tabela 9, adaptado dos estudos de Haith; Mandel; Wu, (1992) e de Li et al. (2010). 
Tabela 9 - Contaminantes dissolvidos em áreas rurais

\begin{tabular}{lll}
\hline Uso do solo & $\begin{array}{l}\text { Nitrogênio } \\
(\mathbf{m g} / \mathbf{L})-\boldsymbol{N} \boldsymbol{C}_{\boldsymbol{k}}^{\boldsymbol{D} \boldsymbol{R}}\end{array}$ & $\begin{array}{l}\text { Fósforo } \\
-\boldsymbol{P} \boldsymbol{C}_{\boldsymbol{k}}^{\boldsymbol{D}}\end{array}$ \\
\hline Agricultura & $0-29$ & $0,1-5,1$ \\
\hline Floresta & $0,19-5$ & $0,006-0,07$ \\
\hline Pasto & $0-29$ & $0,1-5,1$ \\
\hline Solo exposto & 2,6 & 0,10 \\
\hline Cana-de-açúcar & $0-29$ & $0,1-5,1$ \\
\hline
\end{tabular}

Fonte: Haith; Mandel; $\mathrm{Wu},(1992)$ e Li et al. (2010)

A carga de contaminantes em fase sólida proveniente de área rural, $\mathrm{N}_{\mathrm{t}}^{\mathrm{SR}}(\mathrm{g})$, é calculada a partir da produção de sedimentos $\mathrm{ST}_{\mathrm{t}}$ (ton) e da concentração média de sedimentos $\mathrm{NC}_{\mathrm{k}}^{\mathrm{SR}}(\mathrm{mg} / \mathrm{kg})$ dependente do tipo de uso da área, $k$.

$$
\mathrm{N}_{\mathrm{t}}^{\mathrm{SR}}=\mathrm{NC}_{\mathrm{k}}^{\mathrm{SR}} \cdot \mathrm{ST}_{\mathrm{t}}
$$

De acordo com Li et al. (2010), a concentração média dos sedimentos em fase sólida provenientes de fontes rurais, $\mathrm{NC}_{\mathrm{k}}^{\mathrm{SR}}$ e $\mathrm{PC}_{\mathrm{k}}^{\mathrm{SR}}$, situa-se nos intervalos de 500 a $900 \mathrm{mg} / \mathrm{kg}$ e 120 a $393 \mathrm{mg} / \mathrm{kg}$ para as concentrações de nitrogênio e de fósforo, respetivamente.

A carga de contaminantes provenientes de áreas urbanas em fase sólida, $\mathrm{N}_{\mathrm{t}}^{\mathrm{SU}}(\mathrm{mg})$, é calculada a partir da seguinte formulação:

$$
\mathrm{N}_{\mathrm{t}}^{\mathrm{SU}}=\sum_{\mathrm{k}} \mathrm{W}_{\mathrm{kt}} \cdot \mathrm{A}_{\mathrm{k}} \cdot \mathrm{NC}_{\mathrm{k}}^{\mathrm{SU}}
$$

em que $W_{k t}$ é o coeficiente de lavagem de primeira ordem, $A_{k}$ é a área (ha) referente ao tipo de ocupação $k, \mathrm{NC}_{\mathrm{k}}^{\mathrm{SU}}$ é a concentração de nitrogênio em áreas urbanas $(\mathrm{kg} / \mathrm{ha})$.

O modelo de escoamento urbano baseia-se na relação entre a acumulação geral e a lavagem dos contaminantes proposta por Amy et al. (1974) e Sartor e Boyd (1972). A função de acumulação exponencial foi posteriormente utilizada no SWMM (HUBER; DICKINSON, 1988) e a função de lavagem é utilizada em ambos SWMM e STORM (USACE, 1977). O coeficiente de lavagem pode ser calculado pela equação a seguir.

$$
W_{k t}=1-e^{-0,181 \cdot H_{k t}}
$$

em que $\mathrm{H}_{\mathrm{kt}}$ é o escoamento superficial (mm) referente ao tipo de ocupação $k$ no dia $t$. 
Os valores de acumulação de contaminantes em áreas urbanas, $\mathrm{NC}_{\mathrm{k}}^{\mathrm{SU}}$ e $\mathrm{PC}_{\mathrm{k}}^{\mathrm{SU}}$ foram adotados de Haith; Mandel; Wu, (1992) e indicam que para áreas com média a alta densidade populacional a taxa diária de acumulação de contaminantes urbanos varia de 0,028 a 0,031 $\mathrm{kg} / \mathrm{ha}$ para as taxas de nitrogênio e de 0,002 a $0,007 \mathrm{~kg} / \mathrm{ha}$ para as taxas de fósforo.

A carga de contaminantes nas águas subterrâneas, $\mathrm{N}_{\mathrm{t}}^{\mathrm{DG}}(\mathrm{mg})$, pode ser obtida por:

$$
N_{t}^{D G}=N C^{D G} \cdot A \cdot G_{t}
$$

em que $\mathrm{NC}^{\mathrm{DG}}$ é a concentração de contaminantes nas águas subterrâneas (mg/L), A é a área da bacia hidrográfica (m2), e $G_{t}$ é a contribuição do fluxo das águas subterrâneas (mm) para o rio.

As concentrações de contaminantes dissolvidos nas águas subterrâneas, $\mathrm{NC}^{\mathrm{DG}}$, foram determinadas a partir de valores padrão nas águas subterrâneas disponíveis em Li et al. (2010). Neste estudo é apresentado um intervalo de 0,1 a $19 \mathrm{mg} / \mathrm{L}$ para concentração nitrogênio e 0,01 a $0,1 \mathrm{mg} / \mathrm{L}$ para concentração de fósforo nas águas subterrâneas.

\subsubsection{SWAT}

\subsubsection{Nitrogênio}

As três principais formas de nitrogênio em solos minerais são nitrogênio orgânico associado com húmus, formas minerais de nitrogênio presas por coloides do solo e formas minerais de nitrogênio em solução.

O nitrogênio pode ser adicionado ao solo por fertilizantes, esterco ou aplicação de resíduos, fixação por bactérias simbióticas ou assimbióticas e precipitação. Sua remoção do solo ocorre pela absorção das plantas, lixiviação, volatilização, desnitrificação e erosão. A figura 4 apresenta os principais componentes do ciclo do nitrogênio. 
Figura 4 - Representação do ciclo do nitrogênio

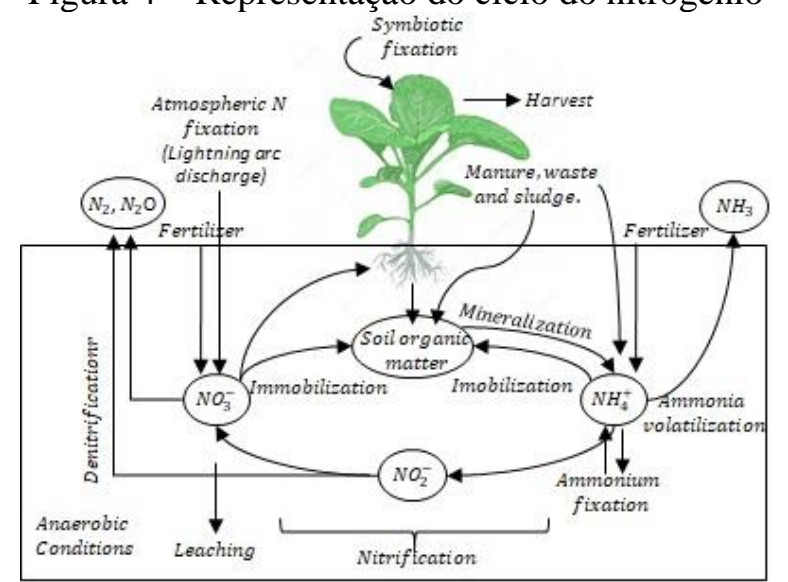

Fonte: Adaptado de Neitsch et al. (2009)

O modelo SWAT monitora cinco reservatórios diferentes de nitrogênio no solo (figura 5). Dois reservatórios são formas inorgânicas de nitrogênio, NH4+ e NO-3, enquanto os outros três são formas orgânicas de nitrogênio.

Os reservatórios de nitrogênio orgânico ativo e estável são associados com o húmus do solo enquanto o nitrogênio orgânico livre está associado com resíduos e biomassa microbiana. O nitrogênio orgânico associado com o húmus é dividido em dois grupos para explicar a variação na disponibilidade de substâncias húmicas para mineralização.

Figura 5 - Representação do particionamento do nitrogênio pelo modelo SWAT

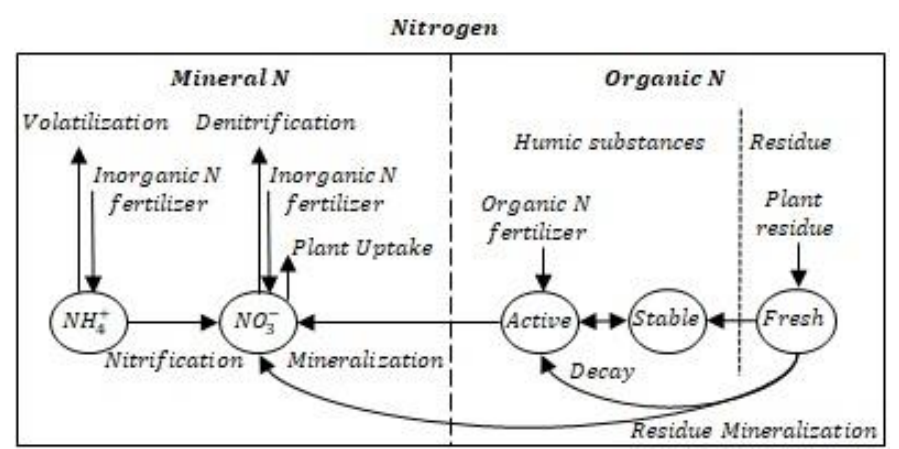

Fonte: Adaptado de Neitsch et al. (2009)

\subsubsection{Fósforo}

As três principais formas de fósforo em solos minerais são fósforo orgânico associado com húmus, formas insolúveis de fósforo mineral e fósforo disponível na vegetação.

O fósforo pode ser acrescentado ao solo através de fertilizantes, esterco ou aplicação residual e pode ser removido pela absorção das plantas e processos erosivos. A figura 6 mostra os principais componentes do ciclo do fósforo. 
Figura 6 - Representação do ciclo do fósforo

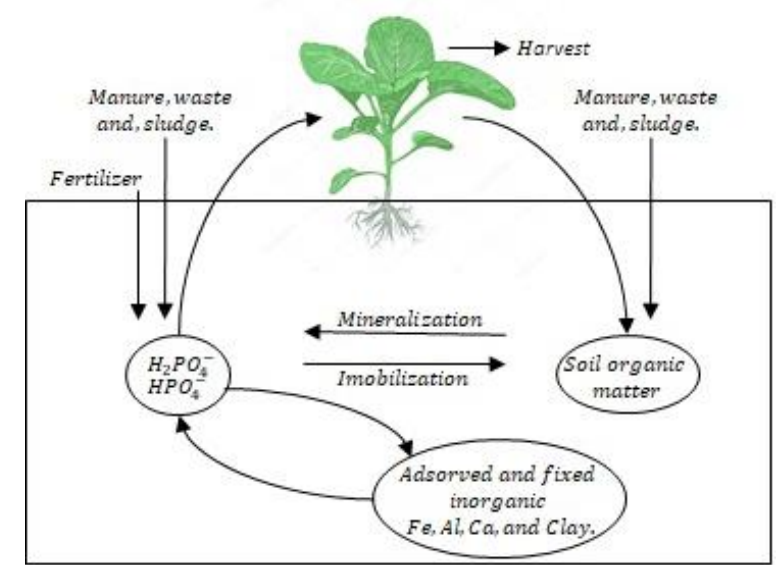

Fonte: Adaptado de Neitsch et al. (2009)

O modelo SWAT monitora seis diferentes reservatórios de fósforo no solo (figura 7). Três reservatórios são formas inorgânicas de fósforo enquanto os outros três reservatórios são formas orgânicas.

Os reservatórios de fósforo orgânico estável e ativo estão associados com o húmus do solo enquanto o fósforo orgânico livre está associado com o resíduo de safras e biomassa microbiana. O fósforo orgânico associado com húmus é dividido em dois reservatórios sendo responsável pela variação na disponibilidade de substâncias húmicas em mineralização.

Figura 7 - Representação do particionamento do fósforo pelo modelo SWAT

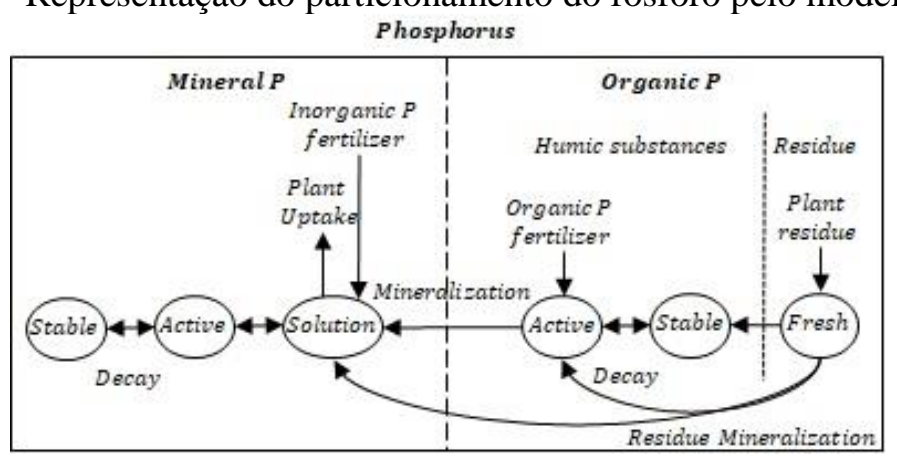

Fonte: Adaptado de Neitsch et al. (2009)

A quantidade de fósforo inorgânico no rio aumenta com a mineralização do fósforo orgânico e sua difusão a partir dos sedimentos no rio e diminui através da absorção por algas. Ao contrário do nitrogênio, que é altamente móvel, a solubilidade do fósforo é limitada, pois este elemento se combina facilmente com outros íons para formar uma série de compostos insolúveis que precipitam fora da solução (NEITSCH et al., 2009). 
Essas características contribuem para a acumulação de fósforo perto da superfície do solo que está prontamente disponível para o transporte no escoamento superficial. Sharpley e Syers (1979) observaram que o escoamento superficial é o principal mecanismo pelo qual o fósforo é exportado da maioria das bacias hidrográficas.

A formulação completa que o SWAT aplica para o cálculo da concentração de nitrogênio e fósforo podem ser encontradas em Neitsch et al. (2009).

\subsection{Propagação de sedimentos e contaminantes por reservatórios}

\subsubsection{Simulação hidrológica de reservatórios}

Os reservatórios são construídos para diversos propósitos, como o armazenamento de água para fornecimento às populações e às atividades agrícolas, o armazenamento de água e criação de condições para a produção de energia elétrica ou, ainda, para reduzir as vazões extremas durante as enchentes (CHANG; CHANG, 2006).

Para fazer o melhor uso da água disponível, os reservatórios são operados de forma criteriosa através de uma sequência de decisões que determinam a acumulação e a liberação de água ao longo do tempo (MISHRA; KAR; SINGH, 2007).

Devido à regulação da vazão, no reservatório e a jusante deste o rio perde potência de escoamento e, consequentemente, capacidade de transporte de sedimentos. O aporte de sedimentos de montante é significativamente reduzido pelo barramento hídrico e a capacidade de erosão a jusante aumenta em resultado dessa redução, causando impactos geomorfológicos nos ambientes fluviais de jusante e nos ambientes costeiros (BRANDT, 2000).

Os reservatórios oferecem também condições para ocorrência de fenômenos de eutrofização, desencadeados pelo excesso de nitrogênio e fósforo e a presença de luz solar na coluna de água. Este crescimento excessivo do fitoplacton, deteriora a qualidade da água armazenada nos reservatórios, o que pode comprometer os usos múltiplos da água, incluindo o abastecimento público.

O monitoramento, para avaliar os efeitos hidrológicos a jusante do reservatório é demorado e não é facilmente transferível para outras condições da bacia hidrográfica, neste sentido, para simular fluxo, sedimentos e contaminantes, uma abordagem alternativa é usar uma modelagem de bacias hidrográficas.

\subsubsection{Modelagem da vazão}

O cálculo da propagação do escoamento em represamentos hídricos da rede hidrográfica exige a consideração de algumas especificidades. O SWAT disponibiliza quatro 
módulos de cálculo de represamento do escoamento fluvial, nomeadamente em reservatórios, zonas húmidas, lagos, e depressões no terreno (ARNOLD et al., 2012).

Para reservatórios o balanço hídrico é calculado pela seguinte equação:

$$
V=V_{\text {stored }}+V_{\text {flowin }}+V_{\text {pcp }}-\left(V_{\text {evap }}+V_{\text {seep }}+V_{\text {flowout }}\right)
$$

sendo $V$, o volume de água no reservatório ao final do dia $\left(\mathrm{m}^{3}\right) ; V_{\text {stored }}$, o volume de água armazenada no reservatório no início do dia, dado pelo usuário $\left(\mathrm{m}^{3}\right) ; V_{\text {flowin }}$ o volume de água que entra no reservatório durante o dia $\left(\mathrm{m}^{3}\right) ; V_{p c p} \mathrm{o}$ volume de precipitação sobre o reservatório durante o dia $\left(\mathrm{m}^{3}\right) ; V_{\text {evap }} \mathrm{o}$ volume de água evaporada do reservatório durante o dia $\left(\mathrm{m}^{3}\right) ; V_{\text {seep }}$ o volume de água perdido para infiltração durante o dia $\left(\mathrm{m}^{3}\right)$; e $V_{\text {flowout }} \mathrm{o}$ volume de água que sai do reservatório durante o dia $\left(\mathrm{m}^{3}\right)$.

O cálculo da área superficial do reservatório é necessário para determinar a quantidade de água precipitada, evaporada e infiltrada sobre o reservatório. A área superficial varia com a mudança no volume de água armazenada no reservatório. A área da superfície é atualizada diariamente a partir da equação:

$$
S A=\beta_{s a} \cdot V^{\text {expsa }}
$$

onde $S A$ é a área superficial do reservatório (ha), $\beta_{s a}$ é coeficiente de variação da área superficial, $V$ é o volume de água no reservatório $(\mathrm{m} 3 \mathrm{H} 2 \mathrm{O})$ e expsa é um expoente de variação da área superficial.

O coeficiente, $\beta_{s a}$ e o expoente expsa, são calculados a partir de duas informações conhecidas: a área da superfície e informações de volume fornecidas para os vertedouros principal e de emergência.

$$
\begin{gathered}
\text { expsa }=\frac{\log _{10} R E S_{E S A}-\log _{10} R E S_{P S A}}{\log _{10} R E S_{E V O L}-\log _{10} R E S_{P V O L}} \\
\beta_{S a}=\left(\frac{R E S_{E S A}}{R E S_{E V O L}}\right)^{\text {expsa }}
\end{gathered}
$$

onde os dados são fornecidos pelo usuário, e $R E S_{E S A}$ é a área superficial quando preenchida pelo vertedouro de emergência (ha), $R E S_{P S A}$ é área superficial quando preenchida pelo vertedouro principal (ha), $R E S_{E V O L}$ Volume de água quando preenchida pelo vertedouro de 
emergência (m3 H2O) e $R E S_{P V O L}$ é o Volume de água quando preenchido pelo vertedouro principal (m3 H2O).

$\mathrm{O}$ volume de precipitação que cai sobre o reservatório num determinado dia, $V_{p c p}$, é calculado da seguinte forma:

$$
V_{p c p}=10 \cdot R_{\text {day }} \cdot S A
$$

onde: $R_{\text {day }}$ é a quantidade de precipitação num determinado dia $(\mathrm{mm})$ e $S A$ é a área superficial do reservatório (ha).

O volume de água evaporada do reservatório em um determinado dia, $V_{\text {evap }}$, é calculado através da seguinte formulação:

$$
V_{\text {evap }}=10 \cdot \eta \cdot E_{o} \cdot S A
$$

onde: $\eta$ é o coeficiente de evaporação e $E_{o}$ é a evapotranspiração potencial do dia (mm)

$\mathrm{O}$ volume de água perdido para infiltração durante o dia, $V_{\text {seep }}$, é calculado através da seguinte formulação:

$$
V_{\text {seep }}=240 \cdot R E S_{K} \cdot S A
$$

onde: $R E S_{K}$ é a condutividade hidráulica saturada efetiva do fundo do reservatório, este valor é dado e calibrado pelo usuário.

Para o cálculo do volume de água que sai do reservatório, $V_{\text {flowout }}$, no SWAT pode-se optar por inserir os dados medidos diários (IRESCO=3), dados medidos mensais (IRESCO=1) da média anual de liberação para reservatórios sem controle (IRESCO=0), e para reservatórios controlados (IRESCO=2).

Uma vez que a vazão é determinada usando um dos quatro métodos anteriores, o usuário pode especificar valores máximos e mínimos de descarga. Se a vazão não atender a vazão mínima ou exceder a vazão máxima especificada, a vazão é alterada para cumprir os critérios definidos.

Neste caso do estudo, devido aos dados disponíveis, foi selecionada a opção 2 para o parâmetro IRESCO, ou seja, o reservatório libera a água como uma função do armazenamento alvo desejado.

Esta abordagem tenta imitar as regras gerais de liberação que podem ser usadas pelos operadores de reservatório. Embora o método seja simplista e não consiga explicar todos os 
critérios de decisão, ele pode simular realisticamente grandes vazões e baixos períodos de fluxo.

Para esta abordagem, o volume do vertedouro principal corresponde à reserva máxima de controle de inundação, enquanto o volume de vertedouro de emergência corresponde a nenhuma reserva de controle de inundação. O modelo requer o mês inicial e final da temporada de cheias.

Na estação de não inundação, nenhuma reserva de controle de inundação é necessária e o armazenamento é definido no volume do vertedouro de emergência. Durante a época das cheias, a reserva de controle de cheias é uma função do teor de água do solo.

Se o armazenamento alvo mensal for especificado:

$$
V_{\text {targ }}=\operatorname{starg}
$$

onde $V_{\text {targ }}$ é o volume alvo do reservatório para um determinado dia $\left(\mathrm{m}^{3} \mathrm{H} 2 \mathrm{O}\right)$, e starg é o volume alvo do reservatório especificado pelo usuário para um determinado mês $\left(\mathrm{m}^{3} \mathrm{H} 2 \mathrm{O}\right)$.

Se o armazenamento alvo mensal não for especificado, o volume alvo do reservatório será calculado:

$$
\begin{gathered}
V_{\text {targ }}=R E S_{E V O L} \\
\text { if } I F L O D 1 R<\operatorname{mon}<I F L O D 2 R \\
V_{\text {targ }}=R E S_{P V O L}+\frac{\left(1-\min \left[\frac{S W}{F C}, 1\right]\right)}{2} \cdot\left(R E S_{E V O L}-R E S_{P V O L}\right) \\
\text { if mon } \leq I F L O D 1 R \text { or mon } \geq I F L O D 2 R
\end{gathered}
$$

onde $V_{\text {targ }}$ é o volume alvo do reservatório para um determinado dia $\left(\mathrm{m}^{3} \mathrm{H} 2 \mathrm{O}\right)$, SW é o conteúdo médio de água do solo na sub-bacia (mm H2O), FC é o teor de água do solo da subbacia na capacidade de campo (mm H2O), mon é o mês do ano, IFLOD1R é o mês inicial da estação da inundação e IFLOD2R, final é o mês final da estação de inundação, ambos dados pelo usuário.

Depois que o armazenamento alvo é definido, o volume de água que sai do reservatório durante o dia é calculado:

$$
V_{\text {flowout }}=\frac{V-V_{\text {targ }}}{N D T A R G R}
$$


onde $V$ é o volume de água armazenado no reservatório $\left(\mathrm{m}^{3} \mathrm{H} 2 \mathrm{O}\right), V_{\text {targ }}$ é o volume alvo do reservatório para um determinado dia $\left(\mathrm{m}^{3} \mathrm{H} 2 \mathrm{O}\right)$ e NDTARGR é o número de dias necessários para o reservatório atingir o armazenamento alvo.

Uma vez que a vazão é determinada, o usuário pode especificar as quantidades máximas e mínimas de descarga com as quais a estimativa de vazão inicial é verificada. Se a vazão não atender a descarga mínima ou exceder a vazão máxima especificada, a vazão será alterada para atender aos critérios definidos.

$$
\begin{array}{ll}
V_{\text {flowout }}=V_{\text {flowout }}^{\prime} & \text { if } q_{\text {rel,mn }} \cdot 86400 \leq V_{\text {flowout }}^{\prime} \leq q_{\text {rel }, m x} \cdot 86400 \\
V_{\text {flowout }}=q_{\text {rel,mn }} \cdot 86400 & \text { if } V_{\text {flowout }}^{\prime}<q_{\text {rel,mn }} \cdot 86400 \\
V_{\text {flowout }}=q_{\text {rel,mx }} \cdot 86400 & \text { if } V_{\text {flowout }}^{\prime}>q_{\text {rel,mx }} \cdot 86400
\end{array}
$$

onde $V_{\text {flowout }}^{\prime}$ é o volume inicial de saída do reservatório durante o dia $\left(\mathrm{m}^{3} \mathrm{H} 2 \mathrm{O}\right), q_{\text {rel,mn }}$ é a vazão média diária mínima para o mês $\left(\mathrm{m}^{3} / \mathrm{s}\right)$, e $q_{r e l, m x}$ é a vazão média diária máxima para o mês $\left(\mathrm{m}^{3} / \mathrm{s}\right)$.

A formulação completa que o SWAT aplica para o cálculo da vazão a jusante dos reservatórios pode ser encontrada em Neitsch et al. (2009).

\subsubsection{Modelagem do transporte de sedimentos}

O modelo SWAT incorpora um modelo simples de balanço de massa para simular o transporte de sedimentos para dentro e para fora dos reservatórios. O modelo considera o sistema como sendo completamente misto, ou seja, quando os sedimentos entram no reservatório eles são distribuídos instantaneamente por todo o volume.

Durante os dias de nenhuma entrada de sedimentos, a quantidade de decantação de sólidos em suspensão que ocorre no reservatório num determinado dia é calculada como uma função da concentração.

A concentração inicial de sólidos em suspensão é:

$$
\operatorname{conc}_{\text {sed }, i}=\frac{\left(S T_{t, i}-S T_{t, i n}\right)}{\left(V_{\text {stored }}-V_{\text {flowin }}\right)}
$$

em que $\operatorname{conc}_{s e d, i}$ é a concentração inicial de sólidos em suspensão no reservatório $\left(\mathrm{Mg} / \mathrm{m}^{3}\right)$, $S T_{t, i}$ é a quantidade de sedimento no reservatório no início do dia (ton), $S T_{t, i n}$ é a quantidade de sedimento adicionado ao reservatório pela afluência (ton), $V_{\text {stored }}$ é o volume de água 
armazenado no reservatório no início do dia $\left(\mathrm{m}^{3}\right)$, e $V_{\text {flowin }}$ é o volume de água que entra no reservatório em um determinado dia $\left(\mathrm{m}^{3}\right)$.

A decantação ocorre somente quando a concentração de sedimento no reservatório excede a concentração de sedimento de equilíbrio especificada e calibrada pelo usuário, $R E S_{S E D}$.

A concentração de sedimentos no reservatório no final do dia é calculada:

$$
\begin{aligned}
& \begin{array}{c}
\operatorname{conc}_{S e d, f}=\left(\begin{array}{c}
\left.\operatorname{conc}_{\text {sed }, i}-R E S_{S E D}\right) \cdot \exp \left[-k_{S} \cdot t \cdot R E S_{D 50}\right] \\
\quad+R E S_{S E D}
\end{array} \quad \text { If } \operatorname{conc}_{S e d, i}<R E S_{S E D}\right.
\end{array} \\
& \text { Conc }_{\text {sed,f }}=\text { Conc }_{\text {Sed }, i} \quad \text { If } \text { conc }_{\text {Sed }, i} \leq R E S_{S E D}
\end{aligned}
$$

em que conc $_{\text {sed,f } f}$ é a concentração final de sedimento no reservatório $\left(\mathrm{Mg} / \mathrm{m}^{3}\right)$, conc $_{\text {sed }, i}$ é a concentração inicial de sólidos em suspensão no reservatório $\left(\mathrm{Mg} / \mathrm{m}^{3}\right)$, conc $_{\text {sed é a }}$ concentração de equilíbrio de sólidos em suspensão no reservatório $\left(\mathrm{Mg} / \mathrm{m}^{3}\right), k_{s}$ é a constante de decomposição (1/dia), $t$ é a duração de um intervalo de tempo (1 dia), e $R E S_{D 50}$ é o tamanho médio de uma partícula de sedimento de entrada $(\mu \mathrm{m})$, valor especificado pelo usuário. Supondo que $99 \%$ das partículas de $1 \mu \mathrm{m}$ precisam de 25 dias para se depositar, ks é igual a 0,184 .

A quantidade de sedimentos transportada a jusante do reservatório no dia é calculada em função da concentração final de sedimentos:

$$
\operatorname{sed}_{\text {flowout }}=\operatorname{conc}_{\text {sed }, f} \cdot V_{\text {flowout }}
$$

onde sed $_{\text {flowout }}$ é a quantidade de sedimentos transportada a jusante do reservatório com a vazão $(\mathrm{m} 3), \operatorname{conc}_{\text {sed,f }}$ é a concentração final de sedimentos no reservatório e $V_{\text {flowout }}$ é o volume de água que sai do reservatório em um determinado dia $\left(\mathrm{m}^{3}\right)$.

A formulação completa que o SWAT aplica para o cálculo da simulação de sedimentos nos reservatórios pode ser encontrada em Neitsch et al. (2009).

\subsubsection{Modelagem da concentração de contaminantes}

Para calcular o comportamento dos contaminantes no reservatório, o modelo SWAT supõe o sistema como sendo completamente misto, em que os nutrientes que entram no reservatório são distribuídos instantaneamente por todo o volume. 
A quantidade inicial de nitrogênio e de fósforo no reservatório em um determinado dia é calculada somando a massa de nutrientes entrando no reservatório naquele dia e a massa de nutriente que já estava presente no reservatório.

$$
M_{i}=M_{\text {stored }}+M_{\text {in }}
$$

em que $M_{i}$ é a quantidade inicial de nutrientes no reservatório em um determinado dia $(\mathrm{kg})$, $M_{\text {stored }}$ é quantidade de nutrientes no reservatório no final do dia anterior $(\mathrm{kg})$, e $M_{\text {in }}$ é a quantidade de nutrientes adicionada ao reservatório em um determinado dia $(\mathrm{kg})$.

Similarmente, o volume inicial de água no reservatório é calculado pela somatória de volume de água entrando no reservatório naquele dia mais o volume que estava presente no reservatório.

$$
V_{i}=V_{\text {stored }}+V_{\text {inflow }}
$$

em que $V_{i}$ é o volume inicial de água no reservatório em um determinado dia $\left(\mathrm{m}^{3}\right), V_{\text {stored }}$ é o volume de água no reservatório no final do dia anterior $\left(\mathrm{m}^{3}\right)$, e $V_{\text {inflow }}$ é o volume de água entrando no reservatório em um determinado dia $\left(\mathrm{m}^{3}\right)$.

A concentração inicial de nutrientes no reservatório é calculada ao se dividir a massa inicial de nutrientes pelo volume inicial de água. A quantidade de nutrientes final no reservatório, é calculada ao remover da quantidade inicial de nutrientes, a massa de nutrientes perdida através da decantação.

$$
M_{f}=M_{i}-M_{\text {set }}
$$

As perdas durante a decantação no reservatório podem ser expressas como um fluxo de massa através da superfície da interface sedimento-água. A massa de nutriente perdida através da decantação é calculada pela multiplicação do fluxo pela área da interface sedimento-água.

$$
M_{\text {set }}=v \cdot c \cdot A_{s} \cdot d_{t}
$$

em que $M_{\text {set }}$ é a massa de nutrientes perdida através da decantação em um dia $(\mathrm{kg}), v$ é a velocidade aparente de decantação (m/dia), $A_{s}$ é a área da interface sedimento-água $\left(\mathrm{m}^{2}\right)$, c é 
a concentração inicial de nutrientes na água $\left(\mathrm{kg} / \mathrm{m}^{3}\right)$, e $\mathrm{d}_{\mathrm{t}}$ é a duração do intervalo de tempo (1 dia).

A velocidade de decantação é rotulada como "aparente" porque ela representa o efeito líquido dos diferentes processos que fornecem nutrientes para os sedimentos do reservatório. Supõe-se que o reservatório tem profundidade uniforme e a área da interface sedimento-água é equivalente à superfície do reservatório.

A concentração final de nutrientes no reservatório é calculada ao dividir a quantidade final de nutrientes pelo volume inicial de água.

A concentração de nutrientes a jusante do reservatório é equivalente à concentração final de nutrientes no reservatório no dia. A quantidade de nutrientes a jusante do reservatório é calculada ao se multiplicar a concentração de nutrientes no escoamento pelo volume de água deixando o reservatório no dia.

A formulação completa que o SWAT aplica para o cálculo da simulação de contaminantes nos reservatórios pode ser encontrada em Neitsch et al. (2009).

\subsection{Mudanças no uso do solo e reflexos nos recursos hídricos}

\subsubsection{A importância da modelagem matemática}

A análise do comportamento hidrológico decorrente das alterações nas condições de uso e ocupação do solo é de grande importância para a gestão dos recursos hídricos. Alterações causadas por atividades antrópicas como o desmatamento de áreas de vegetação natural, a prática de agricultura intensiva e a expansão da área urbana, tem ocasionado uma diminuição das disponibilidades hídricas, uma expressiva deterioração da qualidade da água e uma perda de biodiversidade aquática. Entre outros os impactos decorrentes das alterações do uso do solo, pode-se também citar o aumento no escoamento das águas superficiais e diminuição da água infiltrada no solo, e a intensificação de processos erosivos e de contaminação das águas (VANZELA; HERNANDEZ; FRANCO, 2010).

A redução dos impactos ocasionados pela mudança desordenada do uso do solo, exige o conhecimento dos efeitos da variação do uso do solo sobre o regime hídrico (KUHNLE et al., 1996; MEMARIAN et al., 2014). Embora o conhecimento empírico das consequências das alterações no uso seja óbvio, muitas vezes é muito difícil quantificar explicitamente essas consequências (PIKOUNIS et al., 2003). O monitoramento da cobertura e uso do solo pode contribuir com a avaliação dos possíveis processos de degradação e suas consequências ambientais, através da utilização de informações das modificações espaciais e temporais 
ocorridas na paisagem ao longo do tempo (ALEMAYEHU et al., 2009; COELHO et al., 2014).

O uso de modelos matemáticos é uma alternativa para representar o regime hídrico e ajudar na compreensão de fenômenos envolvendo as variáveis do ciclo hidrológico, para antecipar e prever os impactos de mudanças potenciais no uso do solo (RODRIGUES et al., 2015). Com o auxílio de modelos hidrológicos, podem ser simulados diferentes cenários de usos, para uma mesma bacia hidrográfica. Muitos estudos com esta abordagem foram conduzidos por modelos como o modelo SWAT (ARNOLD e FOHRER, 2005), o Hydrologic Modeling System - HEC-HMS (U.S. Army Corps of Engineers), o Método curva-número (Soil Conservation Service) e o Geospatial Stream Flow Model-GeoSFM model (ARTAN et al., 2008).

No Brasil, os impactos da expansão do cultivo da cana-de-açúcar e da soja e da substituição da floresta por áreas de pastagem de gado têm sido objeto de estudo de diversas pesquisas: Blainski et al. (2011), DEMANBORO; LAURENTIS; BETTINE (2013) e Rodrigues et al. (2015).

\subsubsection{SCS-CN e GWLF}

Nos modelos hidrológicos SCS-CN e GWLF, os atributos da bacia hidrográfica são assumidos como homogêneos no espaço. Para estudar os efeitos de vários cenários de alteração do uso do solo é necessário separar as áreas das bacias de acordo com os tipos de uso e de ocupação do solo para calcular a vazão, a produção de sedimentos e a concentração dos contaminantes proveniente de cada área.

No caso do modelo SCS-CN o valor de CN foi utilizado para representar as mudanças de uso e ocupação do solo sugeridas. Os mapas de uso e ocupação do solo elaborados para cada um dos cenários foram utilizados para calcular valor de $\mathrm{CN}$ para cada cenário juntamente com os mapas de tipos de solos.

No modelo GWLF as áreas de cada tipo de uso são utilizadas como dado de entrada no modelo separadamente para calcular os coeficientes de exportação de sedimentos e contaminantes. Desta forma, estes valores foram alterados consoante as áreas dos tipos de uso e ocupação do solo de cada cenário.

Na simulação da produção de sedimentos, o modelo GWLF utiliza a EUPS, em que o único dado de entrada relacionado com o uso e ocupação do solo é o fator $\mathrm{C}$ de práticas conservacionistas. Este fator foi alterado em ambos os casos de estudo conforme as modificações de uso e ocupação do solo de cada cenário (tabela 6). 
O modelo é calibrado e validado apenas para a simulação do cenário atual e para os demais cenários o modelo corre somente com a alteração do valor de $\mathrm{CN}$ e das áreas correspondentes a cada tipo de uso e ocupação do solo. Como resultados para cada cenário, este modelo apresenta os valores de vazão, produção de sedimentos e concentração de contaminantes, e também é possível verificar as alterações nas variáveis hidrológicas como: teor de água no solo, percolação da água no solo, contribuição do escoamento superficial para a vazão, etc.

\subsubsection{SWAT}

No modelo SWAT, a elaboração dos cenários de uso e ocupação do solo consiste em alterar os dados referentes ao mapa atual de uso e ocupação do solo de cada bacia. Esta alteração é realizada manualmente a partir da alteração dos dados de entrada, que pode ser feita com o auxílio de um software de interface como o ArcView GIS.

O modelo é calibrado e validado para o cenário atual (PIKOUNIS et al., 2003; QUYEN et al., 2014; WOLDESENBET et al., 2017) e em seguida pode-se correr o modelo com a alteração dos dados de uso e ocupação do solo consoante aos cenários desejados.

Como resultado o modelo SWAT apresenta, além dos dados referentes a vazão, produção de sedimentos e concentração dos contaminantes para cada cenário, as alterações que cada cenário acarreta nas variáveis hidrológicas como: teor de água no solo, percolação, contribuição do escoamento superficial para o fluxo, etc.

Estes resultados permitem inferir sobre a influência das mudanças no uso e ocupação do solo no regime hidrológico de cada bacia.

\subsection{Calibração e validação dos modelos}

\subsubsection{Abordagem adotada}

A calibração e validação são fases importantes da modelagem para reduzir as incertezas e aumentar a confiabilidade dos resultados da modelagem. Na calibração são determinados os valores aos parâmetros do modelo que minimizam a diferença entre os resultados do modelo e valores observados. Uma vez calibrado o modelo, este deve ser validado para situações semelhantes àquelas em que se quer aplicá-lo. Para isso, outros conjuntos de dados, diferentes dos utilizados na calibração, devem ser utilizados no processo de validação (ALANSI et al., 2009). Os resultados dessa etapa indicam se o modelo é capaz de reproduzir a série de dados não usados em sua calibração. 
A calibração pode ser feita de maneira manual ou automática. Na calibração manual o processo é do tipo tentativa-e-erro, sendo executado pelo usuário ${ }^{16}$. Após cada ajuste de um ou mais parâmetros, os hidrogramas observados e simulados são justapostos a fim de serem comparados visualmente e estatisticamente. Já a calibração automática, utiliza de técnicas computacionais de otimização para identificação dos melhores valores a atribuir a cada parâmetro e que minimizam uma função objetivo calculada a partir dos dados observados e dos resultados do modelo (TUCCI, 1998),

A calibração dos parâmetros no modelo SWAT pode ser realizada de forma automática ou manual. O software SWAT-CUP possibilita a utilização de cinco procedimentos para a calibração automática (GREEN; VAN GRIENSVEN, 2008): (1) Generalized Likelihood Uncertainty Estimation (GLUE), (2) Parameter Solution (ParaSol), (3) Algoritmo Sequential Uncertainty FItting (SUFI-2), (4) Monte Carlo via Cadeias de Markov (MCMC) e (5) Particle Swarm Optimization (PSO) (GUO et al., 2008).

No entanto, apesar de mais trabalhosa uma combinação de calibração manual e automática é o método mais eficaz devido a algumas peculiaridades na escolha dos valores dos parâmetros que somente o usuário pode identificar (BALASCIO; PALMERI; GAO, 1998; GREEN; VAN GRIENSVEN, 2008; LUBITZ; PINHEIRO; KAESFMANN, 2013).

Uma revisão bibliográfica indicou uma primeira seleção dos parâmetros no modelo SWAT mais sensíveis: Abbaspour et al. (2007); Arnold et al., (2012); Lenhart; Eckhardt; Fohrer (2002); Muleta (2012); Neitsch et al. (2001); Van Griensven et al. (2006). O SWATCUP foi depois utilizado para realizar a análise de sensibilidade identificar os parâmetros que mais afetam os resultados do modelo. Entre os cinco procedimentos oferecidos pelo SWATCUP para realizar a análise de sensibilidade e para suportar o esforço de calibração, utilizouse o método de ajuste de SUFI2. Este é um passo importante, pois o número de parâmetros do SWAT dificulta a possibilidade de calibrar manualmente todos os parâmetros.

Após esta análise, a calibração manual dos parâmetros selecionados procurou reter o melhor conjunto de valores dos parâmetros únicos que assegurasse um bom equilíbrio no cumprimento de diferentes objetivos. A calibração dos dois modelos foi realizada em conjunto para os dois estudos de caso com o objetivo de obter valores de parâmetros consistentes que levassem a resultados aceitáveis em ambas as bacias hidrográficas. Acresce que visou múltiplos objetivos, nomeadamente os desvios de diferentes aspectos dos

\footnotetext{
16 Utilizador em português europeu.
} 
hidrogramas e aos valores observados de cargas de sedimentos e de concentrações de nutrientes, medidos em múltiplos locais. Trata-se, por isso, de problema de otimização multiobjetivo em que a solução é um conjunto de soluções ótimas de Pareto.

Procurou-se ainda que os parâmetros que são comuns às formulações dos dois modelos, SWAT e SCS-CN, assumissem os mesmos valores. São o caso dos parâmetros que dependem ou caracterizam os tipos de solo e os tipos de uso e ocupação do solo. Este requisito é um passo fundamental para assegurar a consistência e a robustez dos resultados quando aplicados os modelos separadamente.

A calibração adotou um procedimento sistemático (MADSEN, 2000), que primeiro se concentrou na reprodução da partição de precipitação e no balanço hídrico geral de cada bacia. Em seguida, procedeu-se a reproduzir os registros de fluxos altos e baixos e seu tempo. Finalmente, a atenção concentrou-se nos dados de produção de sedimentos e nos dados de nitrogênio e fósforo.

Para facilitar a comparação entre os resultados dos modelos, foram utilizados os mesmos conjuntos de dados de precipitação diária e evapotranspiração potencial em ambos os modelos. Para o modelo SCS-CN, a precipitação média e a evapotranspiração em toda a bacia hidrográfica foram calculadas como médias ponderadas dos valores de precipitação e evapotranspiração de cada sub-bacia, conforme atribuído pelo SWAT.

Os modelos foram calibrados e validados, usando dois períodos distintos. Usando o período de calibração, várias simulações de cada modelo determinaram o conjunto de valores de parâmetro que leva a um desempenho adequado do modelo, conforme medido pela semelhança dos resultados do modelo com os dados observados. O conjunto de parâmetros obtidos e o desempenho do modelo foram então validados com uma única simulação.

\subsubsection{Indicadores de avaliação de desempenho dos modelos}

O desempenho de cada modelo na reprodução das séries históricas observadas foi medido por um conjunto de indicadores que incluem a eficiência de Nash e Sutcliffe (NASH; SUTCLIFFE, 1970), a tendência dos resultados em percentagem (Pbias) e o coeficiente de determinação (r2)

A eficiência de Nash e Sutcliffe (NSE) calcula a soma da diferença quadrática entre os resultados do modelo e os dados históricos, e normaliza os resultados com a soma da diferença quadrática entre os dados históricos e sua média. NSE é calculado por: 


$$
N S E=1-\left(\frac{\sum\left(T_{t}^{o b s}-T_{t}^{s i m}\right)^{2}}{\sum\left(T_{t}^{o b s}-\overline{T_{t}^{o b s}}\right)^{2}}\right)
$$

onde $T_{t}^{o b s}$ é o valor observado, $\overline{T_{t}^{o b s}}$ é a média dos valores observados, $T_{t}^{s i m}$ é o valor simulado, $\overline{T_{t}^{s l m}}$ é a média dos valores simulados. O valor de NSE varia de 0 a 1 , sendo este o melhor valor. Os valores entre 0,0 e 1,0 geralmente são vistos como níveis aceitáveis de desempenho, enquanto os valores negativos indicam que o valor observado médio é um melhor preditor do que o valor calculado (MORIASI, 2007).

O Pbias mede a diferença média entre os valores calculados e medidos durante um período especificado:

$$
P_{B I A S}=\left(\frac{\sum T_{t}^{o b s}-\sum T_{t}^{s i m}}{\sum T_{t}^{o b s}}\right) \cdot 100
$$

Os valores de Pbias perto de 0\% revelam um desvio menor dos resultados do modelo dos valores medidos, mas valores mais altos para Pbias são aceitáveis quando a precisão dos valores medidos é relativamente fraca.

O coeficiente de determinação, $r^{2}$, descreve a proporção da variância dos dados medidos explicados pelo modelo. $\mathrm{O}$ coeficiente $\mathrm{r}^{2}$ varia de 0 a 1 , com valores mais altos indicando um bom ajuste. Os valores acima de 0,5 são geralmente considerados aceitáveis. Como o $\mathrm{r}^{2}$ apenas quantifica a dispersão, um modelo que sistematicamente superestime ou subestime continuará resultando em bons valores de $\mathrm{r} 2$ próximos de 1,0, mesmo que todas as previsões estejam erradas (KRAUSE; BOYLE; BÃSE, 2005).

$$
r^{2}=\frac{\left(\sum\left[T_{t}^{o b s}-\overline{T_{t}^{o b s}}\right]\left[T_{t}^{s i m}-\overline{T_{t}^{s l m}}\right]\right)^{2}}{\sum\left(T_{t}^{o b s}-\overline{T_{t}^{o b s}}\right)^{2} \sum\left(T_{t}^{s i m}-\overline{T_{t}^{s l m}}\right)^{2}}
$$

Moriasi et al. (2007) argumentaram que o desempenho de um modelo hidrológico usando um passo de tempo mensal pode ser considerado satisfatório se NSE>0,5 e r2>0,5, mas que os passos de tempo mais curtos levam a piores desempenhos. Vários autores relataram valores de NSE na faixa de 0,15 a 0,3 para uma calibração satisfatória do modelo SWAT que usa um passo de tempo diário (BENHAM et al., 2006; COFFEY; WOEKMAN; TARABA, 2004; NEJADHASHEMI; WARDYNSKI; MUNOZ, 2012). Nejadhashemi; Wardynski; Munoz, (2012) assumiram um critério conservador de que os resultados satisfatórios do modelo em uma base diária podem ser alcançados com r2 e NSE superiores a 0,30 . 


\subsection{Dados de entrada para os modelos}

Os modelos requerem alguns dados de entrada que foram obtidos por diversas fontes da literatura.

O MDT, utilizado pelo modelo SWAT, foi obtido a partir de dados SRTM (Shuttle Radar Topography Mission) com resolução de 30m.

O SWAT também requer dados em 14 parâmetros descritores dos vários tipos de solo que foram obtidos de Freire et al. (1978), Lombardi Neto et al. (1989), Oliveira e Prado (1984) e Saxton e Rawls (2006) e estão apresentados na tabela 10.

A identificação dos tipos de uso e de ocupação do solo da bacia hidrográfica do rio Jacaré-Guaçu ocorreu a partir de uma imagem de satélite Landsat Thematic Mapper do segundo semestre de 2001, com uma resolução espacial de 30x30m. A carta de uso e ocupação do solo da bacia hidrográfica de Atibaia foi obtida pelo mapa de uso e ocupação do solo da UGRHI 5 (2013), com base principalmente na interpretação visual das imagens SPOT (Satélites observadores da Terra), ortorretificados, mosaicos e separados de acordo com o limite dos mapas do Instituto Brasileiro de Geografia e Estatística (IBGE) 1: 25.000, com resolução espacial de $2,5 \mathrm{~m}$.

Os dados relativos as características dos usos e das ocupações do solo, para a simulação do modelo SWAT foram obtidas através de um banco de dados disponibilizado pelo modelo, que contemplam os tipos de usos identificados nas áreas de estudo. Cada tipo de uso e cobertura do solo foi associado às informações existentes no banco de dados (quadro 5), sendo assim utilizadas as características padrão do modelo.

Os dados meteorológicos e hidrológicos para ambas as bacias hidrográficas foram

obtidos das bases de dados de duas agências governamentais: Agência Nacional de Águas (ANA) e Departamento de Águas e Energia do Estado de São Paulo (DAEE). 
Tabela 10 - Parâmetros dos solos requeridos pelo SWAT

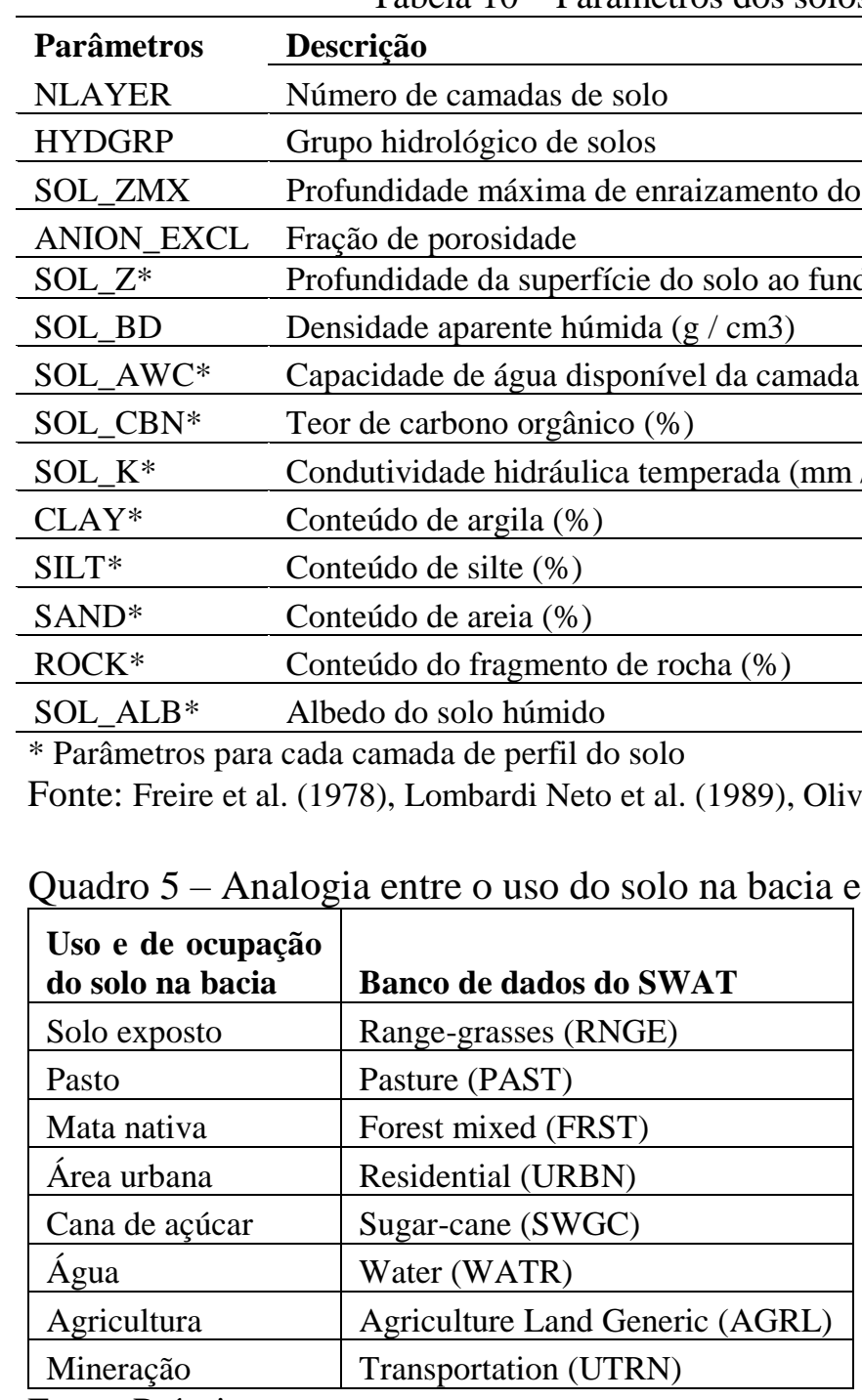

Fonte: Próprio autor

Os dados climáticos de temperatura, umidade, velocidade do vento e radiação solar para a bacia hidrográfica do rio Atibaia também foram obtidos de uma estação meteorológica usada pela ESALQ (Escola Superior de Agricultura Luiz de Queiroz), localizado próximo a área de estudo.

Os dados de precipitação também foram obtidos a partir do trabalho de Xavier; King; Scanlon, (2016), no qual foram desenvolvidos dados de precipitação interpolados (DPI) de alta resolução $(0,25 \circ \times 0,25 \circ)$ a partir de 3625 pluviómetros e 735 estações meteorológicas para o período de 1980-2013, sendo gerada uma base de dados no formato Network Common Data Form (NETCDF) que está disponível online em: https://utexas.app.box.com/v/xavieretal-ijoc-data. Os autores utilizaram uma abordagem de validação cruzada que compara dados observados para determinar as melhores interpolações para cada variável climática. Os métodos de ponderação de distância inversa e de ponderação de distância angular produziram 
os melhores resultados. O desempenho da interpolação variou em diferentes estações para quase todas as variáveis.

Para a simulação da influência do reservatório na vazão e qualidade da água foram necessários dados de entrada relativos ao reservatório de Salto Grande localizado na bacia hidrográfica do rio Atibaia. Os dados foram obtidos por estudos realizados na área (DORNFELD, 2002; LEITE, 1998). A tabela 11 mostra os dados do reservatório requeridos pelo SWAT para simulação.

Tabela 11 - Dados relativos ao reservatório de Salto Grande

\begin{tabular}{|c|c|c|c|}
\hline Parâmetros & Definições & Unidade & Valores \\
\hline RES_ESA & Área superficial quando preenchida pelo vertedouro de emergência & ha & 1325 \\
\hline RES_EVOL & Volume de água quando preenchida pelo vertedouro de emergência & $10^{\wedge} 4 \mathrm{~m} 3$ & 10600 \\
\hline RES_PSA & Área superficial quando preenchida pelo vertedouro principal. & ha & 1150 \\
\hline RES_PVOL & Volume de água quando preenchido pelo vertedouro principal & $10^{\wedge} 4 \mathrm{~m} 3$ & 9700 \\
\hline
\end{tabular}

Fonte: Próprio autor 


\section{CASOS DE ESTUDO}

\subsection{Bacia hidrográfica do Rio Jacaré-Guaçu}

\subsubsection{Descrição geral}

A bacia do rio Jacaré-Guaçu está inserida na UGRHI-13, denominada Tietê-Jacaré, que possui uma área de drenagem de $11.779 \mathrm{~km}^{2}$. A área de estudo é a bacia hidrográfica do rio Jacaré-Guaçu, a montante da confluência com o rio das Cruzes $\left(1934 \mathrm{~km}^{2}\right)$ (figura 8).

No SWAT, esta área de estudo foi dividida em 76 sub-bacias e 1144 HRUs.

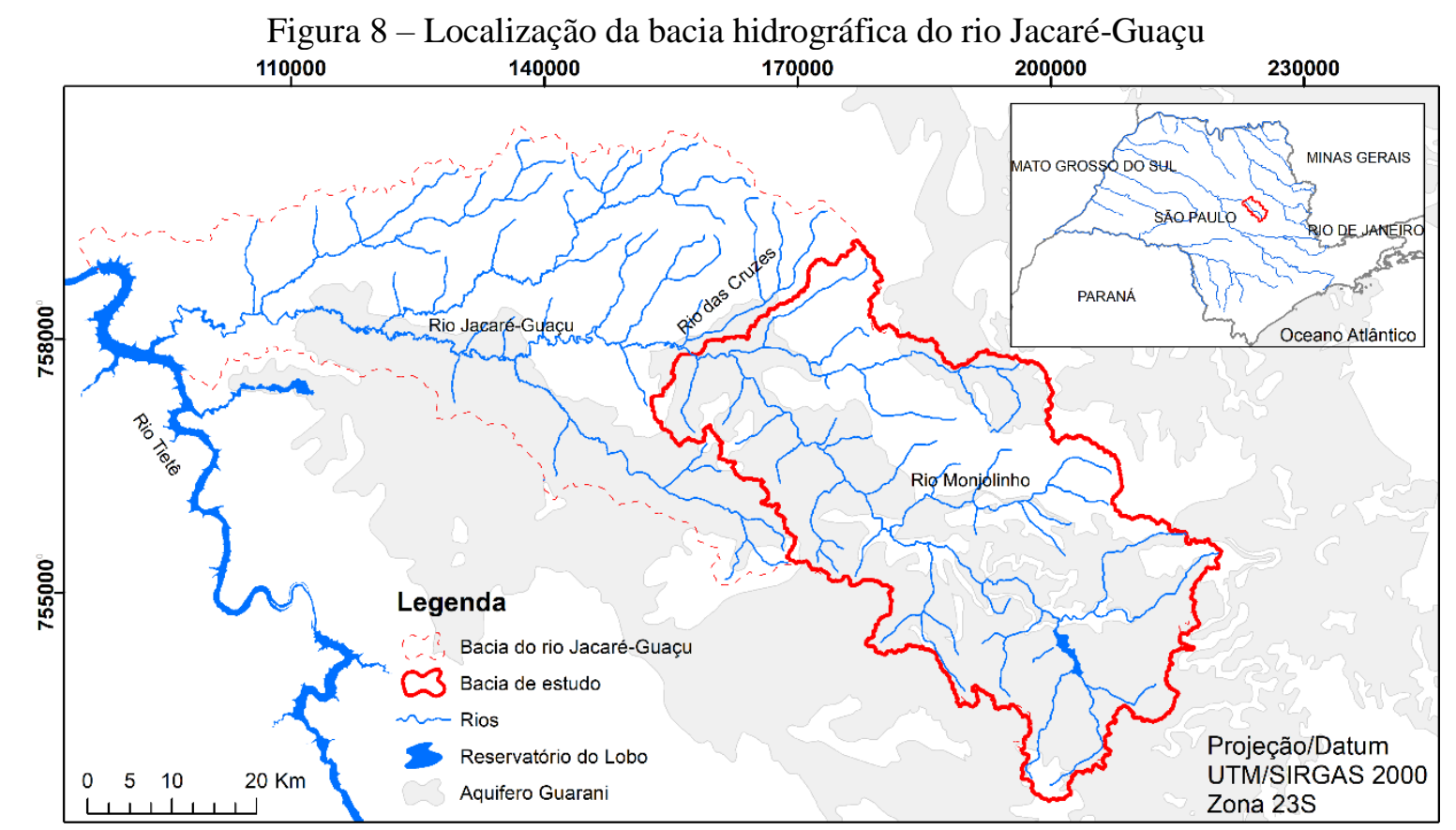

Fonte: Próprio autor

O rio Jacaré-Guaçu está localizado na região centro-norte do Estado de São Paulo, Brasil e é um importante afluente do rio Tietê, um dos maiores afluentes da bacia do alto Paraná. O rio principal tem suas fontes na Serra de Itaqueri (São Carlos, Estado de São Paulo, Brasil) e desagua no reservatório de Ibitinga, na bacia superior do rio Tietê.

A bacia hidrográfica em estudo inclui parte das cidades de Boa Esperança do Sul, Araraquara, São Carlos, Ibaté, Ribeirão Bonito, Brotas, Itirapina, Analândia. Encontra-se sobre o sistema aquífero Guarani (GAS), um dos maiores aquíferos do mundo e uma importante fonte de água potável para várias cidades, incluindo Campo Grande, Ribeirão Preto, São José do Rio Preto e Araraquara, entre outros (RABELO; WENDLAND, 2009). 
Na bacia hidrográfica existe o reservatório do Lobo-Broa, construído em 1936 com o objetivo inicial de gerar energia hidroelétrica, sendo atualmente também utilizado para outros propósitos (TUNDISI, 1986). O volume e a área deste reservatório são $22 \times 106 \mathrm{~m}^{3}$ e 222,7km², respetivamente. $\mathrm{O}$ coeficiente de regularização é 0,26 , o que indica uma reduzida influência na vazão a jusante do reservatório.

A área de estudo insere-se na Província Geomorfológica do Planalto Ocidental Paulista, das Cuestas Basálticas e Depressão Periférica dentro das unidades geomorfológicas do Estado de São Paulo (CORRÊA, 1995; INSTITUTO DE PESQUISAS TECNOLÓGICAS - IPT, 1981). Na área de estudo verifica-se altitudes que variam entre $481 \mathrm{~m}$ no exutório e $1027 \mathrm{~m}$ na parte leste da bacia (figura 9). O relevo da bacia influencia a distribuição espacial das chuvas, com maiores quantidades de chuvas caindo nas partes nordeste da bacia.

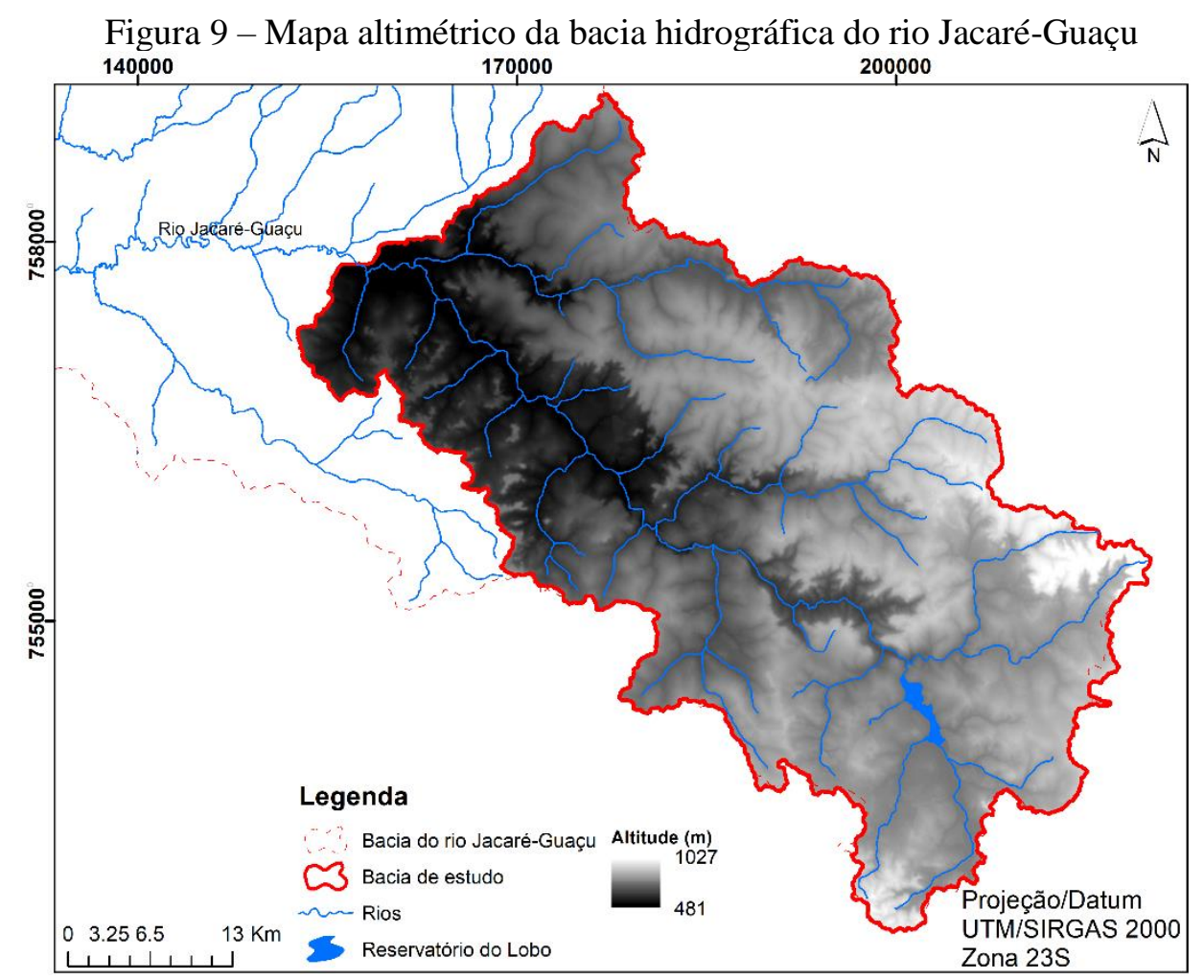

Fonte: Próprio autor

\subsubsection{Clima e hidrologia}

Para a bacia hidrográfica do rio Jacaré-Guaçu, foram selecionadas 10 estações pluviométricas, 3 estações fluviométricas (62760005, 62767500 e 62772500) e 1 estação de monitoramento de qualidade de água (62766400) com base na localização e na completude dos registros (figura 10). Os dados relativos a temperatura, umidade, velocidade do vento e 
radiação solar foram obtidos a partir de um medidor operado pela CRHEA, localizado na bacia.

Figura 10 - Localização das estações pluviométricas, fluviométricas e de qualidade da água da bacia hidrográfica do rio Jacaré-Guaçu

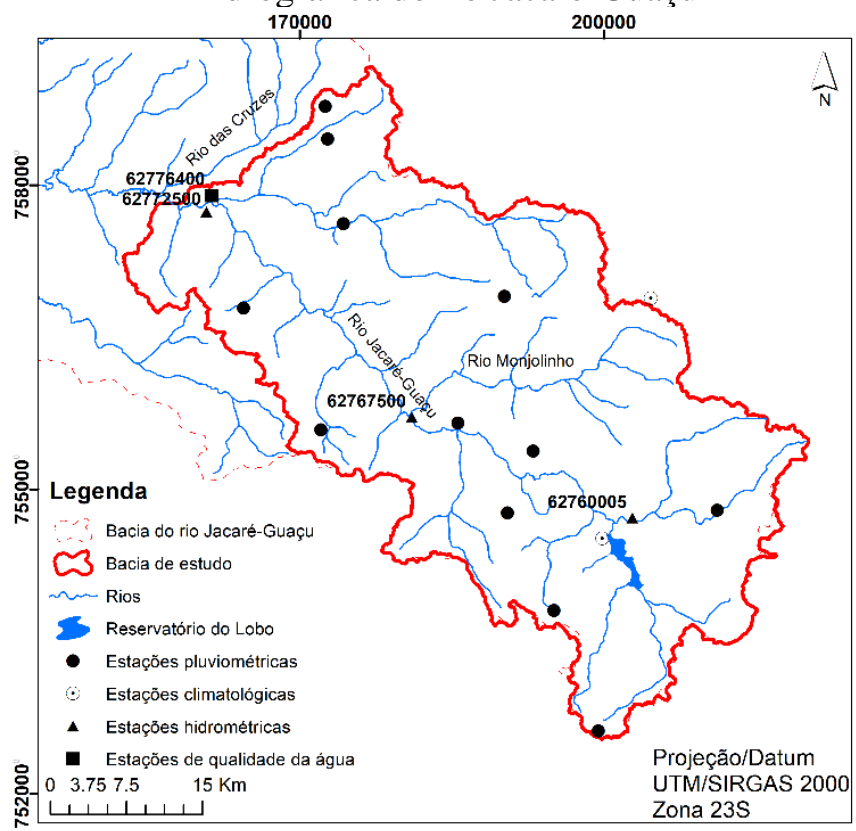

Fonte: Próprio autor

A figura 11 apresentam a espacialização dos DPI obtidos por Xavier; King; Scanlon, (2016) para a bacia hidrográfica do rio Jacaré-Guaçu.

Figura 11 - Localização dos DPI para bacia hidrográfica do rio Jacaré-Guaçu

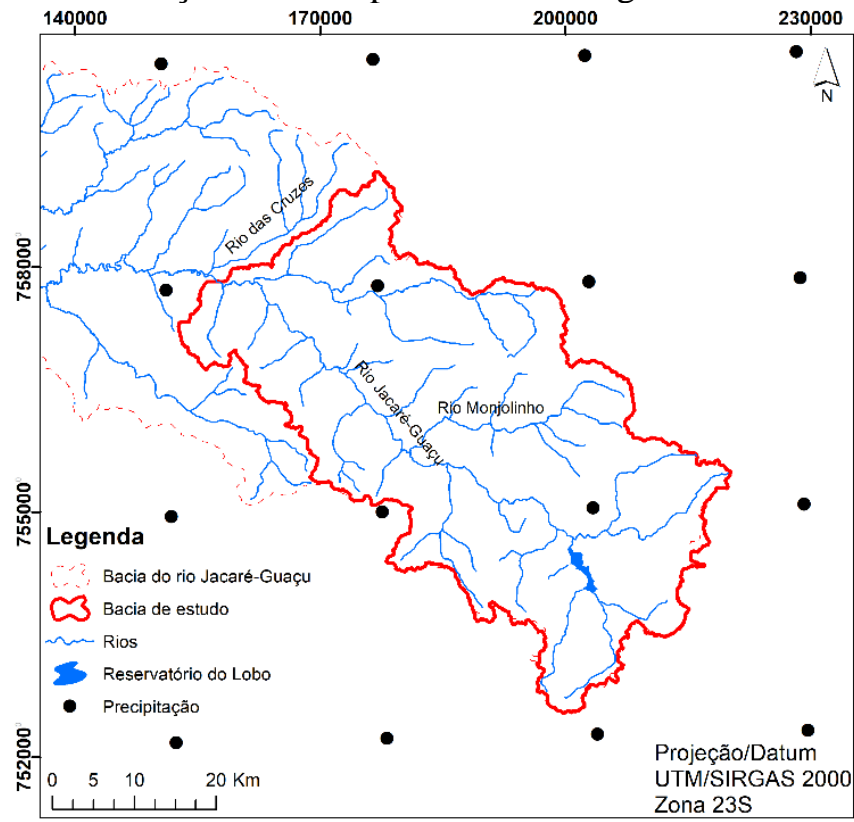

Fonte: Próprio autor 
A área de estudo possui duas estações climáticas bem definidas: a chuvosa, no verão, que ocorre de outubro a março, e a seca, no inverno, que ocorre de abril a setembro. A temperatura do ar acompanha a variação das duas estações gradativamente, com temperaturas mais elevadas no verão e temperaturas mais baixas no inverno.

A figura 12 apresenta a precipitação mensal média e a temperatura média diária da bacia hidrográfica do Rio Jacaré-Guaçu a partir de estações pluviométricas e climatológicas com séries históricas de 1987 a 2014. A partir da observação do mapa de isoietas (figura 13) pode-se notar uma distinção de valores entre as extremidades sudeste e noroeste das bacias, sendo a primeira mais chuvosa.

Figura 12 - Precipitações e temperaturas médias da bacia hidrográfica do rio Jacaré-Guaçu

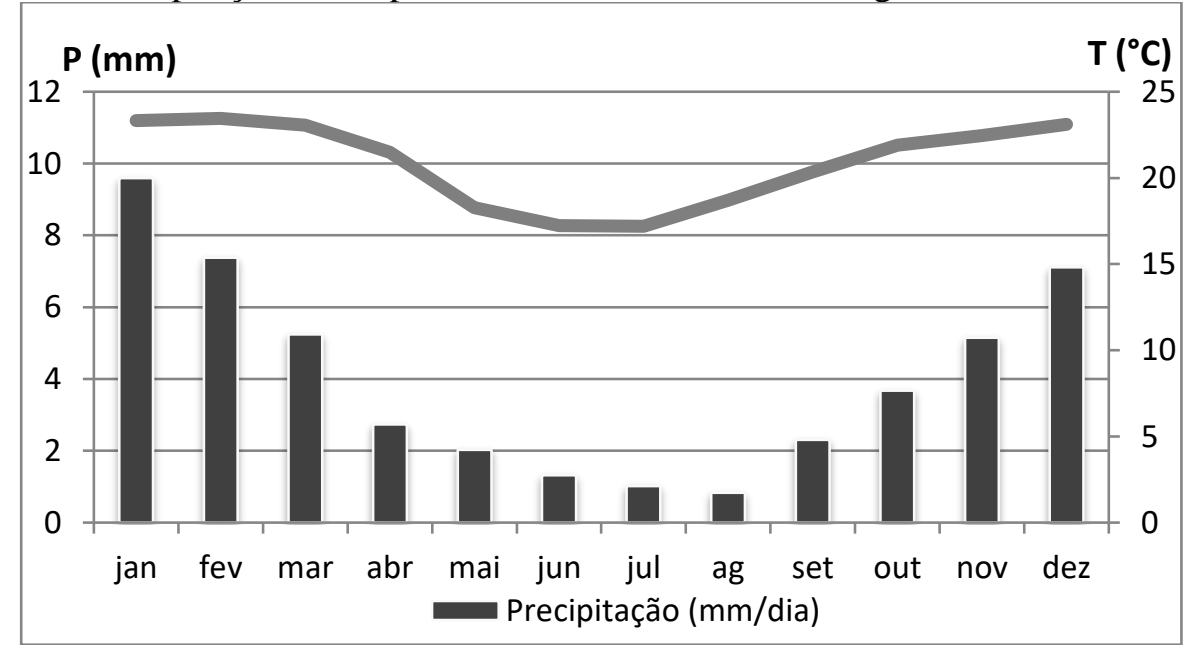

Fonte: Próprio autor

Figura 13 - Mapa de Isoietas (mm) da bacia do rio Jacaré-Guaçu

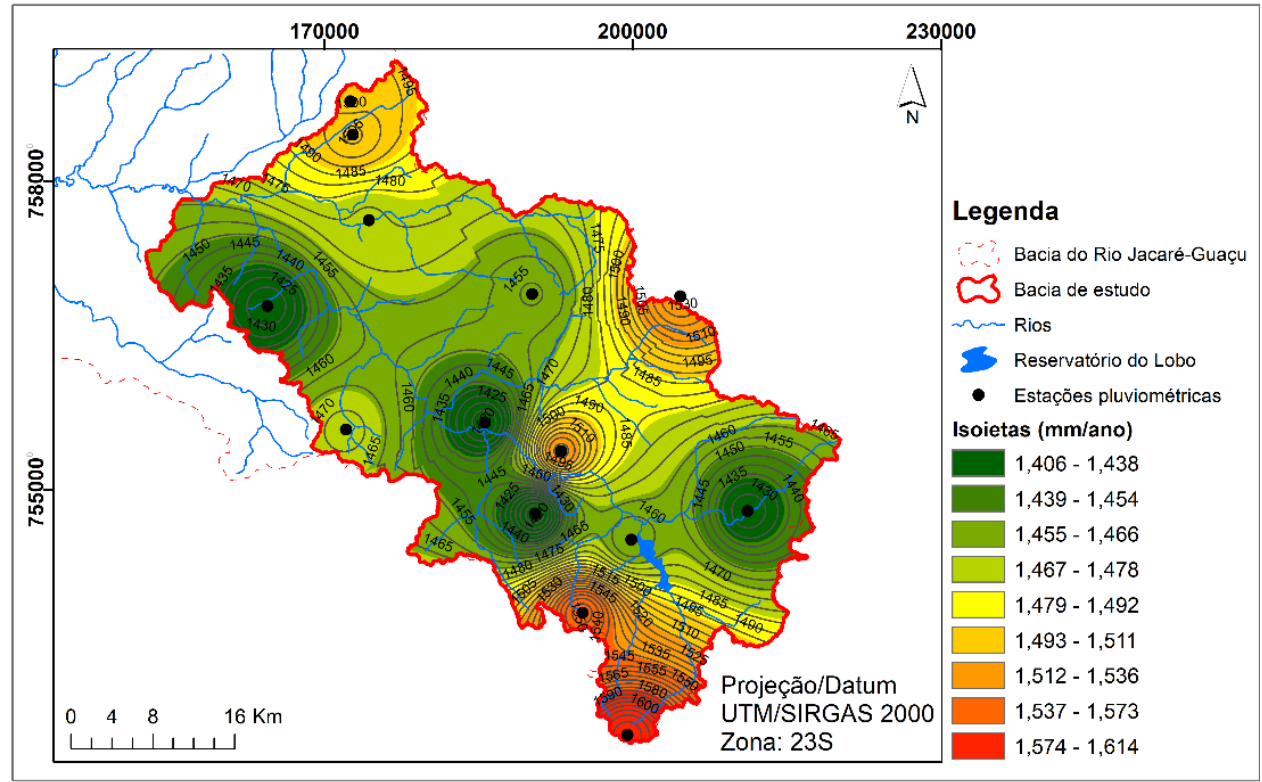

Fonte: Próprio autor 


\subsubsection{Solo, uso e ocupação do solo}

A maior parte da superfície das bacias é ocupada por solos que podem ser classificados pedologicamente como arenosos, resultantes da ação das forças do intemperismo contra os arenitos da Formação Botucatu e Bauru, e que apresentam porosidade elevada.

IPT (2011) classificou os solos da área em dois conjuntos principais, em termos de associações: um contendo solos pedologicamente desenvolvidos e o outro com solos que apresentam alteração incompleta dos minerais constituintes do substrato pedogenético, ou seja, relativamente pouco desenvolvidos em termos da composição mineralógica do solo.

O quadro 6 apresenta os tipos de solo presentes na área de estudo, bem como as siglas que foram utilizadas para elaboração do mapa de solos (figura 14), a nomenclatura anteriormente utilizada pela Comissão de Solos e a nomenclatura do Atual do Sistema Brasileiro de Classificação de Solos (SBCS).

Quadro 6 - Tipos de solo e suas classificações

\begin{tabular}{|c|c|c|c|}
\hline Sigla & $\begin{array}{l}\text { Nomenclatura anteri } \\
\text { Solos }\end{array}$ & rmente utilizada pela Comissão de & Nomenclatura do Atual SBCS \\
\hline $\mathrm{AQ}$ & $\begin{array}{l}\text { Areias Quartzosas } \\
\text { profundas }\end{array}$ & Profundas, álicas, A moderado & $\begin{array}{l}\text { NEOSSOLO QUARTZARÊNICO Órtico } \\
\text { típico A fraco }\end{array}$ \\
\hline LE-1 & $\begin{array}{l}\text { Latossolo } \\
\text { Vermelho-Escuro }\end{array}$ & Álico. A moderado, textura média & $\begin{array}{l}\text { LATOSSOLO VERMELHO Distrófico } \\
\text { típico A moderado textura muito argilosa }\end{array}$ \\
\hline LRd & Latossolo Roxo & Distrófico - A moderado. & $\begin{array}{l}\text { LATOSSOLO } \\
\text { Distroférrico típico A moderado textura } \\
\text { muito argilosa }\end{array}$ \\
\hline $\mathrm{LV}-2$ & $\begin{array}{l}\text { Latossolo } \\
\text { Vermelho- Amarelo }\end{array}$ & Álico, A moderado, Textura média & \\
\hline LV-5 & $\begin{array}{l}\text { Latossolo } \\
\text { Vermelho-Amarelo }\end{array}$ & $\begin{array}{l}\text { Álico, A moderado, } \\
\text { argilosa ou média }\end{array}$ & $\begin{array}{l}\text { LATOSSOLO AMARELO Distrófico } \\
\text { típico A proeminente textura média }\end{array}$ \\
\hline LV-6 & $\begin{array}{l}\text { Latossolo } \\
\text { Vermelho-Amarelo }\end{array}$ & $\begin{array}{l}\text { Álico, A preponderante, textura } \\
\text { muito argilosa ou argilosa + } \\
\text { Plintossolos }\end{array}$ & $\begin{array}{l}\text { LATOSSOLO VERMELHO AMARELO } \\
\text { Distrófico A moderado textura argilosa }\end{array}$ \\
\hline $\mathrm{Li}-3$ & Solos Litólicos & $\begin{array}{llll}\begin{array}{l}\text { Eutrófico. } \\
\text { chernozênico, textura argilosa }\end{array} & \text { moderado } \\
\text { cheu }\end{array}$ & $\begin{array}{lll}\begin{array}{l}\text { NEOSSOLO } \\
\text { chernossólico }\end{array} & \text { LITÓLICO } & \text { Eutrófico } \\
\end{array}$ \\
\hline OR & Solos Hidromórficos & $\begin{array}{l}\text { Solos orgânicos com ou sem Gley } \\
\text { húmico }\end{array}$ & $\begin{array}{l}\text { GLEISSOLO HÁPLICO Ta Distrófico } \\
\text { típico A moderado, textura errática }\end{array}$ \\
\hline PV -2 & $\begin{array}{l}\text { Podzólico Vermelho } \\
\text { amarelo }\end{array}$ & $\begin{array}{l}\text { Argila de atividade baixa, álico, } \\
\text { abruptivo, A moderado espesso, } \\
\text { textura arenosa/média }\end{array}$ & 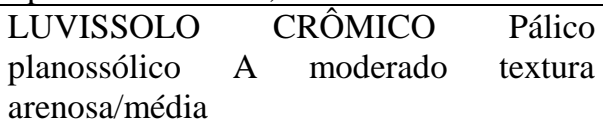 \\
\hline PV-3 & $\begin{array}{l}\text { Podzólico Vermelho } \\
\text { Amarelo }\end{array}$ & $\begin{array}{l}\text { Abrúpto eutrófico ou álico, A } \\
\text { moderado espesso, textura média/ } \\
\text { argilosa }\end{array}$ & $\begin{array}{l}\text { NITOSSOLO HÁPLICO Distrófico } \\
\text { típico A moderado textura média / } \\
\text { argilosa }\end{array}$ \\
\hline $\mathrm{PV}-4$ & $\begin{array}{l}\text { Podzólico Vermelho } \\
\text { Amarelo }\end{array}$ & $\begin{array}{l}\text { Distrófico, A moderado textura } \\
\text { média ou média/argilosa }\end{array}$ & \\
\hline $\mathrm{PV}-5$ & $\begin{array}{l}\text { Podzólico Vermelho } \\
\text { Amarelo }\end{array}$ & $\begin{array}{l}\text { Distrófico, A proeminente ou } \\
\text { chernozênico, textura } \\
\text { média/argilosa fase pedregosa I. }\end{array}$ & $\begin{array}{l}\text { ARGISSOLO VERMELHO-AMARELO } \\
\text { Distrófico típico A moderado textura } \\
\text { média/argilosa }\end{array}$ \\
\hline TE-2 & $\begin{array}{l}\text { Terra } \\
\text { estruturada }\end{array}$ & $\begin{array}{l}\text { Eutrófico ou } \begin{array}{l}\text { Distrófico, } \\
\text { intermediária para latossolo roxo, A } \\
\text { moderado }\end{array} \\
\end{array}$ & $\begin{array}{l}\text { NITOSSOLO VERMELHO Eutroférrico } \\
\text { típico A moderado textura muito argilosa }\end{array}$ \\
\hline
\end{tabular}

Fonte: Próprio autor 
As características do solo foram obtidas através da Empresa Brasileira de Pesquisa Agropecuária (EMBRAPA), tendo-se identificado oito tipos de solo na bacia, latossolo vermelho-amarelo (abrangendo 55,4\% da área da bacia hidrográfica), quartzosas (13,2\%), latossolo vermelho-escuro $(10,6 \%)$, latossolo roxo $(6,5 \%)$, podzólico vermelho-amarelo $(5,1 \%)$, solos litólicos $(4,6 \%)$, solos hidromórficos $(4,2 \%)$ e terra roxa estruturada $(0,4 \%)$.

A cobertura vegetal original da área (cerrado) é indicativa das altas profundidades e do caráter arenoso-quartzoso dos solos. Esses fatos demonstram que as condições de infiltração das águas pluviais são boas, garantindo um bom aproveitamento para recarga dos aquíferos existentes na área (CÔRREA, 1998).

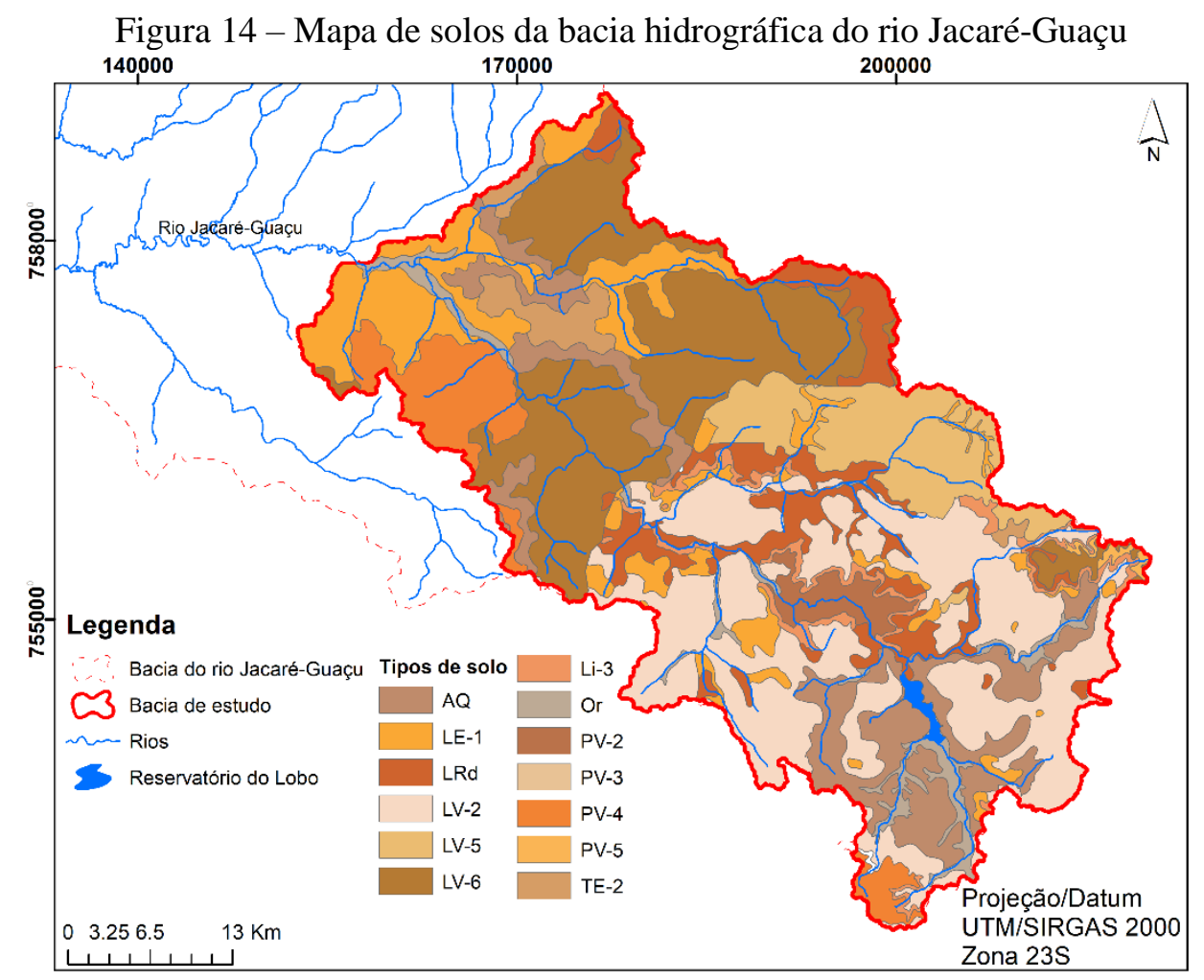

Fonte: Próprio autor

As unidades geológicas que afloram na área de estudo são compostas por rochas sedimentares pertencentes ao Grupo São Bento e Grupo Bauru. As rochas do Grupo São Bento na área de estudo compreendem os arenitos das Formações Piramboia e Botucatu, recobertos por derrames basálticos da Formação Serra Geral. O Grupo Bauru na área de estudo é representado por arenitos e lamitos da Formação Adamantina (Comitê da Bacia Hidrográfica do rio Tietê-Jacaré - CBH TJ, 2009).

A ocupação efetiva da região ocorreu no século XIX, e durante este processo a formação vegetal original foi substituída parcialmente por cultura de cana de açúcar, pasto, 
café e agricultura de subsistência (FERREIRA; ALVES, 2009). Atualmente a bacia hidrográfica possui grande importância no contexto econômico do Estado de São Paulo, com destaque para as atividades relacionadas ao setor agropecuário.

Foram identificados 7 tipos de uso e ocupação do solo sendo o mais expressivo a agricultura com $38,7 \%$ da área, seguindo pela cana de açúcar $(27,6 \%)$, pasto $(19,8 \%)$, mata nativa $(6,2 \%)$, área urbana $(3,7 \%)$, solo exposto $(3,4 \%)$ e água $(0,6 \%)$.

A figura 15 apresenta o mapa de uso e ocupação do solo da área da bacia hidrográfica do rio Jacaré-Guaçu.

Figura 15 - Mapa de uso e ocupação do solo da bacia hidrográfica do rio Jacaré-Guaçu

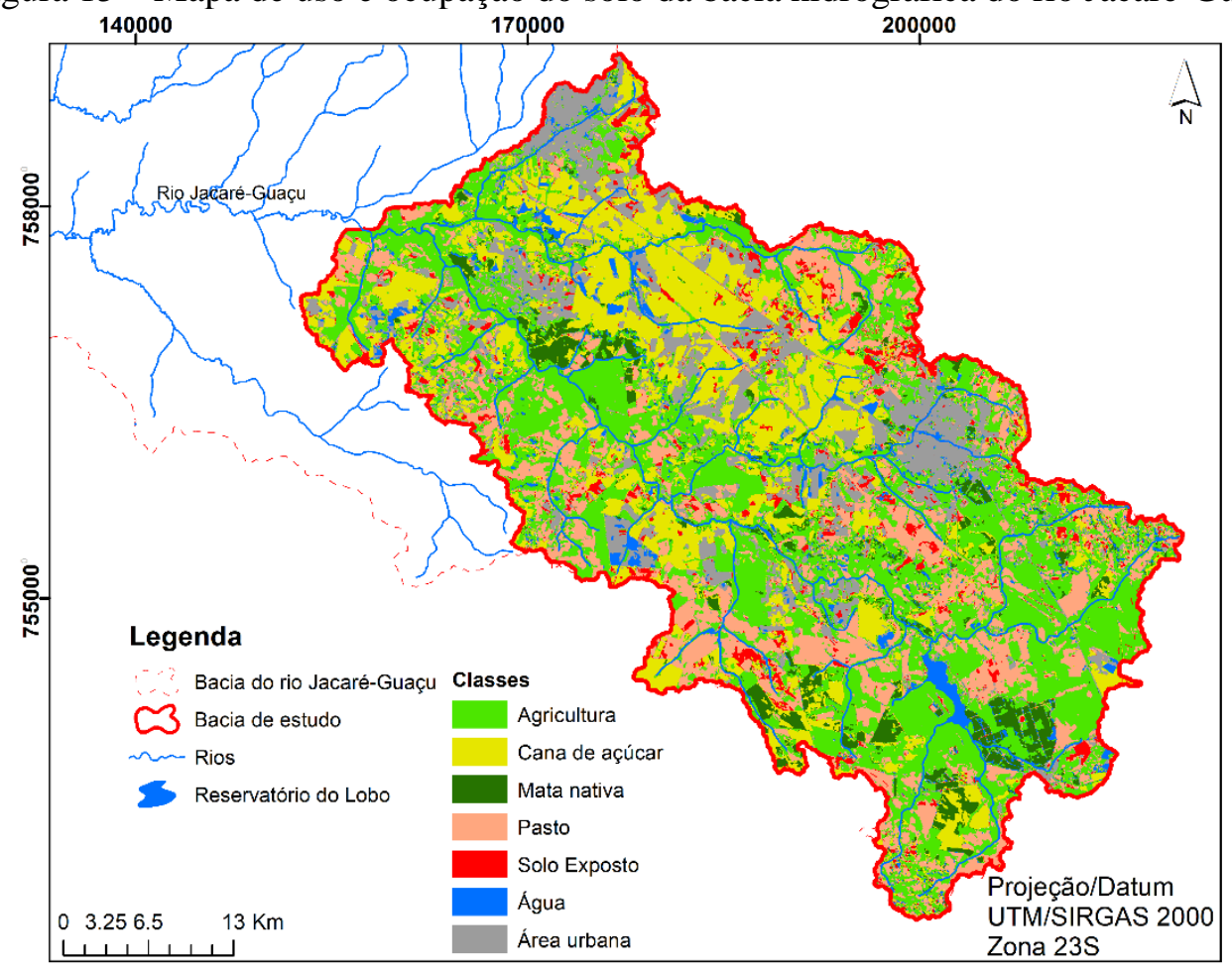

Fonte: Próprio autor

\subsection{Bacia hidrográfica do rio Atibaia}

\subsubsection{Descrição geral}

A bacia do rio Atibaia está inserida na UGRHI-5, denominada PCJ - Piracicaba, Capivarí e Jundiai, e possui uma área de drenagem de $2817,88 \mathrm{~km}^{2}$ na qual estão inseridos, total ou parcialmente, municípios dos estados de São Paulo e Minas Gerais. A figura 16 apresenta a localização da bacia do rio Atibaia. A bacia do rio Atibaia localiza-se no centro leste do Estado de São Paulo, aproximadamente entre os paralelos $22^{\circ} 41^{\prime}$ e $23^{\circ} 18^{\prime}$ sul e os meridianos $46^{\circ} 00^{\prime}$ e $47^{\circ} 16^{\prime}$ oeste. 
No SWAT esta área de estudo foi dividida em 177 sub-bacias e 1117 HRUs.

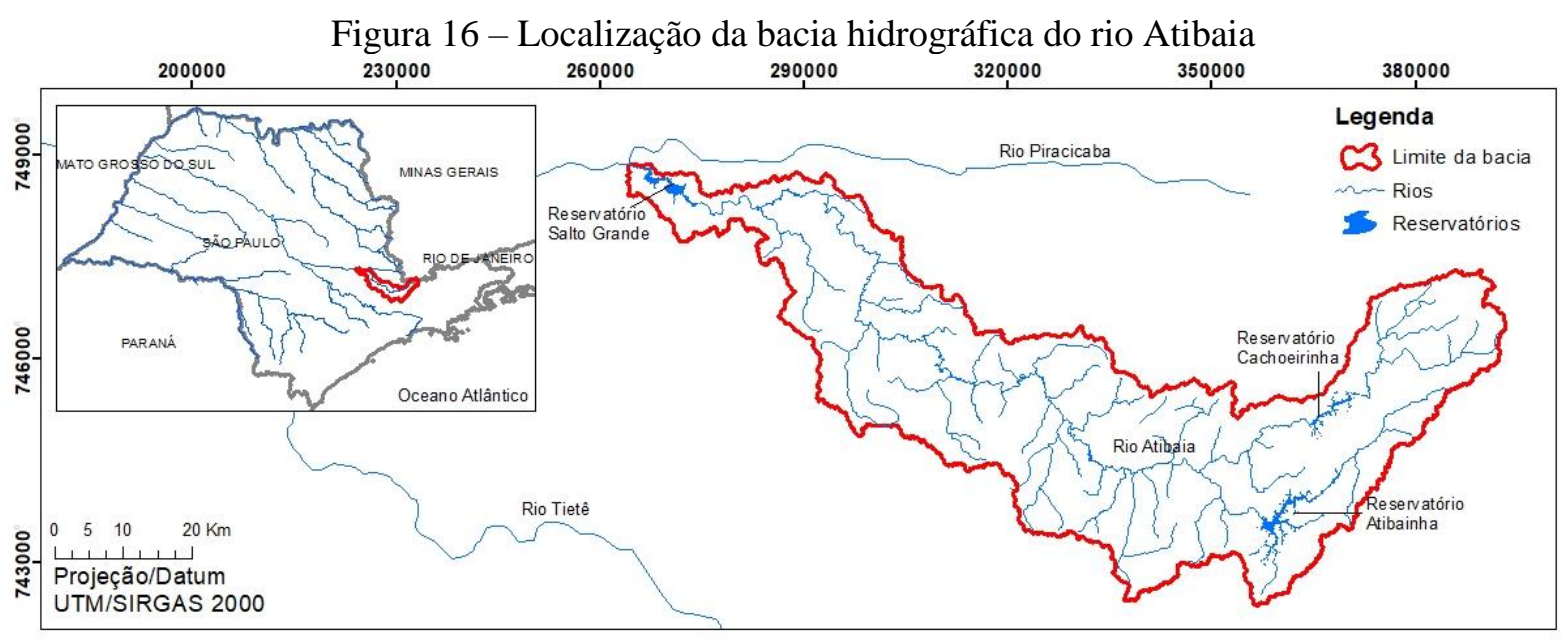

Fonte: Próprio autor

A bacia do rio Atibaia é formada pela junção dos rios Atibainha e Cachoeira, entre os municípios de Bom Jesus dos Perdões e Atibaia, e as nascentes do rio Cachoeira, em Minas Gerais.

De acordo com Sistema Integrado de Gerenciamento de Recursos Hídricos (SIGRH, 2017), a população total da bacia é de aproximadamente 372.456 habitantes, e a maioria dos sistemas de abastecimento de água dos municípios tem suas captações em mananciais superficiais.

Atualmente a bacia do rio Atibaia apresenta-se como crítica em relação aos usos de seus recursos hídricos.

A bacia do rio Atibaia possui três importantes reservatórios: Cachoeirinha, Atibainha e Salto Grande. Os dois primeiros reservatórios fazem parte do sistema Cantareira, principal produtor de água potável da Região Metropolitana de São Paulo - RMSP, e estão localizados nos principais formadores do rio Atibaia, um localizado no rio Cachoeira e outro localizado no rio Atibainha (figura 14).

O reservatório de Salto Grande está localizado no exutório do rio Atibaia, aproximadamente a $700 \mathrm{~m}$ acima do rio Piracicaba formado pela confluência entre os rios Atibaia e Jaguari e possui uma potência total instalada de 30 MW. O reservatório da usina foi construído entre 1940 e 1949 com objetivo principal de produção de energia elétrica, e destina-se também a outras atividades como: irrigação, recreação, piscicultura e abastecimento de água. O reservatório possui um volume de $107.000 .000 \mathrm{~m}^{3}$ no nível máximo operativo (cota 501,30m), o que representa uma área inundada de $11.566 .312 \mathrm{~m}^{2}$. 
A bacia hidrográfica do rio Atibaia apresenta altitudes entre 508 e $1973 \mathrm{~m}$, com as maiores altitudes na parte oeste e sul e as menores no exutório da bacia (figura 17).

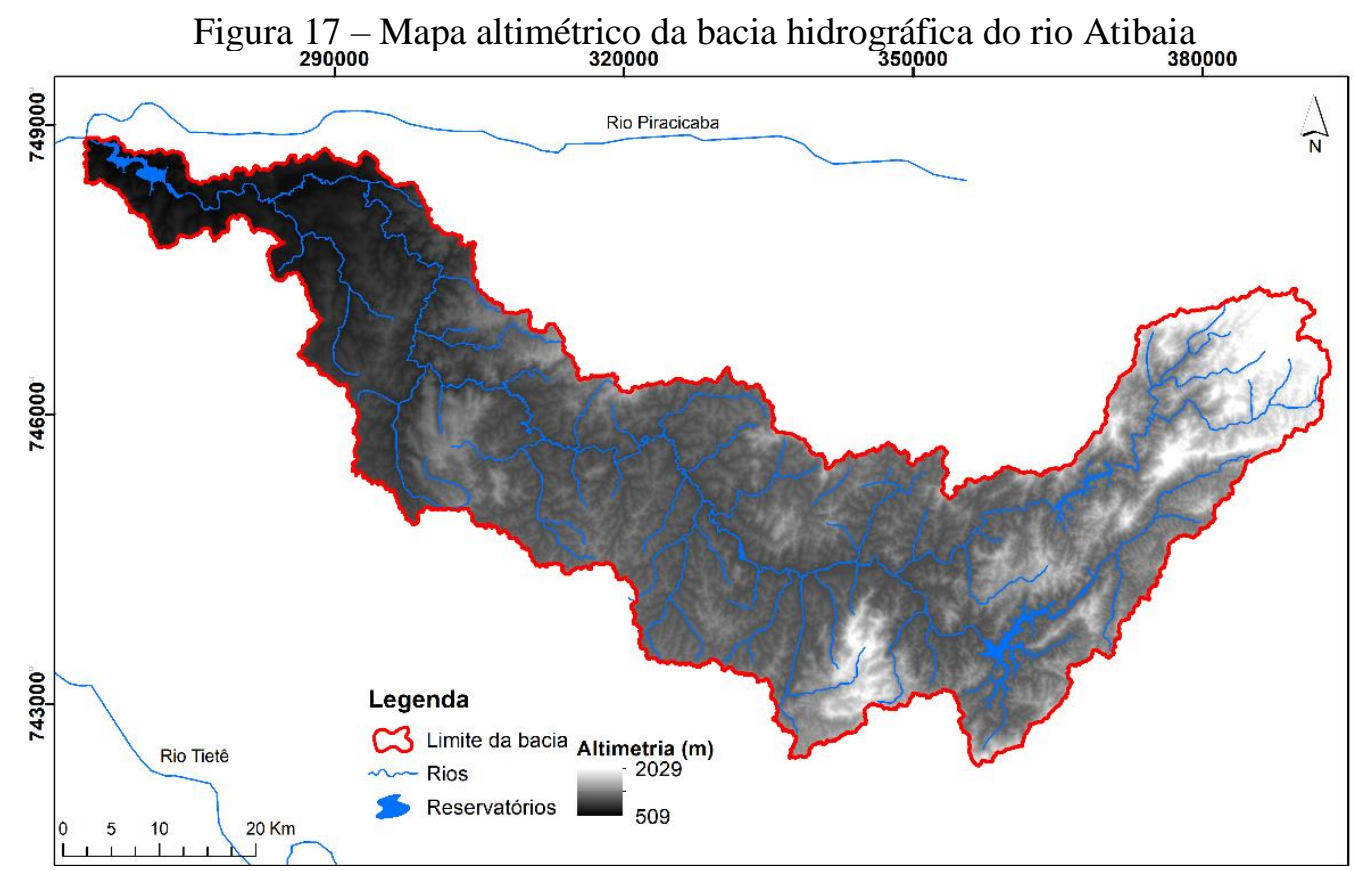

Fonte: Próprio autor

\subsubsection{Clima e hidrologia}

Para a bacia hidrográfica de Atibaia 17 estações pluviométricas, 5 estações fluviométricas $(62693100,4009,3003,3006$ e 3007) e 2 estações de monitoramento de qualidade de água foram selecionados com base na sua localização e na completude dos registros (figura 18). 
Figura 18 - Localização das estações pluviométricas, fluviométricas e de qualidade da água da bacia

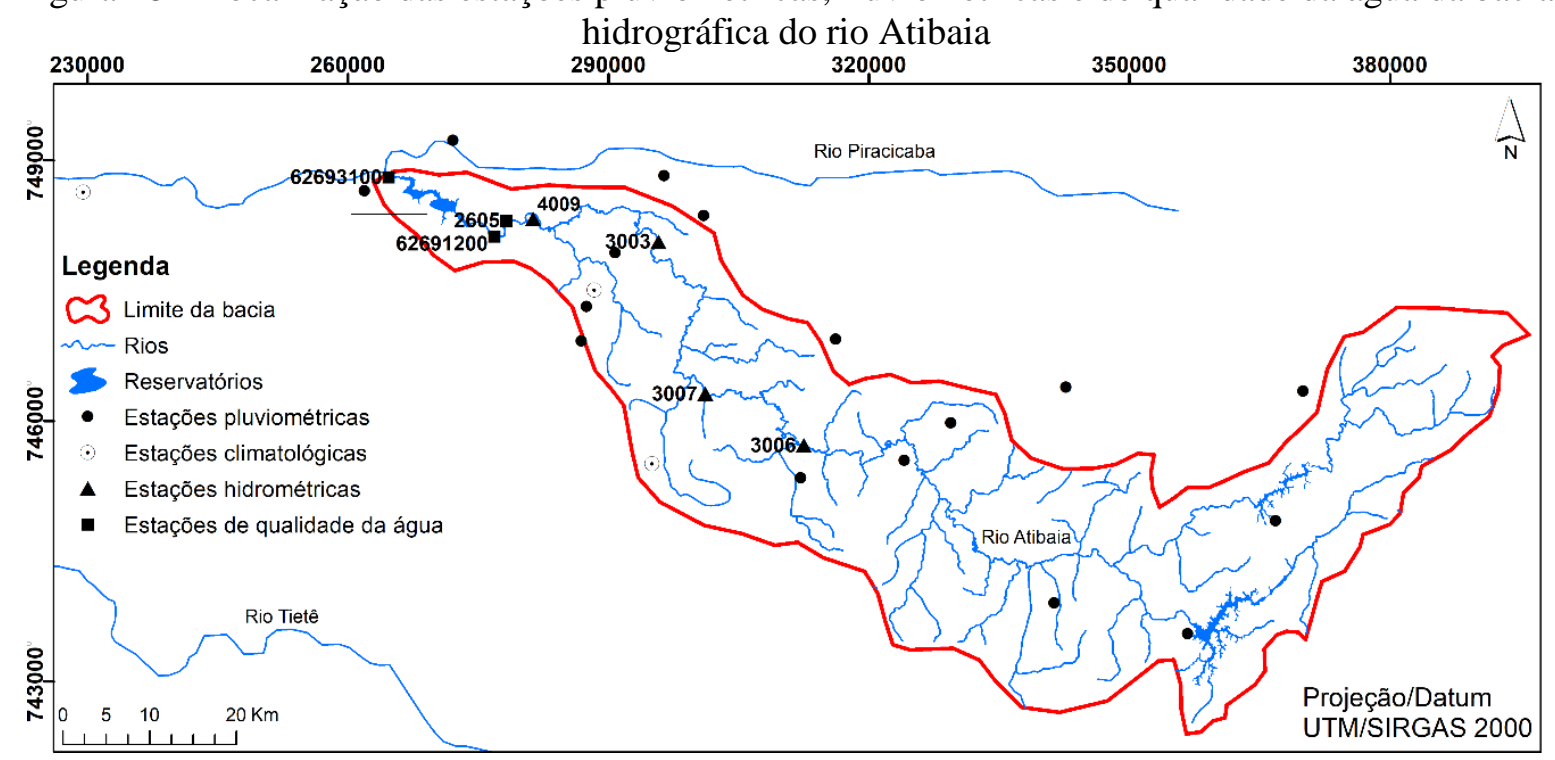

Fonte: Próprio autor

A figura 19 apresentam a espacialização dos DPI obtidos por Xavier; King; Scanlon, (2016) para a bacia hidrográfica do rio Jacaré-Guaçu.

Figura 19 - Localização dos DPI para bacia hidrográfica do rio Atibaia

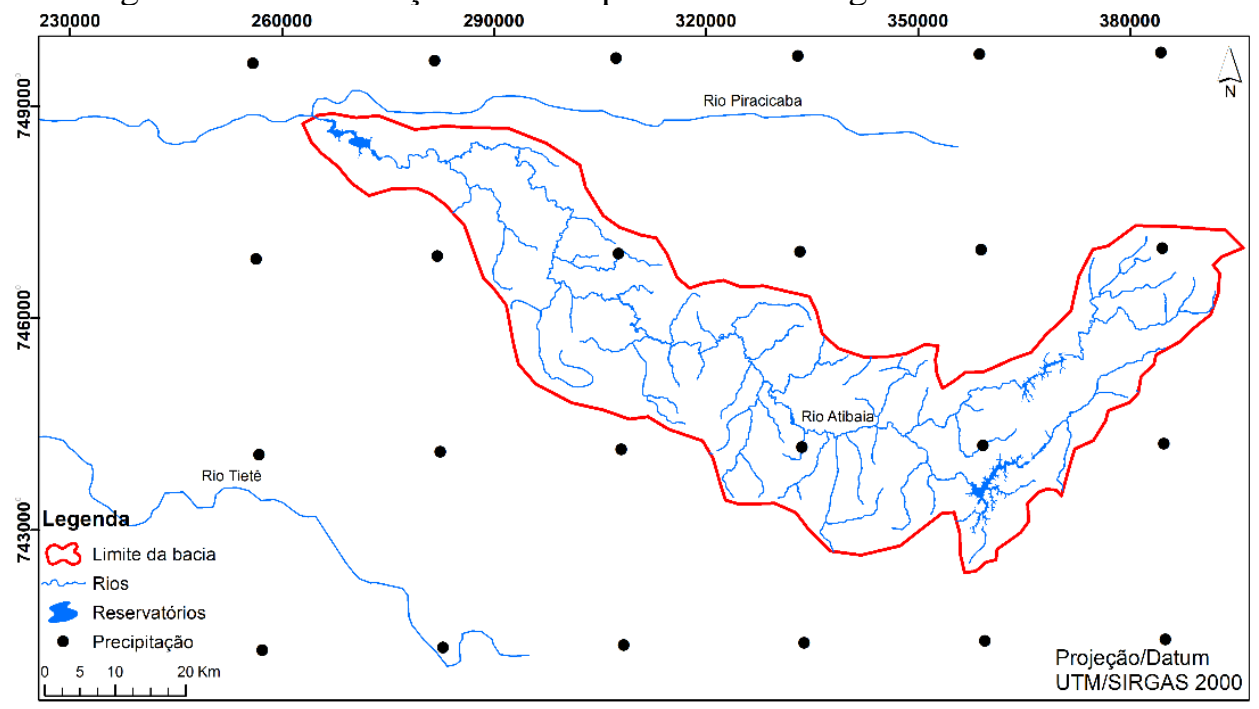

Fonte: Próprio autor

A figuras 20 apresenta as precipitações e as temperaturas médias da área a partir de estações pluviométricas e climatológicas com séries de 1987 a 2016. A temperatura média anual varia de $18^{\circ} \mathrm{C}$ Sudoeste a $20^{\circ} \mathrm{C}$ Leste. Os meses de dezembro, janeiro e fevereiro apresentam as temperaturas mais elevadas e as maiores precipitações e os meses de junho, julho e agosto são os que apresentam menores temperaturas e menores precipitações. 
A partir da observação do mapa de isoietas (figura 21) pode-se notar uma distinção de valores entre as extremidades sudeste e sul das bacias, sendo a última mais chuvosa.

Figura 20 - Precipitações e temperaturas médias da bacia hidrográfica do rio Atibaia

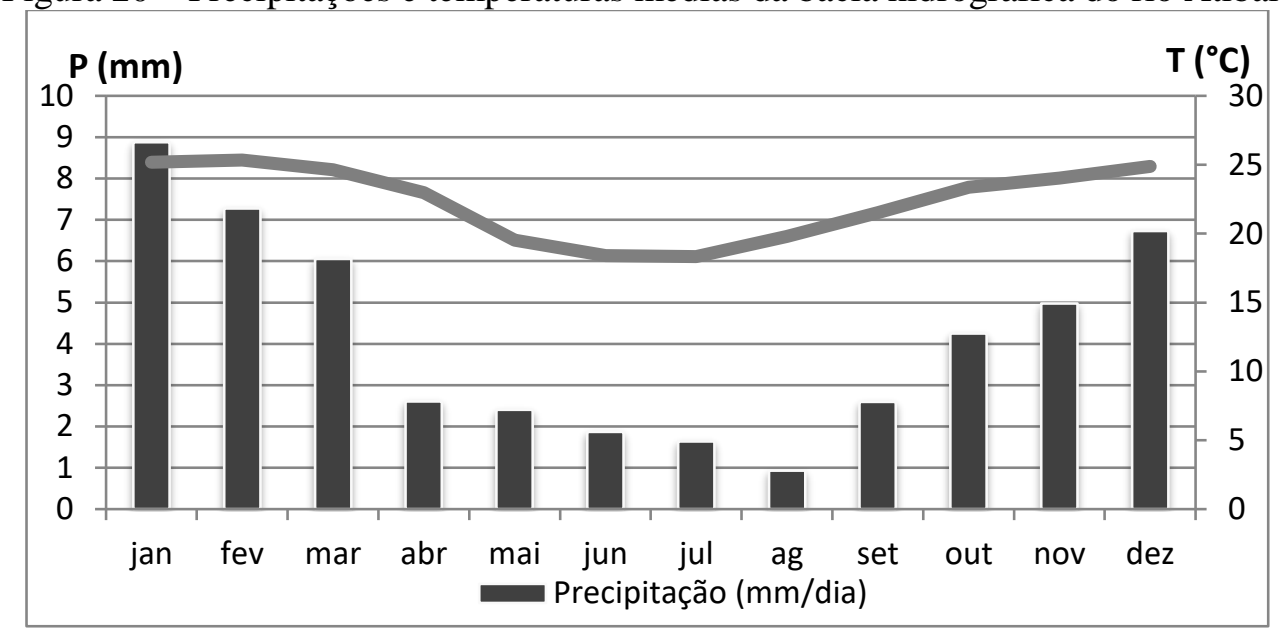

Fonte: Próprio autor

Figura 21 - Mapa de Isoietas (mm) da bacia hidrográfica do rio Atibaia

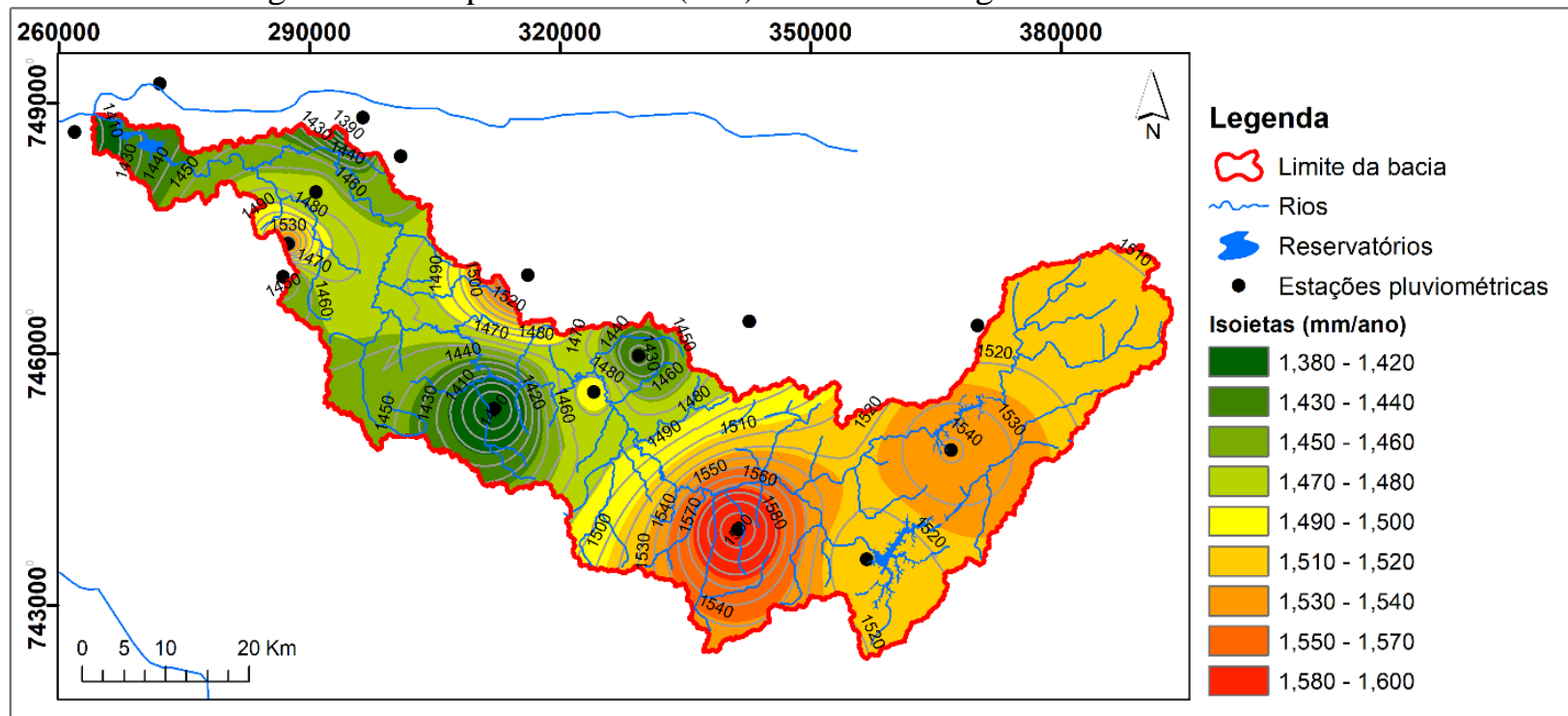

Fonte: Próprio autor

\subsubsection{Solo, uso e ocupação do solo}

Os solos da bacia hidrográfica do rio Atibaia compreendem o latossolo vermelhoamarelo (cobrindo $61,01 \%$ da área da bacia hidrográfica), latossolo roxo $(37,75 \%)$, latossolo vermelho-escuro $(1,24 \%)$.

O quadro 5 apresenta os tipos de solo presentes na área de estudo, bem como as siglas que foram utilizadas para elaboração do mapa de solos (figura 22). 
Figura 22 - Mapa de solos da bacia hidrográfica do rio Atibaia

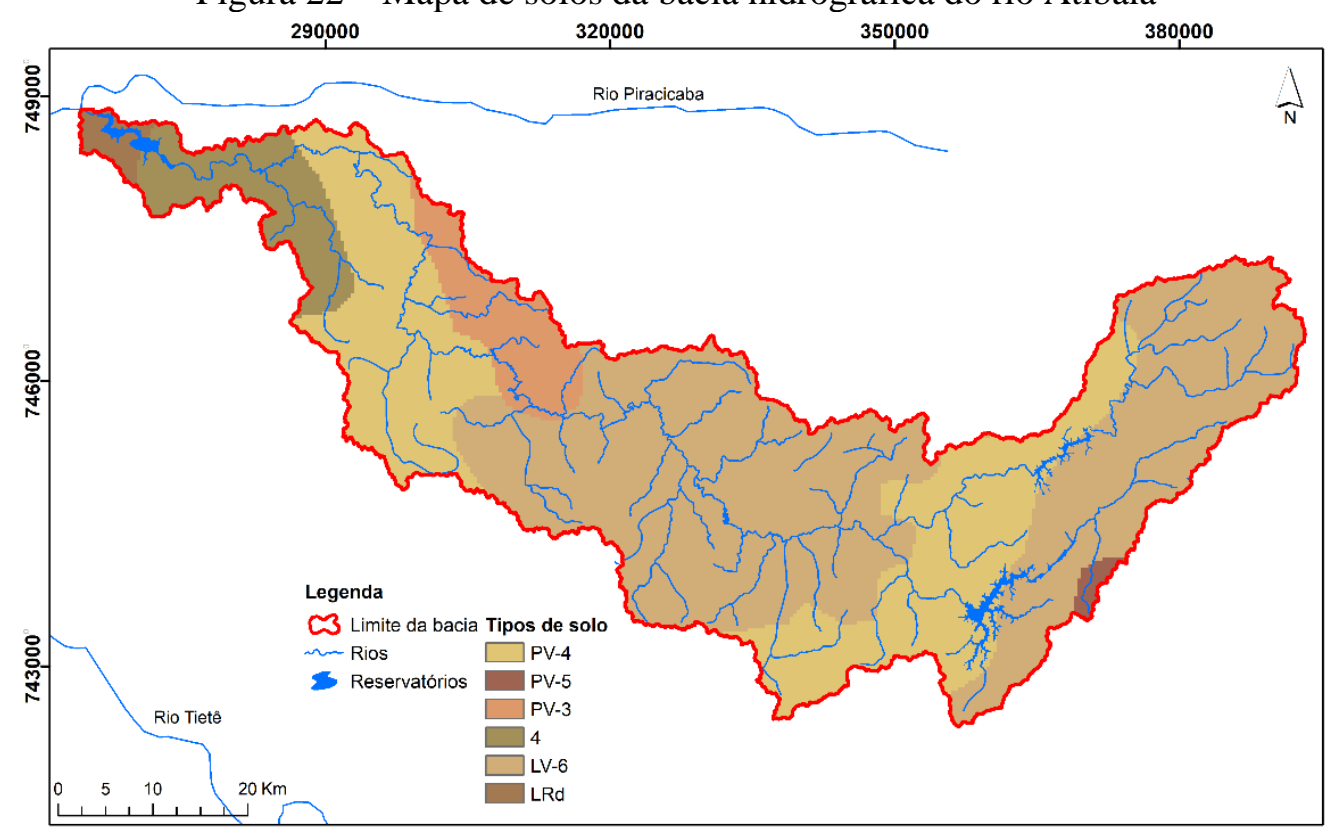

Fonte: Próprio autor

A geologia da bacia hidrográfica do Rio Atibaia consiste em rochas granitizadas, granitos, gnaisses embrechíticos do grupo Amparo, predominando no médio e baixo Atibaia, depósitos aluviais, areias, argilas e conglomerados na base (Mapa Geológico do Estado de São Paulo, 1982).

O uso do solo é representado em grande parte por pasto apesar da agricultura apresentar crescimento no território paulista nas últimas décadas, com a intensificação do uso do solo e o aumento da produtividade, ou ainda pela substituição de culturas. As culturas que tiverem maiores possibilidades de êxito econômico ocuparão as áreas das demais, como tem sido os casos da cana de açúcar e da laranja.

O reflorestamento também é uma atividade significativa em algumas sub-bacias do Comitê PCJ, como a do rio Jundiaí devido principalmente, à proximidade das indústrias de papel e celulose. A vegetação original encontrando-se apenas em alguns remanescentes, como nas margens dos cursos de água e em outras Áreas de Preservação Permanente - APP.

Foram identificados oito tipos de uso da terra na bacia: floresta (cobrindo 43,53\% da área da bacia hidrográfica), pasto $(29,25 \%)$, área urbana $(17,03 \%)$, agricultura $(3,77 \%)$, solo exposto $(3,04 \%)$, água $(1,91 \%)$, cana-de-açúcar $(1,43 \%)$ e transporte mineral $(0,04 \%)$. A figura 23 apresenta o mapa de uso e ocupação do solo da área da bacia hidrográfica do rio Atibaia. 
Figura 23 - Mapa de uso e ocupação do solo da bacia hidrográfica do rio Atibaia

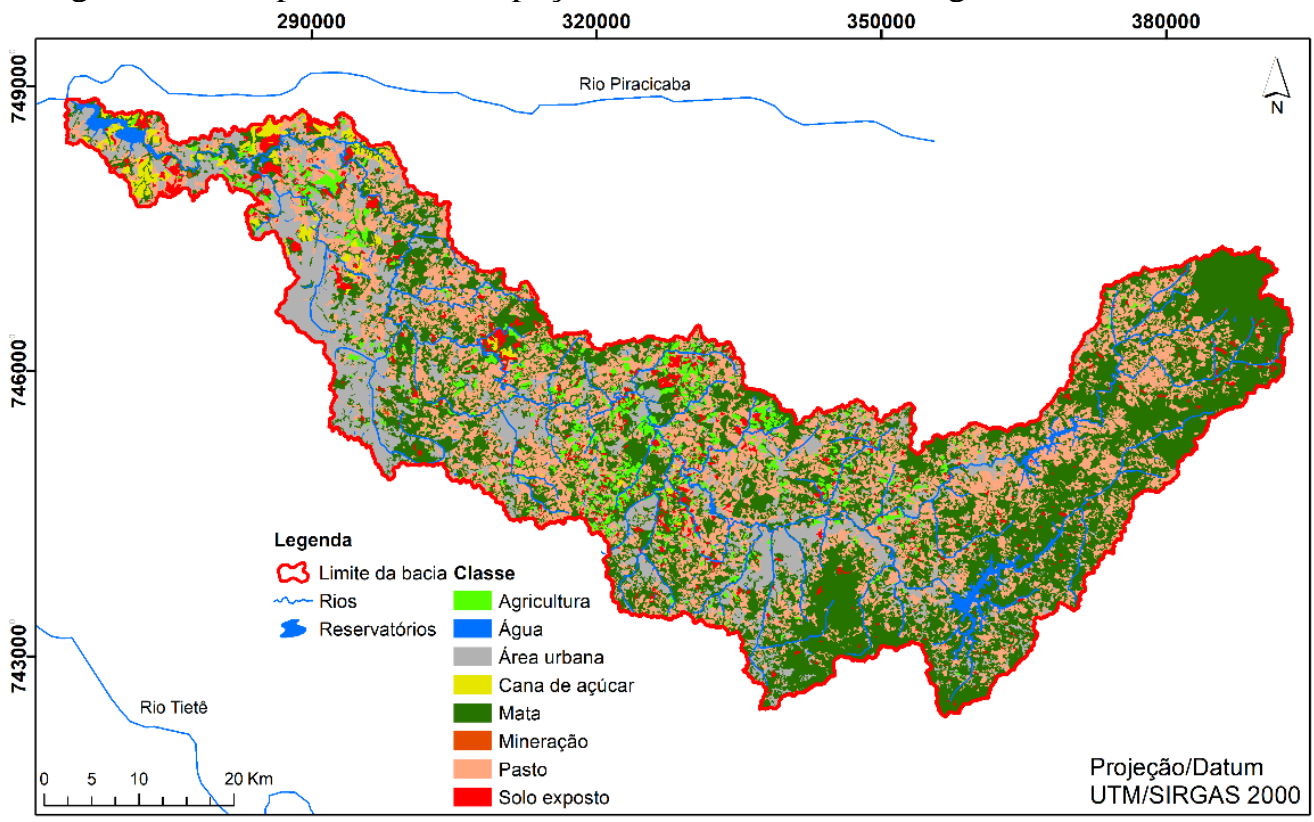

Fonte: Próprio autor 


\section{RESULTADOS E DISCUSSÃO}

\subsection{Calibração e validação dos modelos}

\subsubsection{Calibração da vazão}

Uma revisão da literatura relevante identificou 17 parâmetros aos quais os resultados do SWAT são mais sensíveis (tabela 12). Para selecionar entre estes os mais importantes para a previsão de fluxo foram realizadas duas execuções independentes de SWAT-CUP, uma para cada caso de estudo. Essas duas corridas identificaram os mesmos 10 parâmetros, também destacados na tabela 12. A tabela agrupa os parâmetros por componente de modelo, ou seja, fluxo de água subterrânea, retenção de superfície, hidráulica fluvial, características do solo, bem como transporte de sedimentos e nutrientes. Para cada parâmetro, a tabela indica o intervalo esperado de valores, o valor padrão e o valor final obtido após a calibração (valores calibrados).

As execuções preliminares do SWAT, usando os valores padrão dos parâmetros, levaram a uma superestimação ${ }^{17}$ do registro da vazão observada, particularmente os valores mais elevados do fluxo. O procedimento de calibração prosseguiu para reduzir essa vazão de pico. Os números de curva $(\mathrm{CN} 2)$ foram reduzidos em $30 \%$ uniformemente ao longo da bacia para promover a infiltração e o fluxo de base. A capacidade de água disponível no solo (SOL_AWC) também foi reduzida em 10\% para diminuir a capacidade de retenção do solo, aumentar a percolação da água subterrânea e retardar o fluxo que chega ao rio. O fator de compensação de evaporação do solo (ESCO) foi reduzido para 0,4 , para promover a demanda evaporativa das camadas inferiores do solo. O parâmetro GW_REVAP, um coeficiente que reflete a capacidade de mover a água do aquífero pouco profundo para a zona de solo não saturado sobreposto, foi definido em 0,12, o que indica que mais água está disponível para a descarga do fluxo de base. O REVAPMN, que define a profundidade limiar da água no aquífero pouco profundo para que ocorra o fluxo de retorno para a zona de raiz foi reduzido para $300 \mathrm{~mm}$.

De acordo com Arnold et al. (2012), a profundidade mínima do aquífero pouco profundo para ocorrer escoamento subterrâneo (GWQMN) e o fator alfa do fluxo de base (ALPHA_BF) também são importantes na calibração. No início da calibração, o fluxo de base

\footnotetext{
${ }^{17}$ Sobrestimação em português europeu.
} 
era muito alto, então o valor GWQMN foi diminuído de 1000 para $300 \mathrm{~mm}$, para regular o movimento da água dentro do aquiífero. A variável ALPHA_BF afeta a forma do hidrograma, e foi necessário diminuir esse parâmetro para 0,001. O parâmetro GW_DELAY que reflete o intervalo de tempo que leva água no solo para entrar no aquífero pouco profundo foi reduzido para 20 dias.

Uma vez reproduzida a magnitude e a variabilidade do fluxo de base e dos picos do hidrograma, o balanço hídrico geral foi ajustado usando o parâmetro RCHRG_DP. O valor para RCHRG_DP foi ajustado para 0,04, o que significa que 4\% da água infiltrada é perdida para um aquífero profundo. CANMX que descreve a capacidade de armazenamento do dossel florestal (cobertura superior da floresta formada pelas copas das árvores) foi alterada para aumentar a intercepção da precipitação e o armazenamento de água, tanto quanto possível. Os valores de $\mathrm{CH} \_\mathrm{K} 1$ e $\mathrm{CH} \_\mathrm{K} 2$ que indicam a taxa de perda de água dos fluxos para a água subterrânea foram definidos como $5 \mathrm{~mm} / \mathrm{h}$ e $3,2 \mathrm{~mm} / \mathrm{h}$ respetivamente, o que pressupõe a perda de água pelos córregos dentro das bacias hidrográficas (GITAU; CHAUBEY, 2010).

Em relação aos parâmetros relacionados às características do solo, o comprimento da encosta para o escoamento subsuperficial lateral (SLSOIL), relacionado à geração do interfluxo, foi ajustado para 40m. O coeficiente de pesagem para cálculo da retenção dependente da evapotranspiração da planta (CNCOEF) foi modificado para 1,6. O armazenamento inicial de água no solo expresso como uma fração do conteúdo de água de capacidade de campo (FFCB) foi alterado para o valor 1.

Os parâmetros n de Manning para os canais principal e tributário $\left(\mathrm{CH}_{-} \mathrm{N} 1\right.$ e CH_N2) foram ajustados para 0,03 e 0,05, respectivamente, que são maiores do que os valores esperados para as condições do canal natural.

No que respeita ao SCS-CN e GWLF, os parâmetros que afetam a vazão são o número da curva $(\mathrm{CN})$, a capacidade de armazenamento de água na bacia hidrográfica $\left(\mathrm{U}_{\max }\right)$, a constante de recessão da água subterrânea $(\alpha)$ e o coeficiente de recarga profundo $(\beta)$. Estes parâmetros foram calibrados para cada sub-bacia hidrométrica, começando nas estações hidrométricas a montante, passando para as estações intermediárias e finalmente para a estação a jusante. A tabela 13 mostra os valores padrão dos parâmetros dos modelos SCS-CN e GWLF sugeridos pela literatura: Haith e Shoemaker (1987), Haith; Mandel; Wu, (1992), Li et al. (2010) e Niraula et al. (2013), baseados nas características das bacias hidrográficas tal como nos valores obtidos após a calibração. 
Tabela 12 - Valores originais e calibrados dos parâmetros do modelo SWAT

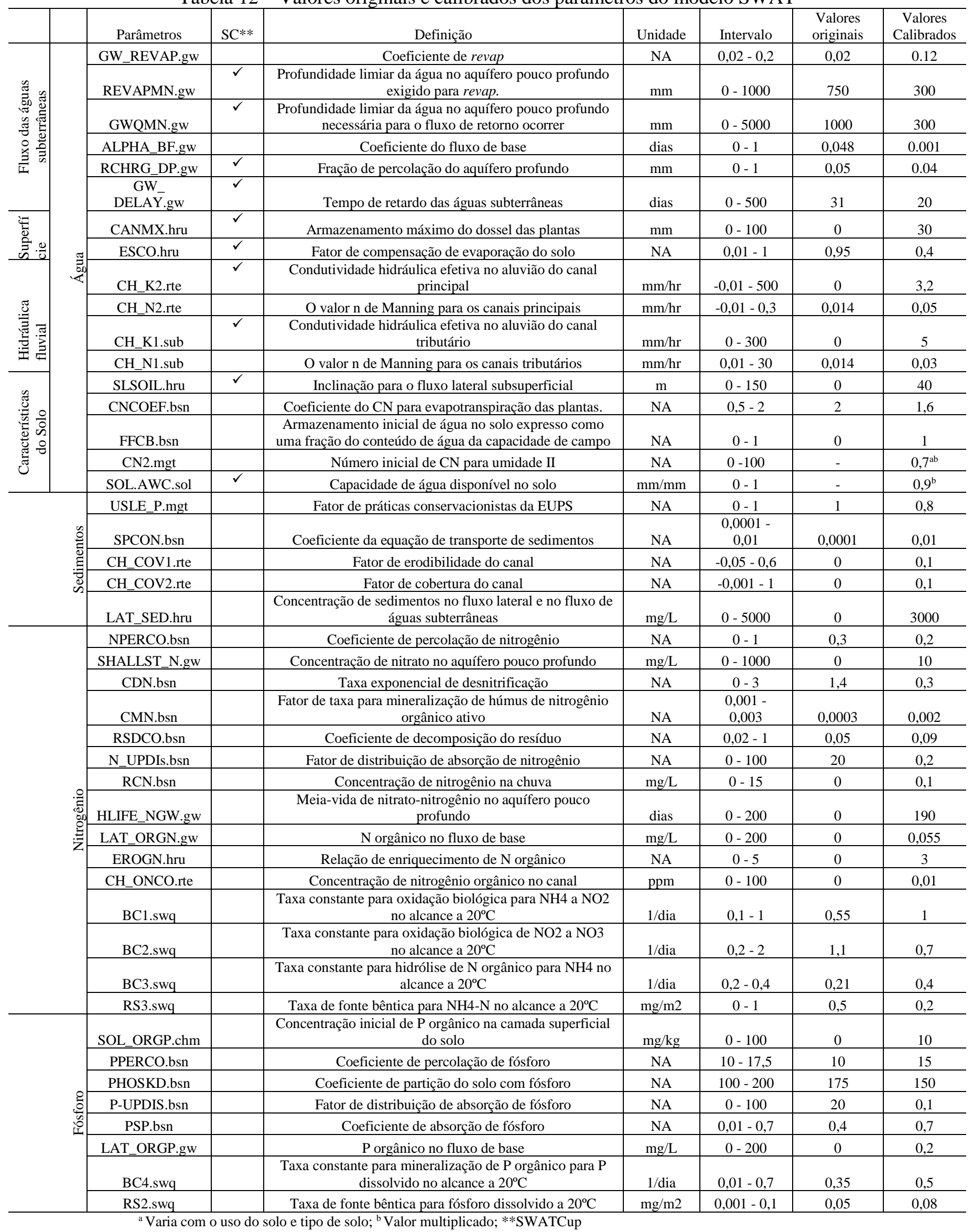

Fonte: Próprio autor 
Tabela 13 - Valores originais e calibrados dos parâmetros dos modelos SCS-CN e GWLF

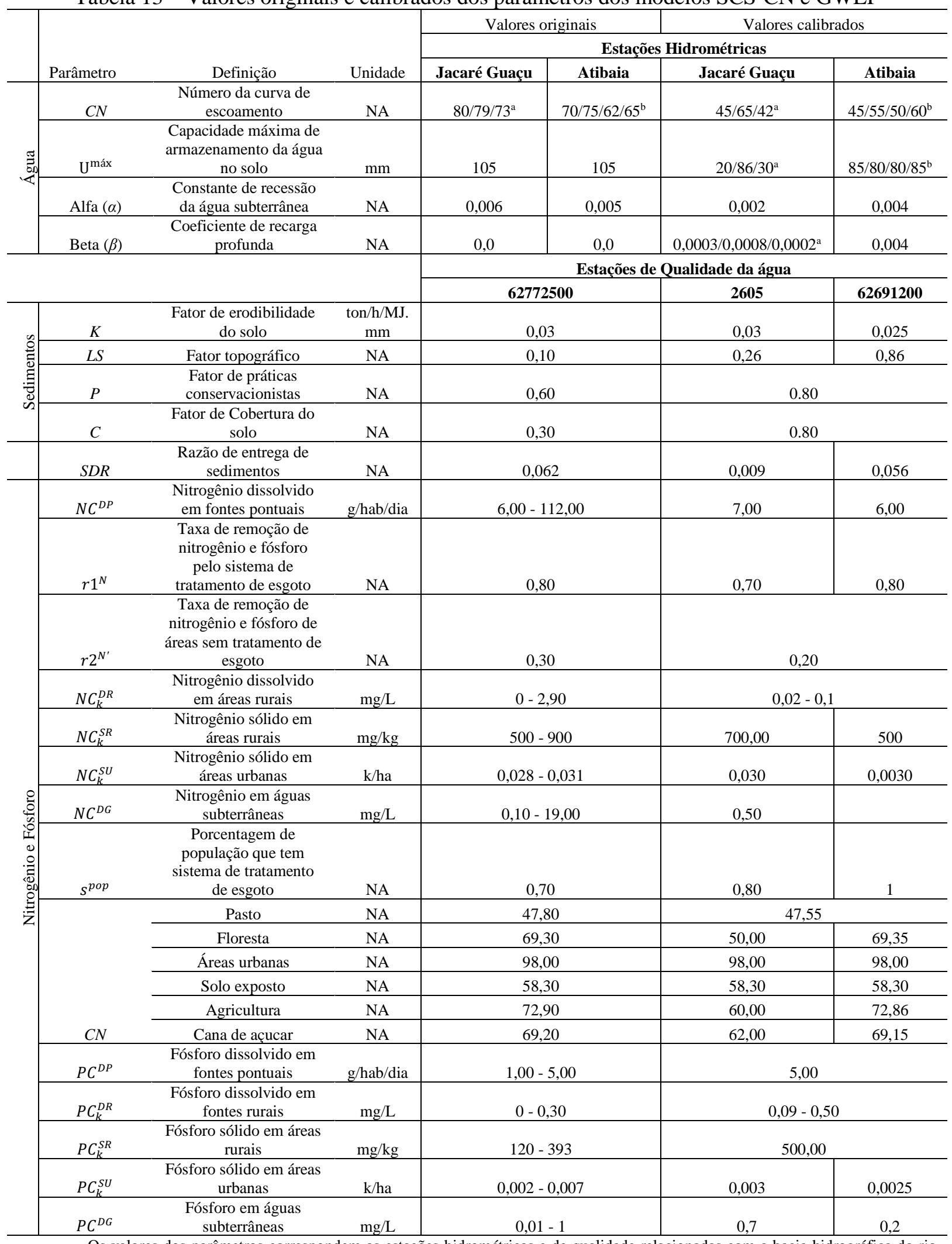

Os valores dos parâmetros correspondem as estações hidrométricas e de qualidade relacionadas com a bacia hidrográfica do rio Jacaré-Guaçu e com a bacia hidrográfica do rio Atibaia respectivamente: ${ }^{a} 62760005,62767500$ e 62772500 e b 3006, 3007, 3003 e 4009.

Fonte: Próprio autor 
Em ambos os casos de estudo, os valores de $\mathrm{CN}$ atribuídos a cada bacia são iguais nos modelos e estes valores foram reduzidos do valor original para aumentar a infiltração. As capacidades de armazenamento de água das bacias hidrográficas ( $U^{\text {máx }}$ ) também foram reduzidas dos valores padrão para reduzir a evapotranspiração e aumentar a infiltração. Essa necessidade também foi sentida calibrando os parâmetros correspondentes do SWAT, que são CN2 e SOL_AWC respectivamente.

A constante de recessão da água subterrânea $(\alpha)$ foi ajustada para valores mais baixos do que os originais, reduzindo assim o tempo de resposta para recarga. Durante a calibração do modelo SWAT, o parâmetro correspondente (ALPHA_BF) também foi reduzido do valor padrão.

No caso da bacia hidrográfica do rio Jacaré Guaçu, o procedimento de calibração do modelo SCS-CN iniciou na estação hidrométrica a montante (62760005), depois foi movido para a estação intermediária (62767500) e finalmente para a estação a jusante (62772500). Para a bacia hidrográfica do rio Atibaia a calibração seguiu o mesmo procedimento, iniciando-se pela estação mais a montante (3006), continuando em sequências para as demais estações (3007, 3003 e 4009).

\subsubsection{Calibração da produção de sedimentos}

A calibração de ambos os modelos para produção de sedimentos, cargas de nitrogênio e fósforo foi realizada pela alteração dos parâmetros associados a cada tipo de solo e/ou uso do solo que afetam a produção de sedimentos e as cargas poluidoras. Os desempenhos dos modelos foram avaliados na estação de qualidade de água de jusante (62776400), no caso da bacia hidrográfica do rio Jacaré Guaçu, e nas estações a montante do reservatório (2605 e 62691200), para a bacia hidrográfica do rio Atibaia.

Na calibração do SWAT para a produção de sedimentos no SWAT, alguns parâmetros foram identificados como mais importantes. O fator de práticas conservacionistas da EUPS (USLE_P) foi calibrado com valor de 0,8, o que indica a existência de práticas conservacionistas na área. As variáveis relacionadas com a degradação e deposição de sedimentos também foram alteradas e incluem o coeficiente de transporte de sedimentos (SPCON) calibrado com valor de 0,01 o que indica uma maior quantidade de sedimento que entra no canal. $\mathrm{O}$ fator de erodibilidade do canal (CH_COV1) e o fator de cobertura do canal (CH_COV2) são fatores que também influenciam no transporte de sedimentos no canal, uma vez que determinam a suscetibilidade do canal à erosão e a proteção do canal à erosão. Ambos 
os parâmetros foram definidos para 0,1 , indicando uma baixa susceptibilidade à erosão do canal.

Para o modelo GWLF, os parâmetros mais importantes para a calibração da carga de sedimentos são os relativos à EUPS. Esses parâmetros são compartilhados com a formulação do SWAT, de modo que os mesmos valores foram adotados em ambos os modelos.

\subsubsection{Calibração da concentração de contaminantes}

Em relação a calibração do SWAT para a calibração das concentrações de nitrogênio, os principais parâmetros foram o coeficiente de percolação do nitrogênio (NPERCO) e a concentração de nitrato no aquífero pouco profundo (SHALLST_N). Já para a simulação das concentrações de fósforo os principais parâmetros consistiram na concentração inicial de fósforo orgânico na camada superficial do solo (SOL_ORGP), o coeficiente de percolação do fósforo e o coeficiente de particionamento do fósforo no solo (PPERCO, PHOSKD).

As demais variáveis, aqui não citadas, mas apresentadas na tabela 13 representam os parâmetros que foram modificados para uma calibração mais precisa dos sedimentos e contaminantes.

Para o modelo GWLF a calibração dos sedimentos teve como parâmetros mais importantes os relacionados com a EUPS, já para os contaminantes, os parâmetros identificados mais relevantes na calibração estão relacionados com os contaminantes dissolvidos em áreas urbanas $\left(N C_{k}^{D R}\right.$ e $\left.P C_{k}^{D R}\right)$.

\subsubsection{Resultados}

Os períodos de calibração e validação foram distintos e definidos de acordo com a disponibilidade dos dados. Na bacia hidrográfica do rio Jacaré-Guaçu, a calibração utilizou os dados de outubro/1990 a setembro/2000, tendo o modelo validado com dados os de outubro/2000 a setembro/2013 da estação hidrométrica 62760005 , de outubro/1990 a setembro/2000 da estação 62767500 e de outubro/2000 a setembro/2011 para a estação 62772500. Na bacia hidrográfica do rio Atibaia a calibração usou os dados de outubro/1990 a setembro/2003, com excepção da estação 3007 em foram usados os dados de outubro/1999 a setembro/2007. A validação usou os dados de outubro/2003 a outubro/2016, com exceção dos da estação 3007 em que usou os dados de outubro/2007 a outubro/2016.

As figuras 24 a 29 comparam as vazões médias diárias e mensais observadas nas estações 62760005, 62767500 e 62772500 da bacia hidrográfica do rio Jacaré-Guaçu. As 
figuras 30 a 37 comparam as vazões médias diárias e mensais observadas nas estações 3006, 3007, 3003 e 4009 da bacia hidrográfica do rio Atibaia.

$\mathrm{Na}$ análise dos valores diários os gráficos demostram que ambos os modelos são capazes de reproduzir a temporização dos principais eventos de inundação, mas não conseguem em alguns casos reproduzir valores específicos, principalmente os valores de pico. Os gráficos mostram uma superestimação significativa dos picos de fluxo observados, principalmente o modelo SCS-CN.

Quando se analisam os valores mensais, o desempenho do modelo melhora, em particular quando medido pela correlação linear entre fluxos mensais computados e observados

Figura 24 - Comparação da simulação da vazão diária para estação 62760005 da hidrográfica do rio Jacaré-Guaçu

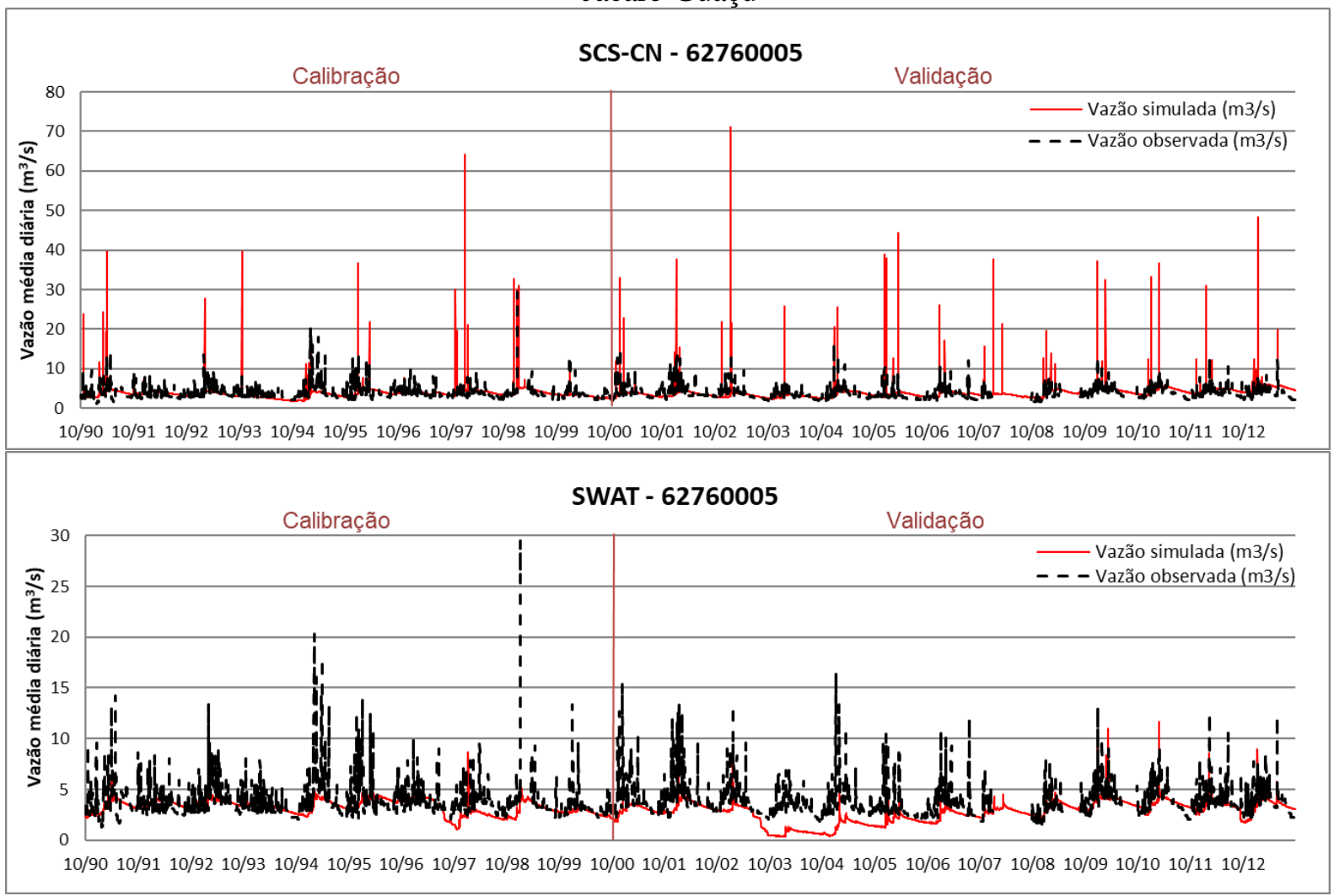

Fonte: Próprio autor 
Figura 25 - Comparação da simulação da vazão mensal para estação 62760005 da hidrográfica do rio Jacaré-Guaçu

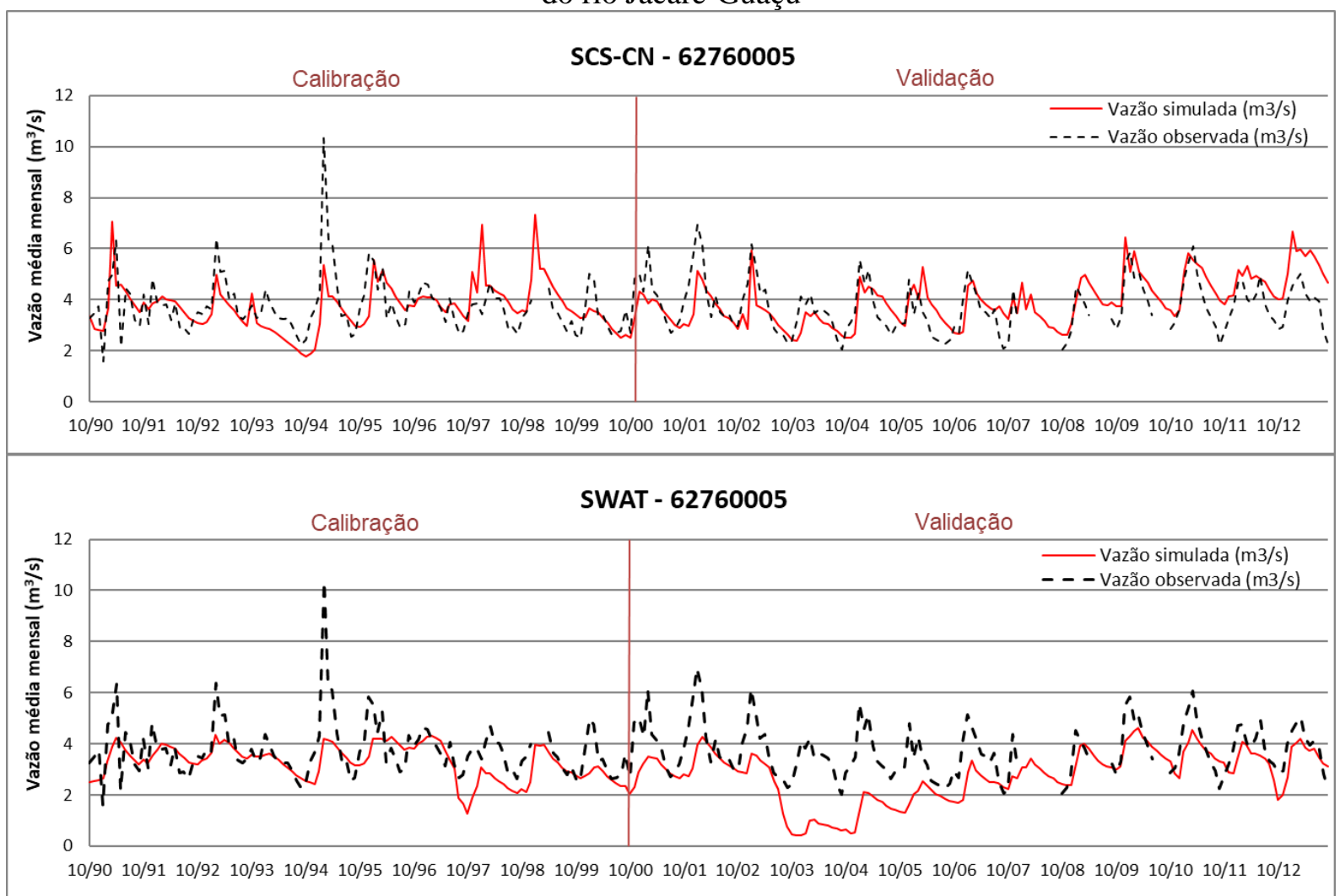

Fonte: Próprio autor

Figura 26 - Comparação da simulação da vazão diária para estação 62767500 da hidrográfica do rio Jacaré-Guaçu

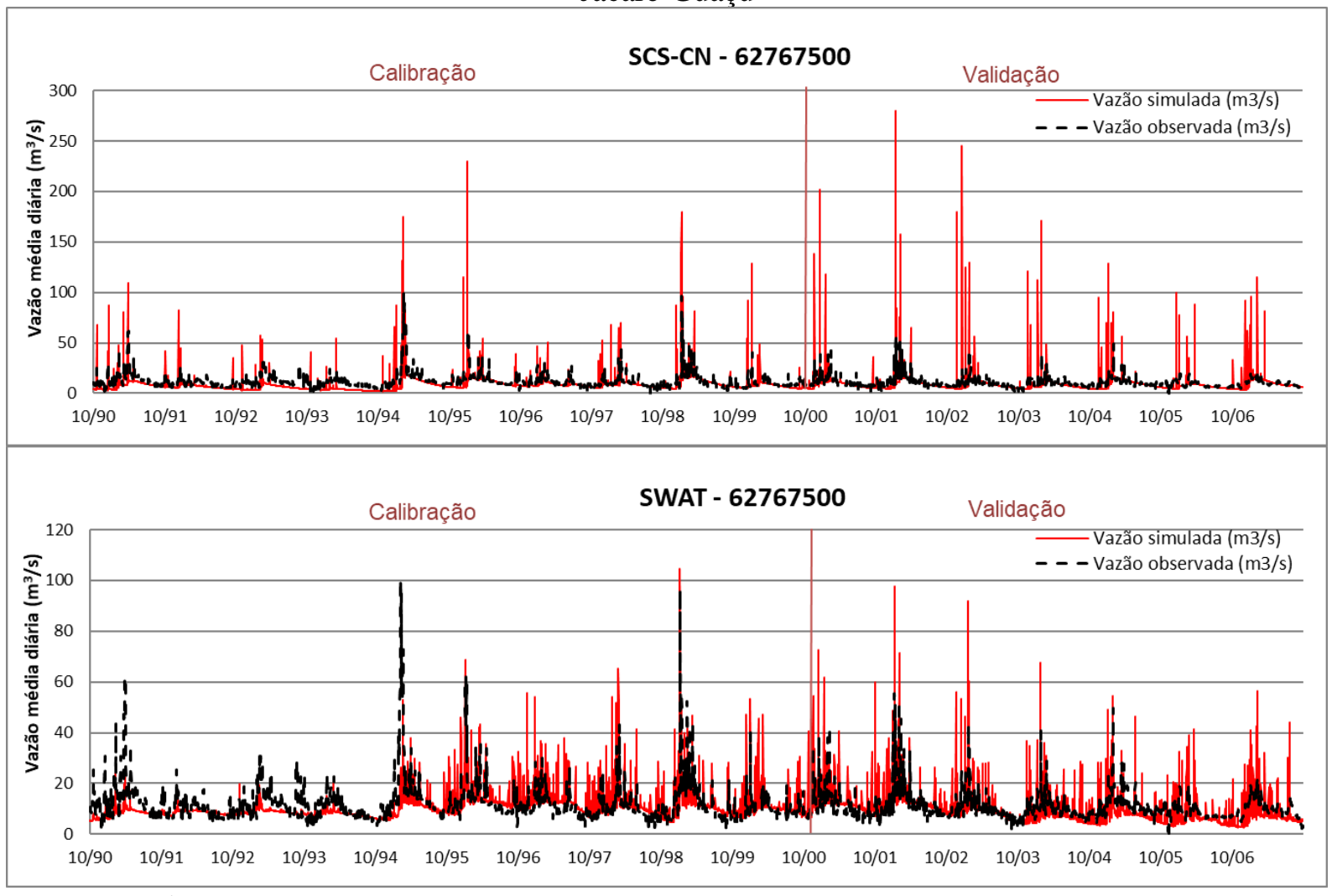

Fonte: Próprio autor 
Figura 27 - Comparação da simulação da vazão mensal para estação 62767500 da hidrográfica do rio Jacaré-Guaçu

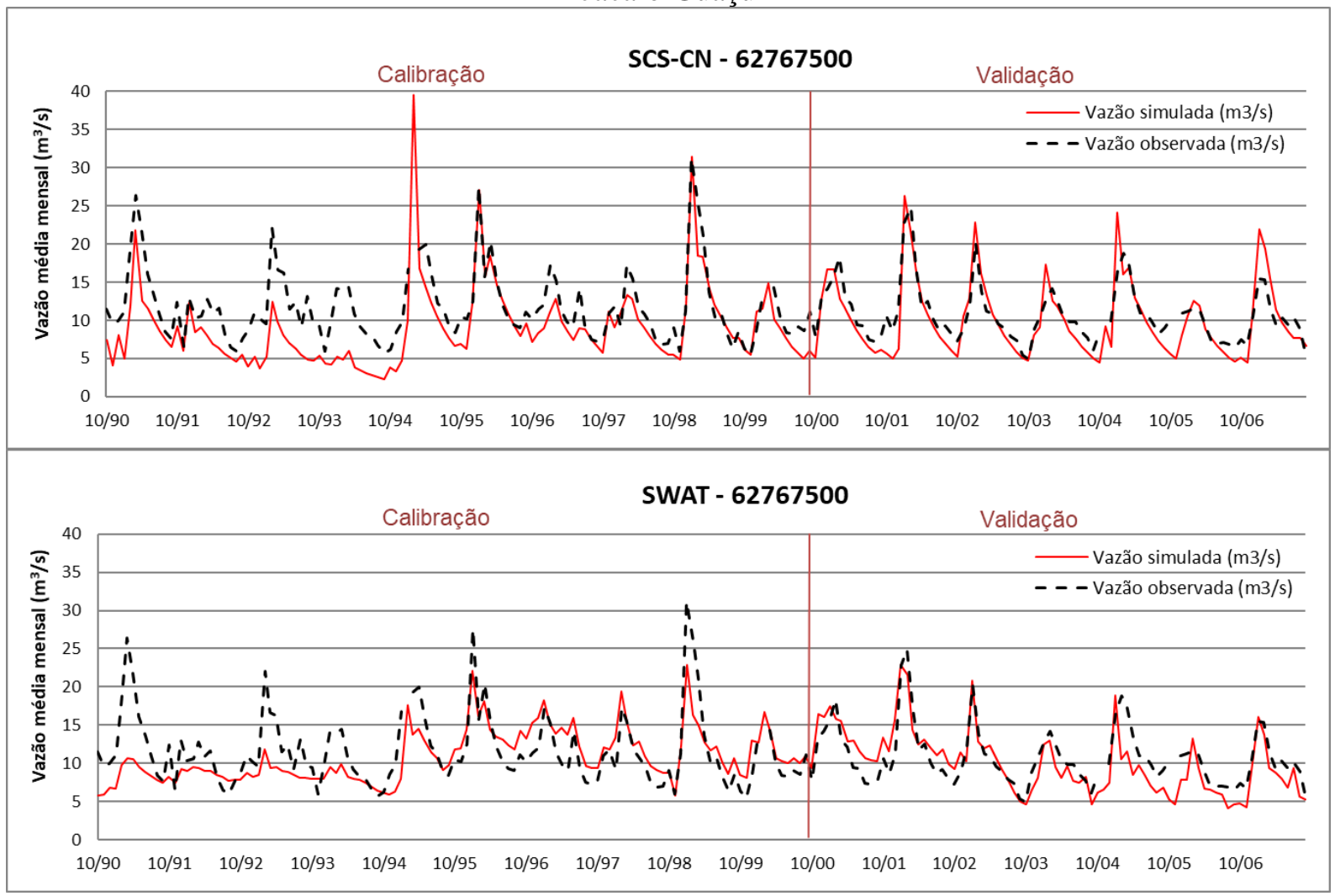

Fonte: Próprio autor

Figura 28 - Comparação da simulação da vazão diária para estação 62772500 da hidrográfica do rio Jacaré-Guaçu

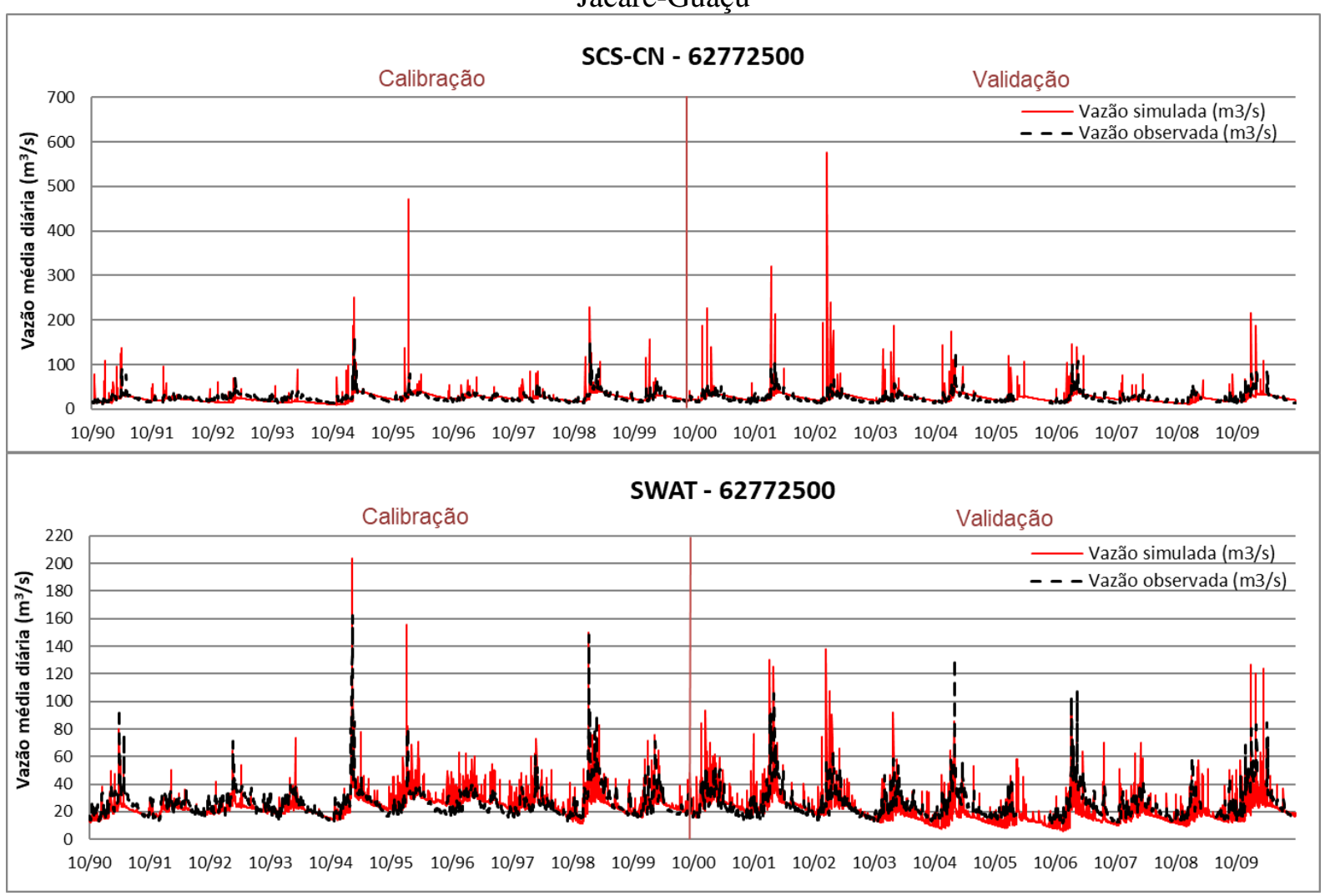

Fonte: Próprio autor 
Figura 29 - Comparação da simulação da vazão mensal para estação 62772500 da hidrográfica do rio Jacaré-Guaçu

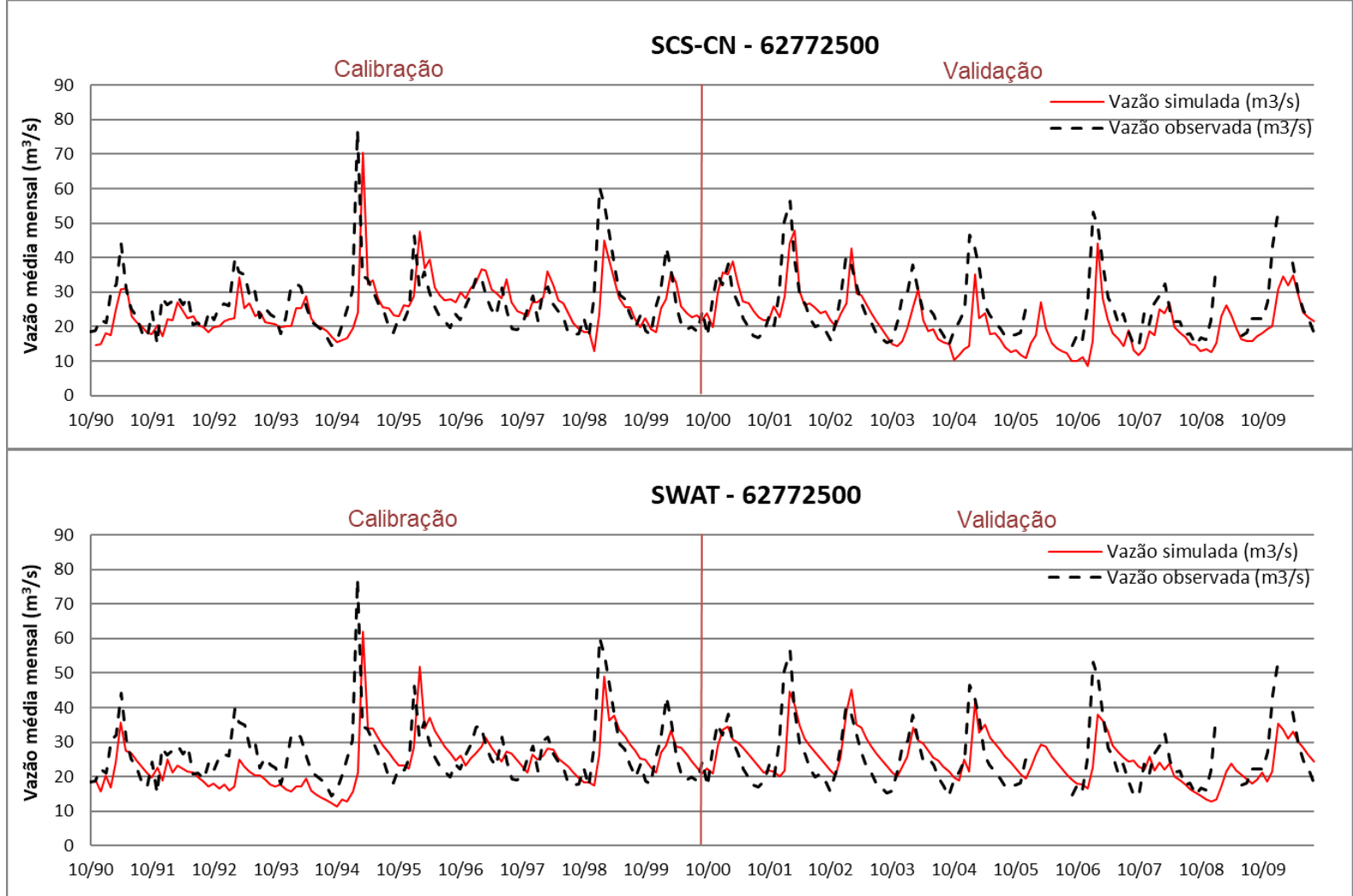

Fonte: Próprio autor

Figura 30 - Comparação da simulação da vazão diária para estação 3006 da hidrográfica do rio Atibaia

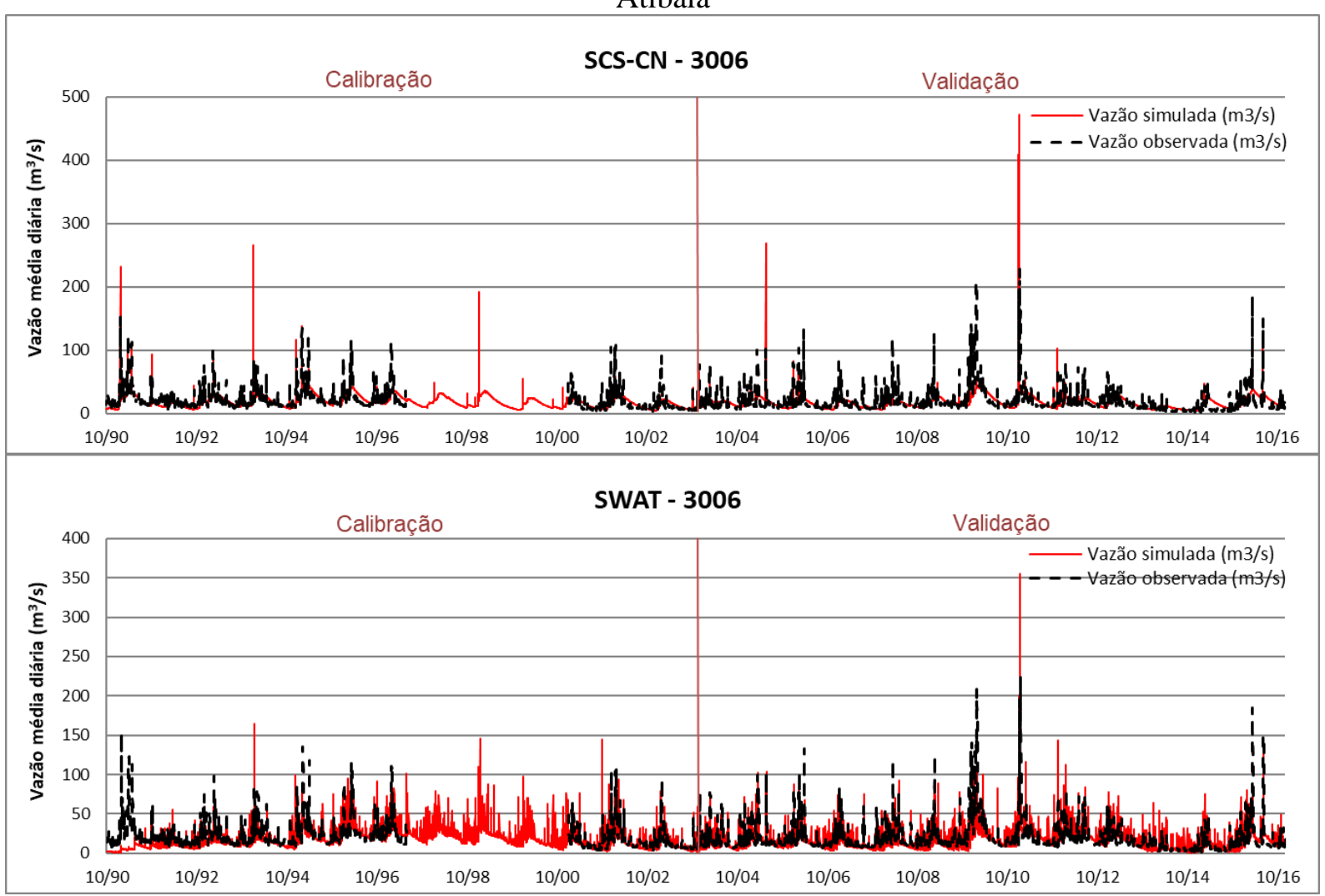

Fonte: Próprio autor 
Figura 31 - Comparação da simulação da vazão mensal para estação 3006 da hidrográfica do rio Atibaia

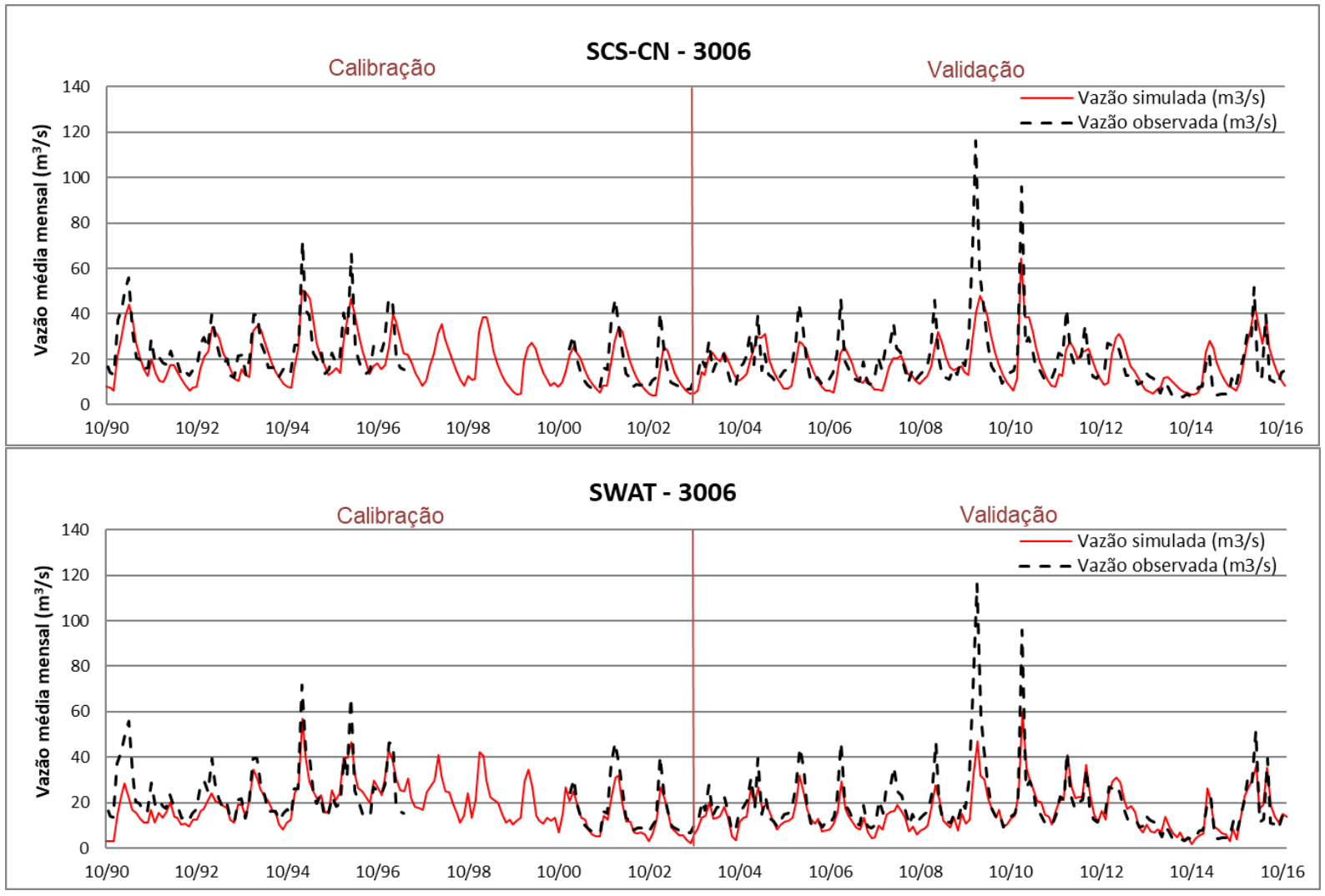

Fonte: Próprio autor

Figura 32 - Comparação da simulação da vazão diária para estação 3007 da hidrográfica do rio Atibaia

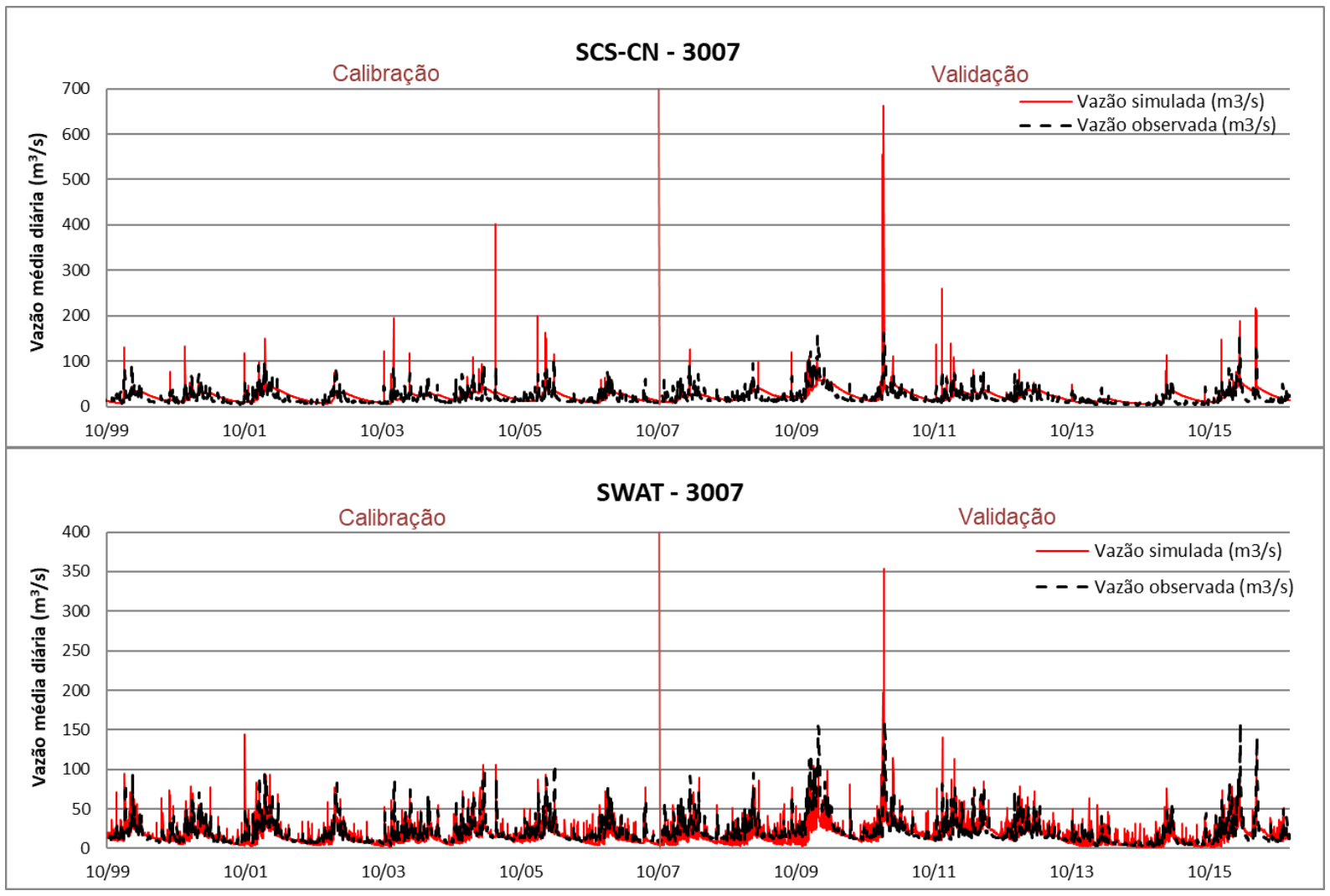

Fonte: Próprio autor 
Figura 33 - Comparação da simulação da vazão mensal para estação 3007 da hidrográfica do rio Atibaia

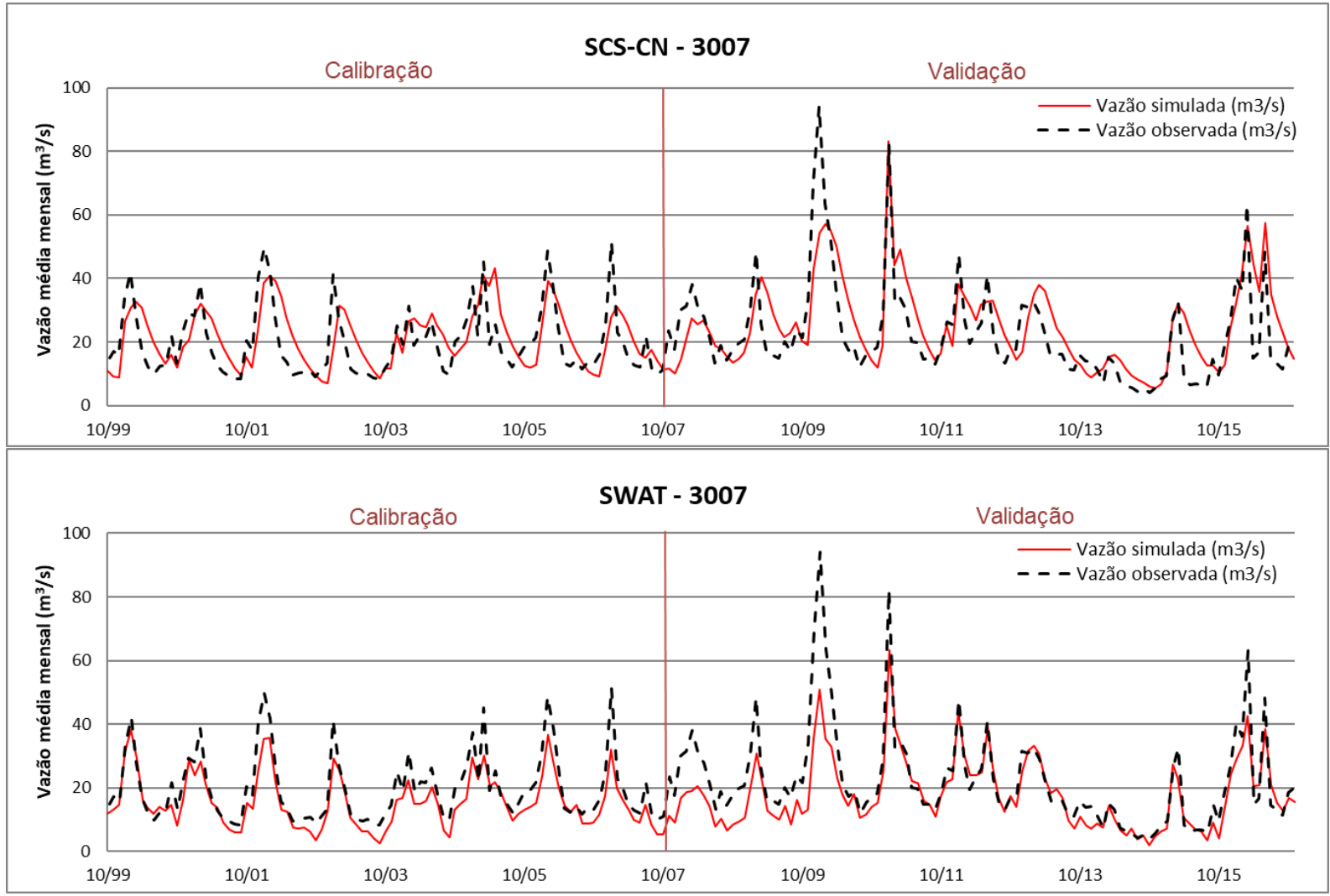

Fonte: Próprio autor

Figura 34 - Comparação da simulação da vazão diária para estação 3003 da hidrográfica do rio Atibaia

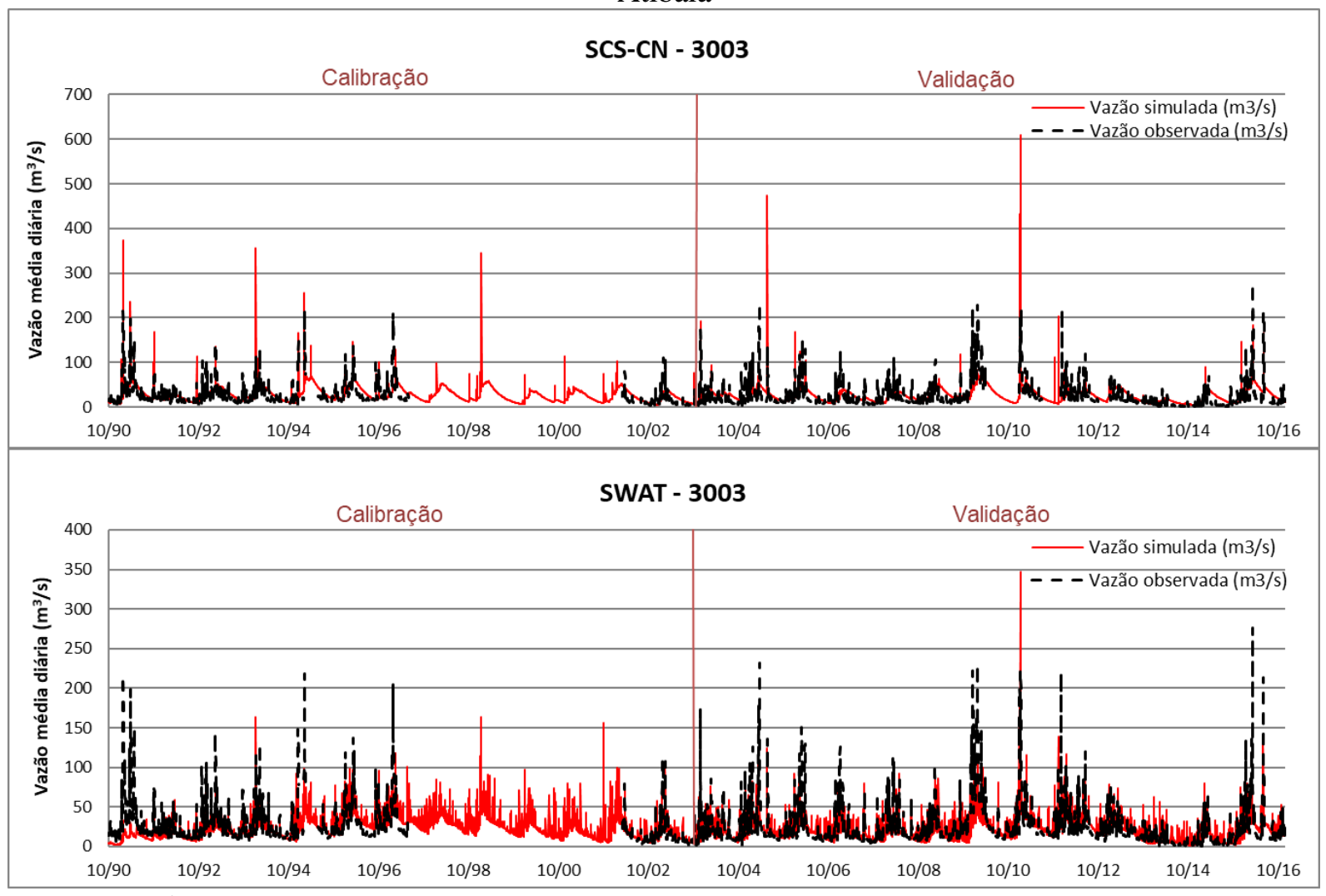

Fonte: Próprio autor 
Figura 35 - Comparação da simulação da vazão mensal para estação 3003 da hidrográfica do rio Atibaia

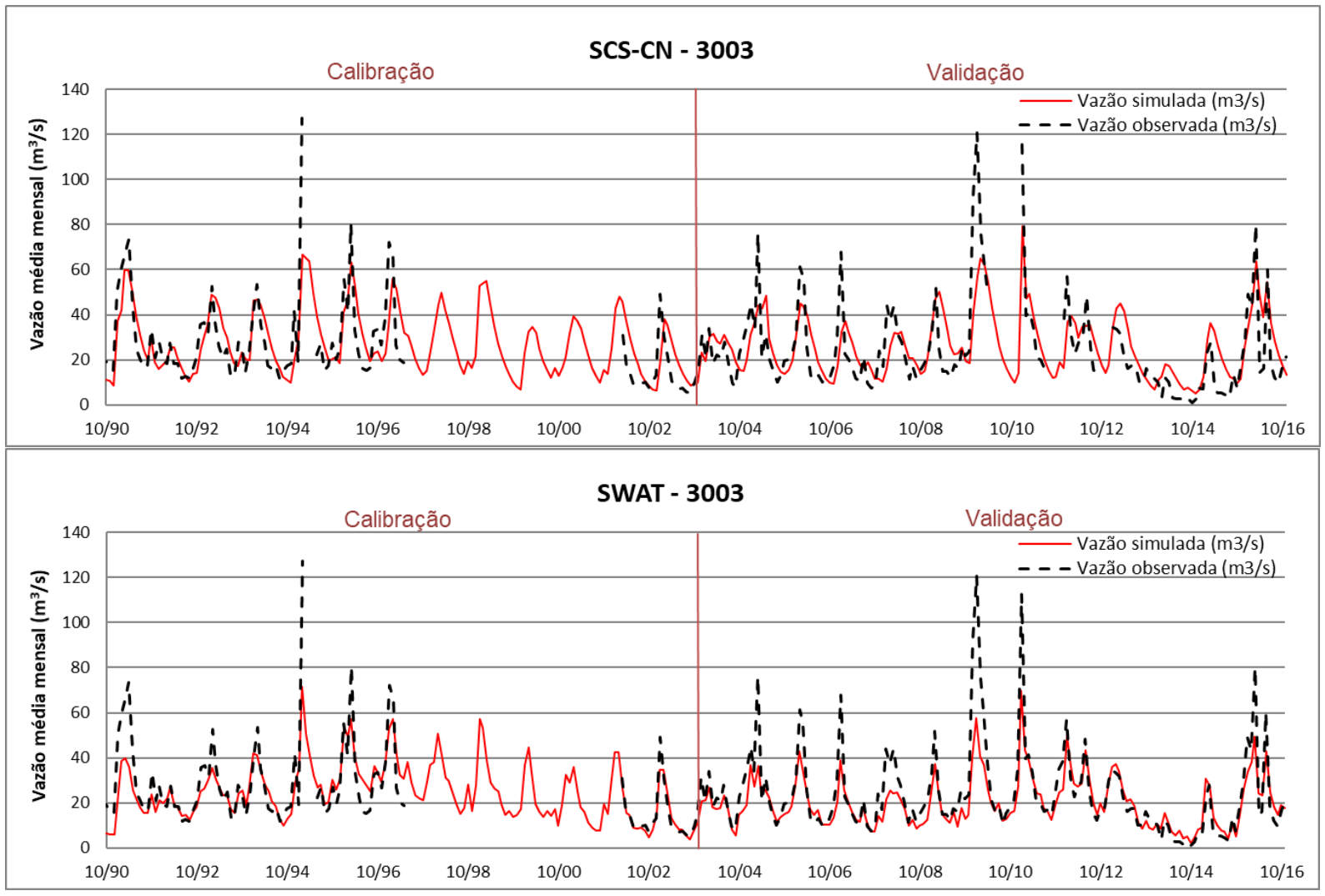

Fonte: Próprio autor

Figura 36 - Comparação da simulação da vazão diária para estação 4009 da hidrográfica do rio Atibaia

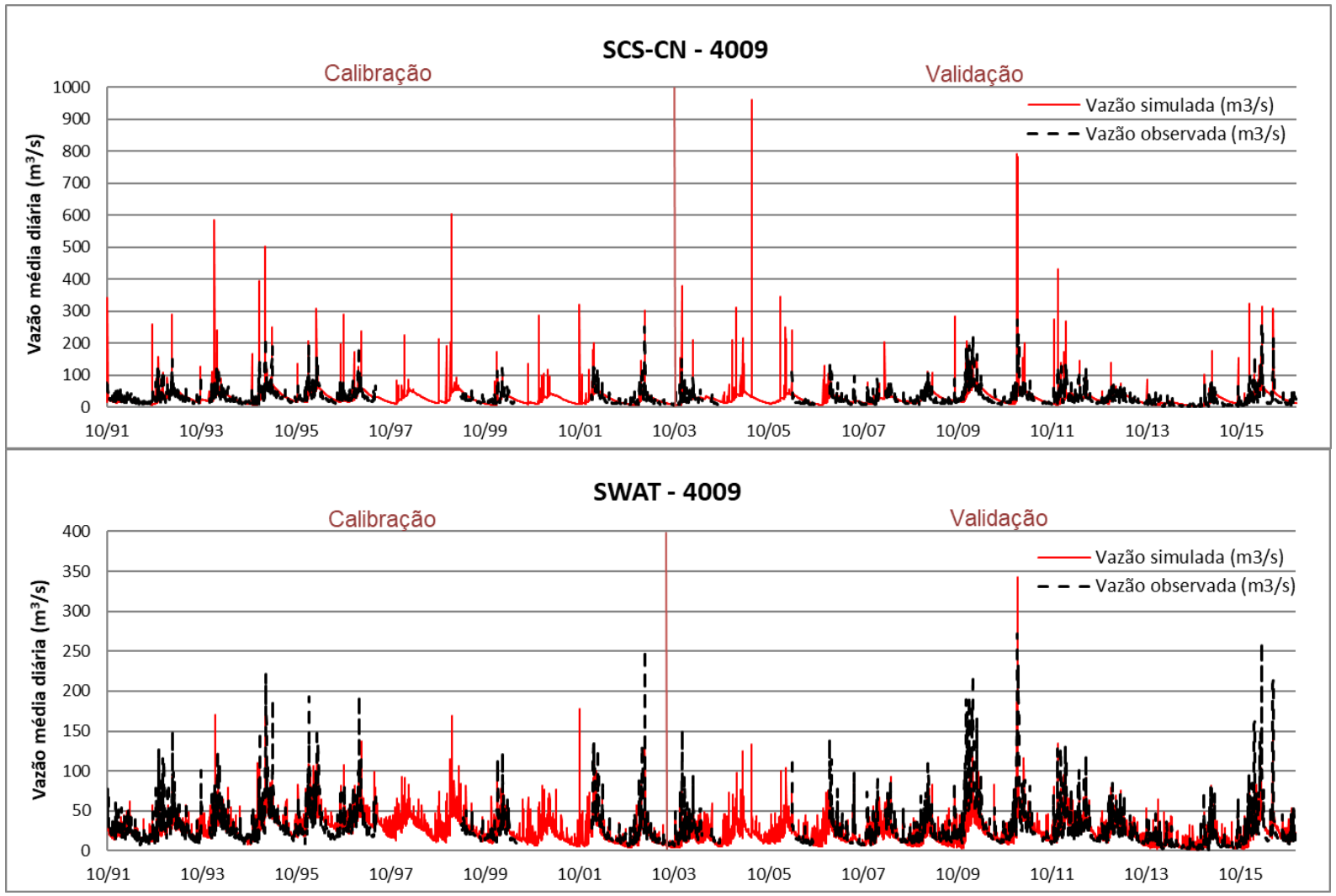

Fonte: Próprio autor 
Figura 37 - Comparação da simulação da vazão mensal para estação 4009 da hidrográfica do rio Atibaia

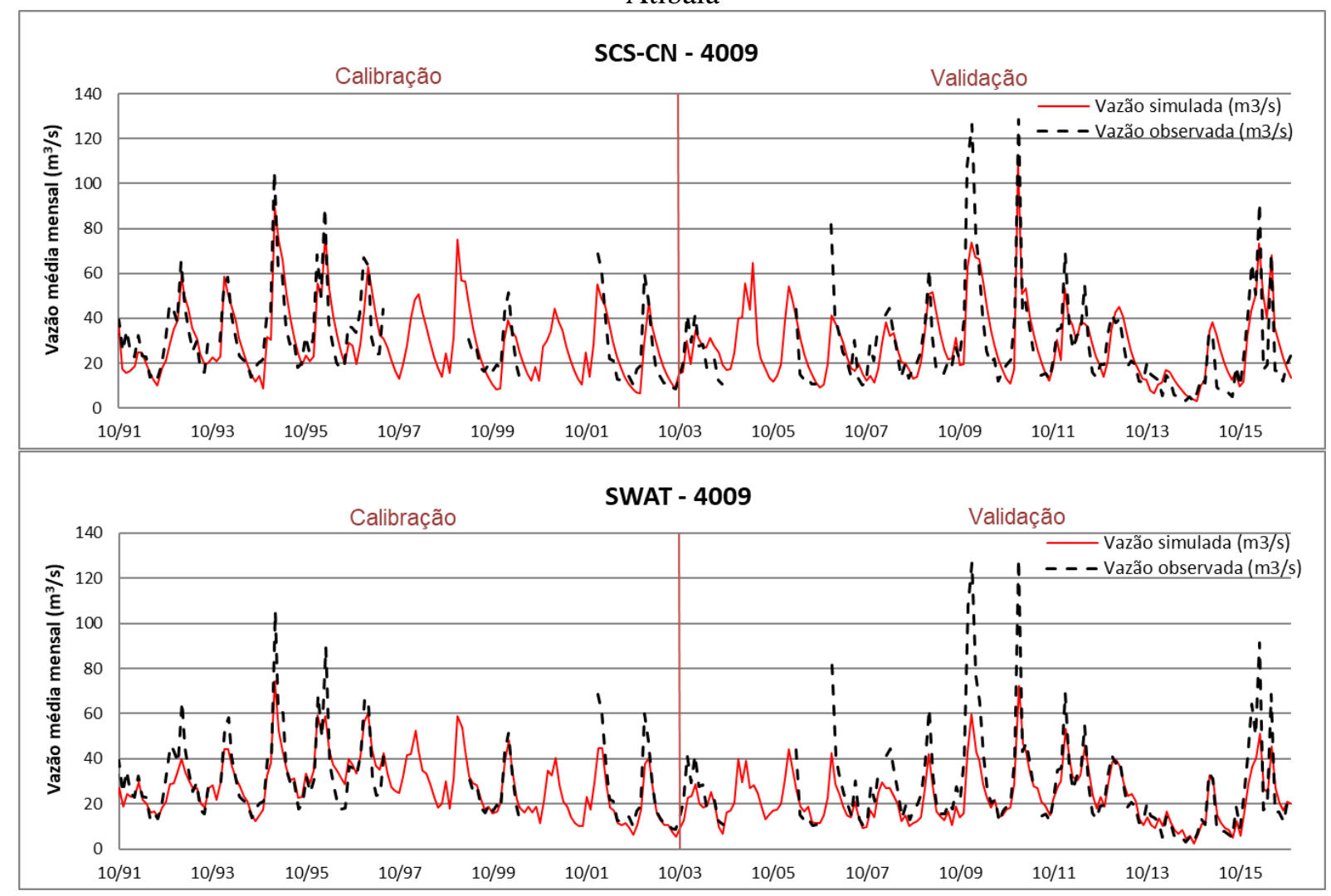

Fonte: Próprio autor

A tabela 14 apresenta os valores obtidos para cada indicador de desempenho (NSE, Pbias e r2). Os valores dos indicadores de desempenho obtidos para os períodos de calibração são geralmente melhores que os valores obtidos para o período de validação, particularmente os resultados do indicador NSE, que foi considerado o indicador fundamental durante a calibração.

$\mathrm{Na}$ análise dos resultados mensais, ambos os modelos apresentam um desempenho satisfatório, com a NSE chegando a 0,86 em algumas situações, e continuam a apresentar um melhor desempenho na bacia do rio Atibaia do que na bacia do rio Jacaré-Guaçu. O desempenho do melhor modelo é obtido nas estações a jusante de ambas as bacias hidrográficas (62772500 e 4009), onde a NSE está sempre acima de 0,55, mesmo para o período de validação.

O melhor desempenho dos modelos nas estações a jusante indica que o efeito de agregação proveniente de bacias hidrográficas maiores facilita a calibração dos modelos. $\mathrm{O}$ mesmo efeito de agregação pode explicar por que os resultados dos modelos agregados em um intervalo de tempo mensal se comparam melhor com os valores observados, do que quando essa comparação é realizada em uma etapa de tempo diária. Ambos os modelos e o 
modelo SCS-CN, em particular, têm dificuldade em reproduzir a variabilidade do fluxo em períodos mais curtos.

O desempenho do modelo também é fortemente condicionado por estimativas de precipitação e, portanto, pela disponibilidade de dados de precipitação e localização das estações de monitoramento. As bacias hidrográficas menores que não são bem cobertas pela rede de monitoramento de precipitação são difíceis de simular, especialmente num intervalo de tempo diário. Um bom exemplo desse desafio é a bacia hidrográfica da estação a montante de Jacaré Guaçu (62760005), que se espalha por uma região montanhosa e é monitorada por uma única estação de precipitação. A influência do aquífero Guarani sobre a correnteza também pode contribuir para os resultados obtidos.

A estimativa da precipitação média em uma sub-bacia ou uma HRU a partir de medições pontuais em estações pluviométricas é a chave para um bom desempenho do modelo. O modelo SWAT atribui a mesma estação climatológica a todas as HRUs de uma sub-bacia, escolhendo automaticamente o registro da estação pluviométrica que está mais próxima do centróide de cada sub-bacia. Se as estações estiverem esparsamente distribuídas no espaço, isso pode levar a relevantes erros de estimativa.

A utilização do modelo SCS-CN é dependente da seleção da técnica de interpolação mais apropriada. Para minimizar a influência das técnicas de interpolação de precipitação ao comparar os modelos, o registro de precipitação submetido ao SCS-CN foi calculado como médias ponderadas dos valores de precipitação de cada sub-bacia, conforme atribuído pelo SWAT.

Tabela 14 - Desempenho dos modelos SWAT e SCS-CN em reproduzir as vazões diárias e mensais

\begin{tabular}{|c|c|c|c|c|c|c|c|c|c|c|c|c|c|}
\hline \multirow[t]{3}{*}{ Bacia } & \multirow[b]{3}{*}{ Estação } & \multicolumn{12}{|c|}{ Diários } \\
\hline & & \multicolumn{3}{|c|}{ Calibração - SWAT } & \multicolumn{3}{|c|}{ Validação - SWAT } & \multicolumn{3}{|c|}{ Calibração - SCS-CN } & \multicolumn{3}{|c|}{ Validação - SCS-CN } \\
\hline & & NSE & Pbias & $\mathrm{r}^{2}$ & NSE & Pbias & $\mathrm{r}^{2}$ & NSE & Pbias & $\mathrm{r}^{2}$ & NSE & Pbias & $\mathrm{r}^{2}$ \\
\hline \multirow{3}{*}{$\begin{array}{l}\text { Jacaré- } \\
\text { Guaçu }\end{array}$} & 62760005 & 0,15 & $-1,31$ & 0,09 & $-0,03$ & 1,38 & 0,15 & $-0,66$ & 2,16 & 0,09 & $-0,57$ & $-6,85$ & 0,11 \\
\hline & 62767500 & 0,21 & $-3,30$ & 0,29 & $-0,74$ & $-10,88$ & 0,24 & 0,18 & 21,82 & 0,34 & $-0,84$ & 0,95 & 0,23 \\
\hline & 62772500 & 0,27 & $-6,77$ & 0,38 & 0,49 & 3,15 & 0,32 & $-0,64$ & 3,24 & 0,24 & $-0,59$ & $-3,95$ & 0,13 \\
\hline \multirow{4}{*}{ Atibaia } & 3006 & 0,36 & 28,28 & 0,21 & 0,26 & 9,11 & 0,31 & 0,23 & $-13,05$ & 0,29 & 0,23 & 8,64 & 0,24 \\
\hline & 3007 & 0,31 & 8,84 & 0,40 & 0,27 & 15,91 & 0,36 & 0,21 & $-6,50$ & 0,24 & 0,21 & $-6,50$ & 0,24 \\
\hline & 3003 & 0,53 & 23,31 & 0,26 & 0,43 & 10,88 & 0,43 & 0,52 & $-0,48$ & 0,26 & 0,30 & $-8,09$ & 0,27 \\
\hline & 4009 & 0,67 & 13,05 & 0,47 & 0,52 & 14,52 & 0,43 & 0,50 & 2,49 & 0,34 & 0,16 & $-0,94$ & 0,27 \\
\hline
\end{tabular}




\begin{tabular}{|c|c|c|c|c|c|c|c|c|c|c|c|c|c|}
\hline \multicolumn{14}{|c|}{ Conclusão } \\
\hline & & & & & & & & nsais & & & & & \\
\hline & & Cali & ração & WAT & Valid & ão - SW & & Calibr & io - SC & & Valid & ão - SC & $-\mathrm{CN}$ \\
\hline \multirow{3}{*}{$\begin{array}{l}\text { Jacaré- } \\
\text { Guaçu }\end{array}$} & 62760005 & 0,30 & $-1,75$ & 0,15 & 0,35 & 10,30 & 0,21 & 0,34 & 2,28 & 0,24 & 0,68 & $-6,76$ & 0,36 \\
\hline & 62767500 & 0,32 & $-4,84$ & 0,31 & 0,68 & $-10,83$ & 0,73 & 0,31 & 20,88 & 0,56 & 0,66 & 0,45 & 0,71 \\
\hline & 62772500 & 0,55 & $-6,65$ & 0,59 & 0,81 & 3,21 & 0,65 & 0,59 & 5,70 & 0,64 & 0,84 & $-2,65$ & 0,69 \\
\hline \multirow{4}{*}{ Atibaia } & 3006 & 0,54 & 28,34 & 0,32 & 0,61 & 9,18 & 0,67 & 0,70 & 17,26 & 0,47 & 0,42 & 10,40 & 0,44 \\
\hline & 3007 & 0,74 & 13,95 & 0,86 & 0,66 & 14,85 & 0,74 & 0,71 & $-7,74$ & 0,43 & 0,53 & $-9,36$ & 0,57 \\
\hline & 3003 & 0,66 & 23,96 & 0,38 & 0,64 & 11,30 & 0,76 & 0,76 & 0,73 & 0,47 & 0,60 & $-8,21$ & 0,55 \\
\hline & 4009 & 0,86 & 12,92 & 0,68 & 0,68 & 14,83 & 0,72 & 0,86 & 2,60 & 0,70 & 0,76 & $-1,09$ & 0,70 \\
\hline
\end{tabular}

Fonte: Próprio autor

Os resultados mostram que ambos os modelos são capazes de reproduzir a variabilidade diária e mensal da vazão, embora não repliquem todos os valores com precisão, em particular nos casos de valores de pico de vazões superestimadas, principalmente pelo modelo SCS-CN. Quando os resultados do modelo são concentrados em um intervalo de tempo mensal, as vazões de pico são reproduzidas com razoável precisão, com o modelo SCS-CN apresentando um ajuste ligeiramente melhor aos valores observados do que o modelo SWAT.

Os gráficos de dispersão dos valores observados e simulados pelos modelos comprovam este fato. São apresentados nas figuras 38, 39 e 40 para o estudo de caso da bacia hidrográfica do rio jacaré-Guaçu, e nas figuras 41, 42, 43 e 44 para o caso de estudo da bacia hidrográfica do rio Atibaia.

Figura 38 - Gráfico de dispersão dos dados diários e mensais simulados pelos modelos para estação 62760005 da Bacia hidrográfica do rio Jacaré-Guaçu

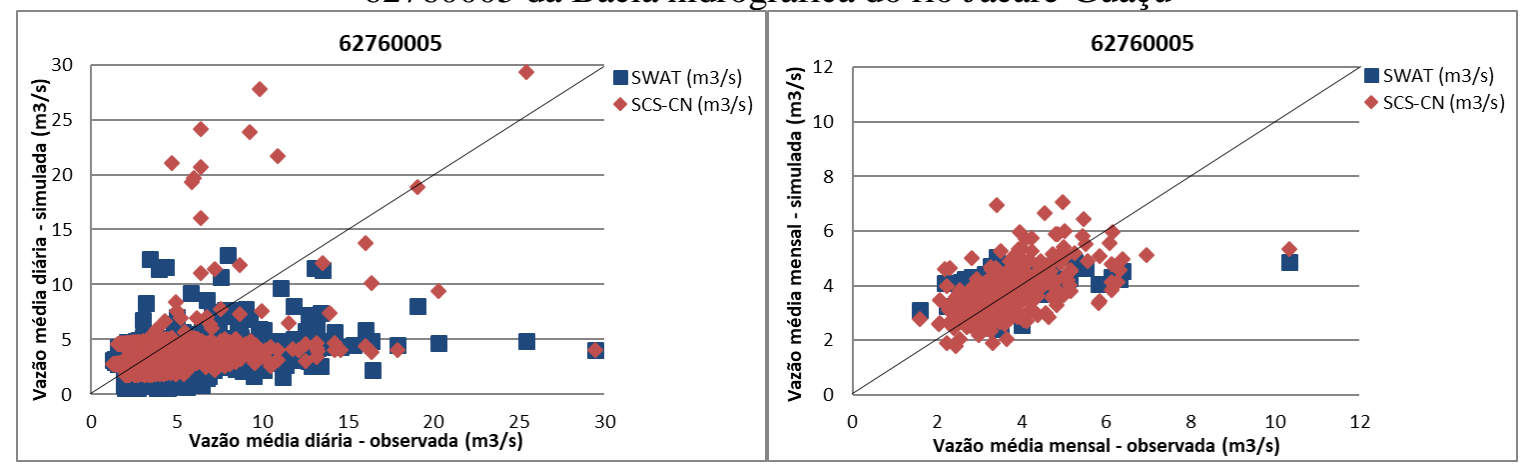

Fonte: Próprio autor 
Figura 39 - Gráfico de dispersão dos dados diários e mensais simulados pelos modelos para estação 62767500 da bacia hidrográfica do rio Jacaré-Guaçu

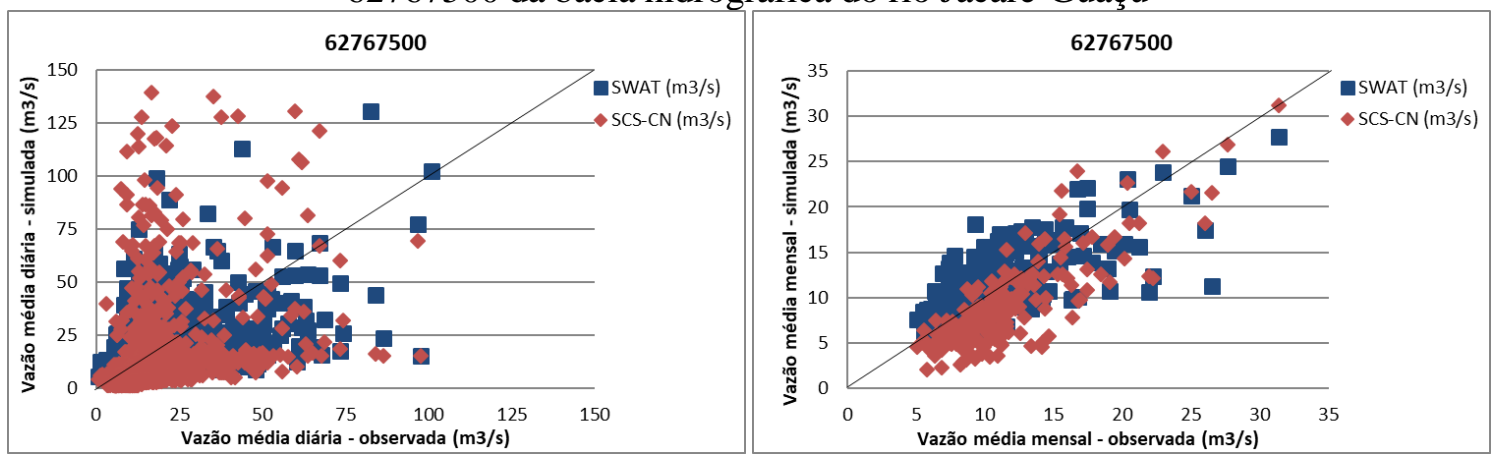

Fonte: Próprio autor

Figura 40 - Gráfico de dispersão dos dados diários e mensais simulados pelos modelos para estação 62772500 da bacia hidrográfica do rio Jacaré-Guaçu

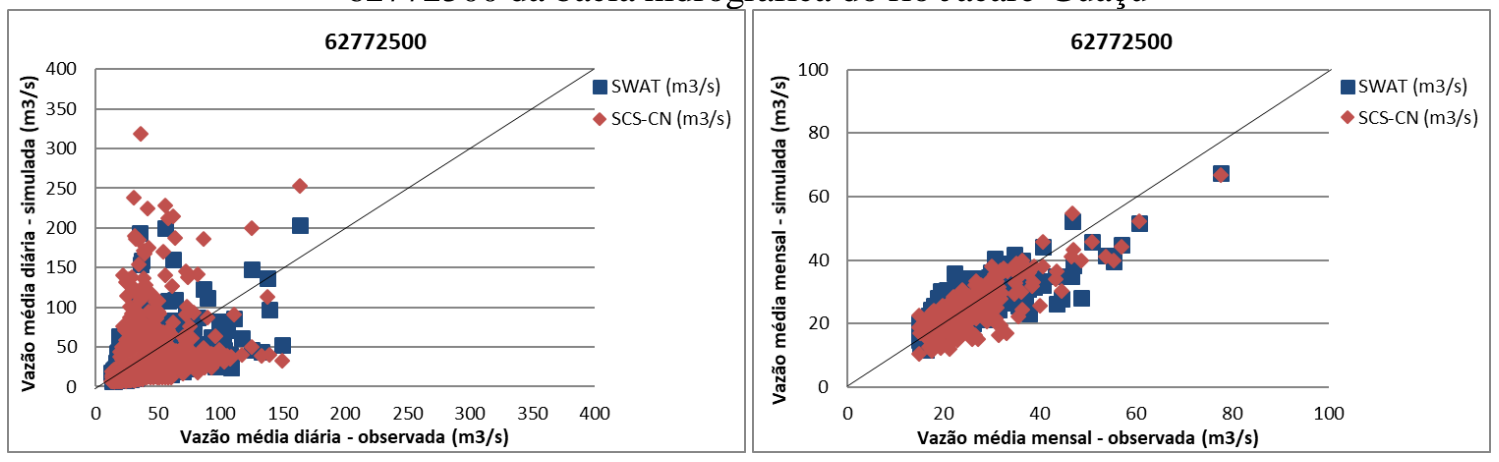

Fonte: Próprio autor

Figura 41 - Gráfico de dispersão dos dados diários e mensais simulados pelos modelos para estação estação 3006 da bacia hidrográfica do rio Atibaia

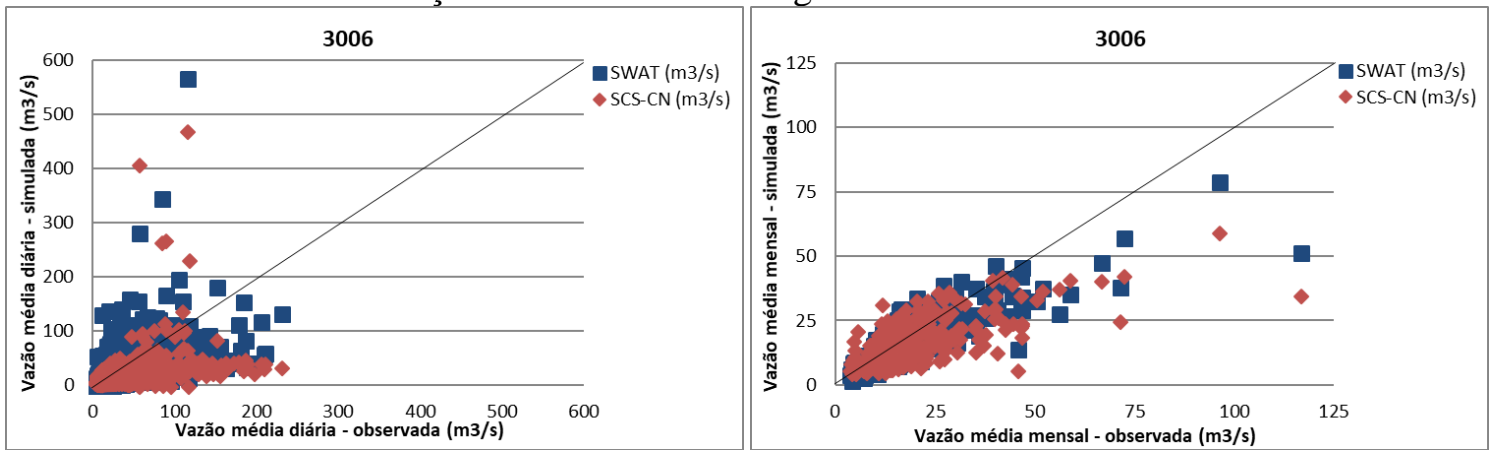

Fonte: Próprio autor 
Figura 42 - Gráfico de dispersão dos dados diários e mensais simulados pelos modelos para estação 3007 da bacia hidrográfica do rio Atibaia

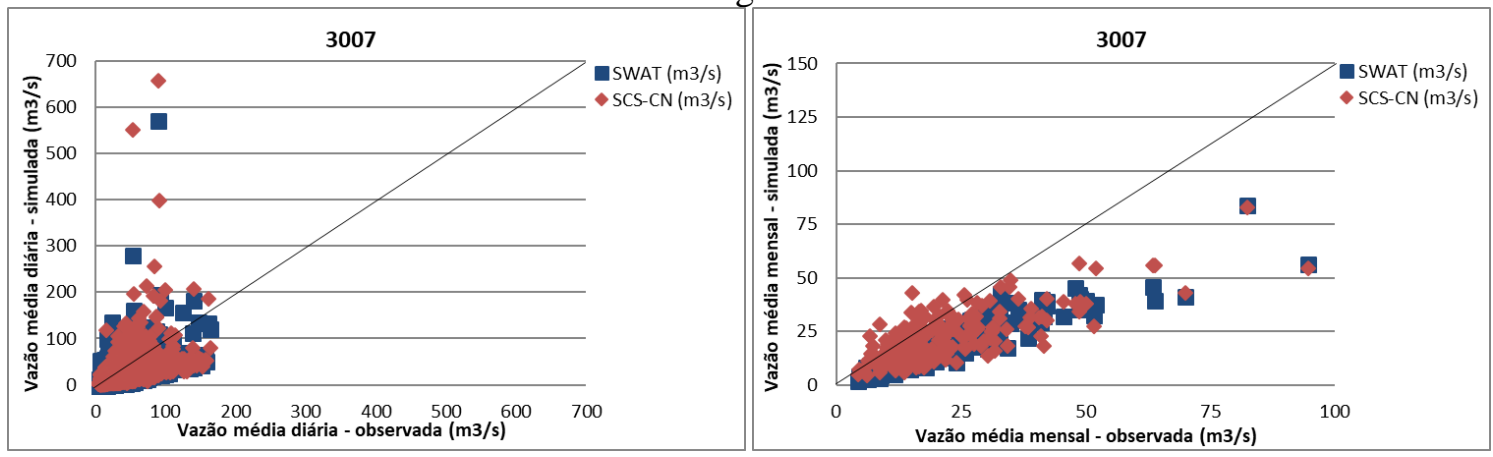

Fonte: Próprio autor

Figura 43 - Gráfico de dispersão dos dados diários e mensais simulados pelos modelos para estação 3003 da bacia hidrográfica do rio Atibaia

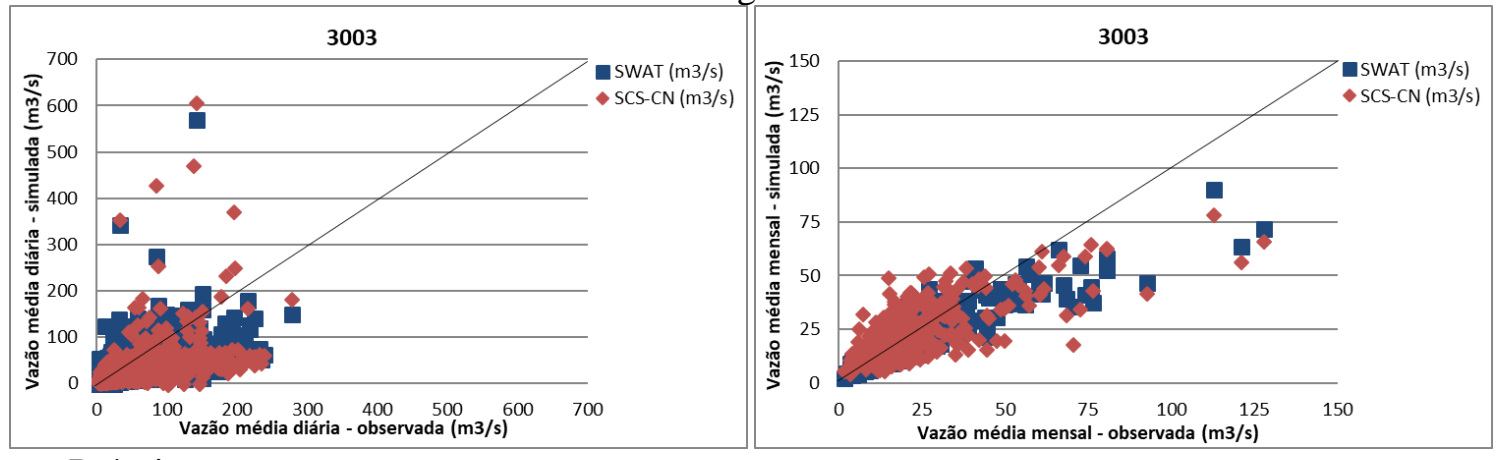

Fonte: Próprio autor

Figura 44 - Gráfico de dispersão dos dados diários e mensais simulados pelos modelos para estação 4009 da bacia hidrográfica do rio Atibaia

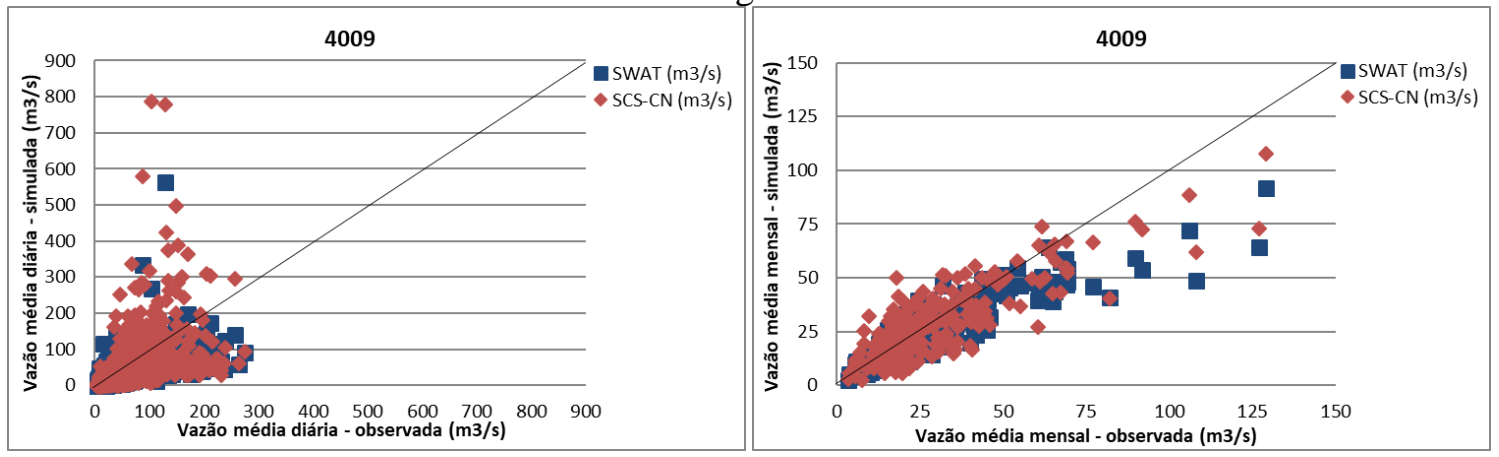

Fonte: Próprio autor

Os valores computados pelos modelos SWAT e GWLF da produção de sedimentos e concentrações totais de nitrogênio e fósforo foram comparados com os valores observados de janeiro/2001 a dezembro /2010 na estação de qualidade bacia do rio Jacaré-Guaçu (62776400) (figuras 45, 46 e 47) e de janeiro/2009 a dezembro/ 2016 para as estações de qualidade da bacia do rio Atibaia (2605 e 62691200) (figuras 48, 49 e 50). Nas figuras as concentrações de nitrogênio e fósforo foram expressas em carga $(\mathrm{kg} / \mathrm{dia})$. 
Figura 45 - Desempenho dos modelos para estimativa produção de sedimentos para estação 62776400 da bacia hidrográfica do rio Jacaré-Guaçu

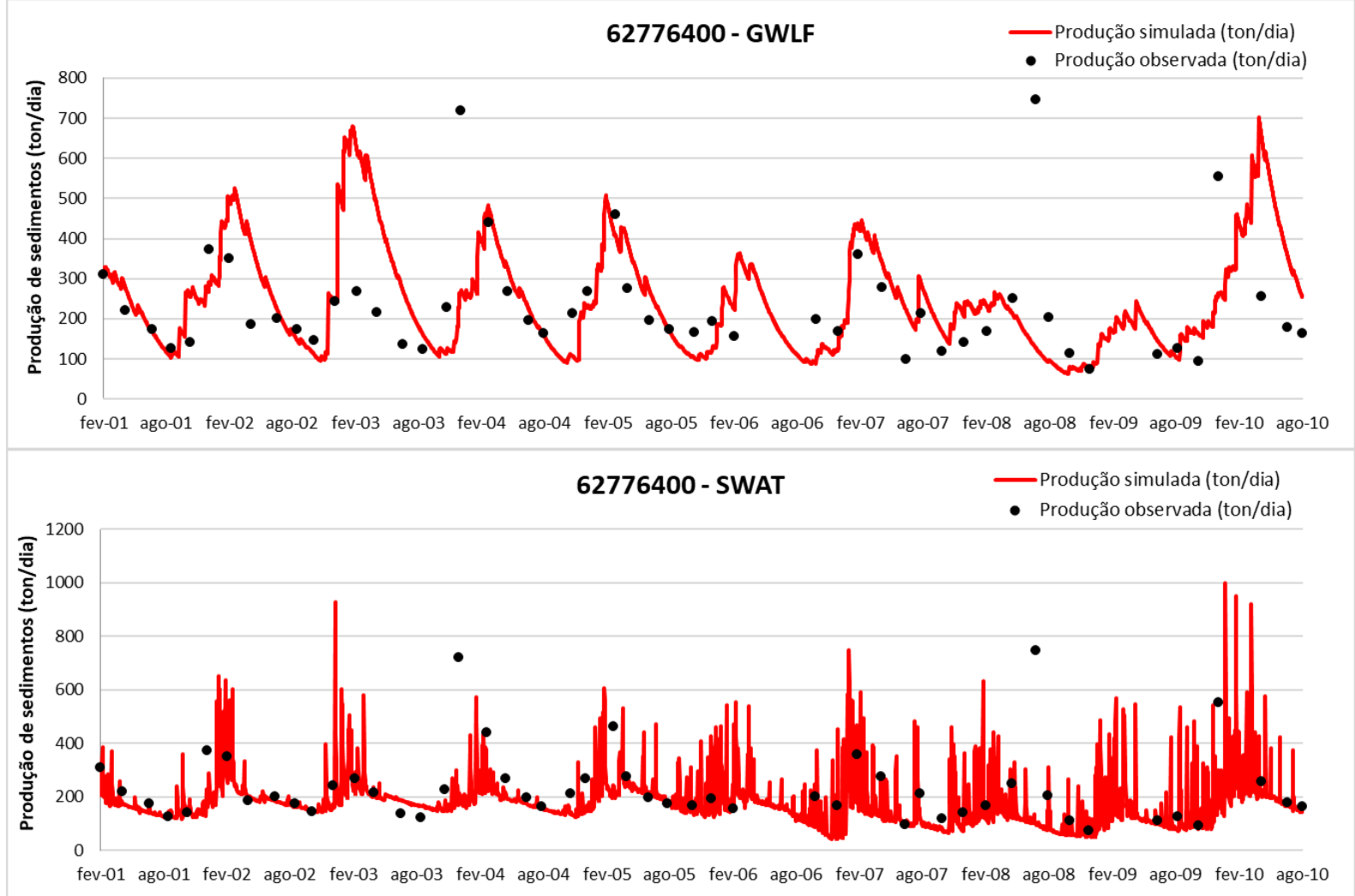

Fonte: Próprio autor

Figura 46 - Desempenho dos modelos para estimativa produção de sedimentos para estação 2605 da bacia hidrográfica do rio Atibaia

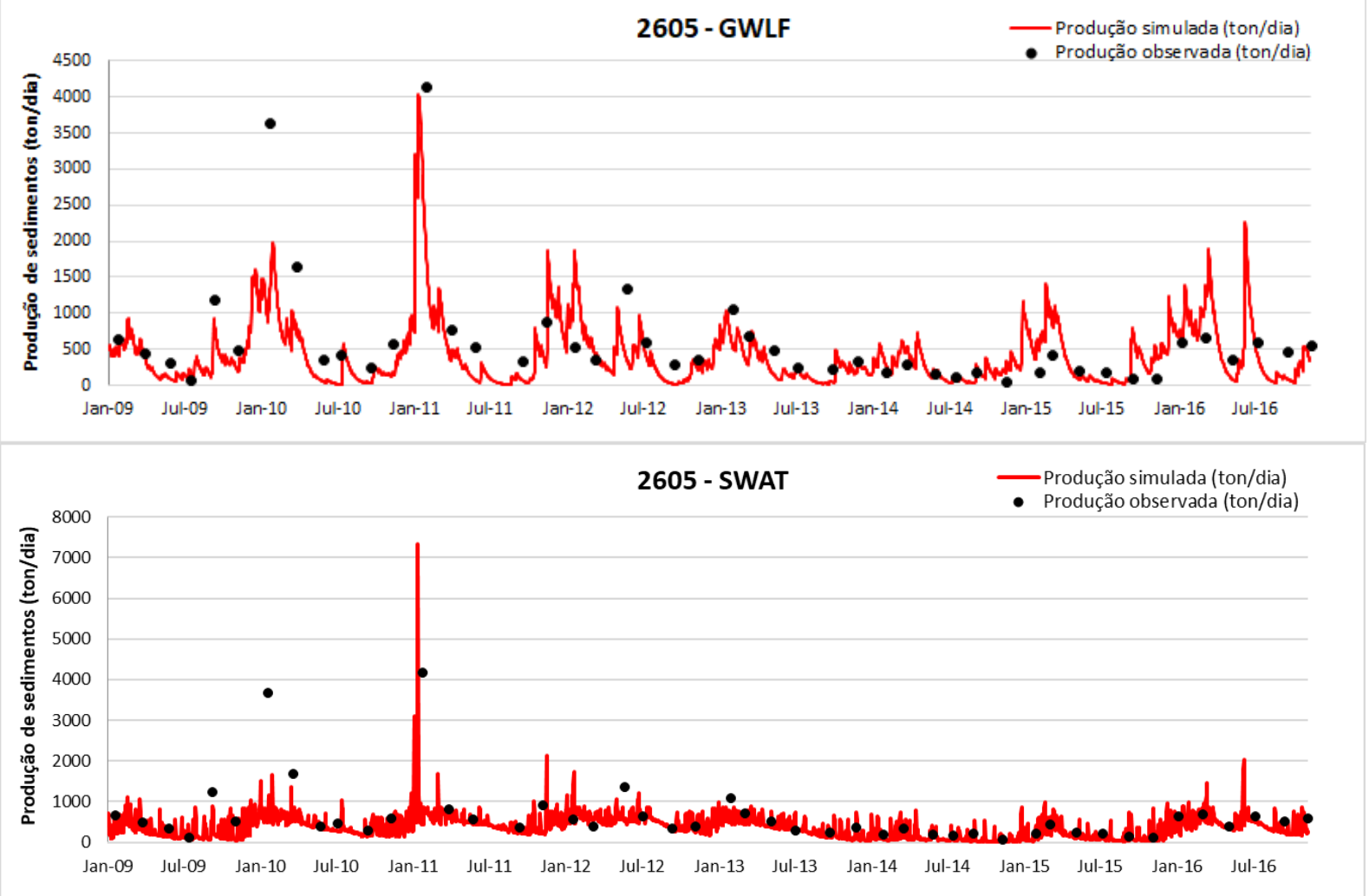

Fonte: Próprio autor 
Figura 47 - Desempenho dos modelos para estimativa produção de sedimentos para estação 62691200 da bacia hidrográfica do rio Atibaia

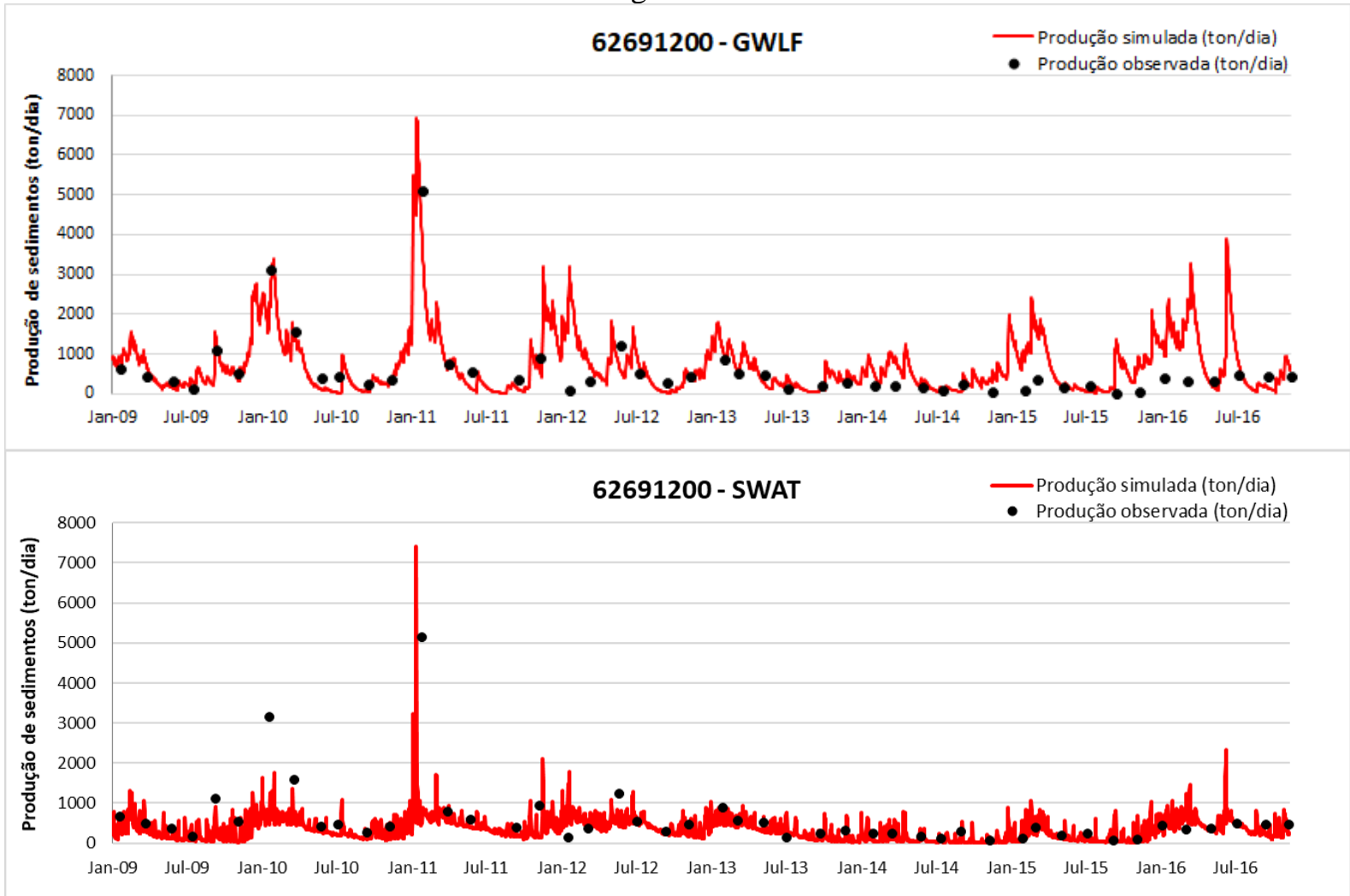

Fonte: Próprio autor

Figura 48 - Desempenho dos modelos para estimativa da carga de nitrogênio para estação 62776400 da bacia hidrográfica do rio Jacaré-Guaçu

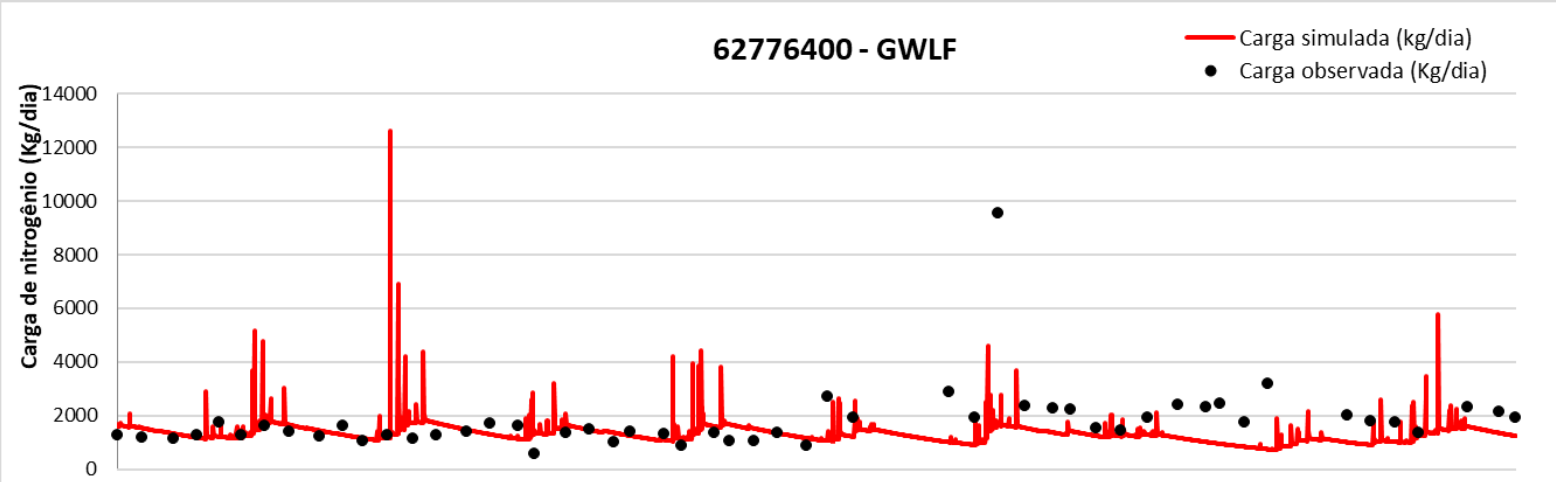

fev-01 ago-01 fev-02 ago-02 fev-03 ago-03 fev-04 ago-04 fev-05 ago-05 fev-06 ago-06 fev-07 ago-07 fev-08 ago-08 fev-09 ago-09 fev-10 ago-10

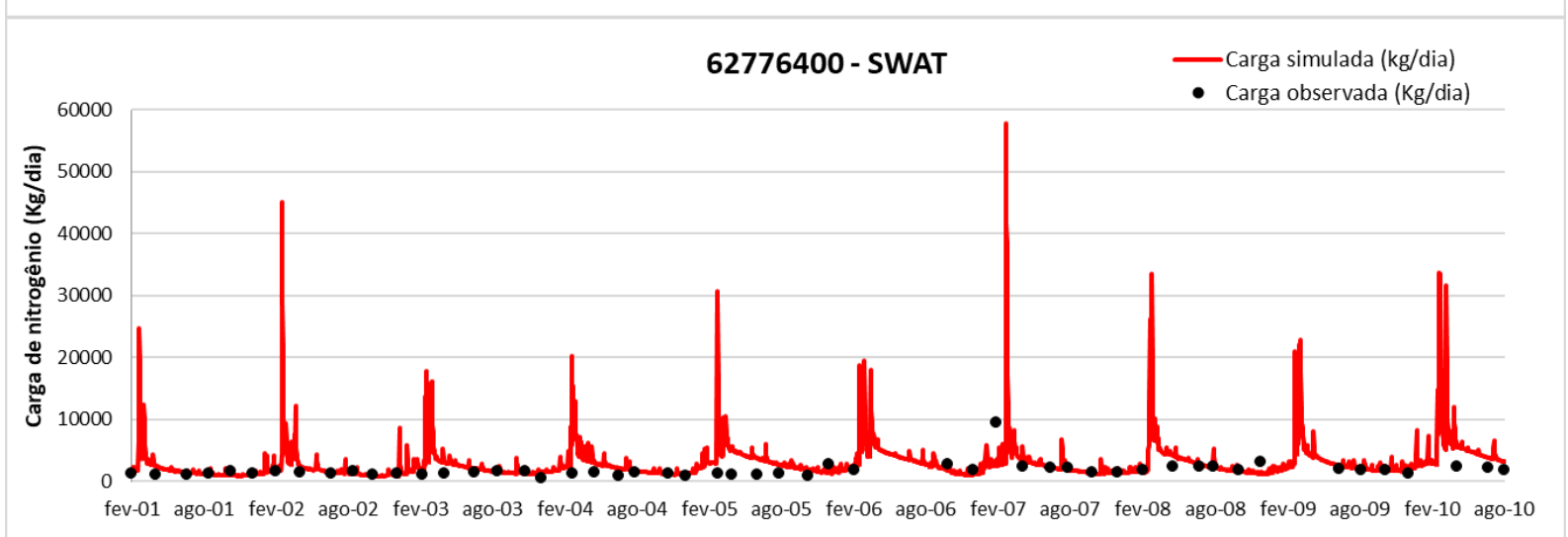

Fonte: Próprio autor 
Figura 49 - Desempenho dos modelos para estimativa da carga de nitrogênio para estação 2605 da bacia hidrográfica do rio Atibaia

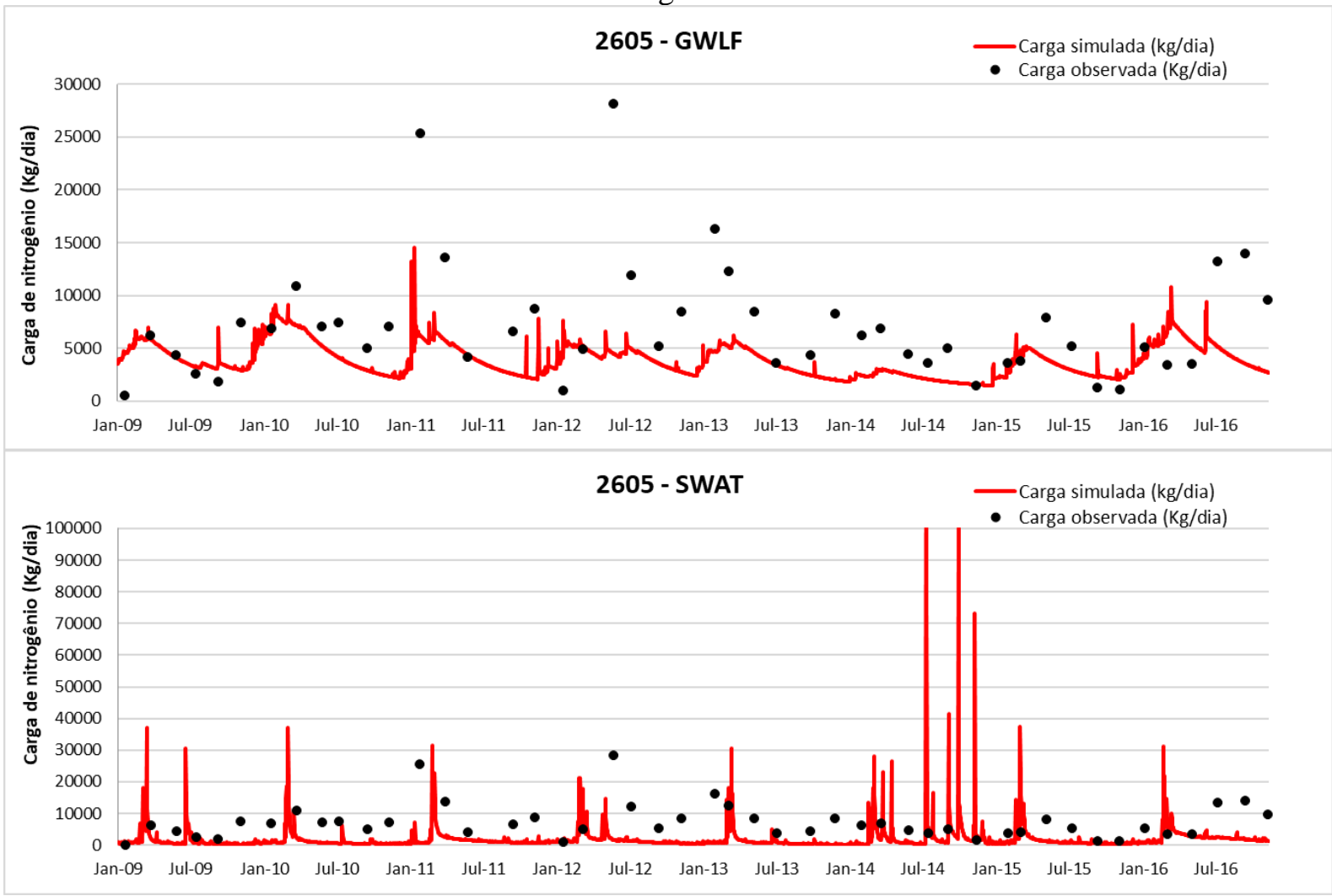

Fonte: Próprio autor

Figura 50 - Desempenho dos modelos para estimativa da carga de nitrogênio para estação 62691200 da bacia hidrográfica do rio Atibaia

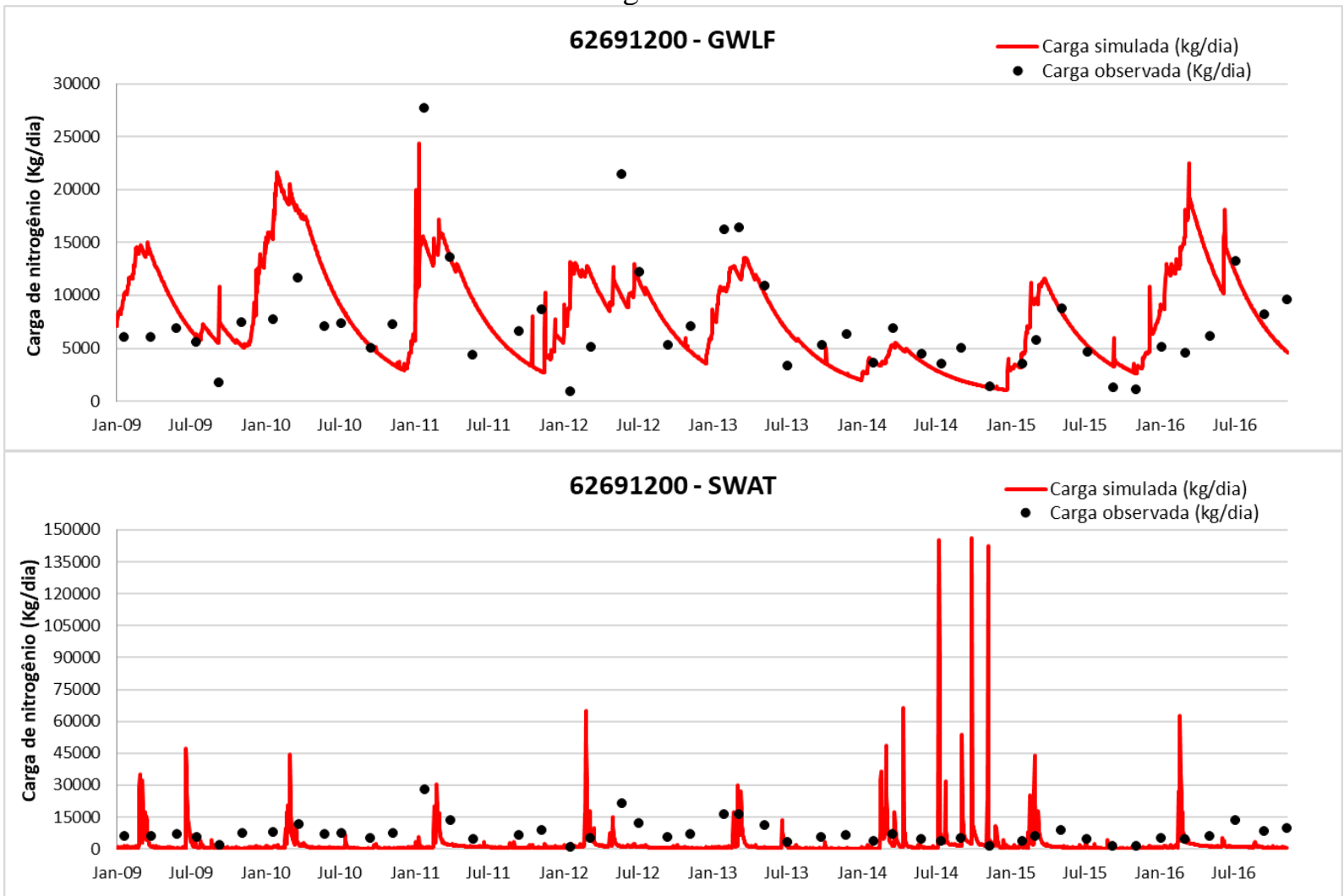

Fonte: Próprio autor 
Figura 51 - Desempenho dos modelos para estimativa da carga de fósforo para estação 62776400 da bacia hidrográfica do rio Jacaré-Guaçu

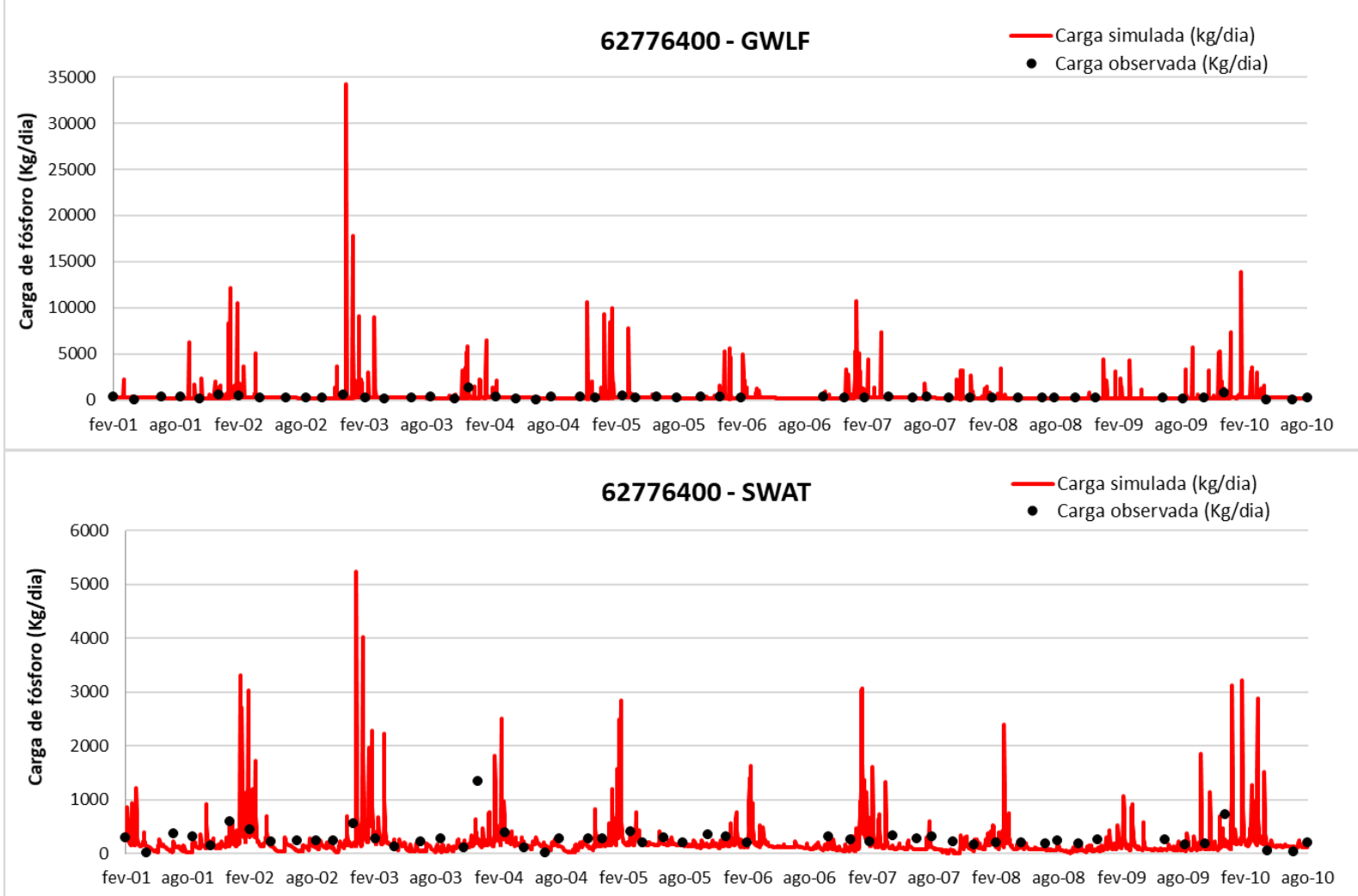

Fonte: Próprio autor

Figura 52 - Desempenho dos modelos para estimativa da carga de fósforo para estação 2605 da bacia hidrográfica do rio Atibaia

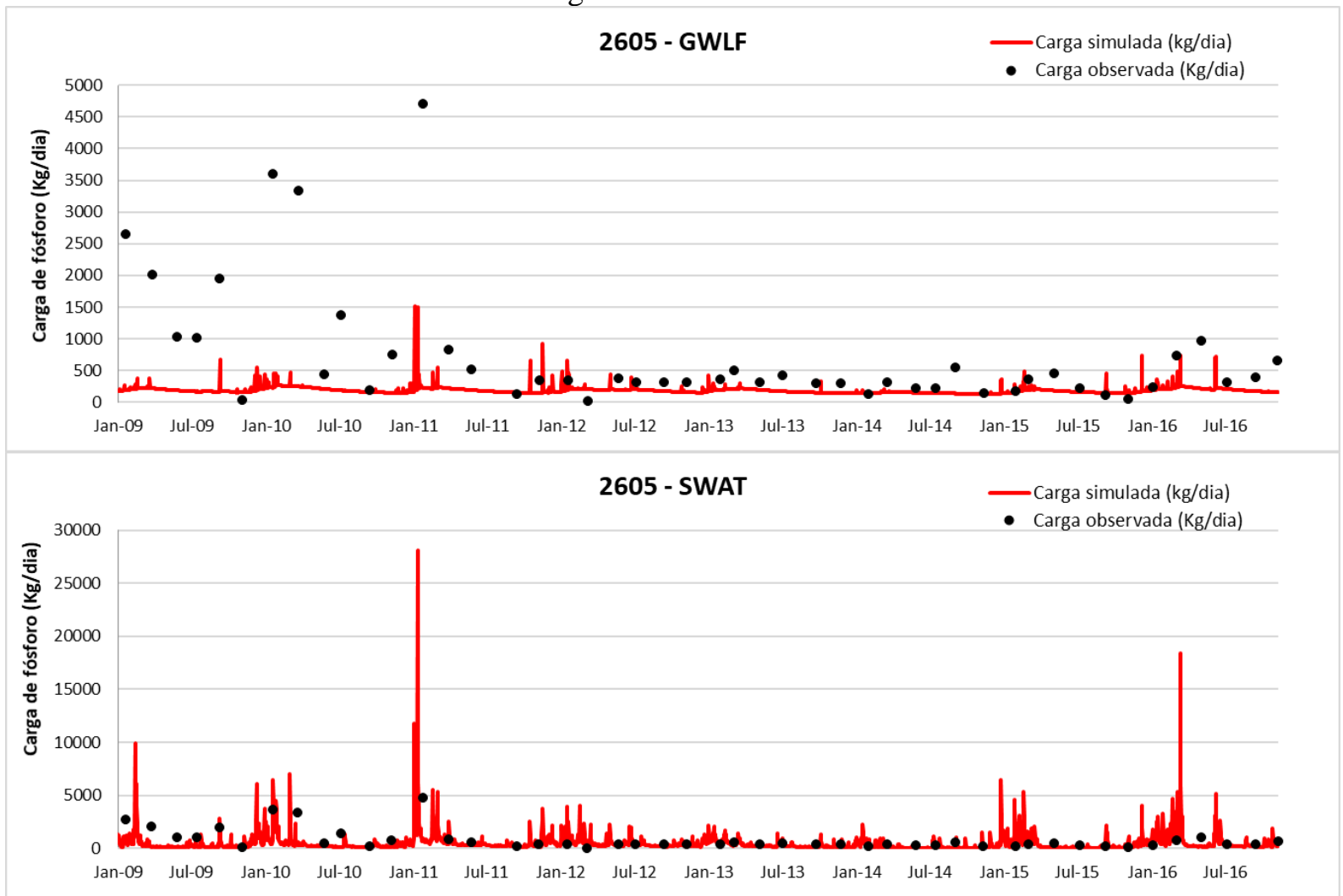

Fonte: Próprio autor 
Figura 53 - Desempenho dos modelos para estimativa da carga de fósforo para estação 62691200 da bacia hidrográfica do rio Atibaia

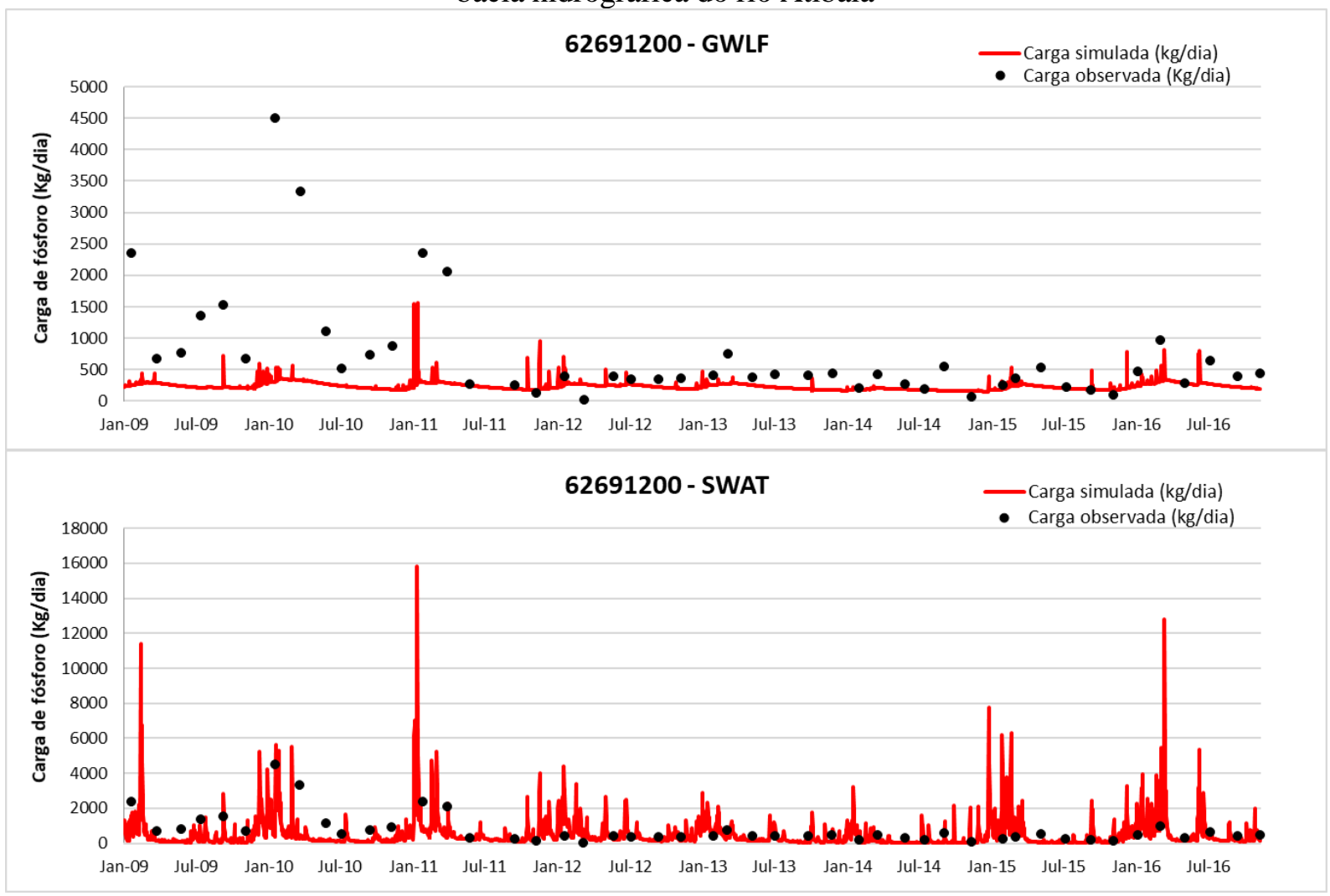

Fonte: Próprio autor

Para ajudar na análise e discussão dos resultados, a tabela 15 mostra os valores calculados para cada indicador de desempenho para ambos os casos de estudo.

Tabela 15 - Desempenho dos modelos SWAT e GWLF na reprodução da qualidade da água

\begin{tabular}{|c|c|c|c|c|c|c|c|c|c|c|c|}
\hline \multirow[t]{2}{*}{ Modelo } & \multirow[t]{2}{*}{ Bacia } & \multirow[t]{2}{*}{ Estação } & \multicolumn{3}{|c|}{$\begin{array}{c}\begin{array}{c}\text { Produção de } \\
\text { sedimentos }\end{array} \\
\end{array}$} & \multicolumn{3}{|c|}{$\begin{array}{c}\begin{array}{c}\text { Concentração de } \\
\text { nitrogênio }\end{array} \\
\end{array}$} & \multicolumn{3}{|c|}{$\begin{array}{c}\text { Concentração de } \\
\text { fósforo }\end{array}$} \\
\hline & & & NSE & Pbias & $\mathrm{r} 2$ & NSE & Pbias & $\mathrm{r} 2$ & NSE & Pbias & $\mathrm{r} 2$ \\
\hline SWAT & Jacaré- & 62776400 & 0,23 & 9,02 & 0,06 & $-9,20$ & $-483,54$ & 0 & 0,23 & 14,72 & 0,19 \\
\hline GWLF & Guaçu & 62776400 & 0 & $-5,86$ & 0,11 & 0 & 26,99 & 0 & $-0,52$ & 6,39 & 0 \\
\hline SWAT & & 2605 & $-0,04$ & 39,50 & 0,07 & $-1,12$ & 76,04 & 0 & $-0,18$ & 20,00 & 0,20 \\
\hline GWLF & Atibaia & 2605 & 0,41 & 34,59 & 0,50 & $-0,28$ & 43,93 & 0 & $-0,25$ & 72,10 & 0 \\
\hline SWAT & & 62691200 & $-0,04$ & 33,33 & 0,04 & $-1,34$ & 76,62 & 0 & $-0,04$ & 18,44 & 0,35 \\
\hline GWLF & & 62691200 & 0,40 & $-20,40$ & 0,47 & 0 & $-10,26$ & 0,19 & $-0,24$ & 65,35 & 0,11 \\
\hline
\end{tabular}

Fonte: Próprio autor

A comparação entre os resultados dos modelos e os valores observados é dificultada devido ao intervalo de amostragem bimensal. No entanto, pode-se observar que ambos os modelos são capazes de reproduzir a ordem de grandeza e as principais variações da produção de sedimentos, embora não com exatidão. As maiores discrepâncias são registradas em altas cargas durante condições de baixa e média vazão. Estes erros podem estar atrelados a qualidade dos dados monitorados. 
As estimativas da produção de sedimentos pelo modelo SWAT apresentam uma variabilidade maior do que as estimativas apresentadas pelo modelo GWLF, por vezes excedendo os valores de pico observados. O modelo GWLF oferece uma série temporal mais suave de resultados que subestimam os valores observados e as estimativas do modelo SWAT durante períodos de recessão. Isso ocorre principalmente porque o GWLF utiliza a equação EUPS como a intensidade da chuva representando o fator erosivo, enquanto o SWAT usa a equação MUSLE que utiliza o volume de escoamento e a taxa de vazão de pico para calcular a produção de sedimentos. A vazão possui uma variabilidade mais suave, quando comparada com a precipitação, devido ao armazenamento de parte do escoamento superficial e à liberação gradativa do escoamento para o canal principal. Além disso o modelo SWAT também utiliza equações de transporte de sedimentos para simular erosão e deposição ao longo do canal principal.

A tabela 15 mostra que a produção de sedimentos simulada pelo modelo GWLF obteve os melhores resultados, especialmente na simulação dos valores computados da bacia do rio Atibaia, com valores de NSE e r2 próximos a 0,5.

Em relação à capacidade dos modelos de reproduzir cargas contaminantes observadas, ambos os modelos são capazes de reproduzir a ordem de magnitude dos valores observados durante fluxos baixos, mas oferecem estimativas altamente variáveis que excedem significativamente os valores observados mensalmente. Os valores dos indicadores de desempenho confirmam este fraco desempenho, com o modelo GWLF mostrando resultados ligeiramente melhores.

A figura 48 mostra que os dois modelos apresentam desempenho semelhante na simulação da concentração de nitrogênio da bacia do rio Jacaré-Guaçu, o que pode ser comprovado pelos resultados dos indicadores de desempenho, todos abaixo dos valores considerados satisfatórios. O mesmo é observado nas estações 2605 e 62691200 da bacia do rio Atibaia, com o modelo GWLF a ter um desempenho ligeiramente melhor. Estes diferentes resultados entre as estações da bacia do rio Atibaia podem estar relacionados à qualidade dos dados observados, uma vez que as duas estações estão no mesmo curso d'água.

Na simulação da carga de fósforo, os resultados de ambos os modelos para a estação localizada na bacia do rio Jacaré-Guaçu apresentaram um bom ajuste para os baixos valores observados (figura 51), o que não ocorre com os valores dos picos. Este fato é comprovado pelos valores insatisfatórios dos indicadores de desempenho, com o modelo SWAT apresentando desempenho ligeiramente melhor que o modelo GWLF. O mesmo ocorre com a 
simulação da concentração de fósforo nas estações da bacia do rio Atibaia, onde o modelo SWAT apresenta resultados um pouco melhores.

As estimativas de fósforo de ambos os modelos, mas especialmente do SWAT, são melhores que as estimativas de nitrogênio. Para ambos os estudos de caso, os valores de pico das cargas de fósforo do modelo SWAT são atrasados quando comparados com as estimativas GWLF, devido à equação de retardo do escoamento usada pelo SWAT.

\subsection{Simulação hidrológica sob influência de um reservatório - Modelagem $\mathrm{SWAT}$}

Na simulação da vazão, da produção de sedimentos e da concentração de nitrogênio e de fósforo sob a influência de um reservatório foi necessário calibrar um conjunto adicional de parâmetros apresentado na tabela 16. A tabela apresenta os valores originais dados pelo modelo e os valores resultantes da calibração e utilizados na simulação.

Tabela 16 - Valores originais e calibrados dos parâmetros do modelo SWAT para simular a vazão do reservatório, a produção de sedimentos, e a concentração dos contaminantes

\begin{tabular}{|c|c|c|c|c|c|c|}
\hline & Parâmetros & Definição & Unidade & Intervalo & $\begin{array}{l}\text { Valores } \\
\text { originais }\end{array}$ & $\begin{array}{c}\text { Valores } \\
\text { calibrados }\end{array}$ \\
\hline \multirow{9}{*}{ : } & RES_K & $\begin{array}{l}\text { Condutividade hidráulica saturada efetiva do fundo } \\
\text { do reservatório }\end{array}$ & $\mathrm{mm} / \mathrm{hr}$ & $0-1$ & 0 & 0,03 \\
\hline & NDTARG & $\begin{array}{l}\text { Número de dias necessários para atingir o } \\
\text { armazenamento alvo }\end{array}$ & dias & $1-200$ & 0 & 1 \\
\hline & IRESCO & Método para o cálculo da vazão & NA & $0-3$ & 0 & 2 \\
\hline & RES_RR & $\begin{array}{l}\text { Taxa média diária de liberação do vertedouro } \\
\text { principal }\end{array}$ & $\mathrm{m}^{3} / \mathrm{s}$ & - & - & 7,2 \\
\hline & OFLOWMN & Saída média diária mínima para o mês & $\mathrm{m}^{3} / \mathrm{s}$ & $0-1$ & 0 & 0,00581 \\
\hline & STARG_FPS & $\begin{array}{l}\text { Volume alvo como uma fração do volume principal } \\
\text { do vertedouro }\end{array}$ & NA & $0-1$ & 0 & 1 \\
\hline & WURTNF & $\begin{array}{c}\text { Fração de água removida perdida como vazão do } \\
\text { reservatório }\end{array}$ & $\mathrm{m}^{3} / \mathrm{m}^{3}$ & $0-1$ & 0,2 & 0 \\
\hline & IFLOD1R & Mês de início da estação chuvosa & mês & $0-12$ & 0 & 5 \\
\hline & IFLOD2R & Mês final da estação chuvosa & mês & $0-12$ & 0 & 9 \\
\hline \multirow{3}{*}{ 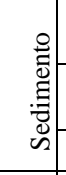 } & RES_SED & $\begin{array}{l}\text { Concentração de sedimentos na água do } \\
\text { reservatório durante o intervalo de tempo }\end{array}$ & $\mathrm{mg} / \mathrm{L}$ & $1-5000$ & 100 & 1000 \\
\hline & RES_NSED & $\begin{array}{c}\text { Concentração de sedimentos de equilíbrio no } \\
\text { reservatório }\end{array}$ & $\mathrm{mg} / \mathrm{L}$ & $1-5000$ & 3500 & 1000 \\
\hline & RES_D50 & Diâmetro médio das partículas de sedimentos & $\mathrm{mm}$ & - & 25 & 10 \\
\hline \multirow{5}{*}{ 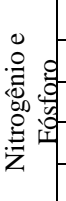 } & RES_ORGN & Concentração inicial de $\mathrm{N}$ orgânico no reservatório & $\mathrm{mg} / \mathrm{L}$ & $0-1$ & 0,23 & 0,01 \\
\hline & RES_NO3 & Concentração inicial de NO3 no reservatório & $\mathrm{mg} / \mathrm{L}$ & $0-1$ & 0,46 & 0,01 \\
\hline & RES_NO2 & Concentração inicial de NO2 no reservatório & $\mathrm{mg} / \mathrm{L}$ & 0,1 & 0,07 & 0 \\
\hline & RES_ORGP & Concentração inicial de P orgânico no reservatório & $\mathrm{mg} / \mathrm{L}$ & 0,1 & 0,08 & 0,01 \\
\hline & RES_SOLP & Concentração inicial de $\mathrm{P}$ solúvel no reservatório & $\mathrm{mg} / \mathrm{L}$ & 0,1 & 0,08 & 0 \\
\hline
\end{tabular}

Fonte: Próprio autor

O parâmetro mais sensível na calibração da vazão de saída do reservatório é o RES_K, que afeta o cálculo da infiltração do reservatório, o que acaba afetando o volume de água armazenada no reservatório (KIM; PARAJULI, 2014). Neste estudo, este parâmetro foi determinado como sendo $0,03 \mathrm{~mm} / \mathrm{h}$. 
O parâmetro NDTARGR define a quantidade de dias necessários para atingir o volume alvo do reservatório. Este parâmetro é utilizado nos métodos para o cálculo da vazão para reservatórios sem controle e para reservatórios controlados. Segundo Neitsch et al. (2005), este parâmetro pode variar de 1 a 200 dias, sendo que neste estudo foi definido para 2 dias, contribuindo para o ajustamento da forma geral dos picos de hidrografia na estação hidrométrica a jusante do reservatório.

A concentração de sedimentos na água do reservatório durante o intervalo de tempo (RES_SED) é o parâmetro mais sensível para calibração da produção de sedimentos do reservatório, os valores padrão são obtidos por Leite (1998) e este valor foi calibrado para $1000 \mathrm{mg} / \mathrm{L}$.

Para nutrientes, a concentração inicial de N e P orgânico (RES_ORGN e RES_ORGP) no reservatório são os parâmetros mais sensíveis para calibração, os valores padrão foram obtidos de Dornfeld (2002) e estes valores foram calibrados para obter o melhor ajuste, obtendo-se o valor de $0.01 \mathrm{mg} / \mathrm{L}$ para ambos os parâmetros.

A figura 54 compara a vazão média diária e mensal da estação a jusante do reservatório (62693100) com os dados de vazão calculados pelo modelo SWAT para o período de calibração e validação. A calibração ocorreu diariamente e mensalmente de 1990 a 2002 e, em seguida, os parâmetros foram validados de 2003 a 2016. A tabela 17 apresenta os valores dos indicadores de desempenho do modelo para esta simulação. 
Figura 54 - Comparação da vazão diário e mensal observada e simulada para a estação 62693100 da bacia hidrográfica do rio Atibaia

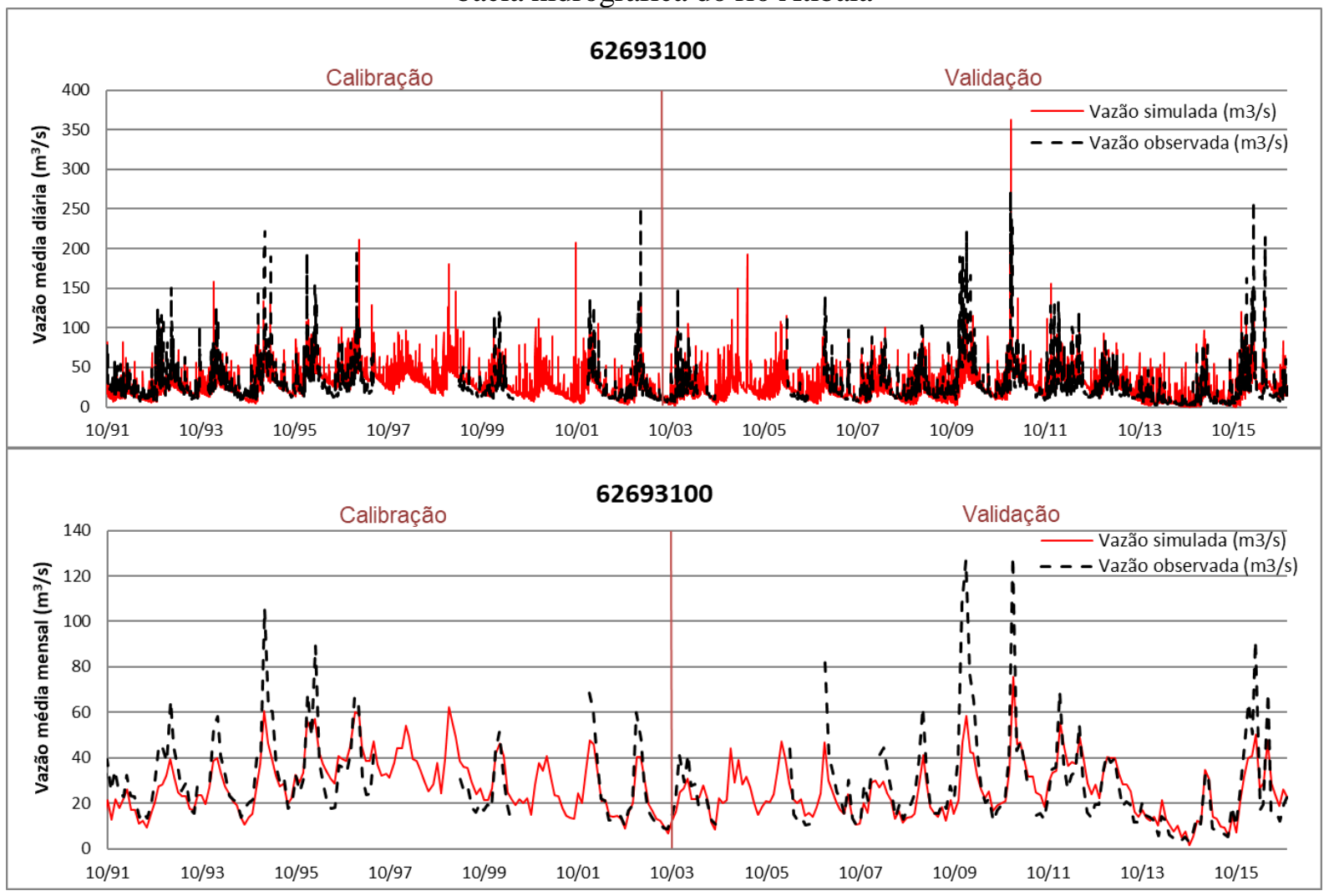

Fonte: Próprio autor

Tabela 17 - Valores do indicador de desempenho do modelo para a estação 62693100

\begin{tabular}{|c|c|c|c|c|c|c|c|c|c|c|c|c|}
\hline \multirow[b]{3}{*}{ Estação } & \multicolumn{6}{|c|}{ Diária } & \multicolumn{6}{|c|}{ Mensal } \\
\hline & \multicolumn{3}{|c|}{ Calibração } & \multicolumn{3}{|c|}{ Validação } & \multicolumn{3}{|c|}{ Calibração } & \multicolumn{3}{|c|}{ Validação } \\
\hline & NSE & Pbias & $\mathrm{r}^{2}$ & NSE & Pbias & $\mathrm{r}^{2}$ & NSE & Pbias & $\mathrm{r}^{2}$ & NSE & Pbias & $\mathrm{r}^{2}$ \\
\hline 62693100 & 0,60 & 1,85 & 0,34 & 0,20 & 10,83 & 0,24 & 0,93 & 1,68 & 0,82 & 0,76 & 11,26 & 0,78 \\
\hline
\end{tabular}

Fonte: Próprio autor

A simulação a jusante do reservatório foi tão boa quanto a simulação a montante. Este fato é confirmado pelos resultados dos indicadores de eficiência, com valores de NSE acima de 0,5 e r2 acima de 0,3 na simulação mensal. Com a vazão calibrada e validada, foi possível proceder à calibração da produção de sedimentos e da concentração dos contaminantes.

A figura 55 compara os valores computados da produção de sedimentos e as cargas de nitrogênio e fósforo com os valores observados bimensais de janeiro/2009 a novembro/2016. $\mathrm{Na}$ figura as concentrações de nitrogênio e fósforo foram expressas em carga (kg/dia).

Para ajudar na análise e discussão dos resultados, a tabela 18 mostra os valores calculados para cada indicador de desempenho e sua comparação com os resultados obtidos das simulações a jusante do reservatório. 
Figura 55 - Simulação da produção de sedimentos e cargas de nitrogênio e fósforo para a estação 62693100 da bacia hidrográfica do rio Atibaia

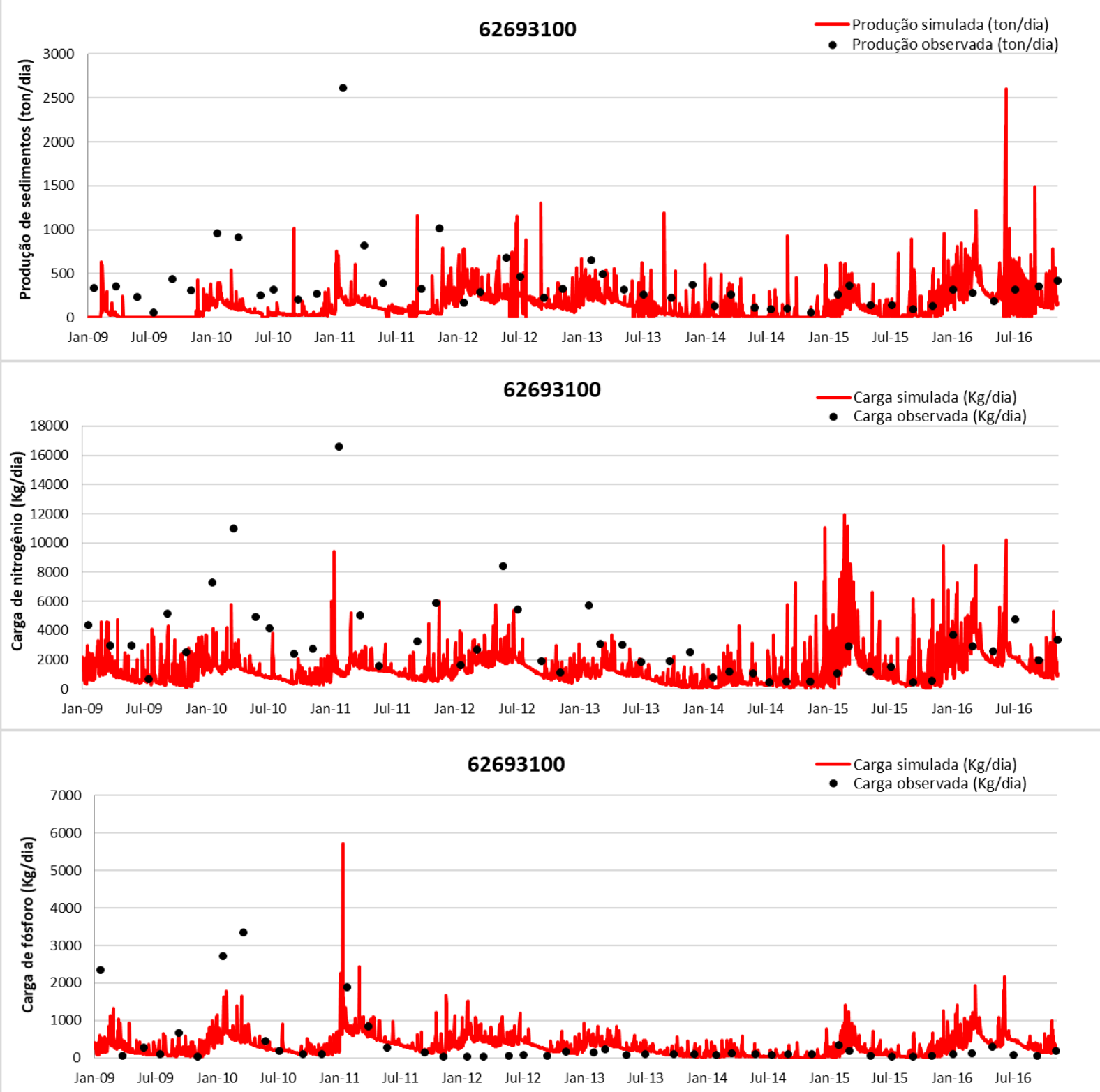

Fonte: Próprio autor

Tabela 18 - Valores do indicador de desempenho do modelo para simulação da concentração dos contaminantes

\begin{tabular}{l|l|l|l|l|l|l|l|l|l}
\hline & \multicolumn{4}{|c|}{$\begin{array}{c}\text { Produção de } \\
\text { sedimentos }\end{array}$} & \multicolumn{3}{c|}{$\begin{array}{c}\text { Concentração de } \\
\text { nitrogênio }\end{array}$} & \multicolumn{3}{c}{$\begin{array}{c}\text { Concentração de } \\
\text { fósforo }\end{array}$} \\
\cline { 2 - 11 } Estação & NSE & Pbias & r2 & NSE & Pbias & r2 & NSE & Pbias & r2 \\
\hline 2605 & $-0,04$ & 39,50 & 0,07 & $-1,12$ & 76,04 & 0 & $-0,18$ & 20,00 & 0,20 \\
\hline 62691200 & $-0,04$ & 33,33 & 0,04 & $-1,34$ & 76,62 & 0 & $-0,04$ & 18,44 & 0,35 \\
\hline 62693100 & $-0,47$ & 63,87 & 0,01 & $-1,05$ & 82,62 & 0, & $-0,30$ & 64,06 & 0,06 \\
\hline
\end{tabular}

Fonte: Próprio autor

O modelo SWAT foi capaz de representar o comportamento do reservatório tanto para a simulação da vazão, com resultados satisfatórios, quanto para a simulação de sedimentos e 
nutrientes, apesar dos resultados menos confiáveis das simulações em comparação com os dados observados.

A comparação entre os resultados do modelo e os valores observados é dificultada devido ao intervalo de amostragem bimestral, mas tanto para os valores a jusante, quanto a montante o modelo é capaz de reproduzir a ordem de grandeza e a variação da produção dos sedimentos, exceto para algumas datas em que altas cargas foram registradas durante condições de vazão baixa a média. Erros de monitoramento podem explicar essas discrepâncias.

Os resultados para as simulações das concentrações de nitrogênio e fósforo são significativamente diferentes para as estações a montante e a jusante, o desempenho fraco é obtido em ambos os casos, mas para a estação a jusante os resultados são melhores.

Para confirmar o desempenho do modelo na simulação dessas variáveis sob a influência do reservatório, foram elaborados gráficos de dispersão (figuras 56) que mostra a relação entre os dados observados da estação a jusante e os dados observados das estações a montante e a relação entre os dados simulados da estação a jusante e os dados simulados das estações a montante.

Observa-se que, em relação aos dados observados, tanto a produção de sedimentos quanto a concentração dos contaminantes encontram-se em maior quantidade a montante do reservatório, como é esperado, uma vez que estes são retidos pelo reservatório.

Em relação aos dados simulados (figura 57), observa-se o mesmo comportamento para a produção de sedimentos e para a concentração de contaminantes. Porém estes gráficos foram elaborados apenas com os valores simulados correspondentes aos dados observados cuja amostragem bimestral pode modificar os resultados e prejudicar a análise.

Desta forma, para comprovar a eficiência do modelo em simular a produção de sedimentos e a concentração de nitrogênio e de fósforo a montante do reservatório, foram elaborados os gráficos de dispersão com os dados simulados pelo modelo para todo o período (2009-2016) (figura 58).

Nestes gráficos podemos verificar que os sedimentos são retidos no reservatório e uma menor quantidade é simulada a jusante, como era esperado. O mesmo comportamento é observado na simulação da concentração dos contaminantes. 
Figura 56 - Relação entre dados observados a jusante e a montante e simulados a jusante e a montante
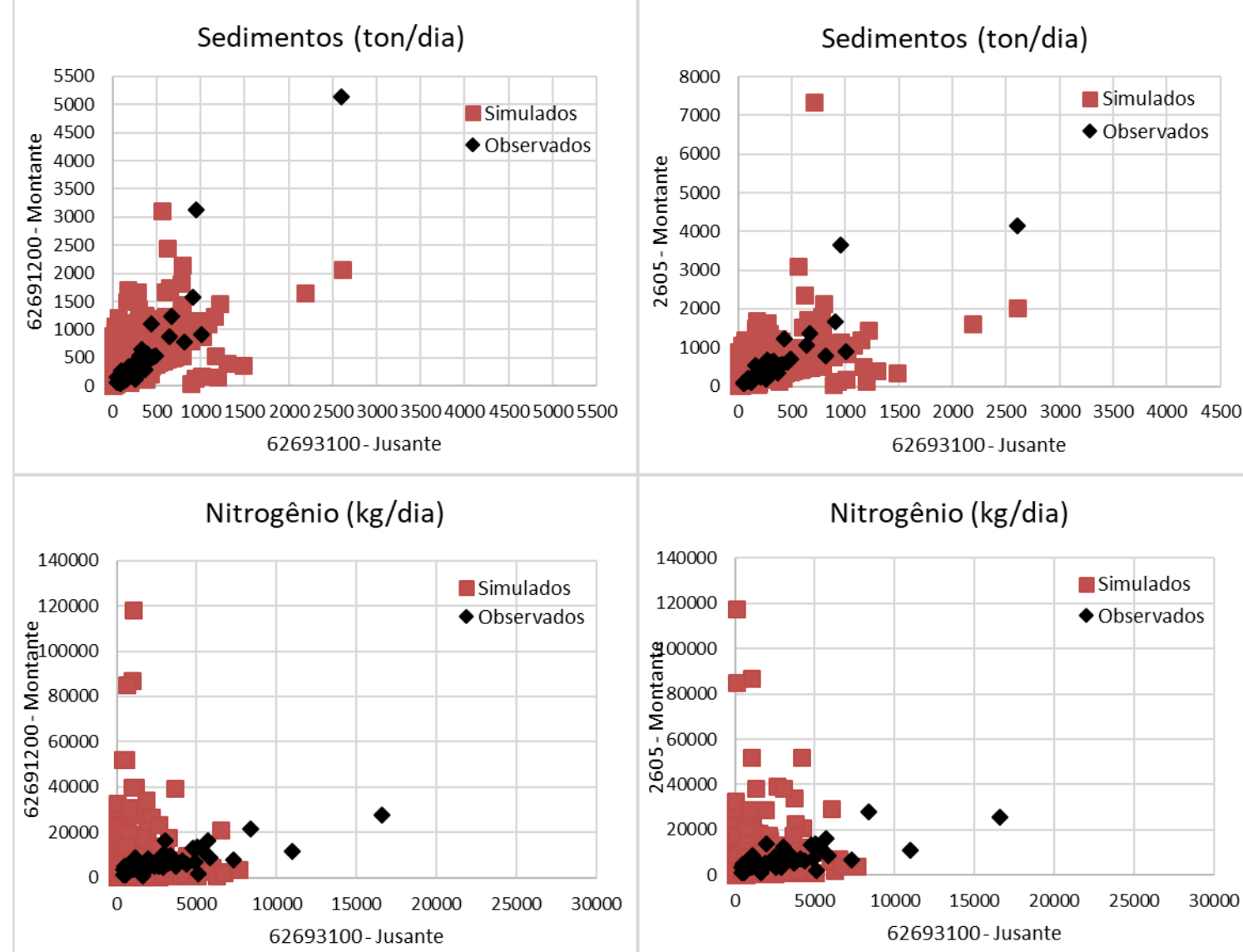
62693100 -Jusante
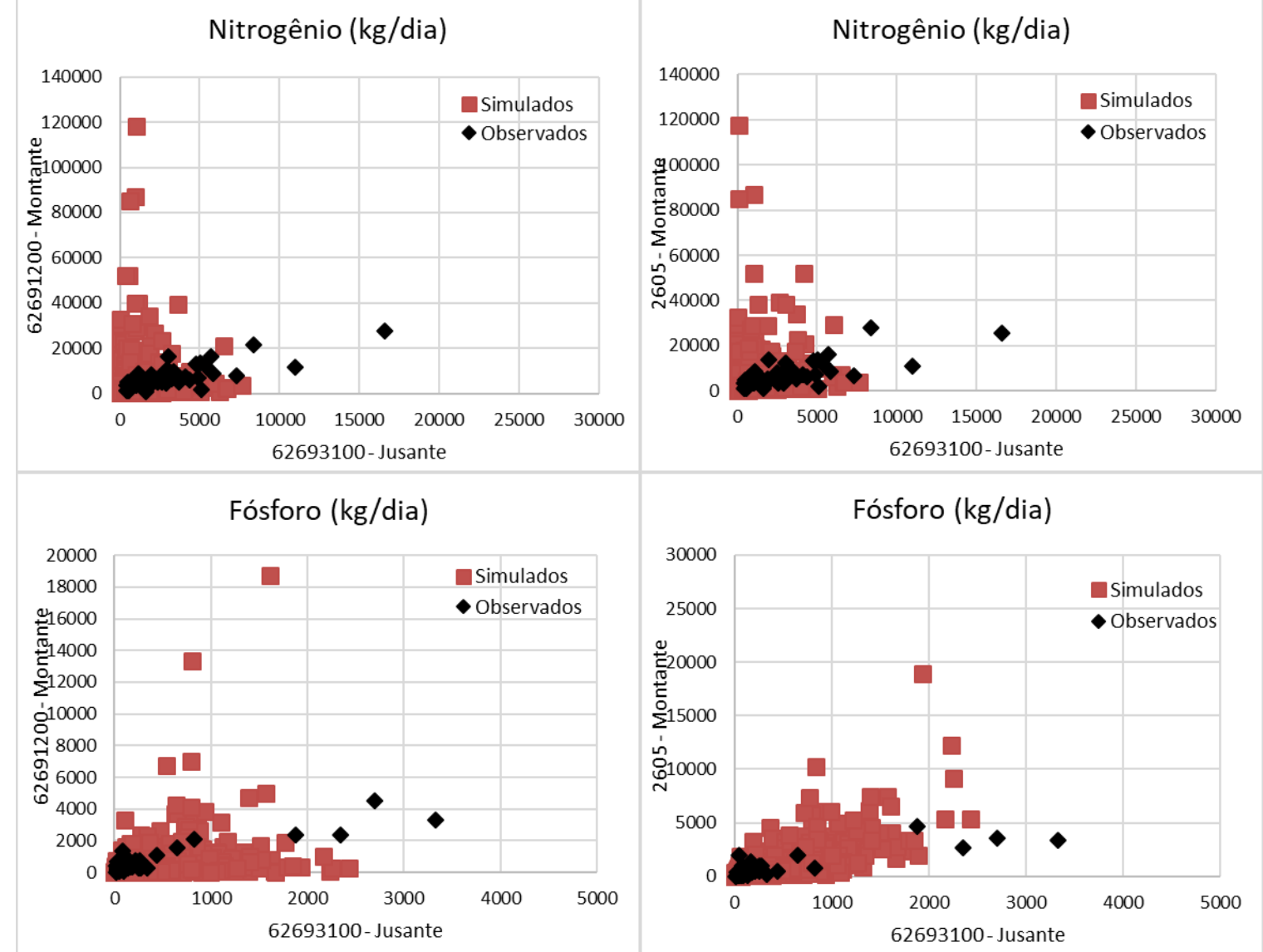

Fonte: Próprio autor 
Figura 57 - Relação entre dados simulados a jusante e a montante para todo o período de simulação

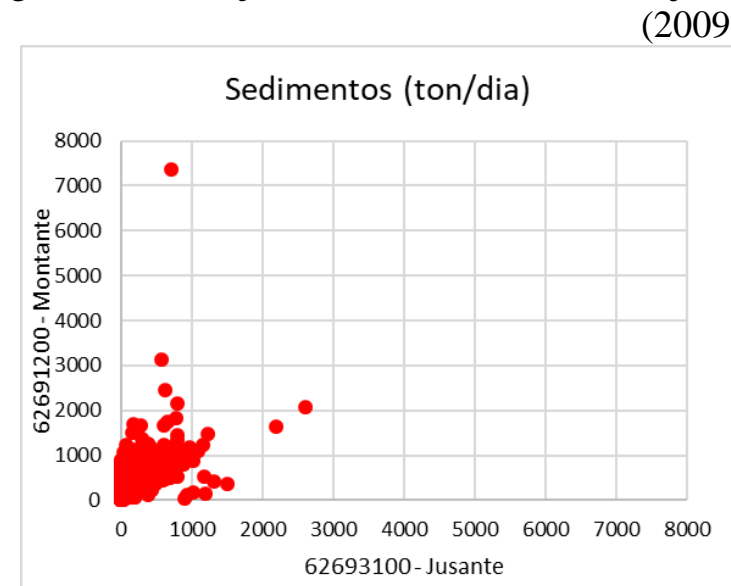
(2009-2016)
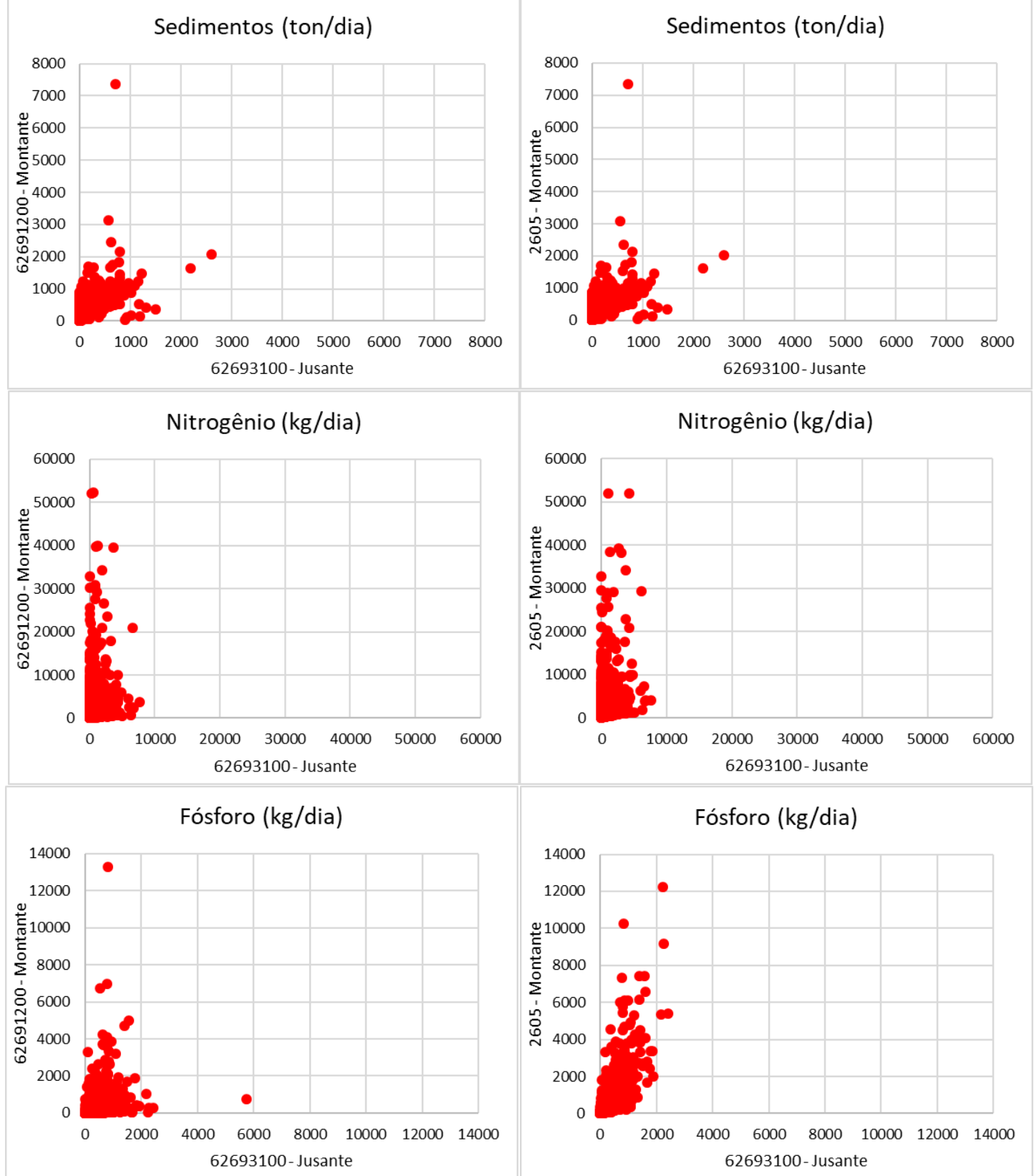

Fonte: Próprio autor 


\subsection{Influência da descrição da precipitação no desempenho dos modelos}

O item 4.1 apresenta os resultados dos modelos SWAT, SCS-CN e GWLF para a simulação da vazão e da qualidade da água dos dois casos de estudo. Foi verificado que alguns dos erros na previsão da vazão, com consequências nas estimativas da qualidade da água, são decorrentes de possíveis falhas no monitoramento da precipitação e/ou da ausência de uma maior densidade de postos pluviométricos na bacia. Esta situação pode ser particularmente relevante na bacia hidrográfica do rio Jacaré-Guaçu onde a qualidade dos resultados do modelo foi menor.

Esta constatação motivou uma nova simulação da vazão com o modelo SWAT para os dois casos de estudo, utilizando os dados precipitação interpolada (DPI) obtidos por Xavier; King; Scanlon, (2016). Neste estudo, os autores utilizaram os dados disponíveis de precipitação monitorados no Brasil para, a partir de técnicas de interpolação, determinar uma grade de precipitação para todo o país (1980-2013) com resolução de $(0,25 \circ \times 0,25 \circ)$.

Os gráficos de dispersão apresentados nas figuras 58 e 59 apresentam a comparação entre a precipitação mensal para as bacias de drenagem simuladas para ambos os casos de estudo, obtida a partir dos dados de precipitação observados (DPO) e dos dados de precipitação interpolados (DPI). Este cálculo foi realizado pelo método da média ponderada de acordo com a atribuição da estação de precipitação do SWAT para cada sub-bacia. Os gráficos mostram que as estimativas da precipitação média sobre cada bacia hidrográfica calculadas com os valores de precipitação interpolados são inferiores às obtidas diretamente a partir dos dados observados nos postos pluviométricos. 
Figura 58 - Gráficos de dispersão dos dados de precipitação observados e interpolados para a bacia hidrográfica do rio Jacaré-Guaçu

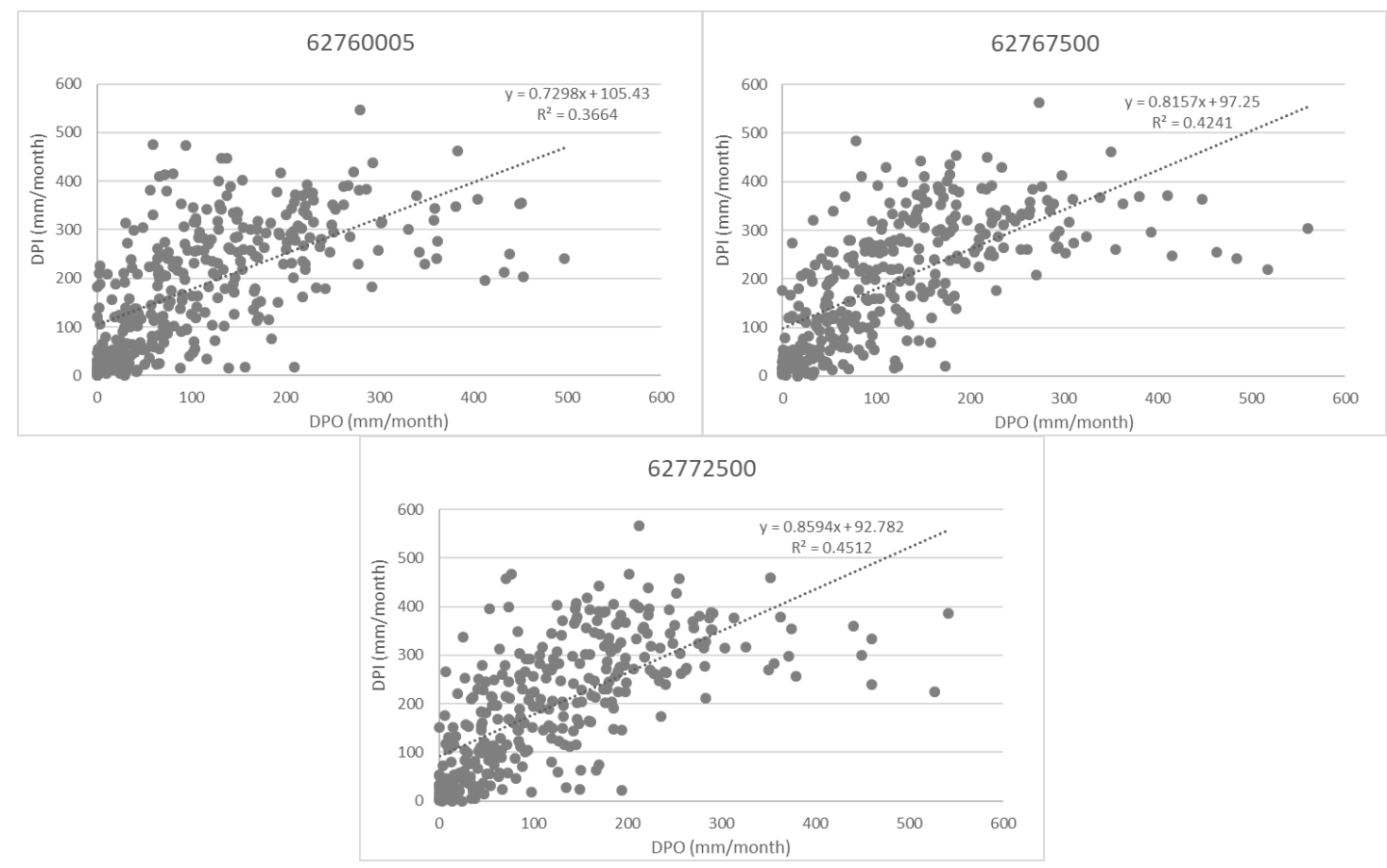

Fonte: Próprio autor

Figura 59 - Gráficos de dispersão dos dados de precipitação observados e interpolados para a bacia hidrográfica do rio Atibaia
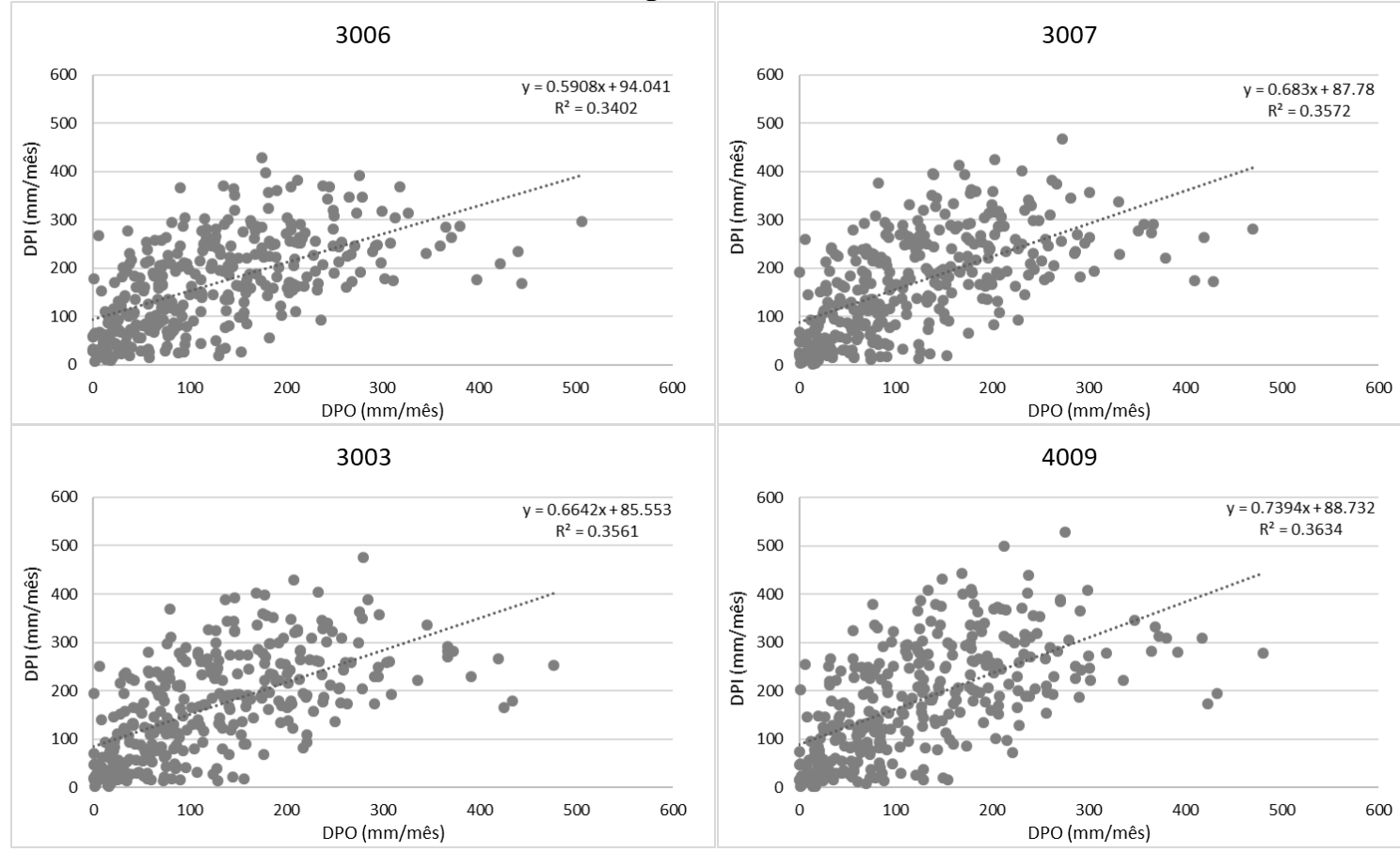

Fonte: Próprio autor

Os parâmetros do modelo SWAT foram novamente calibrados e sendo assim a tabela 19 indica o intervalo de valores, o valor padrão e o valor final obtido após a nova calibração. 
O valor de CN foi reduzido em 10\% uniformemente ao longo da bacia para promover infiltração e fluxo de base, ao invés dos $30 \%$ anteriormente utilizado. A capacidade disponível de água da camada superior do solo (SOL_AWC) também foi reduzida em 10\% para reduzir a capacidade de retenção do solo, aumentar a percolação da água subterrânea e retardar o fluxo que chega ao rio.

$\mathrm{O}$ fator de compensação de evaporação do solo (ESCO) foi mantido em 0,4. O parâmetro GW_REVAP, um coeficiente que reflete a capacidade de mover a água do aquífero pouco profundo para a zona de solo não saturado sobreposto, foi ampliado para 0,2 , o que indica mais água disponível para a descarga do fluxo de base.

O REVAPMN que define a profundidade limiar da água no aquífero pouco profundo para que ocorra o fluxo de retorno para a zona de raiz foi definido para $400 \mathrm{~mm}$ pouco mais que o da simulação com os DPO, de 300mm.

O valor para RCHRG_DP foi reajustado para 0,05 , o que significa que $5 \%$ da água infiltrada é perdida para um aquífero profundo. CANMX que descreve a capacidade de armazenamento de um dossel para manter a precipitação interceptada foi alterado para aumentar o armazenamento de água, porém uma quantidade menor do que o valor máximo utilizado anteriormente, $30 \mathrm{~mm}$.

Tabela 19 - Parâmetros do modelo SWAT calibrados com os DPI

\begin{tabular}{|c|c|c|c|c|c|c|}
\hline & Parâmetros & Definição & Unit & Range & $\begin{array}{c}\text { Valores } \\
\text { originais }\end{array}$ & $\begin{array}{l}\text { Valores } \\
\text { Calibrados }\end{array}$ \\
\hline \multirow{6}{*}{ 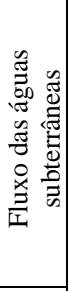 } & GW_REVAP.gW & Coeficiente de revap & NA & $0,02-0,2$ & 0,02 & 0,2 \\
\hline & REVAPMN.gw & $\begin{array}{l}\text { Profundidade limiar da água no aquífero pouco profundo } \\
\text { exigido para revap. }\end{array}$ & $\mathrm{mm}$ & $0-1000$ & 750 & 400 \\
\hline & GWQMN.gw & $\begin{array}{c}\text { Profundidade limiar da água no aquífero pouco profundo } \\
\text { necessária para o fluxo de retorno ocorrer }\end{array}$ & $\mathrm{mm}$ & $0-5000$ & 1000 & 300 \\
\hline & ALPHA_BF.gw & Coeficiente do fluxo de base & dias & $0-1$ & 0,048 & 0,001 \\
\hline & RCHRG_DP.gw & Fração de percolação do aquífero profundo & $\mathrm{mm}$ & $0-1$ & 0,05 & 0,05 \\
\hline & GW_DELAY.gw & Retardamento das águas subterrâneas & dias & $0-500$ & 31 & 5 \\
\hline \multirow{2}{*}{ 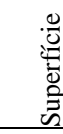 } & CANMX.hru & Armazenamento máximo do dossel das plantas & $\mathrm{mm}$ & $0-100$ & 0 & 30 \\
\hline & ESCO.hru & Fator de compensação de evaporação do solo & NA & $0,01-1$ & 0,95 & 0,4 \\
\hline \multirow{4}{*}{ 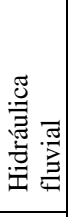 } & CH_K2.rte & $\begin{array}{l}\text { Condutividade hidráulica efetiva no aluvião do canal } \\
\text { principal }\end{array}$ & $\mathrm{mm} / \mathrm{hr}$ & $-0,01-500$ & 0 & 3,2 \\
\hline & CH_N2.rte & $\mathrm{O}$ valor $\mathrm{n}$ de Manning para os canais principais & $\mathrm{mm} / \mathrm{hr}$ & $-0,01-0,3$ & 0,014 & 0,05 \\
\hline & CH_K1.sub & $\begin{array}{l}\text { Condutividade hidráulica efetiva no aluvião do canal } \\
\text { tributário }\end{array}$ & $\mathrm{mm} / \mathrm{hr}$ & $0-300$ & 0 & 5 \\
\hline & CH_N1.sub & $\mathrm{O}$ valor $\mathrm{n}$ de Manning para os canais tributários & $\mathrm{mm} / \mathrm{hr}$ & $0,01-30$ & 0,014 & 0,03 \\
\hline \multirow{5}{*}{ 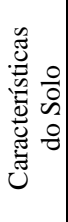 } & SLSOIL.hru & Inclinação para o fluxo lateral subsuperficial & $\mathrm{m}$ & $0-150$ & 0 & 40 \\
\hline & CNCOEF.bsn & Coeficiente para no CN & NA & $0,5-2$ & 2 & 1,5 \\
\hline & FFCB.bsn & $\begin{array}{l}\text { Armazenamento inicial de água no solo expresso como } \\
\text { uma fração do conteúdo de água da capacidade de campo }\end{array}$ & NA & $0-1$ & 0 & 1 \\
\hline & CN2.mgt & Número inicial de CN para umidade II & NA & $0-100$ & - & $0,1^{\mathrm{b}}$ \\
\hline & SOL.awc & Capacidade de água disponível no solo & $\mathrm{mm} / \mathrm{mm}$ & $0-1$ & - & $0,1^{\mathrm{b}}$ \\
\hline
\end{tabular}

Fonte: Próprio autor 
As figuras 60 a 66 apresentam os resultados das simulações diárias e mensais da vazão a partir do modelo SWAT para ambos os casos de estudo. Para facilitar a análise dos resultados a tabela 20 apresenta o resultado da avaliação estatística dos dados.

Figura 60 - Comparação da simulação da vazão diária e mensal para estação 62760005 da bacia hidrográfica do rio Jacaré-Guaçu

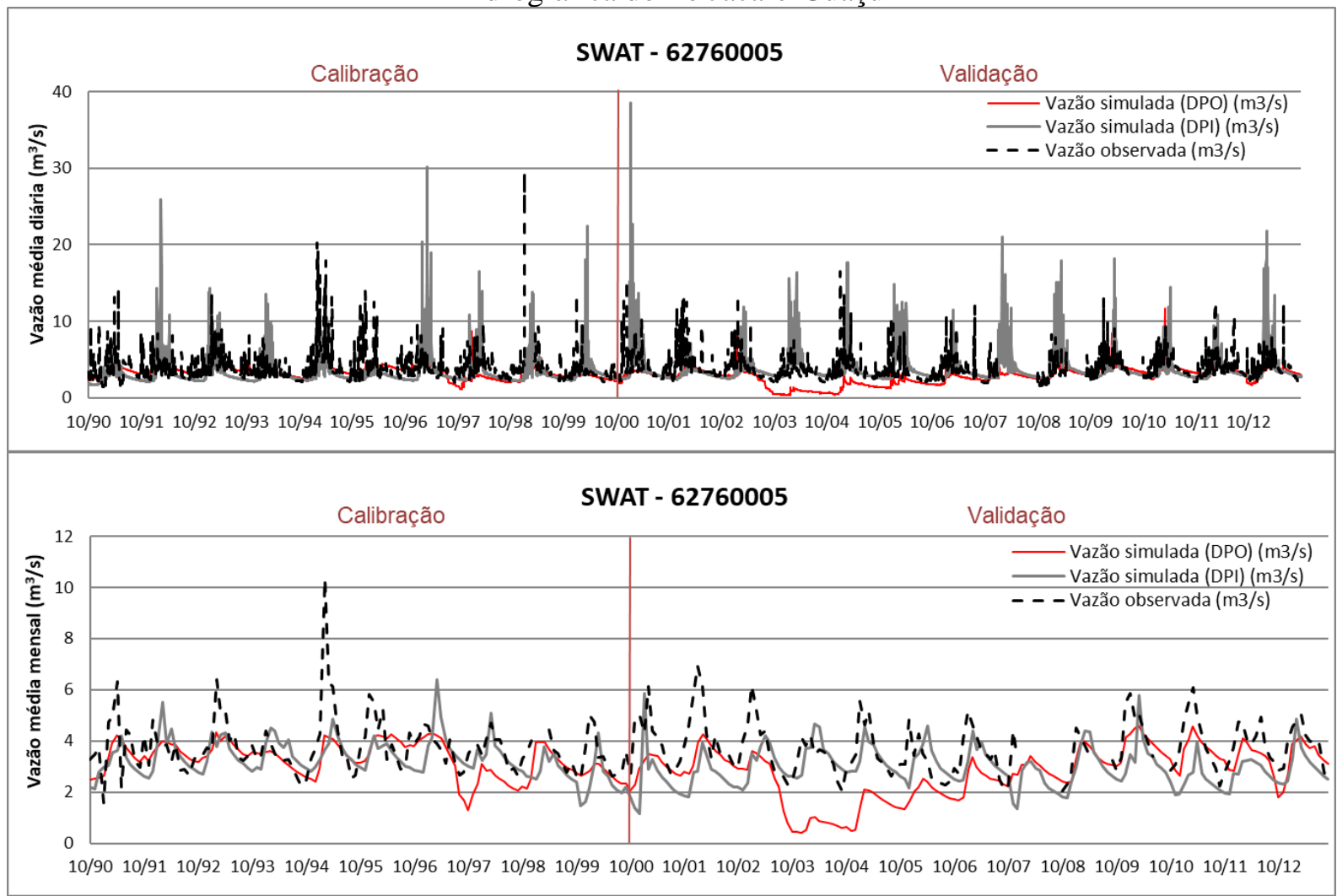

Fonte: Próprio autor 
Figura 61 - Comparação da simulação da vazão diária e mensal para estação 62767500 da bacia hidrográfica do rio Jacaré-Guaçu

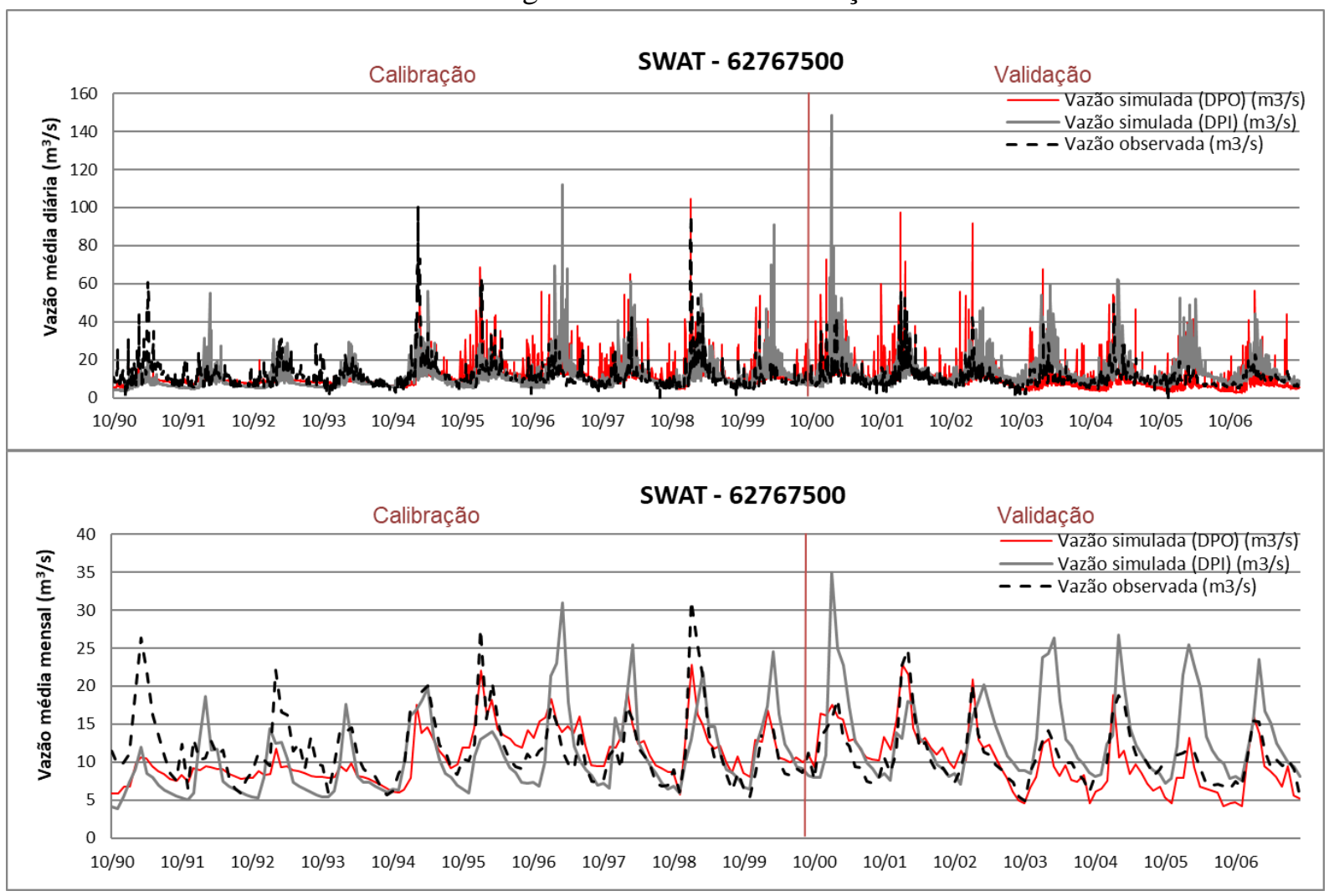

Fonte: Próprio autor

Figura 62 - Comparação da simulação da vazão diária e mensal para estação 62772500 da bacia hidrográfica do rio Jacaré-Guaçu

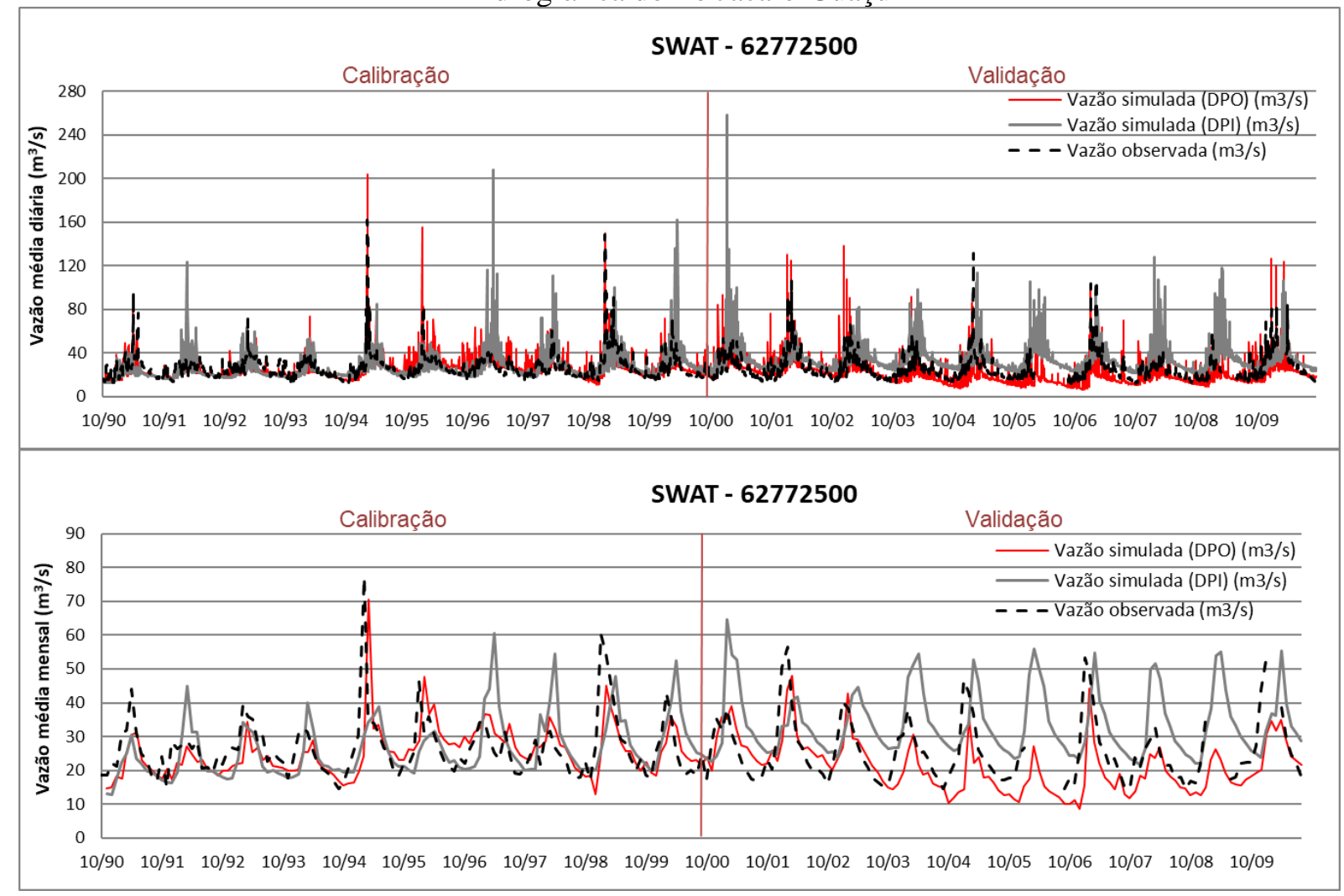

Fonte: Próprio autor 
Figura 63 - Comparação da simulação da vazão diária e mensal para estação 3006 da bacia hidrográfica do rio Atibaia

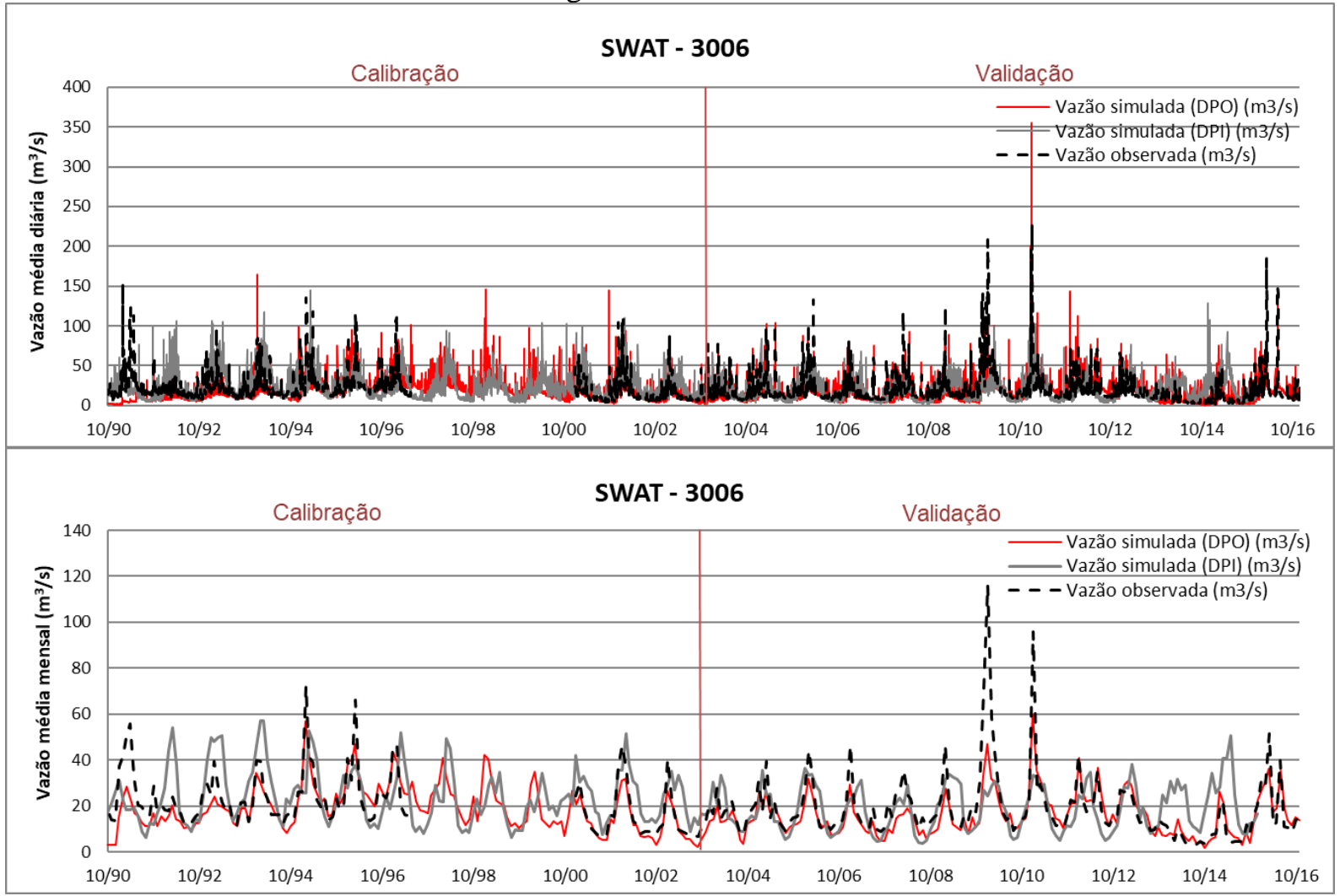

Fonte: Próprio autor

Figura 64 - Comparação da simulação da vazão diária e mensal para estação 3007 da bacia hidrográfica do rio Atibaia

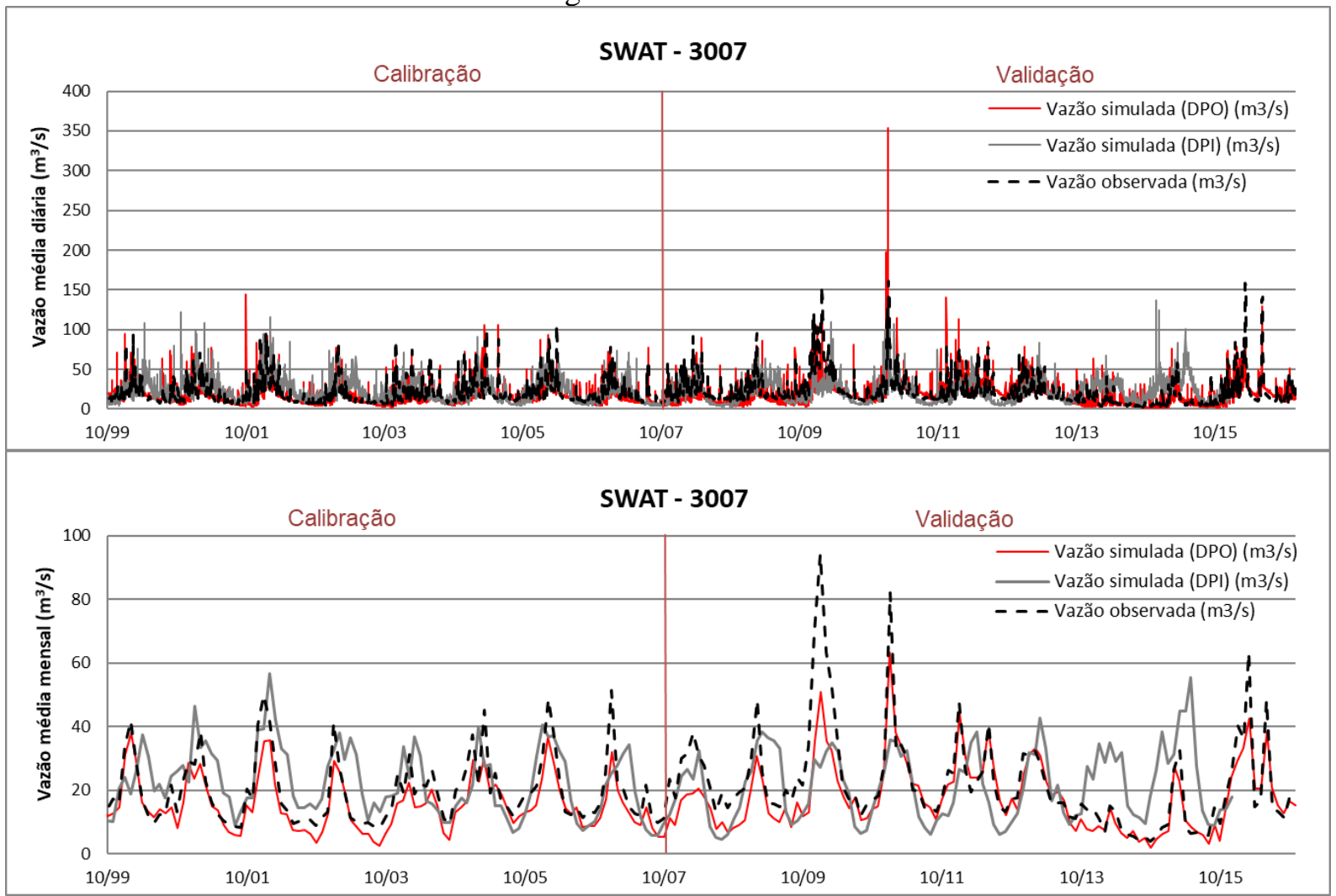

Fonte: Próprio autor 
Figura 65 - Comparação da simulação da vazão diária e mensal para estação 3003 da bacia hidrográfica do rio Atibaia

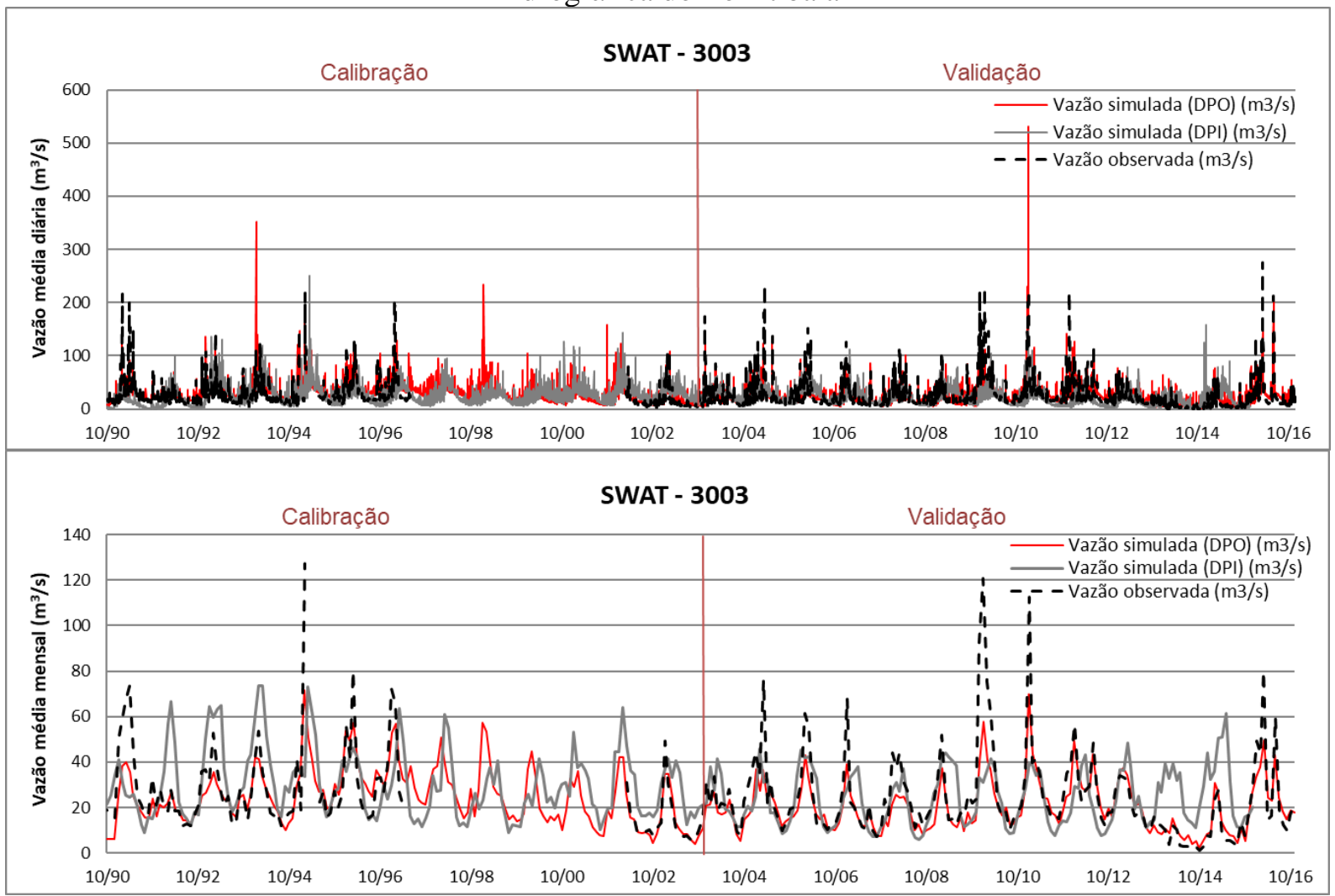

Fonte: Próprio autor

Figura 66 - Comparação da simulação da vazão diária e mensal para estação 4009 da bacia hidrográfica do rio Atibaia

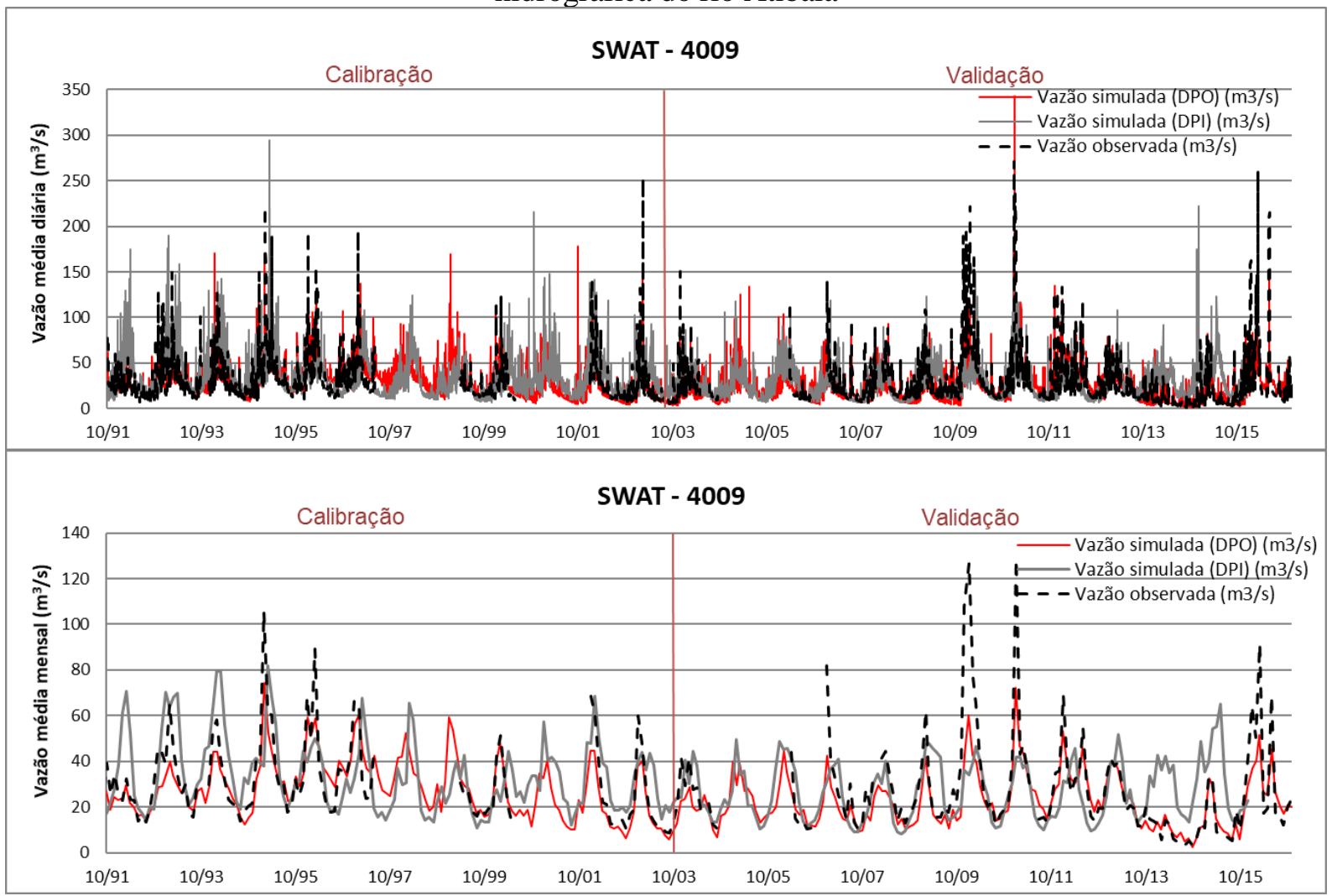

Fonte: Próprio autor 
Tabela 20 - Desempenho do modelo SWAT em reproduzir as vazões diárias e mensais a partir dos DPI

\begin{tabular}{c|c|c|c|c|c|c|c|c|c|c|c|c}
\hline & \multicolumn{9}{|c|}{ Diários } & \multicolumn{6}{c}{ Mensais } \\
\hline & \multicolumn{4}{|c}{ Calibração } & \multicolumn{3}{c|}{ Validação } & \multicolumn{3}{c}{ Calibração } & \multicolumn{3}{c}{ Validação } \\
\hline Estação & NSE & Pbias & r2 & NSE & Pbias & r2 & NSE & Pbias & r2 & NSE & Pbias & r2 \\
\hline 62760005 & $-0,75$ & 11,48 & 0,03 & $-0,32$ & $-0,78$ & 0,04 & $-0,52$ & 11,02 & 0,12 & 0,16 & $-1,01$ & 0,15 \\
\hline 62767500 & $-0,27$ & 14,53 & 0,08 & $-1,53$ & $-24,83$ & 0,09 & 0,06 & 12,44 & 0,24 & $-0,69$ & $-25,31$ & 0,35 \\
\hline 62772500 & $-0,35$ & 1,21 & 0,13 & $-0,06$ & $-28,05$ & 0,15 & 0,13 & 1,33 & 0,30 & 0,33 & $-27,76$ & 0,39 \\
\hline 3006 & 0,10 & $-13,88$ & 0,06 & $-0,23$ & 6,96 & 0,04 & 0,42 & $-13,81$ & 0,17 & $-0,17$ & 6,19 & 0,10 \\
\hline 3007 & $-0,41$ & $-7,40$ & 0,07 & $-0,36$ & 15,12 & 0,05 & $-0,04$ & $-13,16$ & 0,27 & $-0,37$ & 14,60 & 0,10 \\
\hline 3003 & 0,23 & $-17,01$ & 0,04 & $-0,16$ & 7,30 & 0,05 & 0,47 & $-14,89$ & 0,11 & $-0,14$ & 6,62 & 0,12 \\
\hline 4009 & 0,32 & $-15,08$ & 0,10 & 0,01 & 10,16 & 0,05 & 0,65 & $-13,66$ & 0,27 & 0,10 & 9,47 & 0,12 \\
\hline
\end{tabular}

Fonte: Próprio autor

Na tabela 20 pode-se verificar que o ajustamento dos dados de precipitação é melhor para as estações hidrométricas 62767500 e 62772500 (como confirmado pelos valores de r2 próximos de 0,4 em passo de cálculo mensal). Estas estações obtiveram o melhor desempenho para a simulação da vazão, quando utilizados os DPO e o mesmo ocorreu na simulação com os DPI (figuras 61 e 62). Já para a estação 62760005 os resultados insatisfatórios obtidos com os DPO foram observados novamente com a utilização dos DPI.

Nas figuras 63 a 66 verificamos que a utilização dos DPI também não contribuiu para uma melhora significativa dos resultados obtidos com os DPO para a bacia do rio Atibaia. E o mesmo fato se confirma nos resultados dos indicadores de desempenho, todos ligeiramente piores dos que obtidos com os DPO (tabela 19).

Conclui-se que a utilização da nova grade de precipitação não contribuiu para melhorar a calibração do modelo SWAT, apresentando resultados com qualidade inferior para ambos estudos de caso. Esta conclusão pode ser justificada pela dimensão pequena a média das bacias hidrográficas consideradas em cada caso de estudo $\left(1934 \mathrm{~km}^{2}\right.$ e $\left.2817 \mathrm{~km}^{2}\right)$ e pela alta densidade da sua rede pluviométrica (aproximadamente 1.06 postos $/ 100 \mathrm{~km}^{2}$ e 0.51 postos $/ 100 \mathrm{~km}^{2}$ respectivamente).

A utilização da grade de precipitação interpolada pode, no entanto, ser interessante para grandes bacias, com baixa densidade de postos pluviométricos, onde os métodos de interpolação do SWAT para estimar a precipitação em cada sub-bacia falham e apresentam estimativas pouco rigorosas. 


\subsection{Avaliação de cenários de uso e de ocupação de solo}

\subsubsection{Definição dos cenários}

Após a calibração e validação dos modelos SWAT, SCS-CN e GWLF para as bacias hidrográficas estudadas, estimaram-se os impactos na vazão e na produção de sedimentos e de contaminantes para três cenários de uso e ocupação do solo.

Os cenários estudados foram:

I - Cenário atual: Predominância da agricultura na bacia hidrográfica do rio Jacaré Guaçu e da floresta na bacia hidrográfica do rio Atibaia. Este cenário é o resultado dos mapas de uso e ocupação do solo, elaborados a partir de imagens de satélite datadas de 2001, para a bacia do rio Jacaré Guaçu e 2013, para a bacia do rio Atibaia.

II - Cenário tendencial: Este cenário representa a tendência discutida pelo CBH-PCJ, (2006) e CBH-TJ, (2009), que prevê a expansão das áreas urbanas e agrícolas. Esse aumento pode ser representado pela substituição de pastagem e parte da mata nativa por uso agrícola, principalmente a substituição de muitas culturas pela cana-de-açúcar. Essa tendência está alinhada com a tendência atual de uso da terra onde as áreas de estudo estão inseridas (DEMANBORO; LAURENTIS; BETTINE, 2013; NOVO et al., 2010; RUDORFF et al., 2010). A área urbana foi aumentada em $20 \%$, enquanto $20 \%$ da pastagem e $30 \%$ das áreas florestais foram substituídas por agricultura e cana-de-açúcar, em partes iguais.

III - Cenário desejável: Este cenário representa uma projeção positiva para os usos futuros, mas com o mesmo crescimento urbano representado no cenário tendencial. Os demais usos da terra consistiram na substituição de 50\% das áreas de pastagem e $100 \%$ do solo exposto por áreas florestais, para recompor a mata nativa.

As figuras 67 e 68 apresentam a distribuição de uso e ocupação de solo para cada cenário. 
Figura 67 - Cenários para a bacia hidrográfica do rio Jacaré-Guaçu

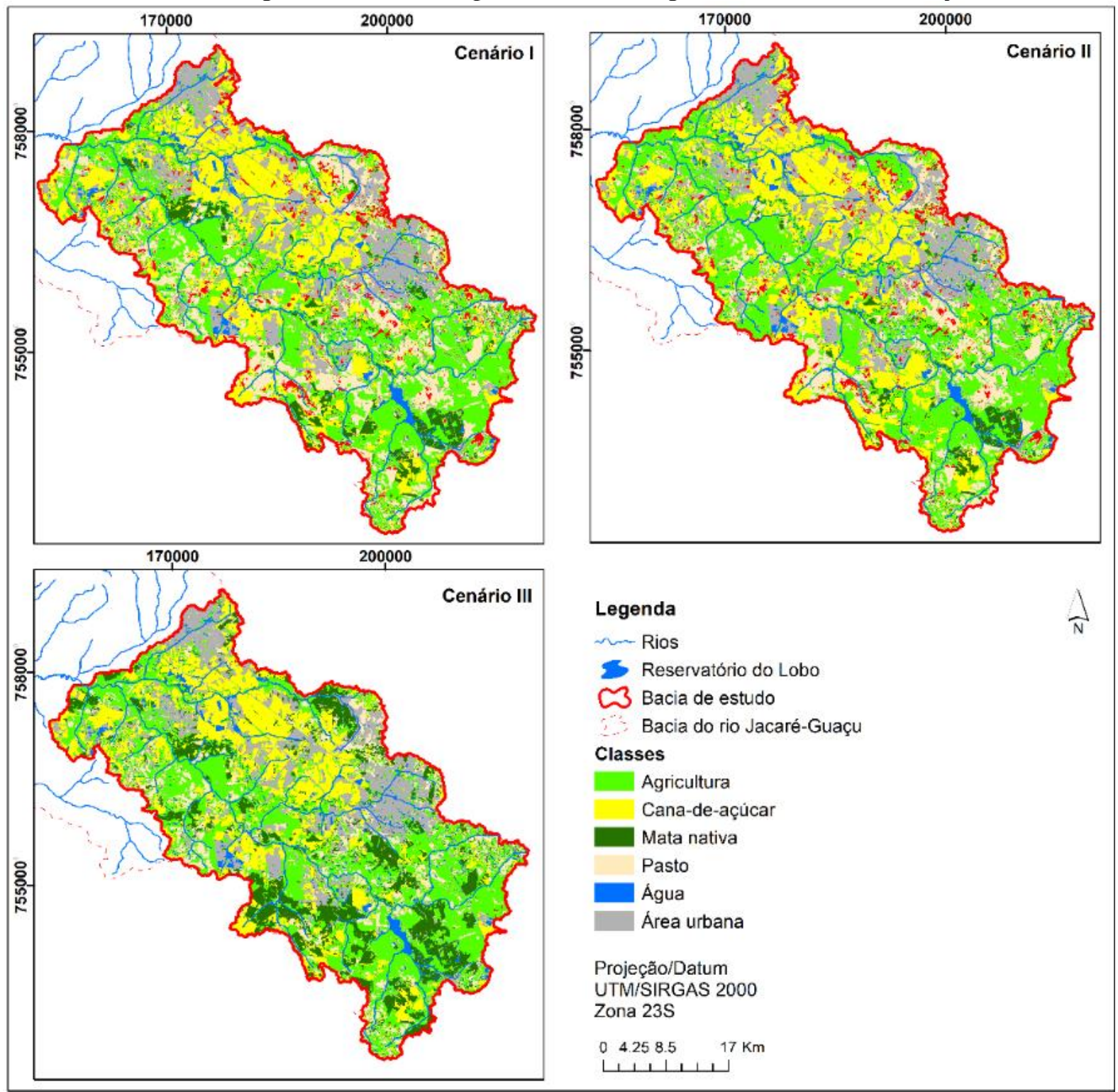

Fonte: Próprio autor 
Figura 68 - Cenários para a bacia hidrográfica do rio Atibaia

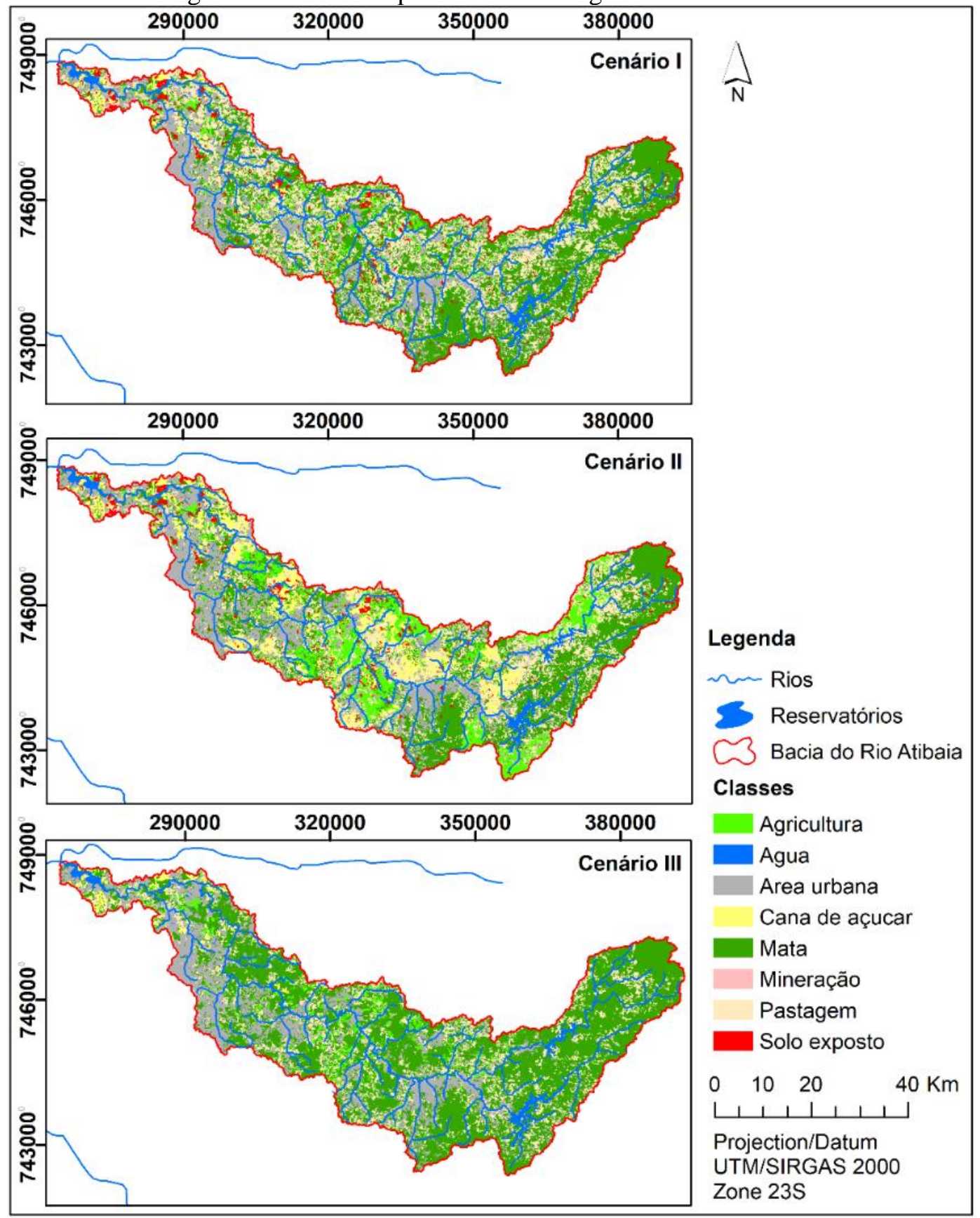

Fonte: Próprio autor

As tabelas 21 e 22 apresentam as áreas de cada uso e ocupação do solo para os vários cenários considerados. Na bacia hidrográfica do rio Jacaré-Guaçu, o cenário II aponta para uma alteração de uso de solo em $187,5 \mathrm{~km}^{2}$, o que equivale a $10 \%$ da área da bacia hidrográfica. As áreas urbanas aumentam entre $15 \%$ e 30\% nas várias sub-bacias e a área da cana de açúcar na sub-bacia intermédia aumenta 37\%, substituindo a área de mata que se reduz entre $20 \%$ e $47 \%$, em todas as subbacias. O cenário III sugere uma alteração do uso do solo em $511 \mathrm{~km}^{2}$ (26\% da área da bacia hidrográfica), através do mesmo aumento das áreas 
urbanas e de um aumento significativo da área de mata, entre $166 \%$ e $322 \%$ em toda a bacia hidrográfica, e ainda da eliminação total das áreas de solo exposto da bacia hidrográfica do rio Jacaré-Guaçu para cada cenário.

Na bacia hidrográfica do rio Atibaia, os cenários II e III apresentam uma alteração do uso de solo em $1153 \mathrm{~km}^{2}$ e $1043 \mathrm{~km}^{2}$, respectivamente, o que corresponde a $40 \%$ e $37 \%$ da área da bacia hidrográfica. O cenário II prevê a expansão das áreas de cana de açúcar e agricultura em toda a bacia hidrográfica, mas em menor grau na sub-bacias de jusante. A áreas urbanas também aumentam, com destaque para a sub-bacia intermédia superior. Estes aumentos fazem-se à custa da redução das áreas de pasto e de mata. O cenário III sugere o mesmo aumento da área urbana e um aumento generalizado da área de mata, através da eliminação das áreas de solo exposto e da redução da área de pasto

Tabela 21 - Classes de uso e ocupação do solo e respectivas áreas para cada cenário da bacia hidrográfica do rio Jacaré-Guaçu

\begin{tabular}{|c|c|c|c|c|c|c|c|c|c|}
\hline \multirow{2}{*}{$\begin{array}{c}\text { Sub-bacias } \\
\text { Usos }\end{array}$} & \multicolumn{3}{|c|}{$\begin{array}{c}\text { Montante } \\
\text { Montante da EH } 62760005\end{array}$} & \multicolumn{3}{|c|}{$\begin{array}{c}\text { Intermédia } \\
\text { Montante da EH } 62767500 \text { e } \\
\text { jusante da EH } 62760005\end{array}$} & \multicolumn{3}{|c|}{$\begin{array}{c}\text { Jusante } \\
\text { Montante da EH } 62772500 \text { e } \\
\text { jusante da EH } 62760005\end{array}$} \\
\hline & Cenário I & $\begin{array}{c}\text { Cenário } \\
\text { II }\end{array}$ & $\begin{array}{l}\text { Cenário } \\
\text { III }\end{array}$ & $\begin{array}{c}\text { Cenário } \\
\text { I }\end{array}$ & $\begin{array}{c}\text { Cenário } \\
\text { II }\end{array}$ & $\begin{array}{l}\text { Cenário } \\
\text { III }\end{array}$ & $\begin{array}{c}\text { Cenário } \\
\text { I }\end{array}$ & $\begin{array}{l}\text { Cenário } \\
\text { II }\end{array}$ & $\begin{array}{c}\text { Cenário } \\
\text { III }\end{array}$ \\
\hline Área urbana & 12,15 & $\begin{array}{c}15,95 \\
(+31 \%)\end{array}$ & $\begin{array}{c}15,95 \\
(+31 \%) \\
\end{array}$ & 34,63 & $\begin{array}{c}39,93 \\
(+15 \%)\end{array}$ & $\begin{array}{c}39,93 \\
(+15 \%) \\
\end{array}$ & 215,68 & $\begin{array}{l}259,21 \\
(+20 \%)\end{array}$ & $\begin{array}{l}259,21 \\
(+20 \%)\end{array}$ \\
\hline Cana de açúcar & 17,96 & $\begin{array}{l}18,52 \\
(+3 \%) \\
\end{array}$ & $\begin{array}{l}17,96 \\
(0 \%)\end{array}$ & 86,85 & $\begin{array}{l}119,22 \\
(+37 \%) \\
\end{array}$ & $\begin{array}{l}86,85 \\
(0 \%) \\
\end{array}$ & 313,71 & $\begin{array}{c}321,53 \\
(+2 \%)\end{array}$ & $\begin{array}{c}313,71 \\
(0 \%)\end{array}$ \\
\hline Água & 6,96 & $\begin{array}{l}6,96 \\
(0 \%) \\
\end{array}$ & $\begin{array}{l}6,96 \\
(0 \%) \\
\end{array}$ & 21,19 & $\begin{array}{c}21,19 \\
(0 \%) \\
\end{array}$ & $\begin{array}{l}21,18 \\
(0 \%) \\
\end{array}$ & 35,99 & $\begin{array}{l}35,99 \\
(0 \%) \\
\end{array}$ & $\begin{array}{c}35,99 \\
(0 \%) \\
\end{array}$ \\
\hline Agricultura & 124,98 & $\begin{array}{l}125,69 \\
(0,6 \%)\end{array}$ & $\begin{array}{c}121,17 \\
(-3 \%)\end{array}$ & 222,23 & $\begin{array}{r}222,93 \\
(0,3 \%) \\
\end{array}$ & $\begin{array}{l}216,93 \\
(-2,4 \%) \\
\end{array}$ & 342,55 & $\begin{array}{l}341,51 \\
(-0,3 \%)\end{array}$ & $\begin{array}{l}299,01 \\
(-13 \%) \\
\end{array}$ \\
\hline Pasto & 52,91 & $\begin{array}{l}49,87 \\
(-6 \%) \\
\end{array}$ & $\begin{array}{c}33,14 \\
(-37 \%) \\
\end{array}$ & 130,87 & $\begin{array}{l}103,43 \\
(-21 \%)\end{array}$ & $\begin{array}{l}59,17 \\
(-55 \%)\end{array}$ & 148,27 & $\begin{array}{l}114,23 \\
(-23 \%)\end{array}$ & $\begin{array}{l}106,75 \\
(-28 \%)\end{array}$ \\
\hline Solo exposto & 6,86 & $\begin{array}{l}6,86 \\
(0 \%) \\
\end{array}$ & $\begin{array}{c}0 \\
(-100 \%) \\
\end{array}$ & 18,14 & $\begin{array}{l}18,14 \\
(0 \%)\end{array}$ & $\begin{array}{c}0 \\
(-100 \%) \\
\end{array}$ & 45,22 & $\begin{array}{c}45,22 \\
(0 \%)\end{array}$ & $\begin{array}{c}0 \\
(-100 \%)\end{array}$ \\
\hline Mata & 8,27 & $\begin{array}{c}6,24 \\
(-25 \%) \\
\end{array}$ & $\begin{array}{c}34,91 \\
(+322 \%) \\
\end{array}$ & 54,07 & $\begin{array}{c}43,14 \\
(+20 \%) \\
\end{array}$ & $\begin{array}{c}143,92 \\
(+166 \%) \\
\end{array}$ & 34,78 & $\begin{array}{l}18,51 \\
(-47 \%) \\
\end{array}$ & $\begin{array}{r}121,53 \\
(+249 \%) \\
\end{array}$ \\
\hline Total & 230,09 & 230,09 & 230,09 & 567,98 & 567,98 & 567,98 & 1136,2 & 1136,2 & 1136,2 \\
\hline
\end{tabular}

Tabela 22 - Classes de uso e ocupação do solo e respectivas áreas para cada cenário da bacia hidrográfica do rio Atibaia

\begin{tabular}{|c|c|c|c|c|c|c|c|c|c|c|c|c|}
\hline \multirow{2}{*}{$\begin{array}{c}\text { Sub-bacias } \\
\text { Usos } \\
\end{array}$} & \multicolumn{3}{|c|}{$\begin{array}{c}\text { Montante } \\
\text { Montante da EH } 3006 \\
\end{array}$} & \multicolumn{3}{|c|}{$\begin{array}{c}\text { Intermédia Superior } \\
\text { Montante da EH } 3007 \text { e } \\
\text { jusante da EH } 3006\end{array}$} & \multicolumn{3}{|c|}{$\begin{array}{c}\text { Intermédia Inferior } \\
\text { Montante da EH } 3003 \text { e } \\
\text { jusante da EH } 3007\end{array}$} & \multicolumn{3}{|c|}{$\begin{array}{c}\text { Jusante } \\
\text { Montante da EH } 4009 \text { e } \\
\text { jusante da EH } 3003\end{array}$} \\
\hline & $\begin{array}{c}\text { Cenário } \\
\text { I }\end{array}$ & $\begin{array}{c}\text { Cenário } \\
\text { II }\end{array}$ & $\begin{array}{c}\text { Cenário } \\
\text { III }\end{array}$ & $\begin{array}{c}\text { Cenário } \\
\text { I }\end{array}$ & $\begin{array}{c}\text { Cenário } \\
\text { II }\end{array}$ & $\begin{array}{c}\text { Cenário } \\
\text { III }\end{array}$ & \begin{tabular}{|c|} 
Cenário \\
I
\end{tabular} & $\begin{array}{c}\text { Cenário } \\
\text { II } \\
\end{array}$ & $\begin{array}{c}\text { Cenário } \\
\text { III }\end{array}$ & $\begin{array}{c}\text { Cenário } \\
\text { I }\end{array}$ & $\begin{array}{c}\text { Cenário } \\
\text { II }\end{array}$ & $\begin{array}{c}\text { Cenário } \\
\text { III }\end{array}$ \\
\hline $\begin{array}{c}\text { Área } \\
\text { urbana }\end{array}$ & 222,08 & $\begin{array}{c}254,66 \\
(15 \%)\end{array}$ & $\begin{array}{l}254,66 \\
(15 \%)\end{array}$ & 34,35 & $\begin{array}{l}57,74 \\
(68 \%) \\
\end{array}$ & $\begin{array}{l}57,74 \\
(68 \%) \\
\end{array}$ & 99,54 & $\begin{array}{l}118,36 \\
(19 \%)\end{array}$ & $\begin{array}{c}118,36 \\
(19 \% \%) \\
\end{array}$ & 127,32 & $\begin{array}{l}149,02 \\
(17 \%)\end{array}$ & $\begin{array}{l}149,02 \\
(17 \%) \\
\end{array}$ \\
\hline $\begin{array}{l}\text { Cana de } \\
\text { açúcar }\end{array}$ & 1,92 & $\begin{array}{c}160,05 \\
(8236 \%) \\
\end{array}$ & $\begin{array}{l}1,92 \\
(0 \%) \\
\end{array}$ & 2,04 & $\begin{array}{c}47,04 \\
(2206 \%) \\
\end{array}$ & $\begin{array}{l}2,04 \\
(0 \%) \\
\end{array}$ & 1,32 & $\begin{array}{c}53,67 \\
(3966 \%) \\
\end{array}$ & $\begin{array}{r}1,32 \\
(0 \%) \\
\end{array}$ & 35,21 & $\begin{array}{l}48,32 \\
(37 \%) \\
\end{array}$ & $\begin{array}{l}35,21 \\
(0 \%) \\
\end{array}$ \\
\hline Água & 33,83 & $\begin{array}{l}33,83 \\
(0 \%)\end{array}$ & $\begin{array}{l}33,83 \\
(0 \%)\end{array}$ & 1,94 & $\begin{array}{l}1,94 \\
(0 \%)\end{array}$ & $\begin{array}{l}1,94 \\
(0 \%)\end{array}$ & 2,92 & $\begin{array}{l}2,92 \\
(0 \%)\end{array}$ & $\begin{array}{l}2,92 \\
(0 \%)\end{array}$ & 15,28 & $\begin{array}{l}15,28 \\
(0 \%)\end{array}$ & $\begin{array}{l}15,28 \\
(0 \%)\end{array}$ \\
\hline
\end{tabular}


Conclusão

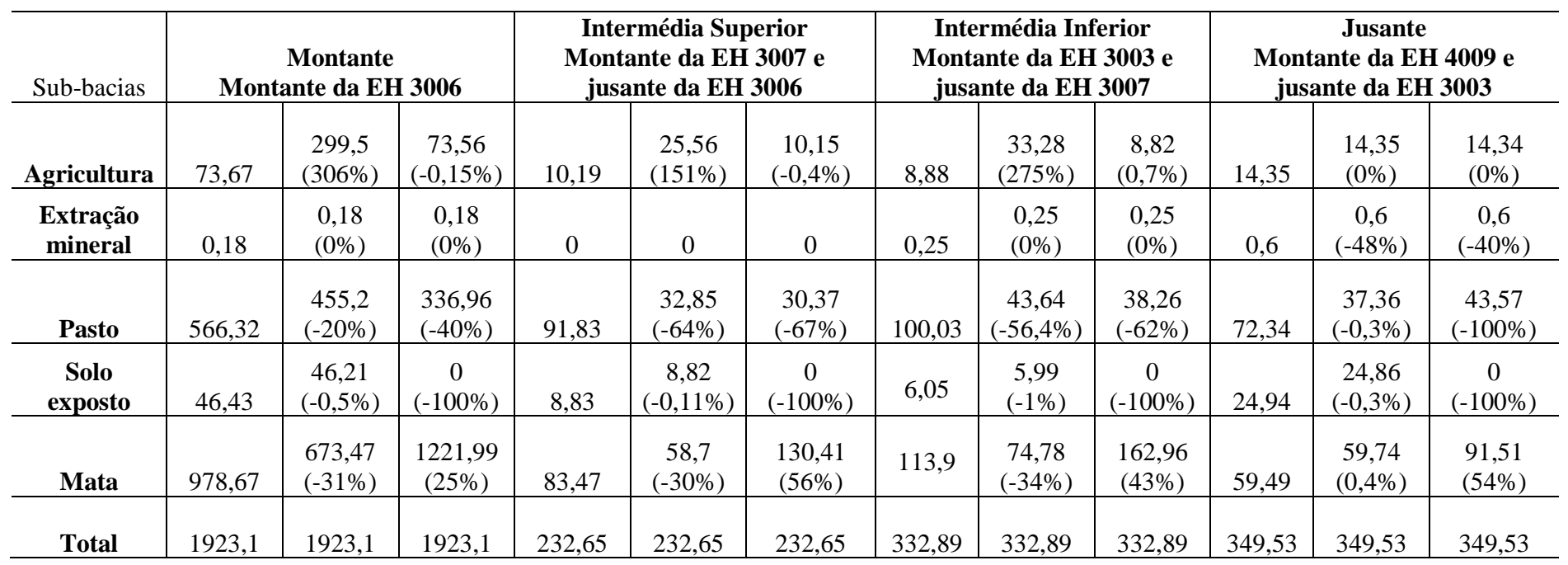

Fonte: Próprio autor

Os mapas de uso e ocupação do solo elaborados para cada um dos cenários foram utilizados para calcular os valores de $\mathrm{CN}$ das bacias hidrográficas e suas sub-bacias. Os valores de $\mathrm{CN}$ atribuídos a cada bacia são iguais em ambos os modelos. Os valores foram calculados pelo SWAT por aplicação das tabelas propostas pelo SCS, e afetados pelo coeficiente de redução resultante da calibração de ambos os modelos. Na tabela 23 são apresentados os valores originais de $\mathrm{CN}$ calculados para cada cenário e os considerados depois de afetados pela redução. A redução do $\mathrm{CN}$ na bacia hidrográfica do Jacaré-Guaçu é inferior a $1 \%$ para o cenário II e varia entre 3\% e 5\% para o cenário III. Na bacia hidrográfica do rio Atibaia, os cenários apontam para uma variação mista, com aumentos do CN nas subbacias intermédia inferior e de jusante de $23 \%$ e $9 \%$ para o cenário II e de $16 \%$ e $3 \%$ para o cenário III, e reduções nas duas sub-bacias de montante da ordem de $15 \%$ para o cenário II e de $40 \%$ para o cenário III.

Tabela 23 - Valores de CN atribuídos para cada cenário

\begin{tabular}{c|c|c|c|c|c|c|c|c}
\hline \multirow{2}{*}{$\begin{array}{c}\text { Bacia } \\
\text { hidrográfica }\end{array}$} & Sub-Bacias & \multirow{2}{*}{ Área } & \multicolumn{2}{c|}{ Cenário I } & \multicolumn{2}{c|}{ Cenário II } & \multicolumn{2}{c}{ Cenário III } \\
\cline { 3 - 9 } & & & $\mathbf{C N}$ & $\mathbf{C N} *$ & $\mathbf{C N}$ & $\mathbf{C N} *$ & $\mathbf{C N}$ & $\mathbf{C N}^{*}$ \\
\hline \multirow{3}{*}{ Jacaré-Guaçu } & Montante & 230,09 & 80 & 45 & 79 & 46 & 78 & 43 \\
\cline { 2 - 9 } & Intermédia & 567,98 & 79 & 65 & 79 & 66 & 77 & 63 \\
\cline { 2 - 9 } & Jusante & 1136,2 & 73 & 42 & 73 & 43 & 72 & 41 \\
\hline \multirow{4}{*}{ Atibaia } & Montante 3006 & 1923,10 & 70 & 45 & 59 & 54 & 50 & 44 \\
\cline { 2 - 9 } & Intermédia superior 3007 & 232,65 & 75 & 55 & 64 & 52 & 55 & 43 \\
\cline { 2 - 9 } & Intermédia inferior 3003 & 332,89 & 62 & 50 & 76 & 56 & 70 & 49 \\
\cline { 2 - 9 } & Jusante & 349,53 & 65 & 60 & 71 & 62 & 67 & 42 \\
\hline
\end{tabular}

Fonte: Próprio autor 
A consideração dos novos mapas de uso e ocupação do solo nos modelos resultou na modificação já discutida dos valores do parâmetro CN. Além desta alteração, a importação dos novos cenários de uso do solo pelo modelo SWAT resulta no cálculo de um novo conjunto de unidades de resposta hidrológica (HRUs) (tabela 24), a quem são atribuídos novos valores dos parâmetros relacionados com a retenção à superfície (CANMX e ESCO), calculados a partir do uso de solo identificado em cada HRU. A produção de sedimentos é calculada pela MUSLE que inclui o fator $\mathrm{C}$, relacionado com o uso e ocupação do solo. $\mathrm{O}$ valor atribuído a este fator é alterado de acordo com o novo uso do solo. Pela mesma razão altera-se o parâmetro LAT_SED (Concentração de sedimentos no fluxo lateral e no fluxo de águas subterrâneas), dependente dos usos de cada HRU recalculada. Para a simulação da concentração de contaminantes o parâmetro EROGN (Relação de enriquecimento de N orgânico) também é alterado conforme os novos usos atribuídos a cada HRU.

\begin{tabular}{c|c|c|c} 
Tabela $24-$ Número de HRU determinadas para cada cenário \\
$\begin{array}{c}\text { Bacia } \\
\text { hidrográfica }\end{array}$ & Cenário I & Cenário II & Cenário III \\
\cline { 2 - 4 } & \multicolumn{3}{|c}{$\mathbf{N}^{\mathbf{0}}$ de HRUs } \\
\hline Jacaré-Guaçu & 1144 & 1137 & 1167 \\
\hline Atibaia & 1117 & 2465 & 1784 \\
\hline
\end{tabular}

Fonte: Próprio autor

No modelo GWLF, a produção de sedimentos é calculada pela EUPS que também inclui o fator $\mathrm{C}$, relacionado com o uso e ocupação do solo. No cenário II o valor atribuído a este fator foi diminuído de 0,8 (cenário I) para 0,6 , uma redução de $20 \%$ resultante do aumento das áreas urbanas e da diminuição das áreas de florestas. No cenário III este fator teve um aumento de 10\% (para 0,9), associado com o solo estar mais protegido nos eventos de chuva (aumento das áreas de florestas). No cálculo das cargas de contaminantes, alteraramse os valores da concentração de nitrogênio e de fósforo dissolvido das águas provenientes de áreas rurais e de nitrogênio e de fósforo sólido das águas provenientes de áreas urbanas. De acordo com as equações 53 e 55 estes valores estão diretamente relacionados com as áreas dos diferentes tipos de usos e ocupações existentes e com os valores de contaminantes dissolvidos em áreas rurais (tabela 9).

A vazão, a produção de sedimentos e as cargas de nutrientes são modificadas com a alteração do uso e cobertura do solo. $\mathrm{O}$ aumento da área urbana e a diminuição das áreas de florestas previsto no cenário II, reduz a água infiltrada no solo e aumenta o escoamento superficial aumenta. Com esta alteração, os sedimentos e contaminantes provenientes, por exemplo de áreas urbanas e agrícolas, são carregados mais rapidamente para os cursos de água. No cenário III, o aumento das áreas de florestas e a diminuição de áreas com solo 
exposto, aumenta a quantidade de água interceptada pelos galhos e folhas em eventos de chuva o que atenua escoamento superficial. A afluência de sedimentos e de contaminantes para os cursos de água ocorre de maneira mais lenta. A continuação deste capítulo procura quantificar estes impactos.

\subsubsection{Impactos na vazão}

As figuras 69 e 77 apresentam os gráficos com os valores mensais médios da vazão diária gerada em cada sub-bacia, para cada um dos três cenários. A vazão apresenta uma pequena variação entre o cenário I (atual) e os cenários II e III que é mais facilmente verificada através dos gráficos das figuras 76 a 82 que apresentam a porcentagem de variação da média mensal da vazão em relação ao cenário atual. Os períodos simulados para cada cenário abrangem os anos de 1990 a 2013 para a bacia hidrográfica do rio Jacaré Guaçu, e os anos de 1990 a 2016 para a bacia hidrográfica do rio Atibaia.

As alterações da vazão previstas para cada um dos cenários de alteração são diminutas, sendo que, em geral, estas alterações são ligeiramente maiores na bacia hidrográfica do rio Atibaia do que na bacia hidrográfica do rio Jacaré-Guaçu. Estas diferenças relativas seriam de esperar tendo em conta a menor alteração do uso de solo, em termos de percentagem de área total, cenarizada para a bacia hidrográfica do rio Jacaré-Guaçu quando comparada com a do rio Atibaia.

$\mathrm{Na}$ bacia hidrográfica do rio Jacaré-Guaçu o modelo SCS-CN prevê um pequeno aumento da vazão nos picos do hidrograma, para a maioria das sub-bacias, principalmente no cenário II. Estes aumentos resultam da expansão da área urbana e da diminuição das áreas de florestas, e do consequente aumento do escoamento superficial das águas nos eventos chuvosos e da aceleração da contribuição das águas para os cursos de água. Note-se que estes aumentos ocorrem, apesar da ligeira redução do $\mathrm{CN}$ que é praticamente nula para o cenário II.

$\mathrm{Na}$ bacia hidrográfica do rio Atibaia, ambos os modelos preveem um aumento quase generalizado das vazões de pico, sobretudo para o cenário II, sendo que o SWAT também o prevê para os valores mais baixos do hidrograma. A exceção são simulações do SCS-CN para a bacia intermédia superior (3007), onde se observa alguma redução da vazão de pico. Recorde-se que os cenários de alteração do uso do solo resultaram em aumentos do CN nas duas sub-bacias montante e reduções nas duas sub-bacias de jusante. 
Figura 69 - Simulação dos cenários de vazão pelos modelos SWAT e SCS-CN para cada sub-bacia 62760005 da bacia hidrográfica do rio Jacaré-Guaçu

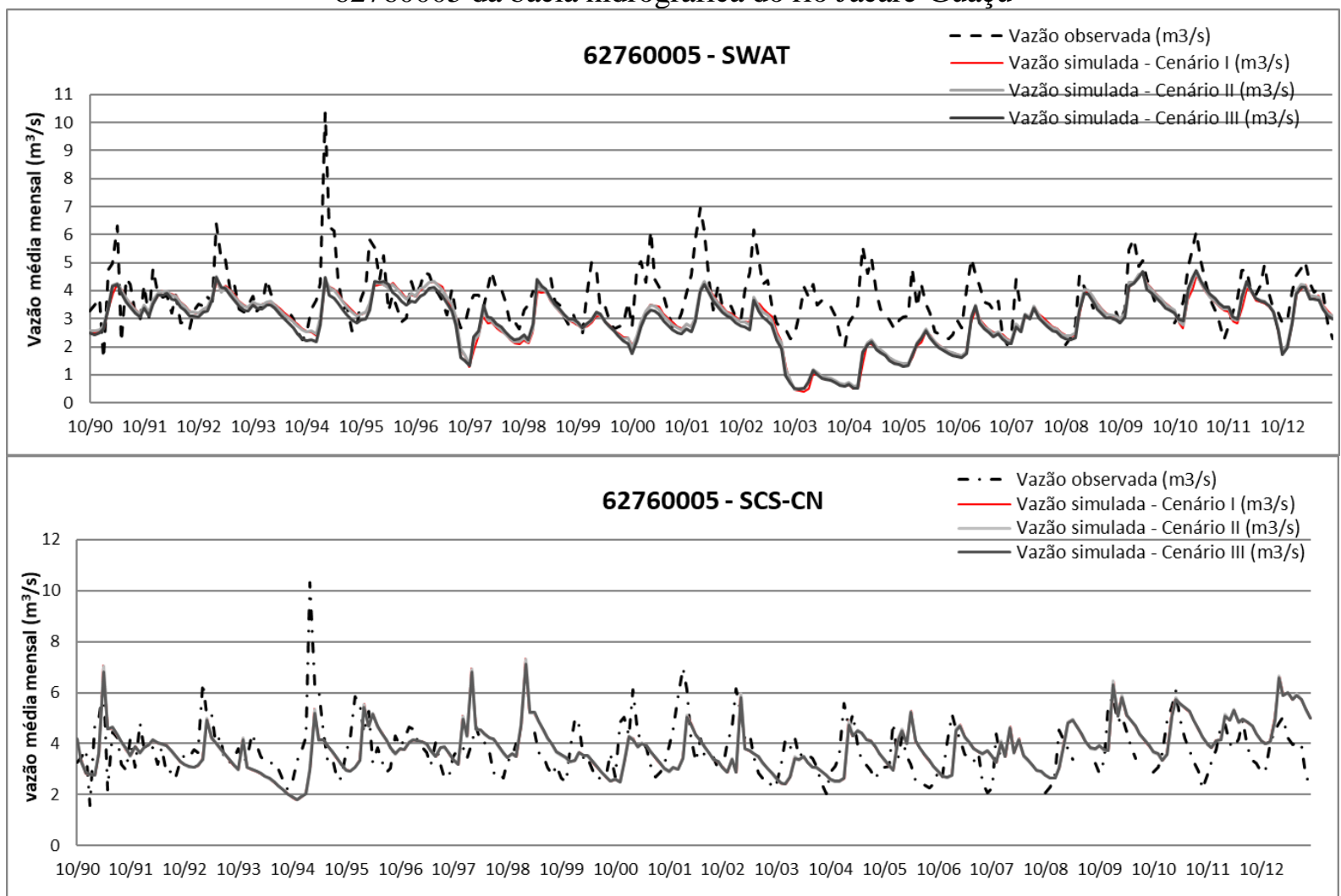

Fonte: Próprio autor

Figura 70 - Simulação dos cenários de vazão pelos modelos SWAT e SCS-CN para cada sub-bacia 62767500 da bacia hidrográfica do rio Jacaré-Guaçu

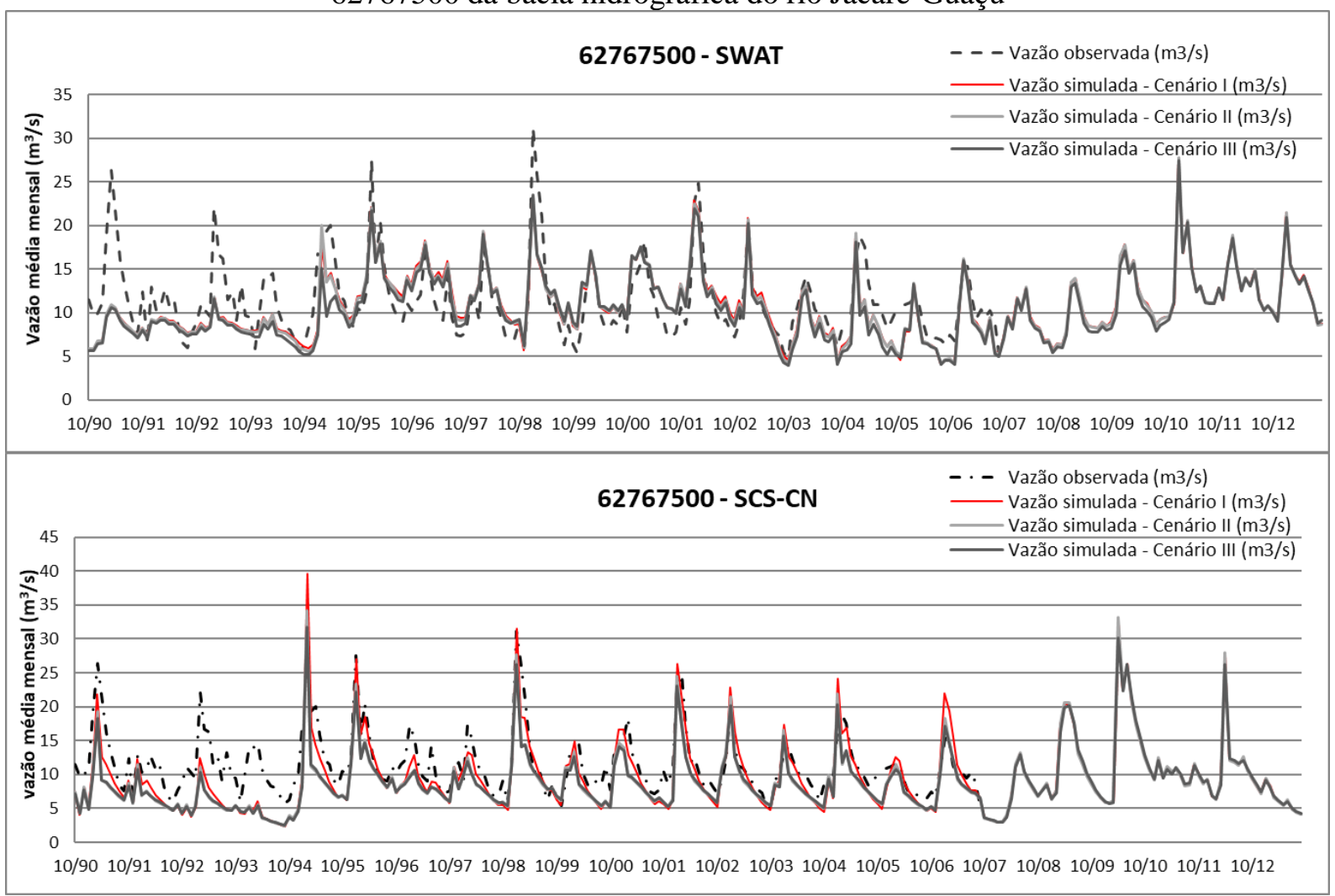

Fonte: Próprio autor 
Figura 71 - Simulação dos cenários de vazão pelos modelos SWAT e SCS-CN para cada sub-bacia 62772500 da bacia hidrográfica do rio Jacaré-Guaçu

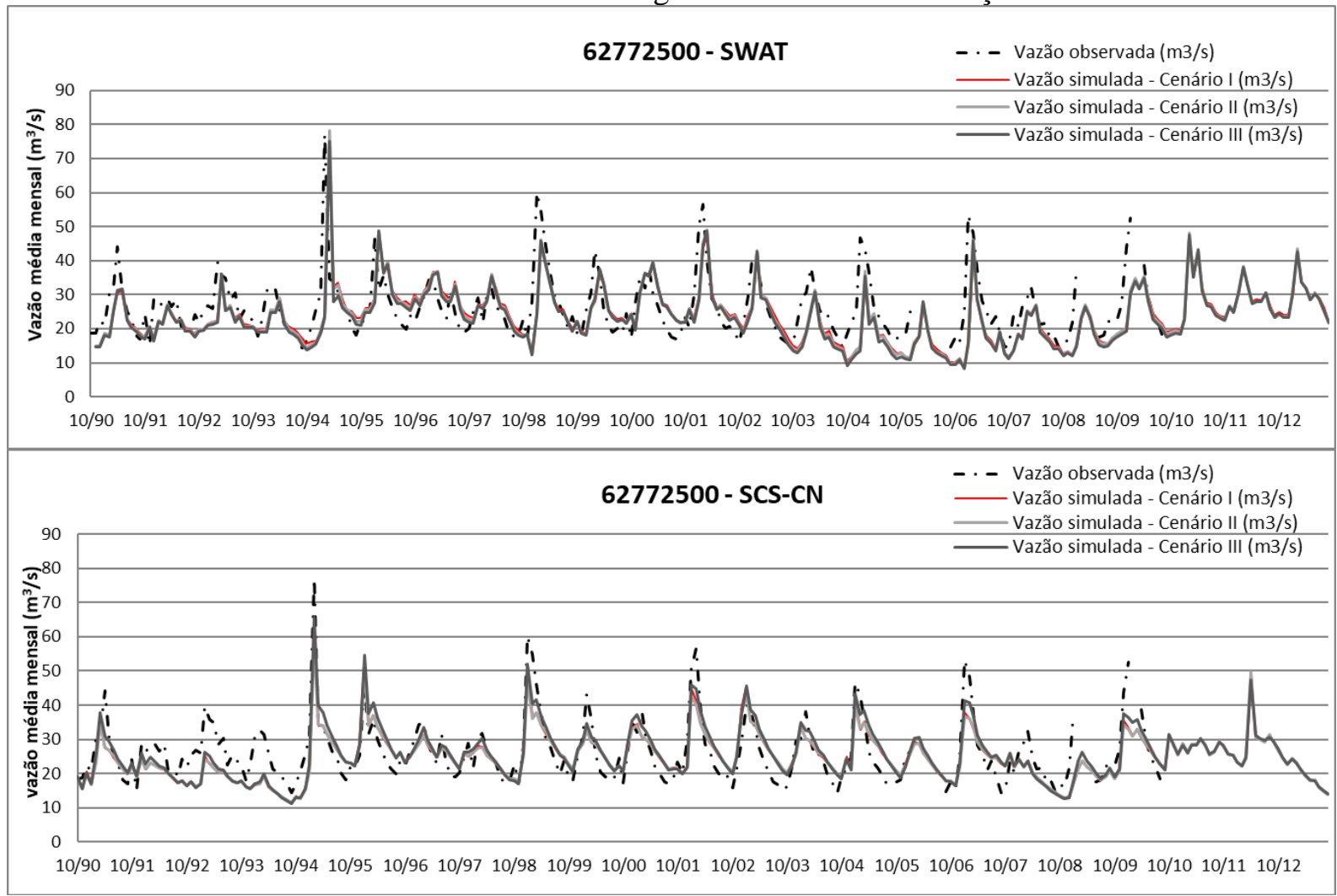

Fonte: Próprio autor

Figura 72 - Simulação dos cenários de vazão pelos modelos SWAT e SCS-CN para sub-bacia 3006 da bacia hidrográfica do rio Atibaia

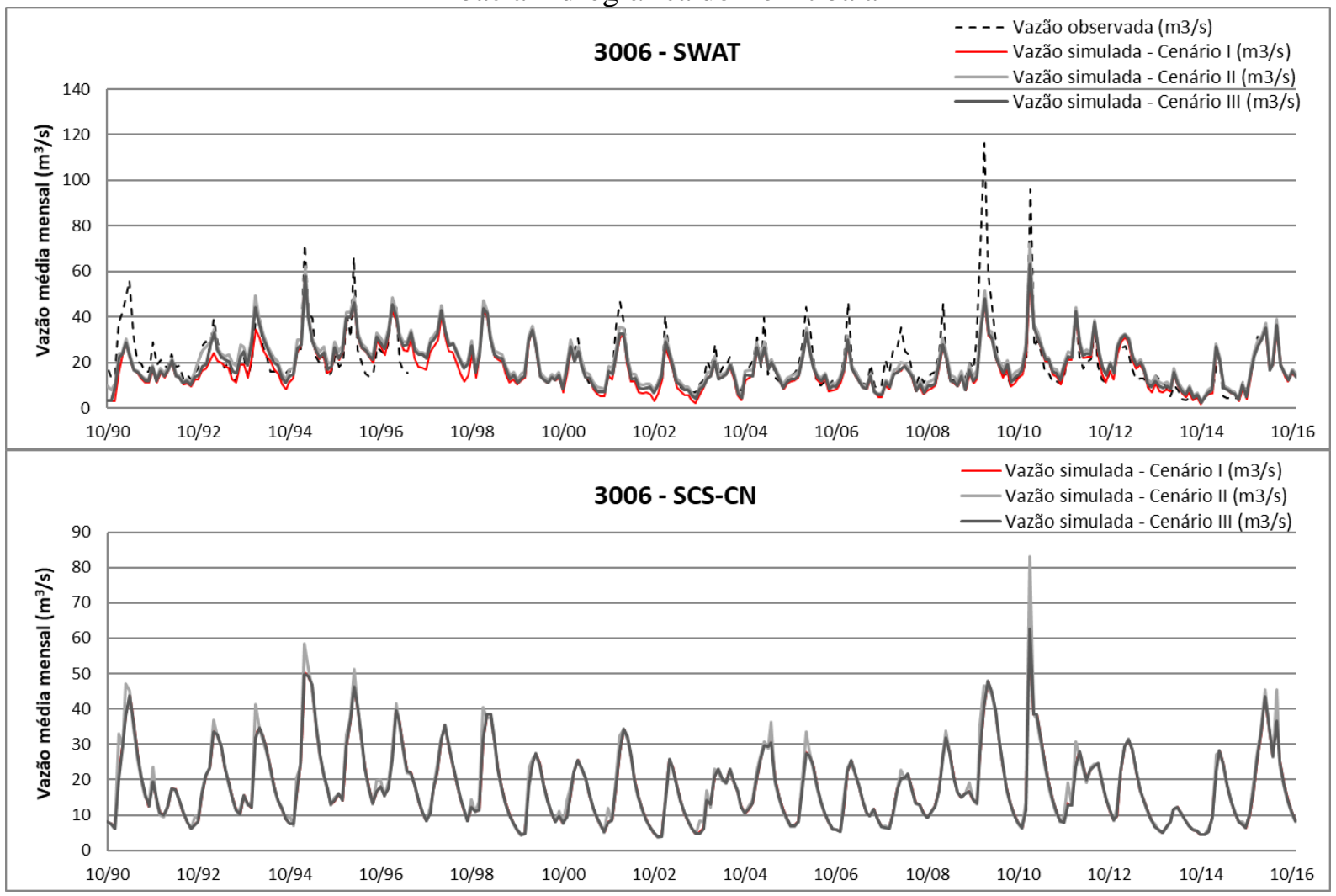

Fonte: Próprio autor 
Figura 73 - Simulação dos cenários de vazão pelos modelos SWAT e SCS-CN para sub-bacia 3007 da bacia hidrográfica do rio Atibaia

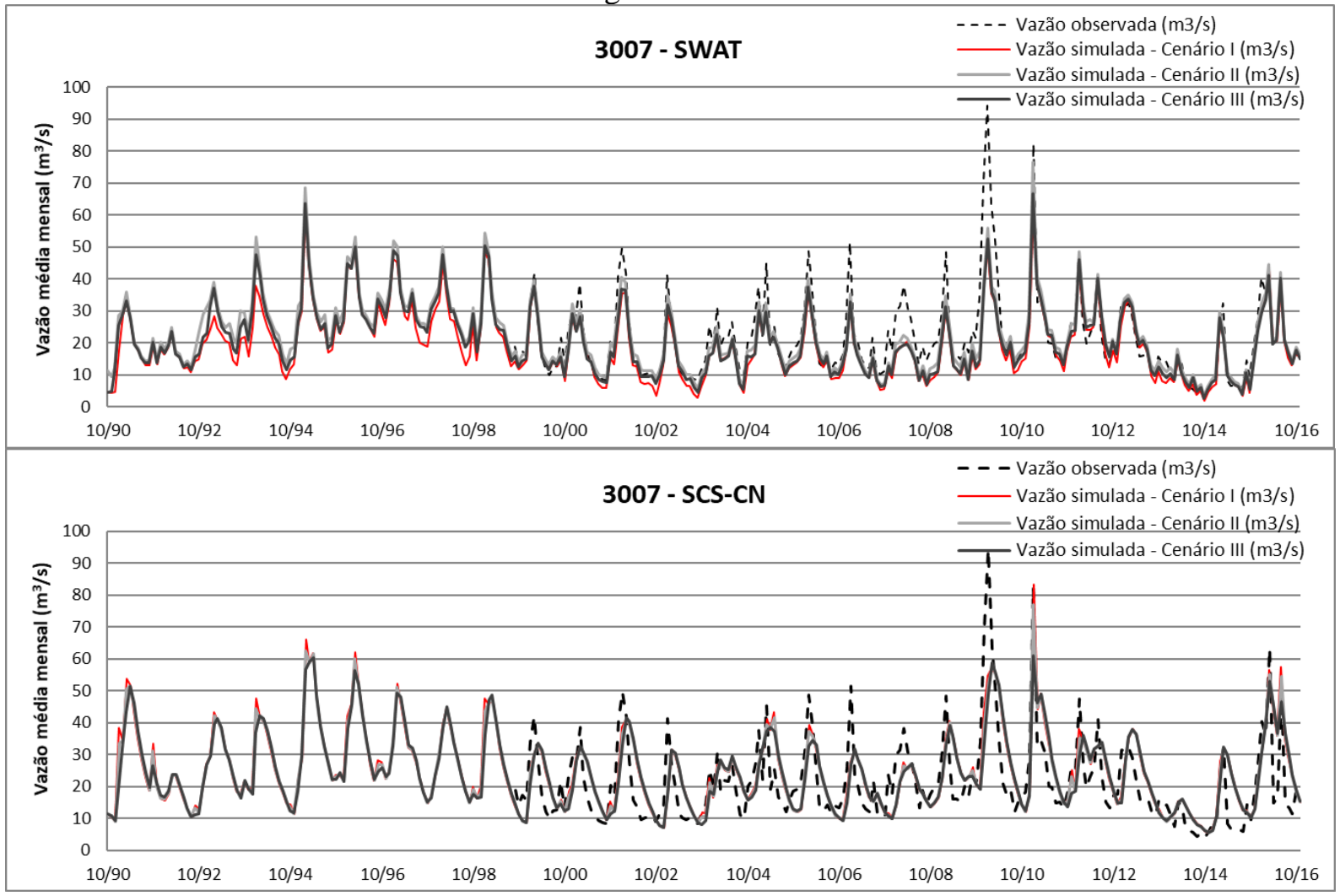

Fonte: Próprio autor

Figura 74 - Simulação dos cenários de vazão pelos modelos SWAT e SCS-CN para sub-bacia 3003 da bacia hidrográfica do rio Atibaia

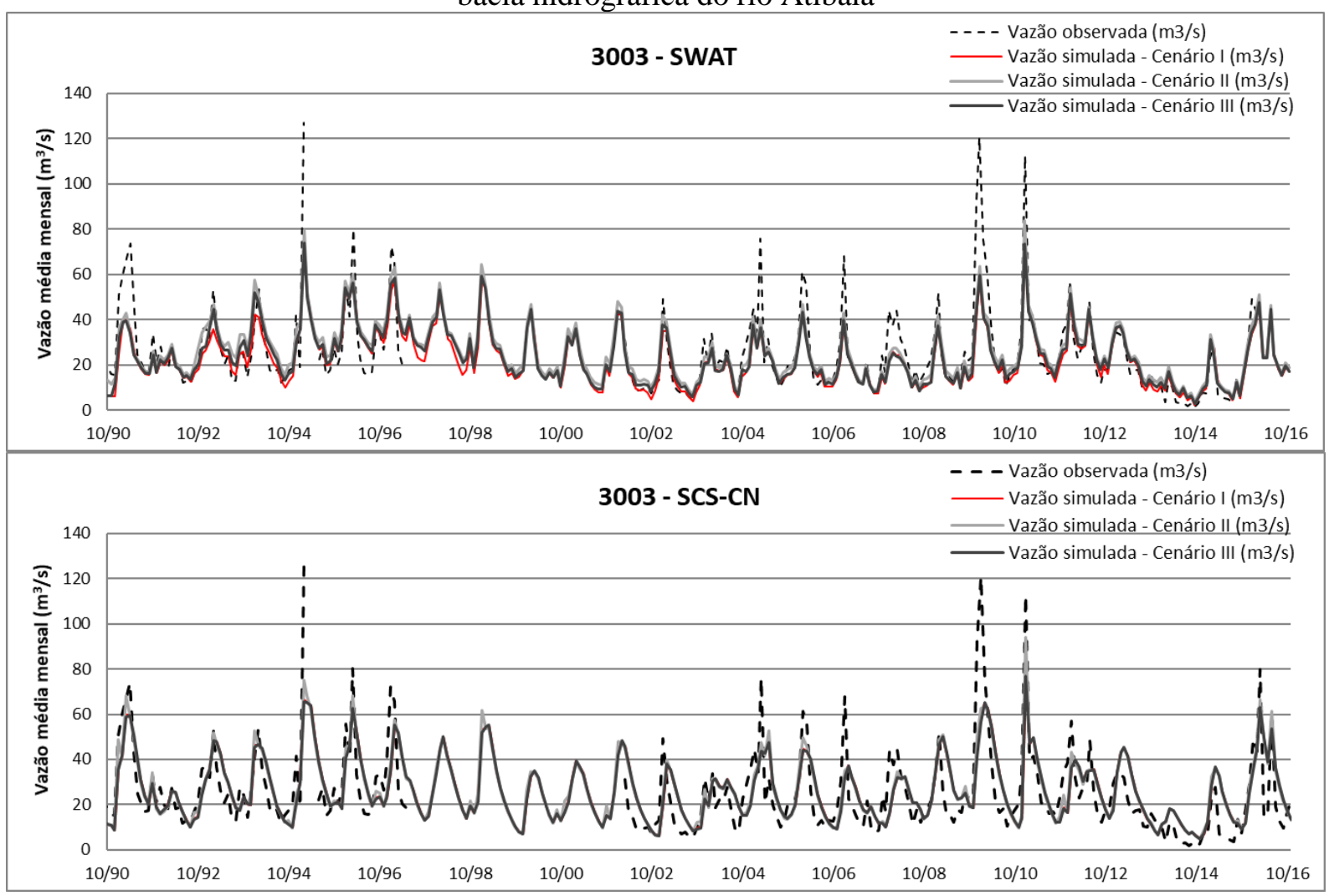

Fonte: Próprio autor 
Figura 75 - Simulação dos cenários de vazão pelos modelos SWAT e SCS-CN para sub-bacia 4009 da bacia hidrográfica do rio Atibaia

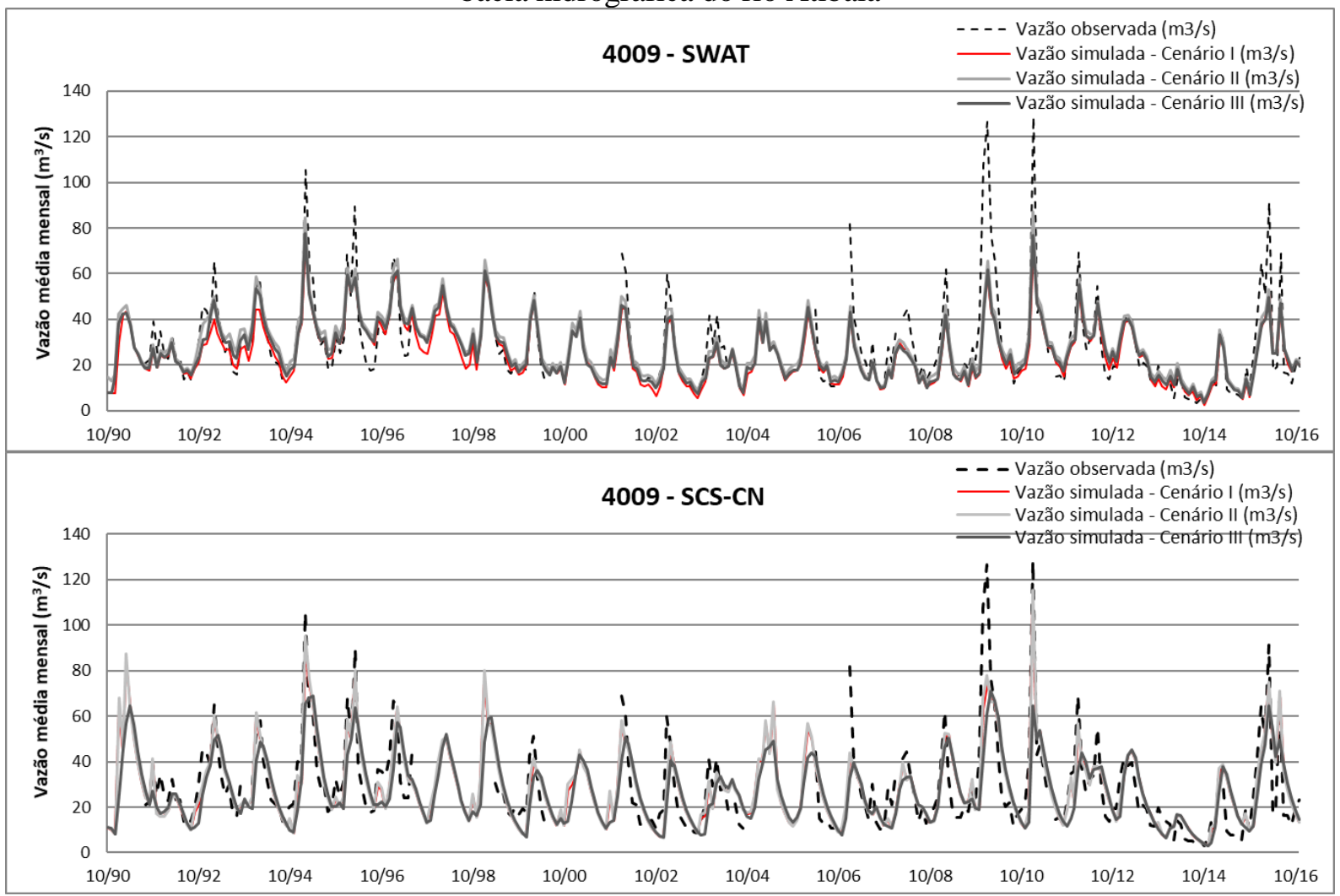

Fonte: Próprio autor 
Figura 76 - Porcentagem de variação da média mensal da vazão em relação ao cenário atual, calculada pelos modelos SWAT e SCS-CN para a sub-bacia 62760005 da bacia hidrográfica do rio Jacaré-

Guaçu

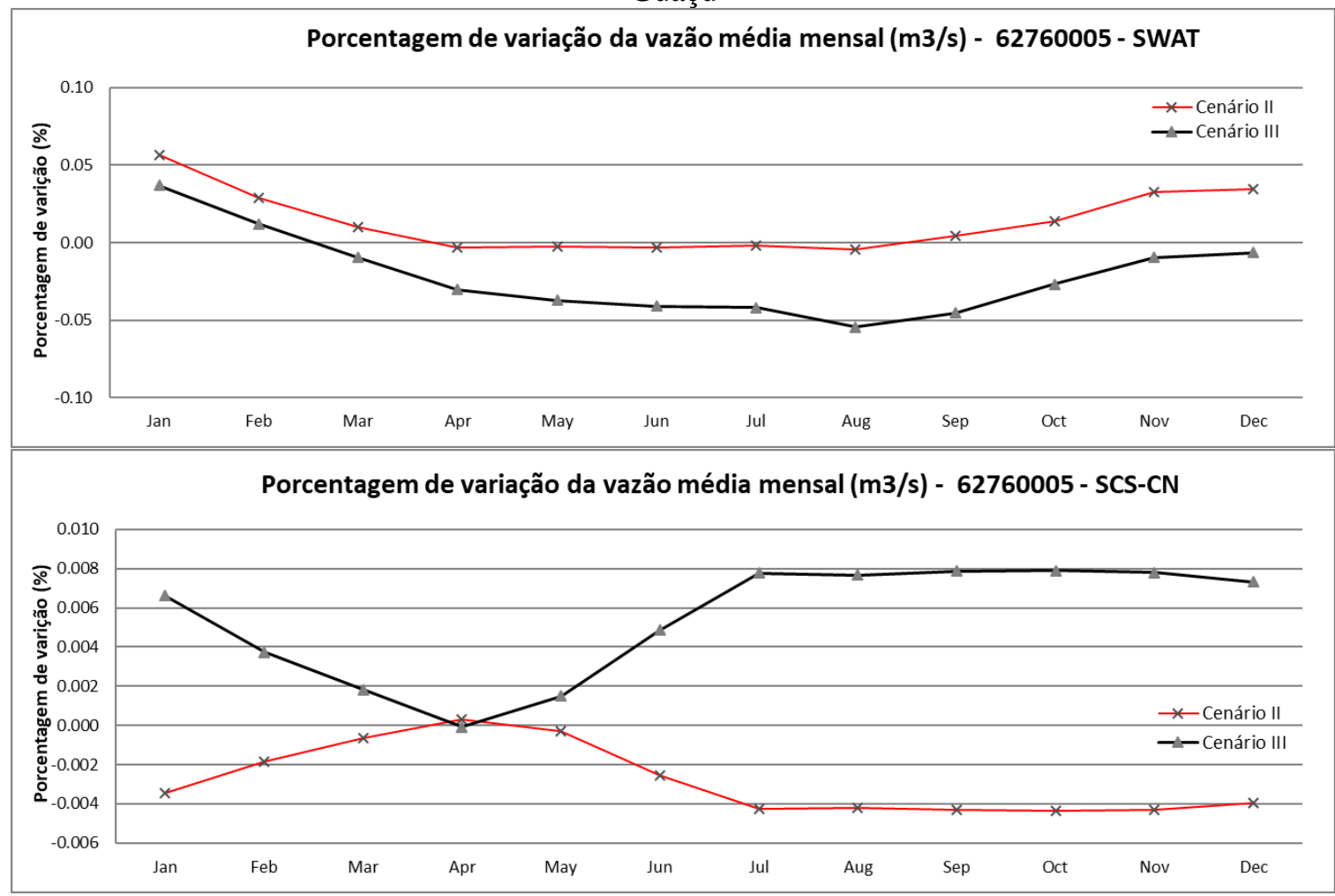

Fonte: Próprio autor

Figura 77 - Porcentagem de variação da média mensal da vazão em relação ao cenário atual, calculada pelos modelos SWAT e SCS-CN para a sub-bacia 62767500 da bacia hidrográfica do rio Jacaré-

Guaçu

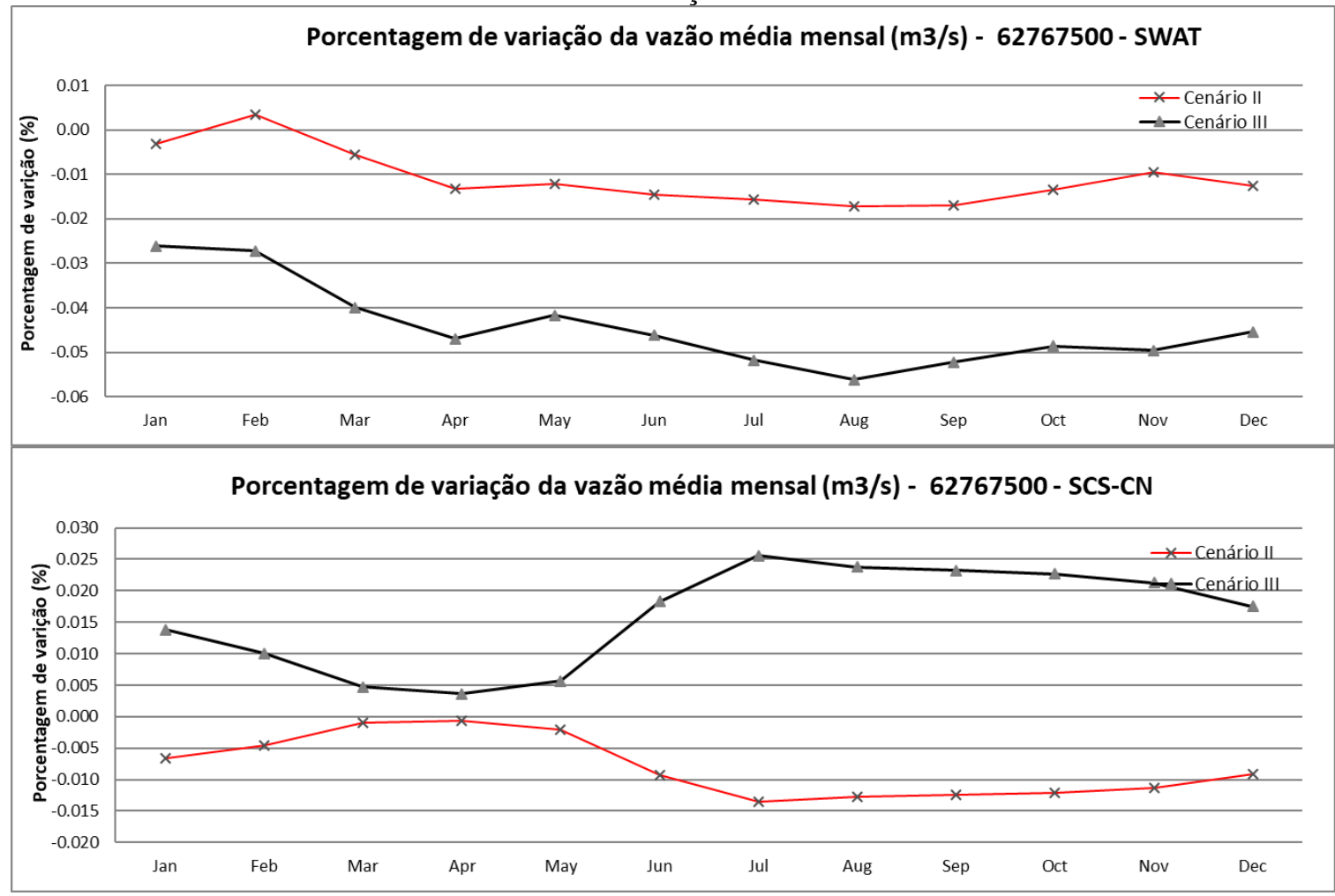

Fonte: Próprio autor 
Figura 78 - Porcentagem de variação da média mensal da vazão em relação ao cenário atual, calculada pelos modelos SWAT e SCS-CN para a sub-bacia 62772500 da bacia hidrográfica do rio Jacaré-

Guaçu

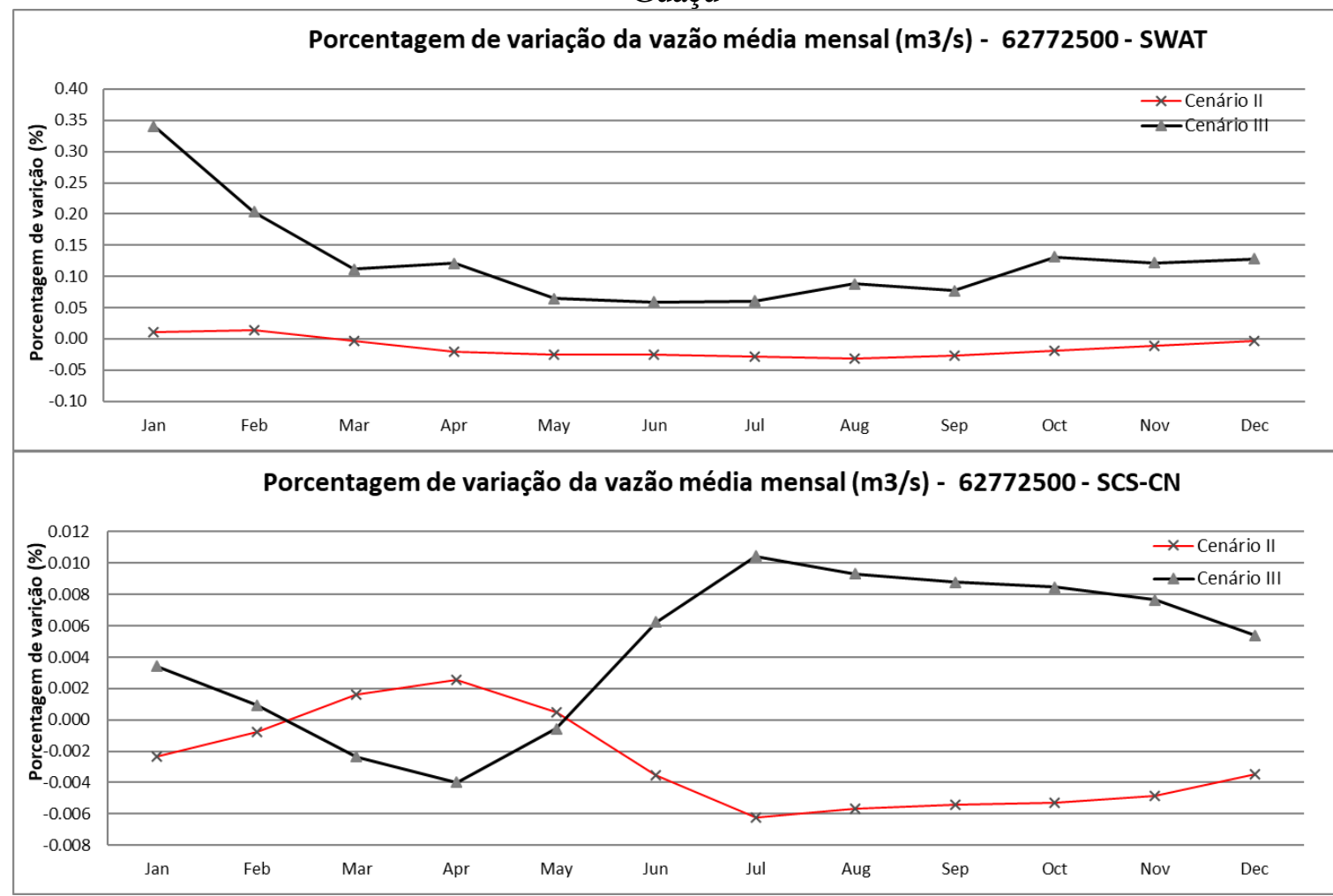

Fonte: Próprio autor

Figura 79 - Porcentagem de variação da média mensal da vazão em relação ao cenário atual, calculada pelos modelos SWAT e SCS-CN para a sub-bacia 3006 da bacia hidrográfica do rio Atibaia

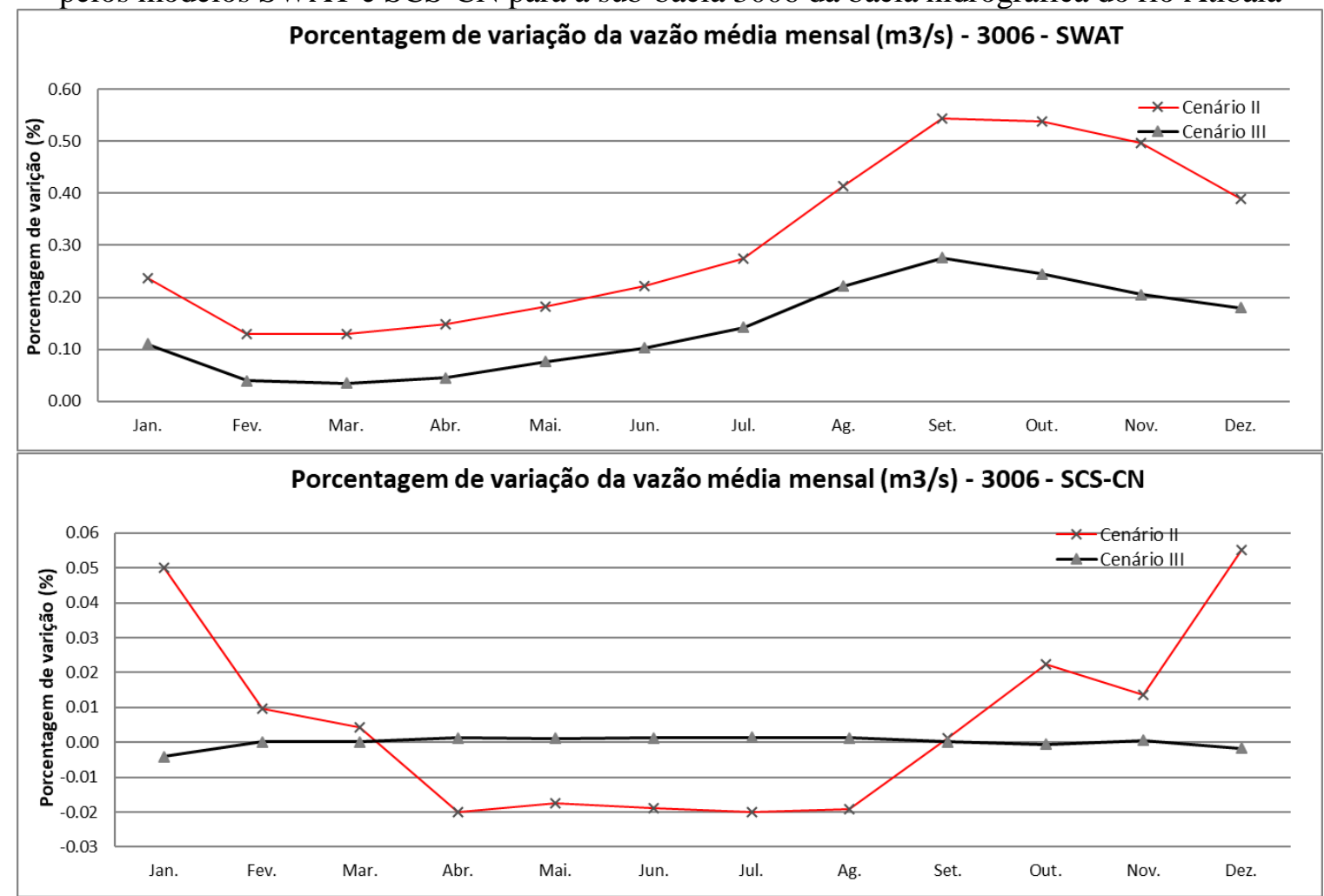

Fonte: Próprio autor 
Figura 80 - Porcentagem de variação da média mensal da vazão em relação ao cenário atual, calculada pelos modelos SWAT e SCS-CN para a sub-bacia 3007 da bacia hidrográfica do rio Atibaia

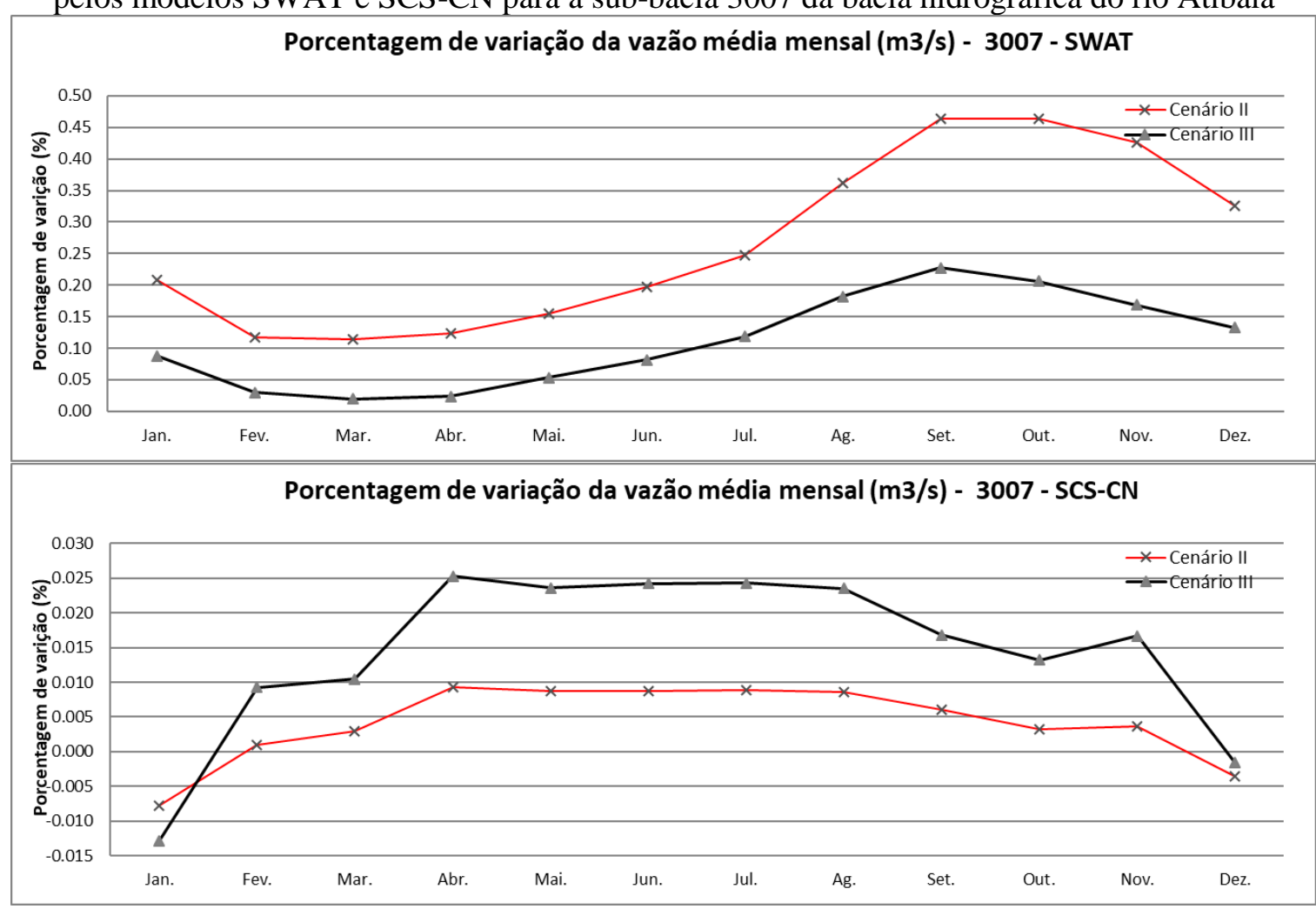

Fonte: Próprio autor

Figura 81 - Porcentagem de variação da média mensal da vazão em relação ao cenário atual, calculada pelos modelos SWAT e SCS-CN para a sub-bacia 3003 da bacia hidrográfica do rio Atibaia

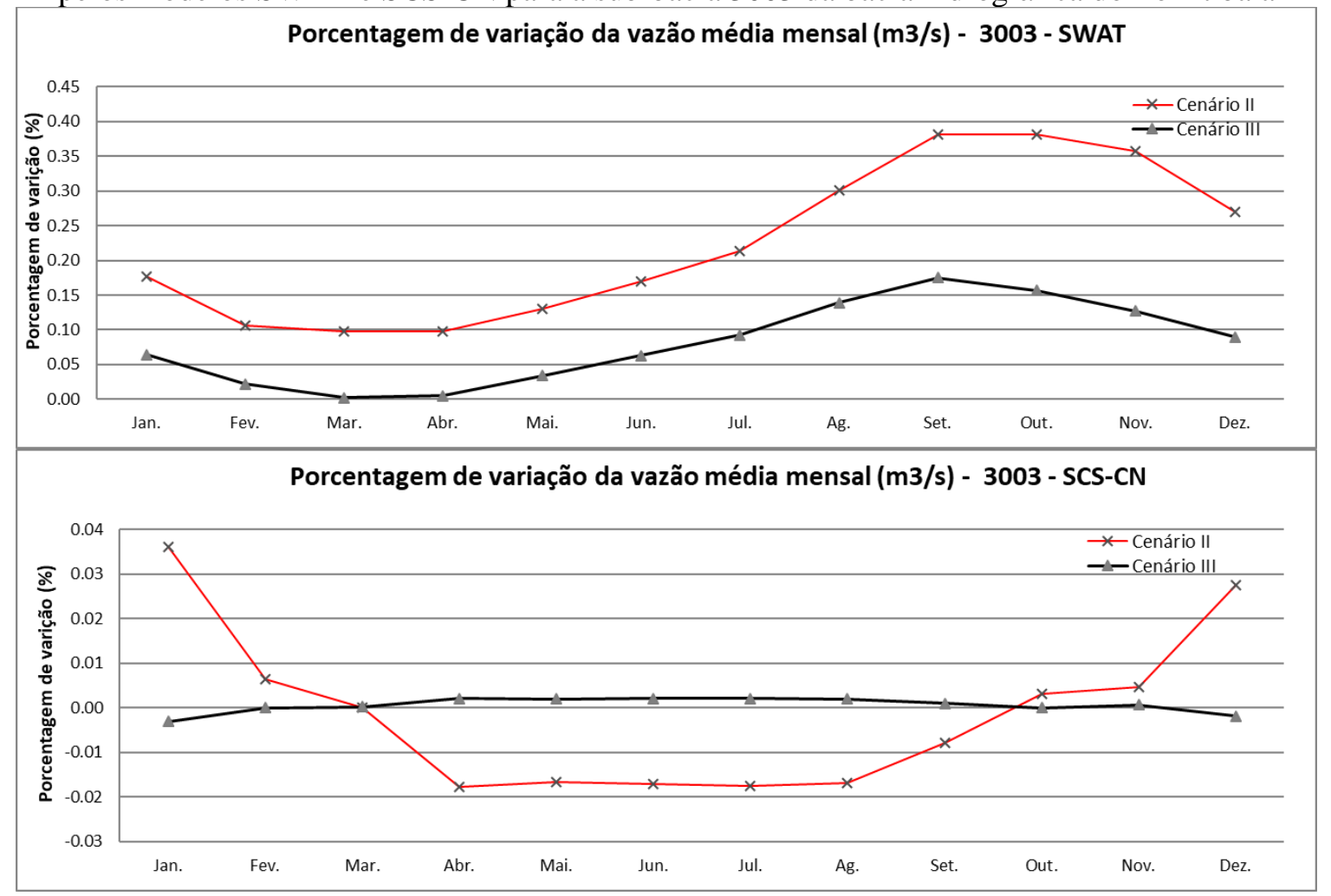

Fonte: Próprio autor 
Figura 82 - Porcentagem de variação da média mensal da vazão em relação ao cenário atual, calculada pelos modelos SWAT e SCS-CN para a sub-bacia 4009 da bacia hidrográfica do rio Atibaia

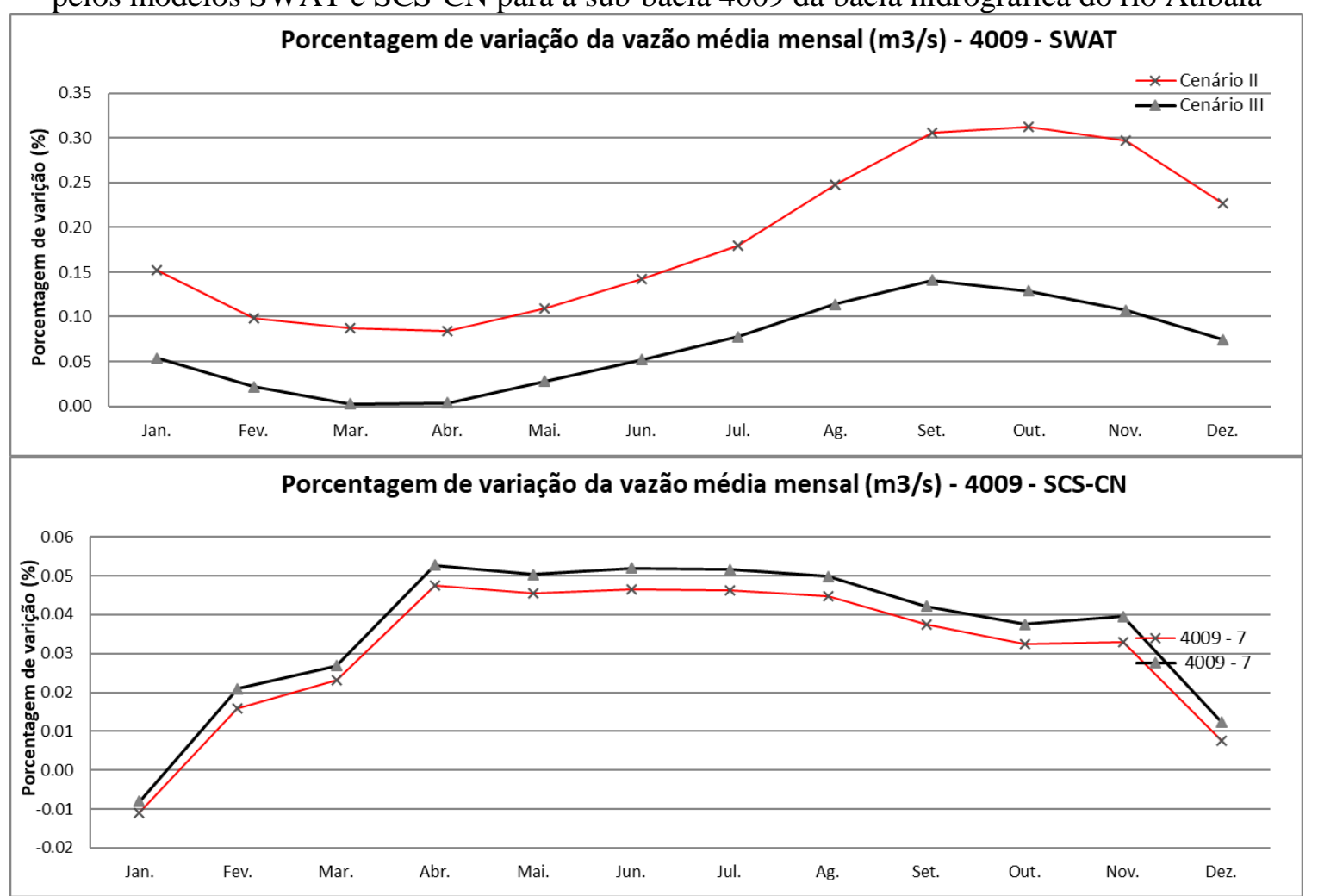

Fonte: Próprio autor

A tabela 25 compara a variação da média diária da vazão para os dois cenários de alteração do uso do solo em relação ao cenário atual. Os dados mostram que os resultados dos dois modelos são em regra consistentes entre si, apontando para uma variação da vazão média muito reduzida.

Na estação de jusante da bacia hidrográfica do rio Jacaré-Guaçu, o SWAT antecipa uma redução da vazão média de $-0,01 \%$ e $-0,04 \%$ para os cenários II e III, enquanto que o SCS-CN não aponta variação nos cenários. Para a estação de jusante da bacia do rio Atibaia, o SWAT antecipa um aumento da vazão média de 0,19\% e 0,07\% para os cenários II e III, e no modelo SCS-CN esse aumento é de $0,03 \%$ no cenário II e 0,04\% no cenário III. É interessante verificar que ambos os modelos sugerem um aumento da vazão média nas sub-bacias de montante que depois é atenuado ou mesmo eliminado com a redução da vazão nas sub-bacias de jusante.

A figuras 83 e 84 apresentam os gráficos da curva de duração média (curva de permanência) da vazão diária para cada sub-bacia, para cada um dos três cenários. As variações na vazão ocorrem principalmente nas simulações do modelo SWAT. No modelo SCS-CN a variação na vazão ocorre em geral nos valores mais elevados. 
Tabela 25 - Gráfico de variação da média diária da vazão para os cenários II e III

\begin{tabular}{|c|c|c|c|c|c|}
\hline & & & Cenário I & Cenário II & Cenário III \\
\hline Bacia & Sub-bacia & Modelo & $\begin{array}{c}\text { Vazão média } \\
\text { diária } \\
\left(\mathrm{m}^{3} / \mathrm{s}\right)\end{array}$ & $\begin{array}{l}\text { Porcentagem de } \\
\text { variação da } \\
\text { vazão média } \\
\text { diária } \\
(\%) \\
\end{array}$ & $\begin{array}{l}\text { Porcentagem } \\
\text { de variação da } \\
\text { vazão média } \\
\text { diária } \\
(\%) \\
\end{array}$ \\
\hline \multirow{6}{*}{$\begin{array}{l}\text { Jacaré- } \\
\text { Guaçu }\end{array}$} & \multirow{2}{*}{62760005} & SWAT & 2,98 & 0,01 & $-0,02$ \\
\hline & & SCS-CN & 3,86 & 0,00 & 0,01 \\
\hline & \multirow{2}{*}{62767500} & SWAT & 10,62 & $-0,01$ & $-0,04$ \\
\hline & & SCS-CN & 9,91 & $-0,01$ & 0,02 \\
\hline & \multirow{2}{*}{62772500} & SWAT & 23,46 & $-0,01$ & $-0,04$ \\
\hline & & SCS-CN & 26,31 & 0,00 & 0,00 \\
\hline \multirow{8}{*}{ Atibaia } & \multirow{2}{*}{3006} & SWAT & 17,18 & 0,31 & 0,14 \\
\hline & & SCS-CN & 18,36 & 0,02 & 0,00 \\
\hline & \multirow{2}{*}{3007} & SWAT & 19,08 & 0,27 & 0,11 \\
\hline & & SCS-CN & 25,51 & 0,00 & 0,01 \\
\hline & \multirow{2}{*}{3003} & SWAT & 22,39 & 0,22 & 0,08 \\
\hline & & SCS-CN & 27,01 & 0,00 & 0,00 \\
\hline & \multirow[t]{2}{*}{4009} & SWAT & 24,98 & 0,19 & 0,07 \\
\hline & & SCS-CN & 29,42 & 0,03 & 0,04 \\
\hline
\end{tabular}

Fonte: Próprio autor 
Figura 83 - Gráficos da curva de duração média (curva de permanência) da vazão diária, calculada pelos modelos SWAT e SCS-CN para as sub-bacias da bacia hidrográfica do rio Jacaré-Guaçu

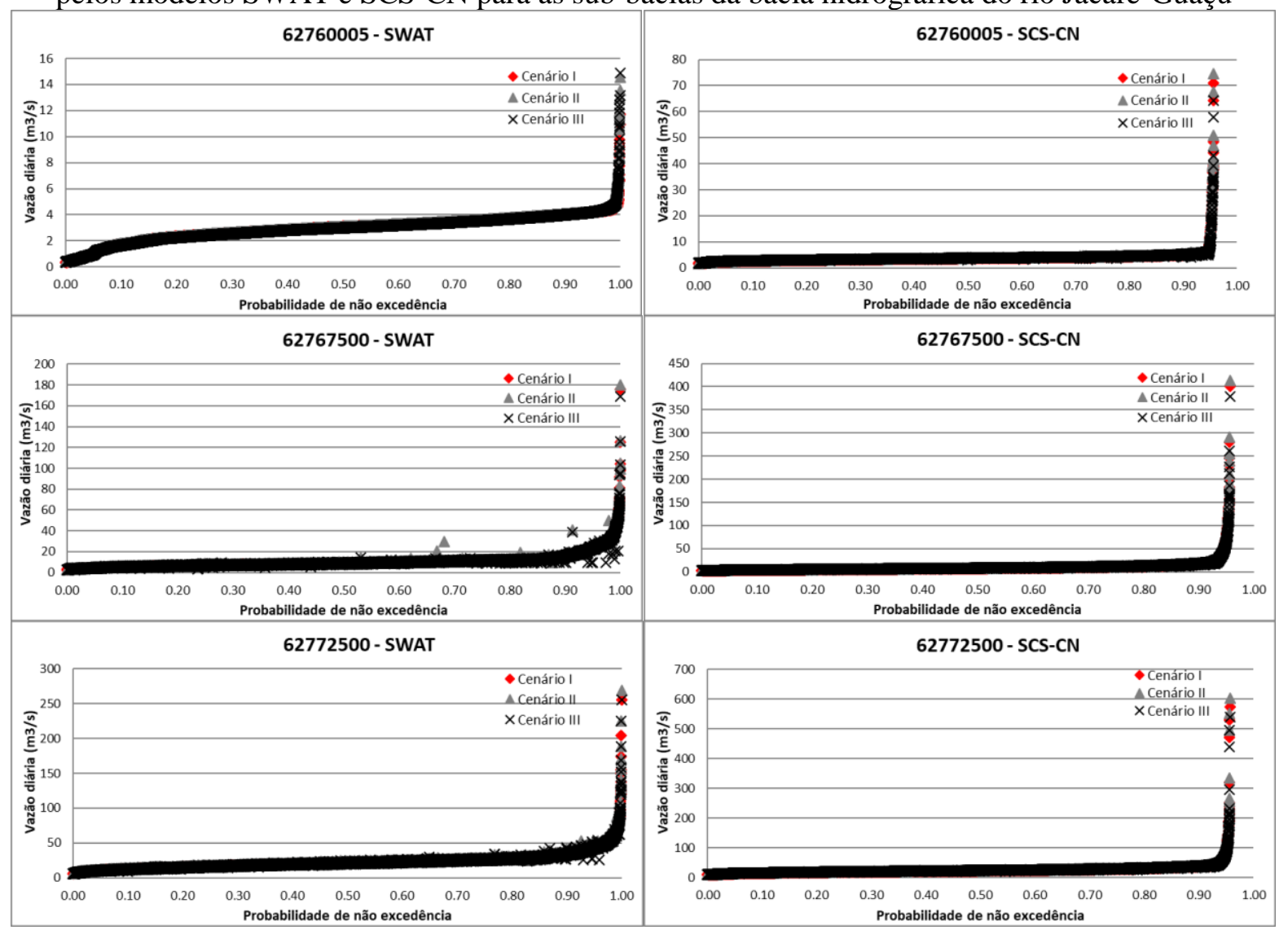

Fonte: Próprio autor 
Figura 84 - Gráficos da curva de duração média (curva de permanência) da vazão diária, calculada pelos modelos SWAT e SCS-CN para as sub-bacias da bacia hidrográfica do rio Atibaia

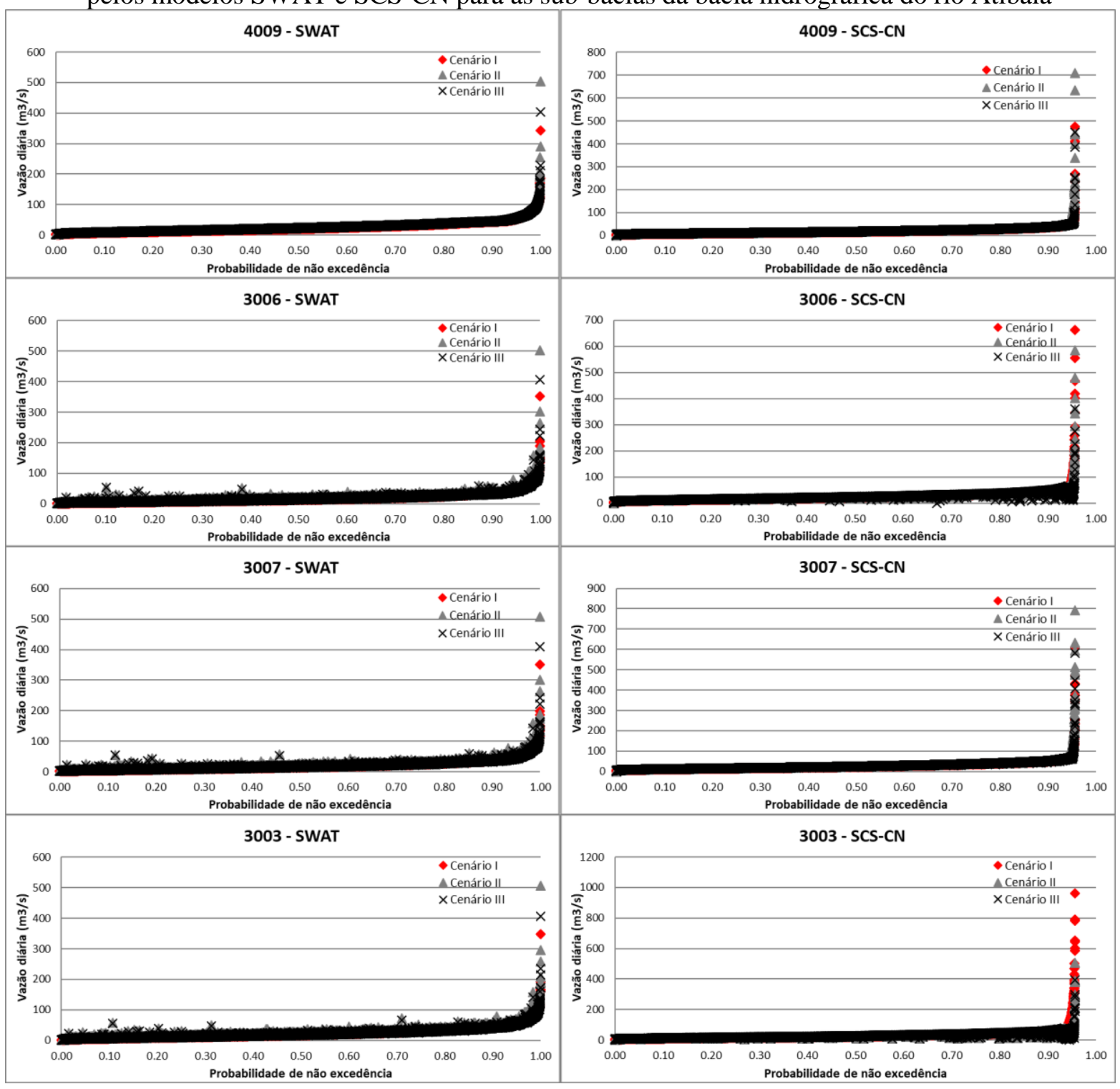

Fonte: Próprio autor

Esta análise pode ser complementada com a análise da variação dos vários componentes do ciclo hidrológico, concretamente os valores de evapotranspiração das culturas existente, a percolação e o teor de água no solo, entre outros (tabela 26). Nos dois cenários simulados para a bacia do rio Jacaré-Guaçu observa-se a diminuição do teor de água no solo ( $\mathrm{Sw}$ ), o aumento da percolação (Perc) e um aumento da contribuição da água subterrânea para a vazão (GwQ). Na bacia hidrográfica do rio Atibaia o aumento das áreas vegetadas (tabela 22) conduz a um aumento no teor de água do solo ( $\mathrm{Sw}$ ) no cenário III, que foi menor que no cenário II, e houve uma diminuição na percolação (Perc) porque a maior parte da água precipitada foi interceptada por folhas e matéria orgânica e assim, a contribuição das águas subterrâneas para o fluxo também foi menor do que para o cenário II. 
Tabela 26 - Valores médios diários das variáveis hidrológicas geradas pelo modelo SWAT para as bacias hidrográficas dos casos de estudo.

\begin{tabular}{|c|c|c|c|c|c|c|c|c|c|c|}
\hline Bacia & Cenário & Modelos & $\begin{array}{l}\mathbf{P} \\
(\mathrm{mm} / \\
\mathrm{dia})\end{array}$ & $\begin{array}{l}\text { PET } \\
(\mathrm{mm} / \\
\mathrm{dia})\end{array}$ & $\begin{array}{l}\text { ET } \\
(\mathrm{mm} / \\
\mathrm{dia})\end{array}$ & $\begin{array}{l}\text { Sw } \\
(\mathrm{mm})\end{array}$ & $\begin{array}{l}\text { Perc } \\
\text { (mm/ } \\
\text { dia) }\end{array}$ & $\begin{array}{l}\text { SurQ } \\
(\mathrm{mm} / \mathrm{dia})\end{array}$ & $\begin{array}{l}\text { GwQ } \\
\text { (mm/ } \\
\text { dia) }\end{array}$ & $\begin{array}{l}\text { LatQ } \\
\text { (mm/ } \\
\text { dia) }\end{array}$ \\
\hline \multirow{6}{*}{ 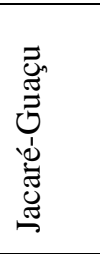 } & \multirow[t]{2}{*}{ I } & SWAT & 3,90 & 3,88 & 2,50 & 94,32 & 1,24 & 0,09 & 0,85 & 1,04 \\
\hline & & SCS-CN & 3,90 & 4,63 & 2,68 & 8,90 & 1,34 & 0,02 & 0,12 & - \\
\hline & \multirow[t]{2}{*}{ II } & SWAT & 3,90 & 3,88 & 2,46 & 86,34 & 1,26 & 0,11 & 0,88 & 1,08 \\
\hline & & SCS-CN & 3,90 & 4,63 & 2,68 & 8,9 & 1,34 & 0,02 & 0,12 & - \\
\hline & \multirow[t]{2}{*}{ III } & SWAT & 3,90 & 3,88 & 2,46 & 85,52 & 1,26 & 0,11 & 0,89 & 1,08 \\
\hline & & SCS-CN & 3,90 & 4,63 & 2,68 & 8,9 & 1,34 & 0,02 & 0,12 & - \\
\hline \multirow{6}{*}{ 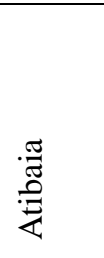 } & \multirow[t]{2}{*}{ I } & SWAT & 4,21 & 5,05 & 2,54 & 107,11 & 1,43 & 0,15 & 0,88 & 1,16 \\
\hline & & SCS-CN & 4,21 & 2,41 & 2,37 & 56,69 & 1,60 & 0,10 & 0,82 & - \\
\hline & \multirow[t]{2}{*}{ II } & SWAT & 4,21 & 4,64 & 2,62 & 113,06 & 1,44 & 0,17 & 0,95 & 1,26 \\
\hline & & SCS-CN & 4,21 & 2,37 & 2,37 & 56,66 & 1,58 & 0,12 & 0,80 & - \\
\hline & \multirow[t]{2}{*}{ III } & SWAT & 4,21 & 4,51 & 2,56 & 106,48 & 1,39 & 0,16 & 0,90 & 1,20 \\
\hline & & SCS-CN & 4,21 & 2,37 & 2,37 & 56,80 & 1,69 & 0,01 & 0,86 & - \\
\hline
\end{tabular}

onde: P: Precipitação (mm); PET: Evapotranspiração potencial (mm); ET: Evapotranspiração real (mm); Sw: Teor de água no solo (mm); Perc: Percolação (mm); SurQ: Contribuição do escoamento superficial para o fluxo (mm); GwQ: Contribuição da água subterrânea para a vazão (mm / dia); LatQ: Contribuição do fluxo lateral para vazão (mm).

Fonte: Próprio autor

\subsubsection{Impactos na produção de sedimentos}

Nas figuras 85 e 86 são apresentados os gráficos com os resultados das simulações de produção de sedimentos e nas figuras 87 e 88 os gráficos com a porcentagem de variação da média mensal da produção de sedimentos e da concentração dos contaminantes em relação ao cenário atual.

Observa-se que o modelo SWAT prevê para os dois casos de estudo uma maior produção de sedimentos nos meses chuvosos e uma menor produção nos meses secos. No modelo GWLF essa variação é constante, porque apenas depende do fator C da EUPS que foi aumentado $10 \%$ no cenário II e reduzido em $20 \%$ no cenário III.

Comparando com a situação atual, o SWAT prevê para a bacia do rio Jacaré-Guaçu um aumento da produção de sedimentos nos meses húmidos entre $2 \%$ e $4 \%$, mais acentuada no cenário II, e uma redução nos meses secos, entre $2 \%$ e $4 \%$. 
Figura 85 - Simulação da produção de sedimentos pelos modelos SWAT e GWLF para cada cenário da bacia hidrográfica do rio Jacaré-Guaçu

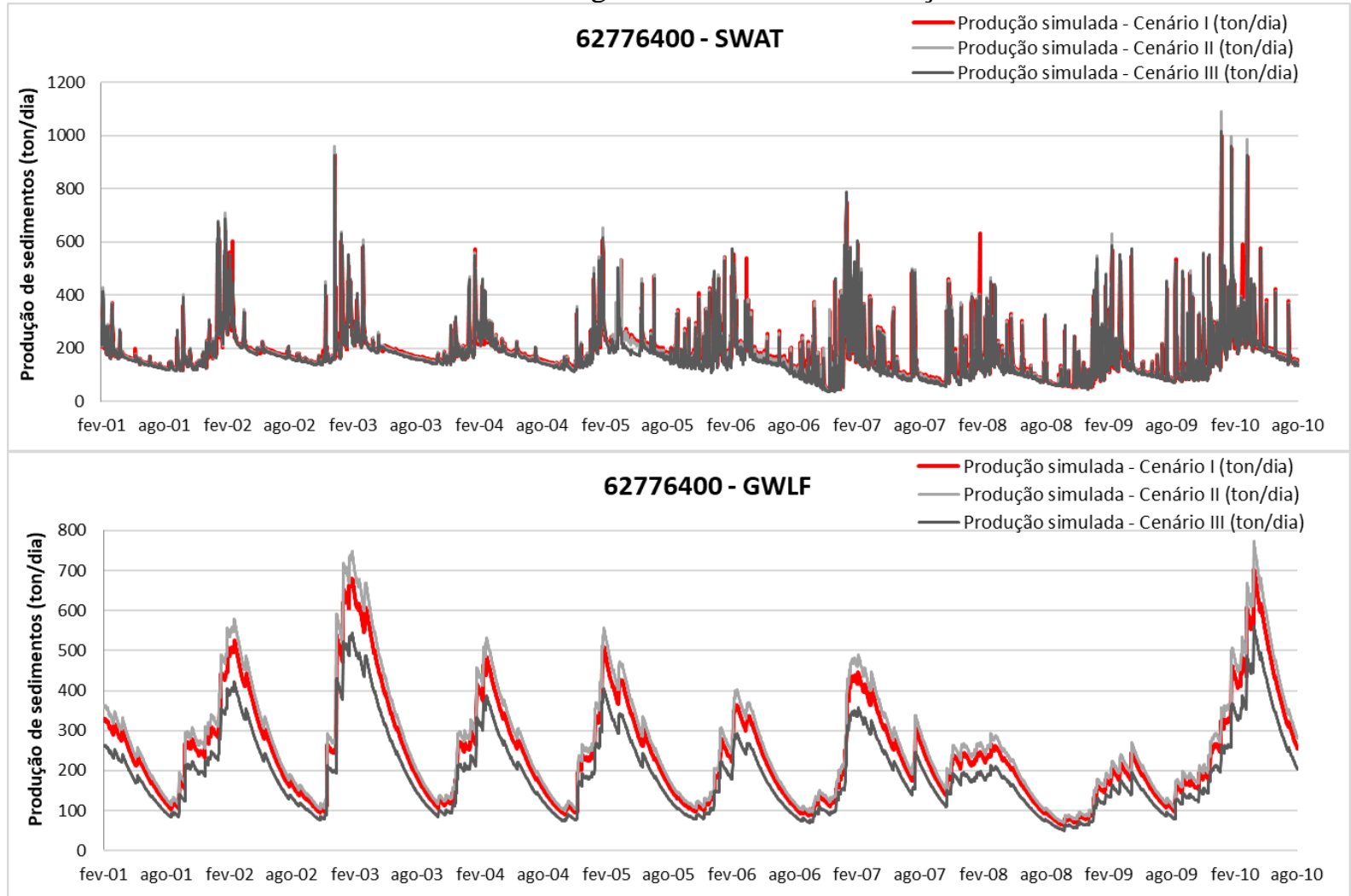

Fonte: Próprio autor

Figura 86 - Simulação da produção de sedimentos pelos modelos SWAT e GWLF para cada cenário da bacia hidrográfica do rio Atibaia

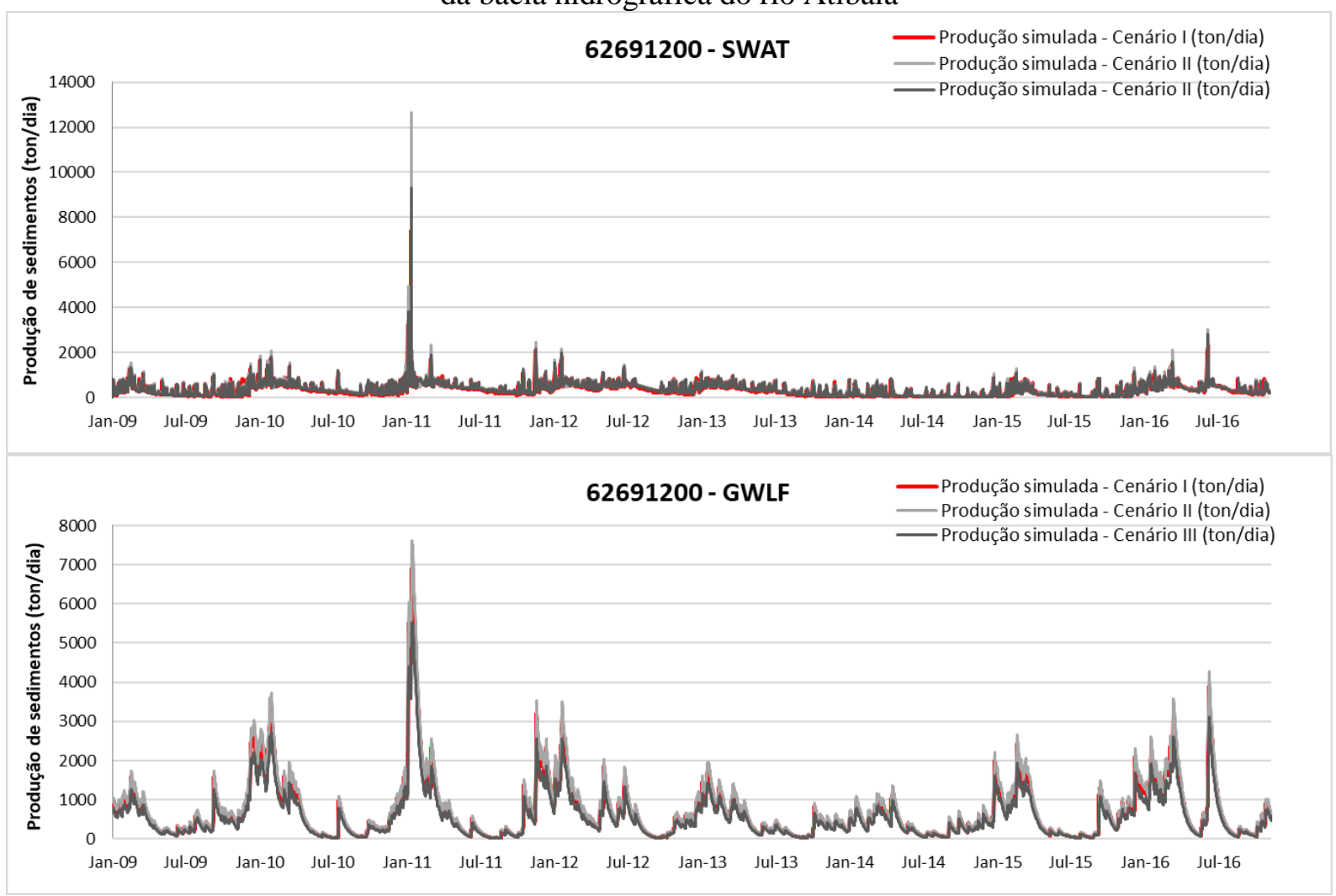

Fonte: Próprio autor 
Figura 87 - Porcentagem de variação da média mensal da produção de sedimentos em relação ao cenário atual, calculada pelos modelos SWAT e GWLF para a bacia hidrográfica do rio Jacaré-Guaçu

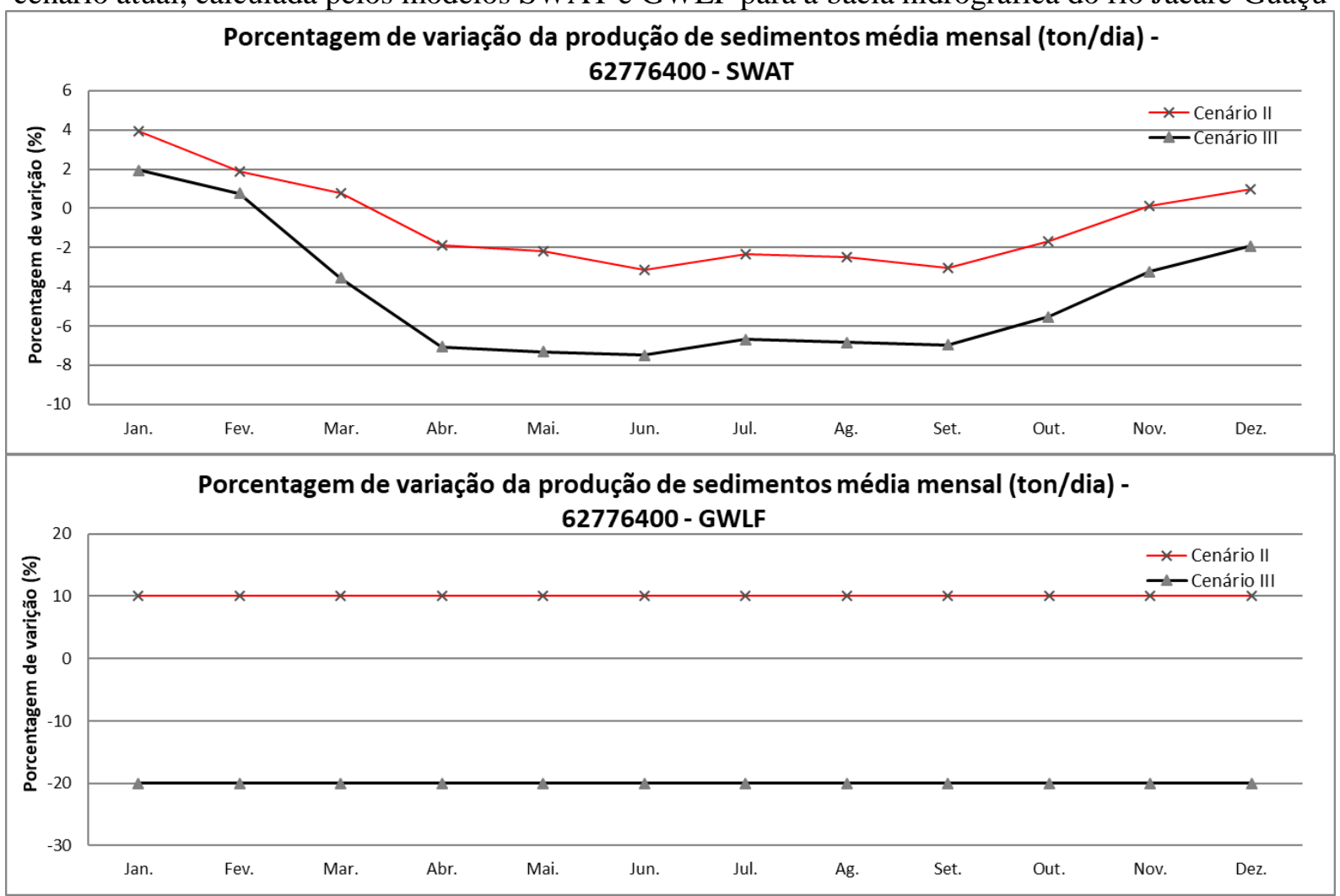

Fonte: Próprio autor

Figura 88 - Porcentagem de variação da média mensal da produção de sedimentos em relação ao cenário atual, calculada pelos modelos SWAT e GWLF para a bacia hidrográfica do rio Atibaia

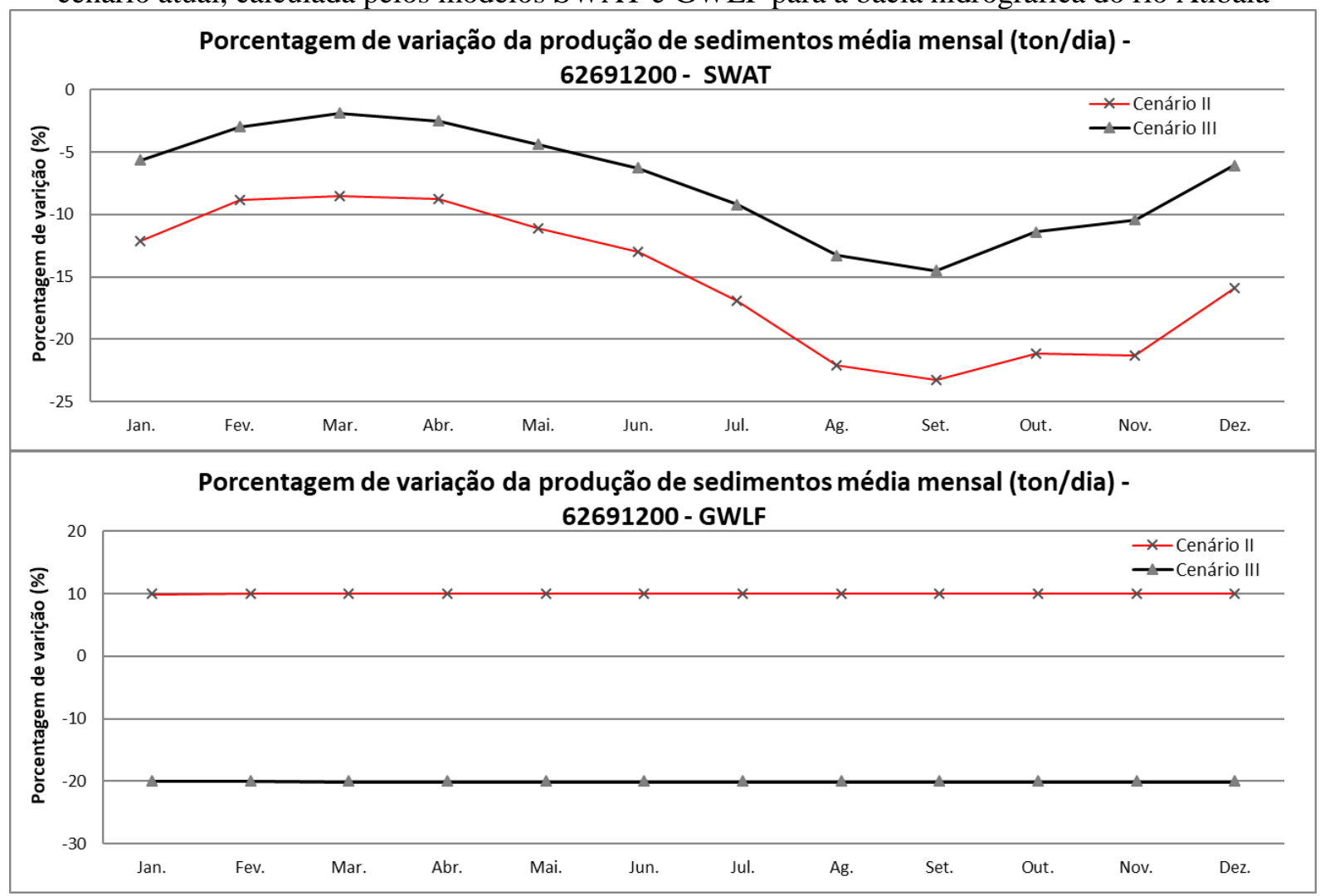

Fonte: Próprio autor 


\subsubsection{Impactos na concentração de contaminantes}

Nas figuras 89 a 92 são apresentados os gráficos da carga dos contaminantes e nas figuras 93 a 96 os gráficos com a porcentagem de variação da média mensal da concentração dos contaminantes em relação ao cenário atual. Nas figuras as concentrações de nitrogênio e fósforo foram expressas em carga ( $\mathrm{kg} / \mathrm{dia})$.

As variações previstas pelo modelo SWAT são superiores às previstas no modelo GWLF e os resultados dos dois modelos não são inteiramente consistentes.

$\mathrm{Na}$ bacia hidrográfica do rio Jacaré-Guaçu prevê-se um aumento da concentração de nitrogênio no cenário III, embora não em todos os meses do ano. Para o cenário II, a variação desta concentração também varia ao longo do ano, em torno de valores mais próximo de zero.

$\mathrm{Na}$ bacia hidrográfica do rio Atibaia, o SWAT prevê uma redução substancial da concentração de nitrogénio para os dois cenários, enquanto o GWLF prevê variações pequenas, mas sempre positivas no cenário III e quase sempre positivas no cenário II.

No que respeita ao fósforo, o SWAT projeta para a bacia do rio bacia do Jacaré-Guaçu um aumento da concentração entre $2 \%$ e $16 \%$ em ambos os cenários. As previsões do modelo GWLF não têm um sinal definido, sendo a variação esperada praticamente nula entre abril e setembro. Para a bacia do rio Atibaia, o SWAT projeta uma redução da concentração do fósforo entre $10 \%$ e 40\%, consoante o cenário, enquanto o GWLF um aumento no cenário II e uma variação praticamente nula no cenário III. 
Figura 89 - Simulação da carga de nitrogênio pelos modelos SWAT e GWLF para cada cenário da bacia hidrográfica rio Jacaré-Guaçu

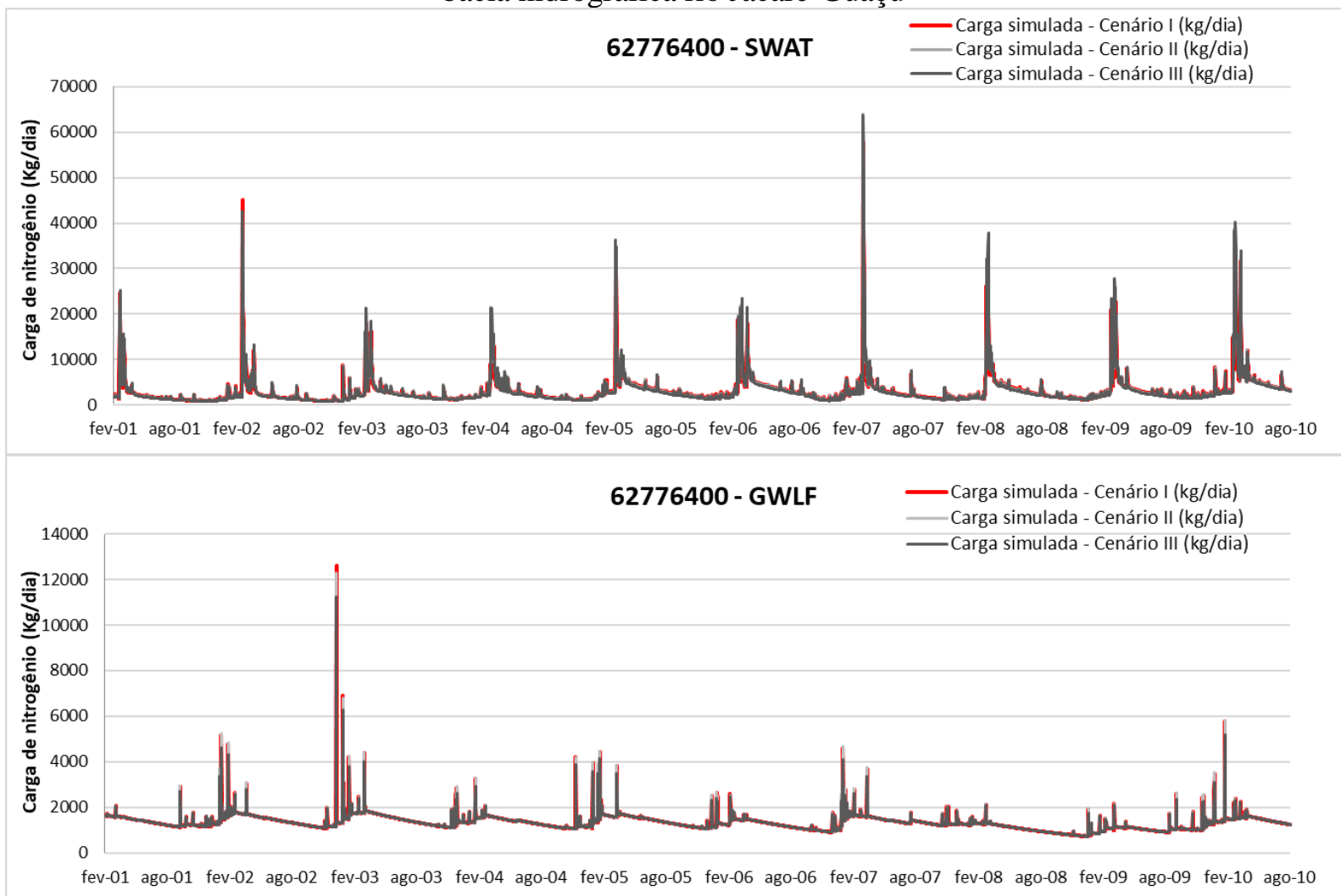

Fonte: Próprio autor

Figura 90 - Simulação da carga de nitrogênio pelos modelos SWAT e GWLF para cada cenário da bacia hidrográfica rio Atibaia

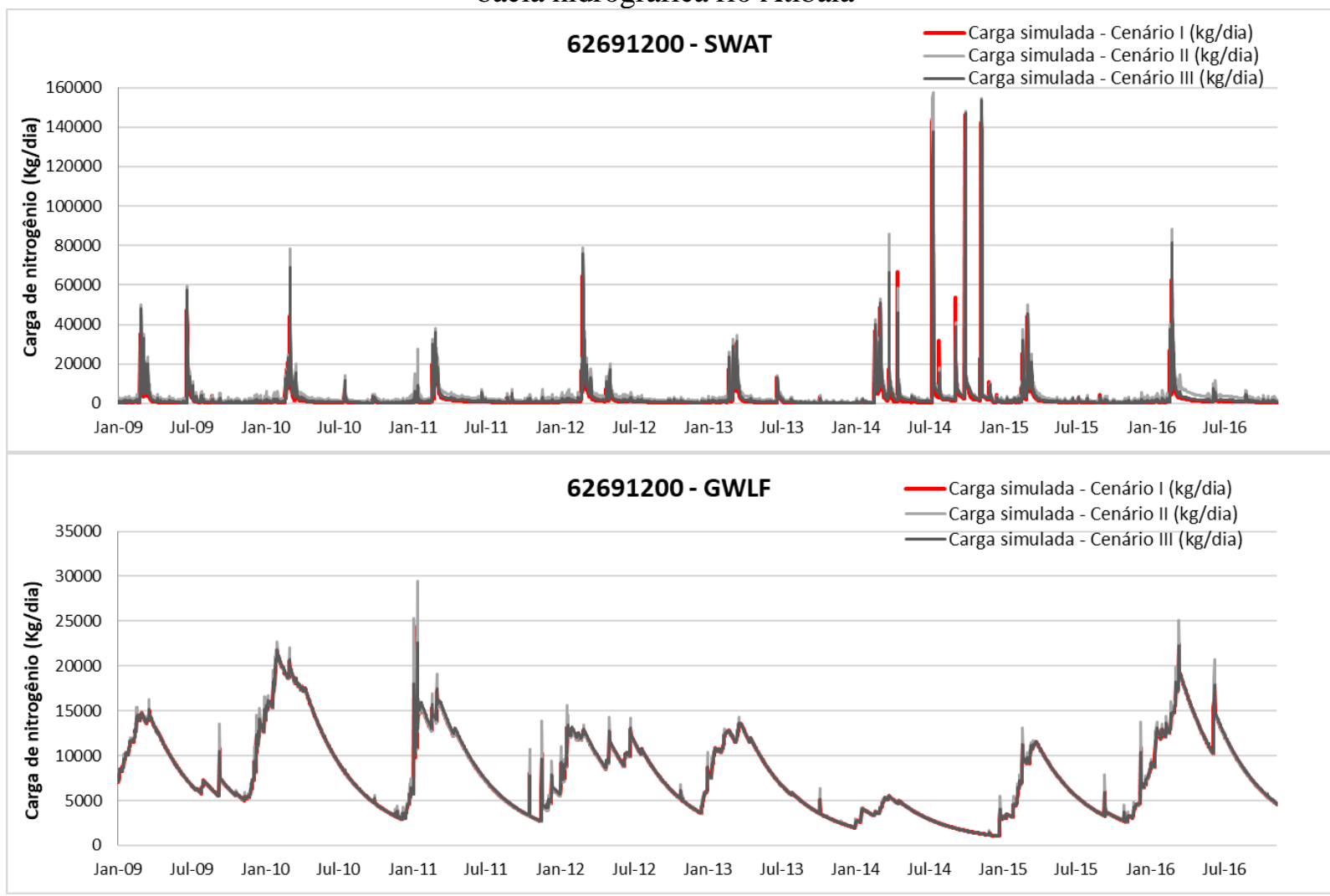

Fonte: Próprio autor 
Figura 91 - Simulação da carga de fósforo pelos modelos SWAT e GWLF para cada cenário da bacia hidrográfica rio Jacaré-Guaçu
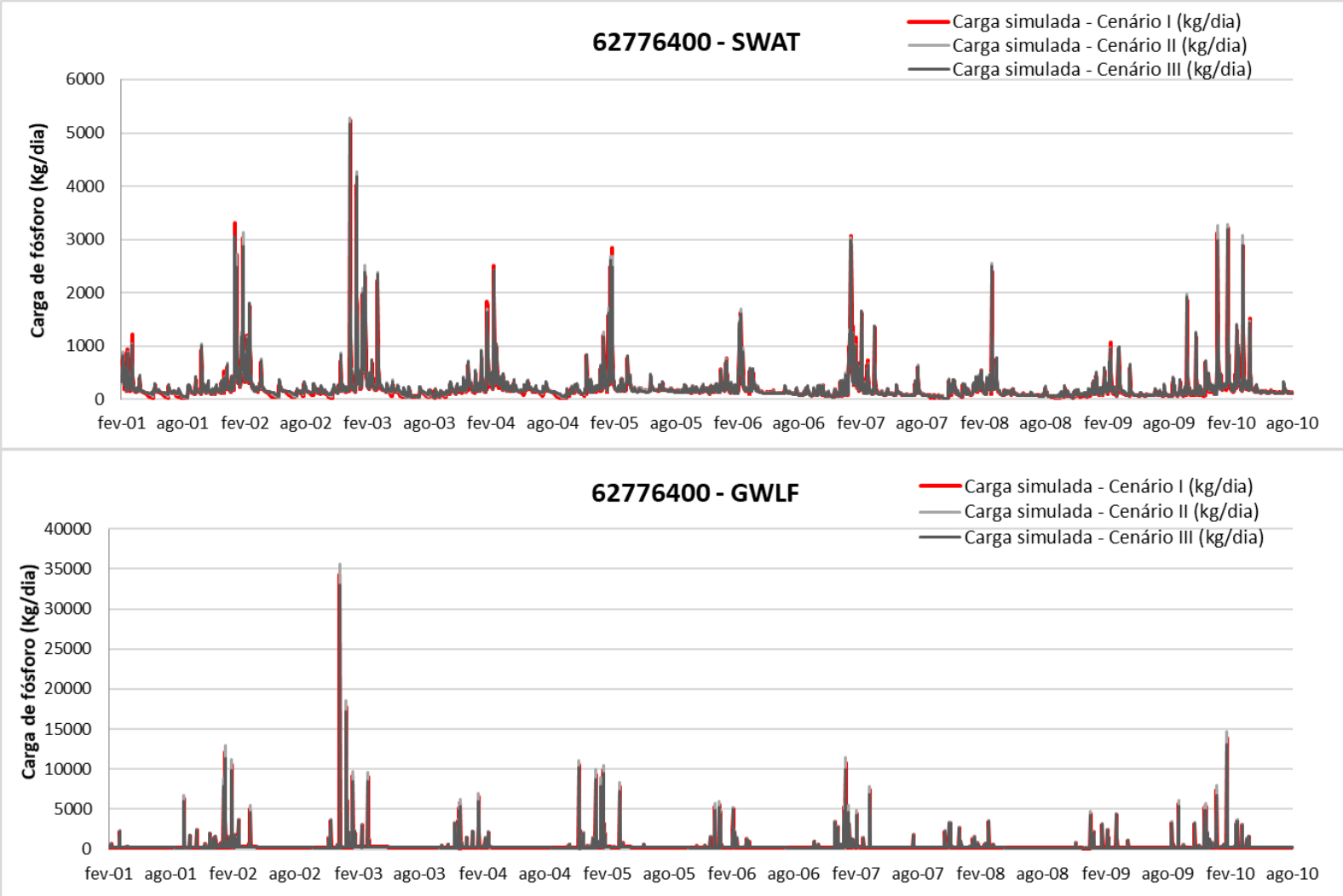

Fonte: Próprio autor

Figura 92 - Simulação da carga de fósforo pelos modelos SWAT e GWLF para cada cenário da bacia hidrográfica rio Atibaia

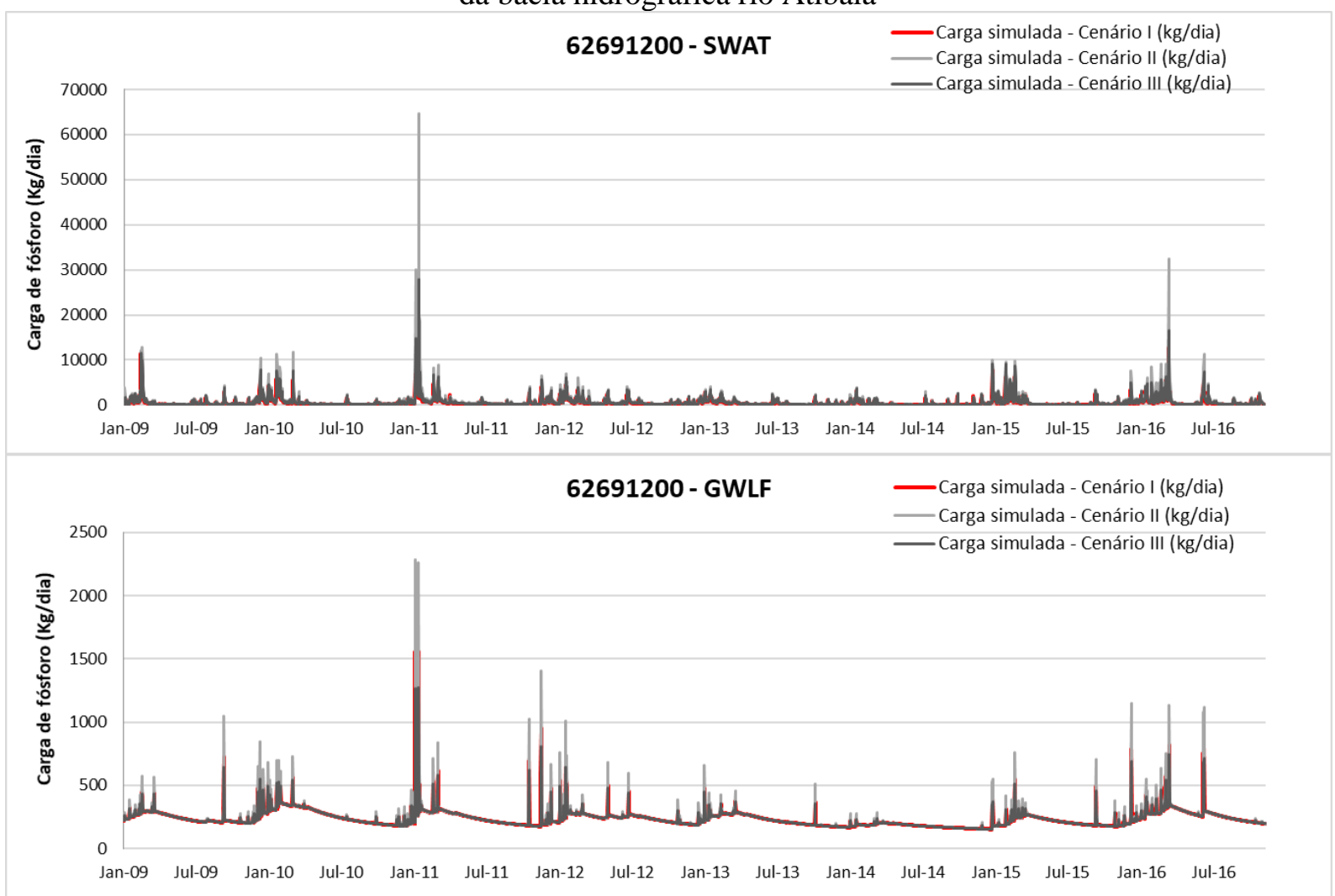

Fonte: Próprio autor 
Figura 93 - Porcentagem de variação da média mensal da carga de nitrogênio em relação ao cenário atual, calculada pelos modelos SWAT e GWLF para a bacia hidrográfica do rio Jacaré-Guaçu

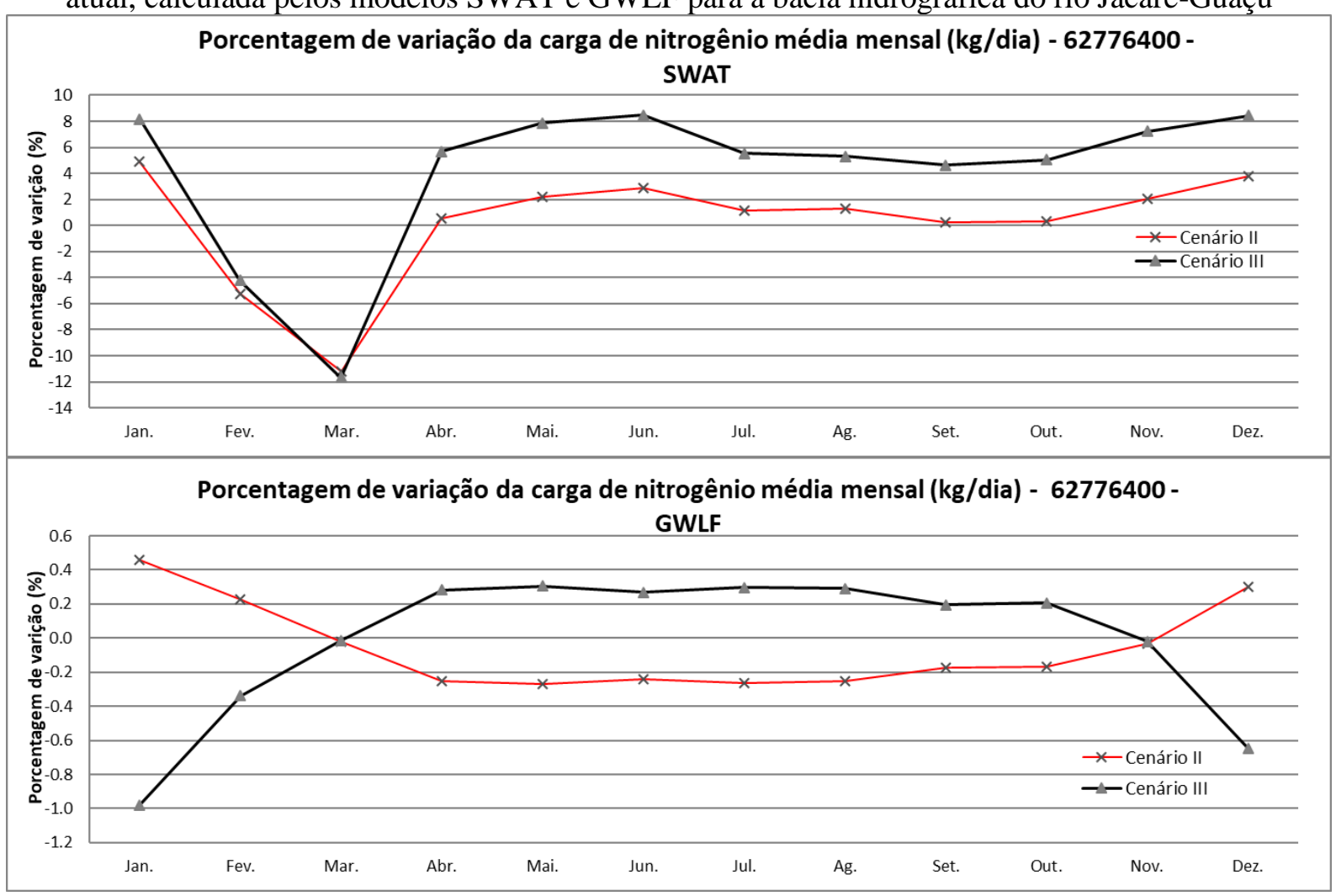

Fonte: Próprio autor

Figura 94 - Porcentagem de variação da média mensal da carga de nitrogênio em relação ao cenário atual, calculada pelos modelos SWAT e GWLF para a bacia hidrográfica do rio Atibaia

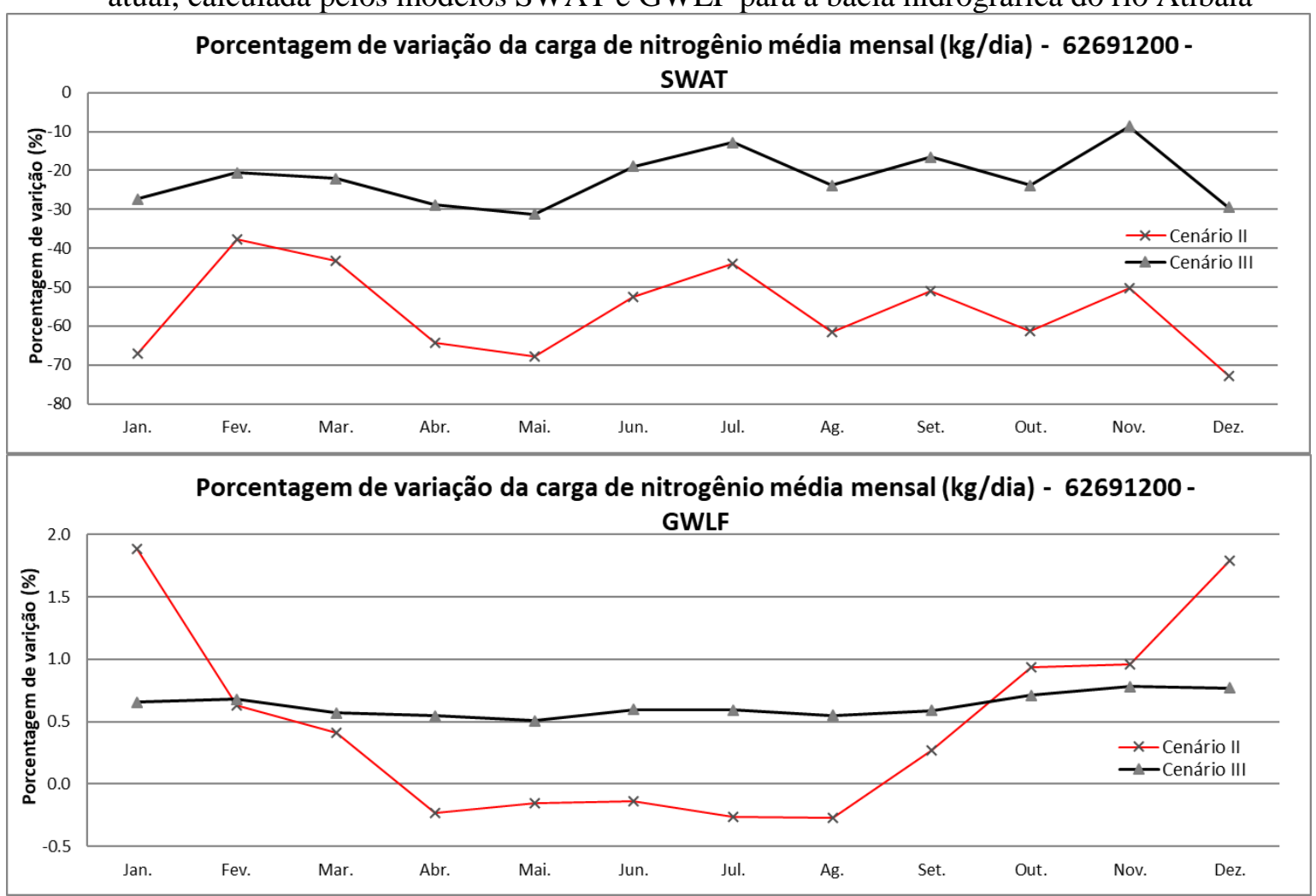

Fonte: Próprio autor 
Figura 95 - Porcentagem de variação da média mensal da carga de fósforo em relação ao cenário atual, calculada pelos modelos SWAT e GWLF para a bacia hidrográfica do rio Jacaré-Guaçu

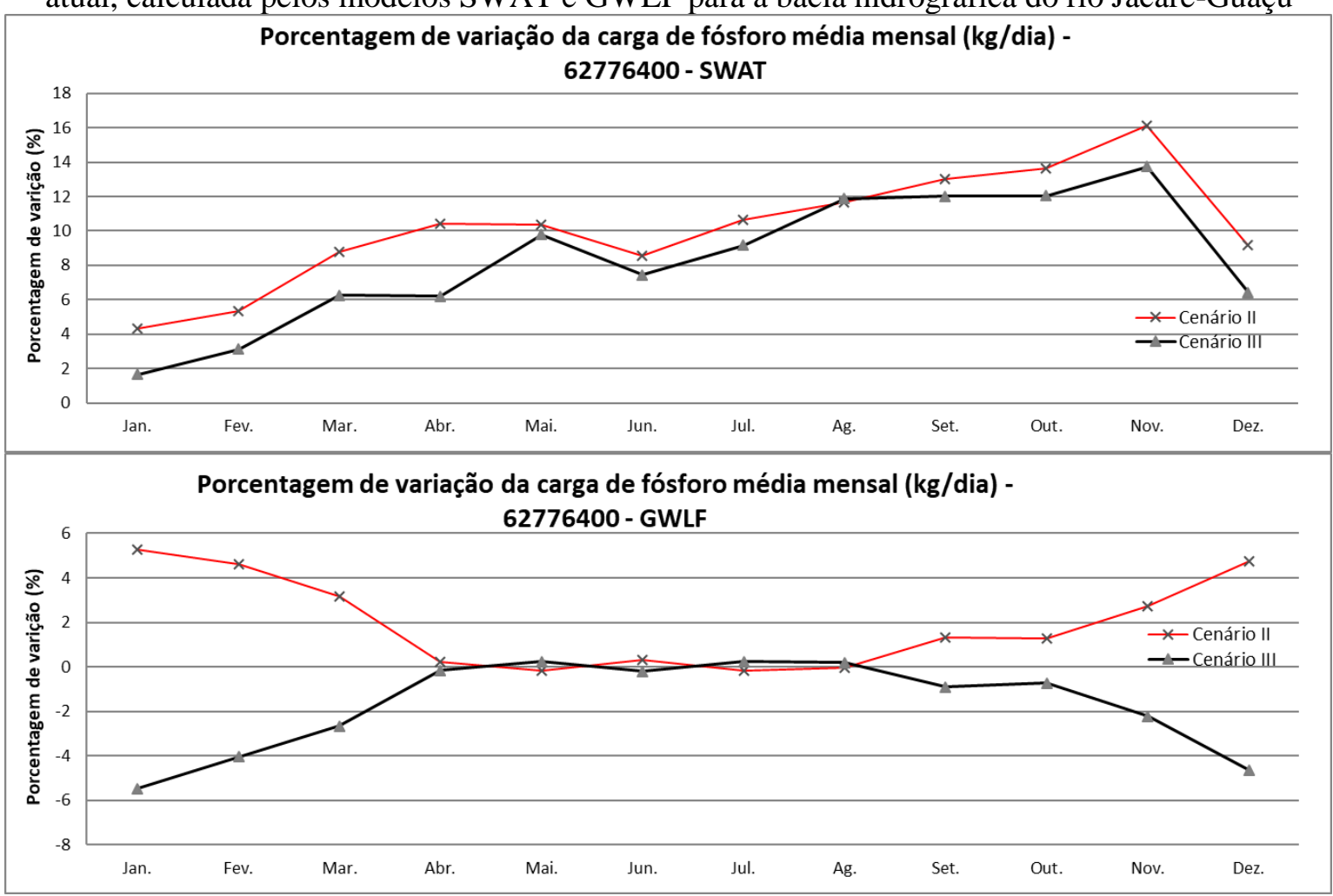

Fonte: Próprio autor

Figura 96 - Porcentagem de variação da média mensal da carga de fósforo em relação ao cenário atual, calculada pelos modelos SWAT e GWLF para a bacia hidrográfica do rio Atibaia

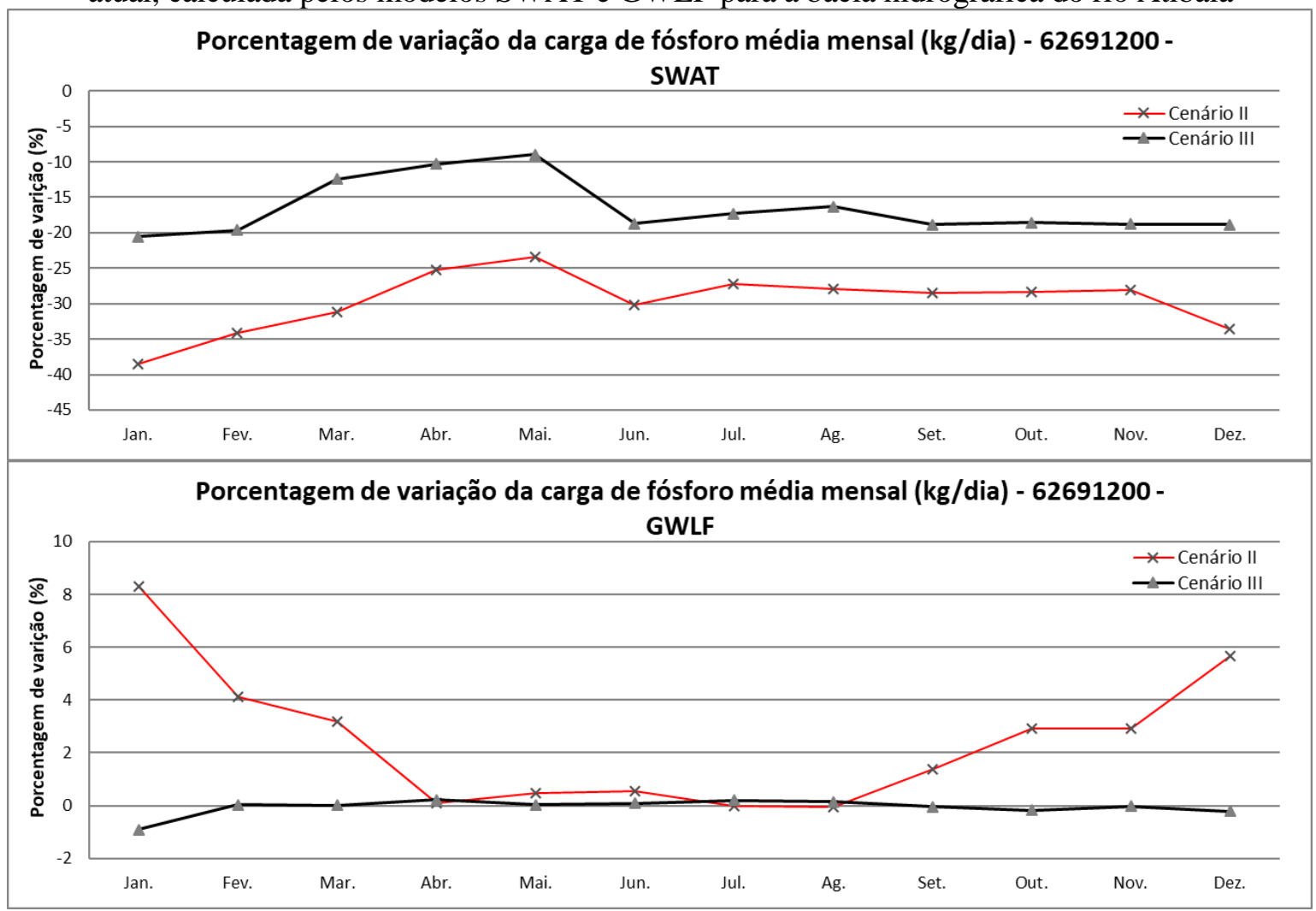

Fonte: Próprio autor 


\section{CONSIDERAÇÕES FINAIS}

Esta pesquisa visou verificar em que condições os modelos hidrológicos mais simples oferecem uma estimativa confiável de variáveis hidrosedimentológicas, quando comparados com os modelos mais complexos.

A modelagem com modelos semi-distribuídos, como o modelo SWAT, necessita de uma ampla gama de parâmetros, o que dificulta sua utilização, especificamente no Brasil, onde há carência de dados em muitas regiões. O procedimento de calibração e validação deste tipo de modelos é uma tarefa demorada e os resultados são fortemente dependentes da disponibilidade e da qualidade dos dados, nomeadamente dos registros de vazão, precipitação e cargas de sedimentos e de contaminantes. Em contraponto, um modelo concentrado demanda um reduzido número de parâmetros para sua calibração e validação, o que faz com que a modelagem seja realizada em menor período do tempo.

O processo de calibração e validação é necessário para obter bons resultados em ambos os modelos, pelo que a alegação de alguns autores de que o SWAT, sendo um modelo baseado na física, não requer calibração parece não ser válida. Quando calibrados, ambos os modelos apresentam um desempenho similar, com o modelo SCS-CN oferecendo, em alguns casos, melhores resultados que o modelo SWAT. O estudo mostrou que tanto o modelo SWAT quanto o modelo concentrado SCS-CN são capazes de reproduzir os principais ciclos da variabilidade da vazão, embora não sejam capazes de estimar com precisão cada valor diário específico. Sua capacidade de estimar valores mensais é significativamente melhor.

A qualidade das estimativas de vazão dos modelos, e especificamente dos valores diários, é fortemente dependente de boas estimativas de precipitação, que são difíceis de alcançar dada a variabilidade espacial e temporal da precipitação. Redes densas de precipitação ou técnicas melhoradas de interpolação espacial são necessárias para este propósito. Como o esforço para coletar dados e calibrar SCS-CN é significativamente menor do que para o SWAT, concluímos que não há vantagem em usar um modelo semi-distribuído mais complexo para simular as vazões de bacias hidrográficas, principalmente quando faltam dados para representar adequadamente a distribuição espacial das variáveis de entrada e dos parâmetros do modelo.

O modelo SWAT, no entanto, é capaz de simular o transporte e as concentrações de contaminantes e nutrientes do solo e o crescimento e decomposição de plantas e prever o impacto das práticas de manejo da terra na água, nos sedimentos e nos rendimentos químicos agrícolas em grandes bacias hidrográficas complexas. Sempre que tais habilidades de simulação são necessárias, o modelo SWAT pode constituir uma ferramenta muito útil. 
Ao estimar a produção de sedimentos, o modelo SWAT e o modelo GWLF são capazes de reproduzir a ordem de grandeza e as principais variações, embora com precisão pouco significativa.

O desempenho dos modelos para reproduzir as concentrações de nitrogênio e de fósforo é fraco, particularmente para as concentrações de nitrogênio. Como as cargas de fósforo estão melhor correlacionadas com a produção de sedimentos, as estimativas do modelo são ligeiramente melhores quando comparadas com os valores observados.

Em resumo, o desempenho do modelo SWAT para estimar a produção de sedimentos, e as concentrações de nitrogênio e fósforo é ligeiramente melhor do que as simulações do modelo GWLF, mas essa vantagem pode não compensar o esforço adicional de calibrá-lo e validá-lo. A aplicação dos modelos SCS-CN e GWLF em Microsoft Excel é uma vantagem em relação ao modelo SWAT, uma vez os resultados para vários cenários são rapidamente calculados e sumarizados ou representados sob a forma gráfica ou através de variados indicadores.

Esta tese mostrou que o modelo GWLF é uma ferramenta de apoio à decisão útil para estudos preliminares, dada a simplicidade de calibrar e aplicar o modelo. Quando os dados estão disponíveis, a capacidade do modelo SWAT de simular processos de bacias hidrográficas detalhadamente tem o potencial de levar a melhores resultados, se for feito um esforço adequado para calibrar e validar o modelo.

Foi feito um esforço para obter um único conjunto de valores calibrados para os parâmetros dos dois modelos e para os dois casos de estudo. A consistência interna deste conjunto de valores reforça a robustez dos resultados dos dois modelos e permite a simulação de bacias hidrográficas com características semelhantes às estudadas.

Para averiguar a importância da qualidade das estimativas da distribuição espaçotemporal da precipitação no cálculo das vazões diárias, o modelo SWAT foi corrido com dois conjuntos de dados de precipitação com diferentes graus de resolução espacial.

A utilização de uma grade regular de valores interpolados, com uma resolução de 30 m, não contribuiu para melhorar a calibração do modelo SWAT. Este facto pode ser justificado, pois nos dois casos de estudo, as bacias hidrográficas são consideradas de área pequena a média $\left(1934 \mathrm{~km}^{2}\right.$ e $\left.2817 \mathrm{~km}^{2}\right)$ e possuem uma alta densidade pluviométrica observada. Este resultado demonstra que a utilização de uma grade de valores interpolados é interessante para bacias com baixa densidade de postos pluviométricos, onde os métodos de interpolação do SWAT para estimar a precipitação em cada sub-bacia falham e apresentam estimativas pouco rigorosas. 
Estudou-se também a capacidade do modelo SWAT em simular a influência de um reservatório. Os resultados revelaram que o modelo é capaz de reproduzir a variabilidade das concentrações de sedimentos, nitrogênio e fósforo a jusante de um reservatório específico, embora não consiga replicar todos os valores com precisão. No geral, o estudo mostrou que o modelo SWAT pode ser uma ferramenta útil para estudar a vazão, produção de sedimentos e concentração de contaminantes a jusante de reservatórios localizados em bacias hidrográficas com um clima tropical.

Por fim foram elaborados cenários de uso e ocupação do solo para os dois casos de estudo, com objetivo de verificar e analisar os impactos dos cenários no regime hidrológico, na produção de sedimentos e na concentração dos contaminantes.

Os casos de estudo apresentaram comportamentos diferenciados em relação aos cenários estudados, isto porque o uso da terra, embora similar, apresenta diferentes proporções nas sub-bacias. As alterações da vazão previstas para cada um dos cenários são diminutas, sendo que, em geral, estas alterações são ligeiramente maiores na bacia hidrográfica do rio Atibaia do que na bacia hidrográfica do rio Jacaré-Guaçu. Estas diferenças estão relacionadas com a menor alteração do uso de solo, em termos de percentagem de área total, cenarizada para a bacia hidrográfica do rio Jacaré-Guaçu quando comparada com a do rio Atibaia.

A produção de sedimentos simulada pelos modelos para os cenários condiz com a metodologia utilizada por cada modelo. O modelo SWAT ao utilizar a MUSLE pressupões que a vazão representa o fator erosivo, já o modelo GWLF utiliza a EUPS, e a intensidade da chuva é a responsável por este fator. Ao modificar o uso do solo pelos cenários, o modelo SWAT possibilita alterar em cada HRUs estas modificações e relacioná-las com a vazão também modificada, já no modelo GWLF o somente o fator C da EUPS é modificado e desta forma, apesar de haver alteração da produção de sedimentoso modelo apresenta essa alteração constante dependente apenas da alteração deste fator.

Para a concentração dos contaminantes, o modelo SWAT e GWLF apresentam resultados diferentes entre si, com o fator comum de antecipação do aumento da concentração pelos modelos no cenário II. 


\section{REFERÊNCIAS}

ABBASPOUR, K. C. et al. Modelling hydrology and water quality in the pre-alpine/alpine Thur watershed using SWAT. Journal of hydrology, v. 333, n. 2, p. 413-430, 2007.

ABBOTT, M. B. et al. An Introduction to the European Hydrologic System-Systeme Hydrologique Europeen, SHE, 1: history and philosophy of a physically-based, distributed modeling system.

Journal of hydrology, v. 87, n. 1, p. 45-59, 1986a.

An Introduction to the European Hydrologic System-Systeme Hydrologique Europeen, SHE,

2: structure of a physically-based, distributed modeling system. Journal of hydrology, v. 87, n. 1, p.

61-77, 1986b.

ADRIOLO, M. V. et al. Calibração do modelo SWAT para a produção e transporte de sedimentos. In: SIMPÓSIO BRASILEIRO SOBRE PEQUENAS E MÉDIAS CENTRAIS HIDRELÉTRICAS, 6. Belo Horizonte, 2008. Anais... Belo Horizonte: Comitê Brasileiro de Barragens, 2008.

AGÊNCIA NACIONAL DE ÁGUAS. Conjuntura dos recursos hídricos no Brasil 2013. Brasília, DF, 2013. Disponível em:<http://pnqa.ana.gov.br/rede-nacional-introducao.aspx>. Acesso em: 20 set. 2018.

Portal da qualidade das águas. Disponível em: $<$ http://portalpnqa.ana.gov.br/ $>$. Acesso em: 10 jan. 2015.

AJAMI, N. K. et al. Calibration of a semi-distributed hydrologic model for stream flow estimation along a river system. Journal of hydrology, v. 298, n. 1, p.112-135, 2004.

ALANSI, A.W. et al. Validation of SWAT model for stream flow simulation and forecasting in Upper Bernam humid tropical river basin, Malaysia. Hydrology and Earth System Science Discussions, v. 6, p. 7581-7609, 2009.

ALEMAYEHU, F. et al. The Impacts of watershed management on land use and land cover dynamics in Eastern Tigray (Ethiopia). Resources, Conservation and Recycling, v. 53, n. 4, p. 192-198, 2009.

AMY, G. et al. Water quality management planning for urban runoff. Washington, DC: U.S. Environmental Protection Agency, 1974.

ARNOLD, J. G.; FOHRER, N. SWAT 2000: vurrent capabilities and research opportunities in applied watershed modeling. Hydrological Processes, v. 19, n. 3, p. 563-572, 2005.

ARNOLD, J. G. et al. Large-area hydrologic modeling and assessment: part 1. Model development. Journal of the American Water Resources Association, v. 34, n. 1, p. 73-89, 1998.

. SWAT: model use, calibration, and validation. Transactions of the ASABE, v. 55, n. 4, p. 1491-1508, 2012.

ARTAN, G. A. et al. Users manual for the geospatial stream flow model(GeoSFM). Reston: U. S. Geological Survey, 2008. (Open-File Report 2007-1440).

BAGNOLD, R. A. Bedload transport in natural rivers. Water Resources Research, v. 13, n. 1, p. 303-312, 1977. 
BAKER, T. J.; MILLER, S. N. Using the soil and water assessment tool (SWAT) to assess land use impact on water resources in an East African watershed. Journal of Hydrology, v. 486, p. 100-111, 2013.

BALASCIO, C.; PALMERI, D.; GAO. H. Use of a genetic algorithm and multi-objective programming for calibration of a hydrologic model. American Society of Agricultural and Biology Engineers, v. 41, n. 3, p. 615-619, 1998.

BATHURST, R.J.; SIMAC, M.R.; SANDRI, D. Lessons learned from the construction performance of a 14 m high segmental retaining wall. Proc. Geosynthetics: Lessons Learned from Failures. Nashville, Tennessee, February 1995, 15 p.

BENHAM, B. L. et al. Modeling bacteria fate and transport in watershed models to support TMDLs. Transactions of the ASABE, v. 49, n.4, p. 987-1002, 2006.

BERTOLINI. D.; LOMBARDI NETO, F. Controle de voçorocas. Campinas: CATI, 1994. v. 5, p. 25-30. (CATI. Manual tecnico, 42).

BERTOLINI, J. O Espaçamento dos terraços em culturas anuais, determinado em função das perdas por erosão. Bragantia, v. 18, n. 1, p. 113-140, 1959.

BERTOLINI, J.; LOMBARDI NETO, F. Conservação do solo. São Paulo: Ícone, 1990. 3.ed. São Paulo: Ícone, 1993.

BEVEN, K. J.; KIRKBY, M. J. A Physically-based variable contributing area model of basin hydrology. Hydrological Sciences Bulletin, v. 24, n. 1, p. 43-69, 1979.

BLAINSKI, E. et al. Simulação de cenários de uso do solo na bacia hidrográfica do rio Araranguá utilizando a técnica da modelagem hidrológica. Agropecuária Catarinense, v. 24, n. 1, p. 65-70, 2011.

BONUMÁ, N. B.; ROSSI, C. G.; ARNOLD, J. G. Hydrology evaluation of the soil and water assessment tool considering measurement uncertainty for a small watershed in southern Brazil. Applied Engineering in Agriculture, v. 29, n. 2, p. 189-200, 2013.

BORK, H. R.; HENSEL, H. Computer-aided construction of soil erosion and deposition maps. Geologisches Jahrbuch, v. 104, n. 1, p. 357-371, 1988.

BRAGA, B.; PORTO, M.; TUCCI, C. E. M. Monitoramento da quantidade e qualidade das águas. In: REBOUÇAS, A. C.; BRAGA, B.; TUNDISI, J. G. Águas doces no Brasil. São Paulo: Escrituras, 2002. p. 637-651.

BRANDT, S. A. Classification of geomorphological effects downstream of dams. Catena, v. 40, n. 4, p. 375-401, 2000.

BRASIL. Ministério do Meio Ambiente. Conselho Nacional do Meio Ambiente. Resolução CONAMA n. ${ }^{\circ}$ 20, de 18 de junho de 1986. Dispõe sobre a classificação de águas doces, salobras e salinasdo território nacional. Diário Oficial da União, Brasília, DF, 30 jul. 1986, p.11356-11361.

Resolução CONAMA n. ${ }^{\circ}$ 357, de 17 de março de 2005. Dispõe sobre a classificação dos corpos de água e diretrizes ambientais para o seu enquadramento, bem como estabelece as condições e padrões de lançamentos de efluentes, e dá outras providências. Diário Oficial da União, Brasília, DF, 18 mar. 2005, p.58-65. 
BRESSIANI, D. A. et al. Review of soil and water assessment tool (SWAT) applications in Brazil: challenges and prospects. International Journal of Agricultural and Biological Engineering, v. 8, n. 3, p. 9, 2015.

BRITO, J. L. S. et al. Uso do geoprocessamento na estimativa da perda de solos por erosão laminar em Irai de Minas-MG. In: SIMPÓSIO BRASILEIRO DE SENSORIAMENTO REMOTO, 9., 1998, Santos. Anais... São José dos Campos: INPE, 1998. p. 501-512.

CARVALHO, N. O. Hidrosedimentologia prática. Rio de Janeiro: Companhia de Pesquisa de Recursos Minerais; Eletrobrás, 1994.

CHANG, F. J.; CHANG, Y. T. Adaptive neuro-fuzzy inference system for prediction of water level in reservoir. Advances in Water Resources, v. 29, n. 1, p. 1-10, 2006.

CHAPMAN, D. Water quality assessment - a guide to use of biota, sediments and water environmental monitoring. $2^{\text {nd }}$ ed. London: EPFN Spon, 1996.

CHAU, K. W.; WU, C. L. A Hybrid model coupled with singular spectrum analysis for daily rainfall prediction. Journal of Hydroinformatics, v. 12, n. 4, p. 458-473, 2010.

CHEN, T. et al. Comparison of spatial interpolation schemes for rainfall data and application in hydrological modeling. Water, v. 9, n. 5, p. 342, 2017.

CHOW, V. T.; MAIDMENT, D. R.; MAYS, L. W. Applied hydrology. Singapura: McGraw-Hill International Student, 1988.

CHU, T. W. et al. Evaluation of the SWAT model's sediment and nutrient components in the piedmont physiographic region of Maryland. Transactions of the ASAE, v. 47, n. 5, p. 1523, 2004.

COELHO, V. H. et al. Dinâmica do uso e ocupação do solo em uma bacia hidrográfica do semiárido brasileiro. Revista Brasileira de Engenharia Agrícola e Ambiental, v. 18, n. 1, p. 64-72, 2014.

COFFEY, S. R.; WORKMAN, J. L.; TARABA, A.W. Fogle statistical procedures for evaluating daily and monthly hydrologic model predictions. Transactions of the ASAE, v. 47, n. 1, p. 59-68, 2004.

COMITÊ DA BACIA HIDROGRÁFICA DO TIETÊ - JACARÉ. Fundamentos para cobrança pelo uso dos recursos hídricos na bacia do Tietê - Jacaré. Araraquara, 2009. Disponível em: <http://www.sigrh.sp.gov.br/sigrh/ARQS/RELATORIO/CRH/CBH-

TJ/1322/fundamentos\%20da\%20cobranca[0].pdf>. Acesso em: 21 nov. 2017.

COMITÊ DAS BACIAS HIDROGRÁFICAS DOS RIOS PIRACICABA, CAPIVARI E JUNDIAÍ. Plano de bacias hidrográfcas 2004-2007 dos rios Piracicaba, Capivari e Jundiaí. 2006. Relatório final. Disponível em:<www.comitepcj.sp.gov.br>. Acesso em: 10 mar. 2017.

CORRÊA, U. M. P. Estudo das águas subterrâneas das bacias hidrográficas dos rios JacaréGuaçu e Jacaré-Pepira no Estado de São Paulo. 1998. 3v. Dissertação (Mestrado) - Escola de Esngenharia de são Carlos, Universidade de São Paulo, São Carlos, 1998.

CRAWFORD, N. H.; LINSLEY, R. K. Digital simulation in hydrology: stanford watershed model IV. Palo Alto: Stanford University, 1966. (Technical Report, 39).

CRONSHEY, R. Urban hydrology for small watersheds. $2^{\text {nd }}$ ed. Washington: USDA; NRCS; CED, 1986. (TR-55). 
CUNHA, S. B. Geomorfologia fluvial. In: GUERRA, A. J. T.; CUNHA, S. B. (Org.).

Geomorfologia: uma atualização de bases e conceitos. 8.ed. Rio de Janeiro: Bertrand Brasil, 2008. p. 211-234.

CUNHA, S. B.; GUERRA, A. J. T. Geomorfologia do Brasil. Rio de Janeiro: Bertrand Brasil, 1998.

DAWDY, D. R.; O'DONNELL, T. Mathematical models of catchment behavior. Journal of the Hydraulics Division, v. 91, n. 4, p. 123-137, 1965.

DEMANBORO, A. C.; LAURENTIS, G. L.; BETTINE, S. D. C. Cenários ambientais na bacia do rio Atibaia. Engenharia Sanitária e Ambiental, v. 18, n. 1, p. 27-37, 2013.

DENARDIN, J. E. Erodibilidade de solo estimada por meio de parâmetros físicos e químicos. 81 f. Tese (Doutorado) - Escola Superior de Agricultura Luiz de Queiroz, Piracicaba, 1990.

DESMET, P. J. J. The Use of digital elevation models in geomorphology. Tijdschrifi Von de Belgische Vereniging Voon Aardrijkskundige Studies - BEVAS, v. 62, n. 1, p. 47-66, 1993.

DESMET, P. J. J.; GOVERS, G. GIs-based simulation of erosion and deposition patterns in an agricultural landscape: a comparison of model results with soil map information. Catena, v. 25, n. 1, p. 389-401, 1995.

DI LUZIO, M. et al. ArcView interface for SWAT2000. Texas: Texas Water Resources Institute, College station, 2002. (TR-193 002).

DORNFELD, C. B. Utilização de análises limnológicas, bioensaios de toxicidade e macroinvertebrados bentônicos para o diagnóstico ambiental do reservatório de Salto Grande (Americana, SP). 2002. 211p. Tese (Doutorado) - Escola de Engenharia de São Carlos, Universidade de São Paulo, São Paulo, 2002.

DU, X. et al. Variations in source apportionments of nutrient load among seasons and hydrological years in a semi-arid watershed: GWLF model results. Environmental Science and Pollution Research, v. 21, n. 10, p. 6506-6515, 2014.

DUAN, Q.; GUPTA, V. K.; SOROOSHIAN, S. Effective and efficient global optimization for conceptual rainfall-runoff models. Water Resources Research, v. 28, n. 1, p. 1015-1031, 1992.

EDSEL, D. B. et al. Watershed modeling and its applications: A state-of-the-art review. The Open Hydrology Journal, v. 5, n. 1, p. 26-50, 2011.

ENVIRONMENTAL PROTECTION AGENCY. Air quality criteria document for lead. North Carolina : Environmental Criteria and Assessment Office, US Environmental Protection Agency, Research Triangle Park, 1986.

FATICHI, S. et al. An Overview of current applications, challenges, and future trends in distributed process-based models in hydrology. Journal of Hydrology, v. 537, p. 45-60, 2016.

FERREIRA, R. E.; ALVES, F. D. Organização espacial da cana de açúcar no Estado de São Paulo: uma análise evolutiva. In: ENCONTRO DE GRUPOS DE PESQUISA AGRICULTURA, DESENVOLVIMENTO REGIONAL E TRANSFORMAÇÕES SOCIOESPACIAIS, 5., Santa Maria, 2009. Anais... Santa Maria: Grupo de Pesquisa em Educação e Território, 2009. p. 1-18.

FLANAGAN, D. C.; NEARING, M. A. (Ed.). USDA-water erosion prediction project: hillslope profile and watershed model documentation. West Lafayette: USDA-ARS National Soil Erosion Research Laboratory, 1995. (NSERL Report, 10). 
FOSTER, G. R.; WISCHMEIER, W. H. Evaluating irregular slopes for soil loss prediction. Transactions of the American Society of Agricultural Engineers, v. 17, p. 305-309, 1974.

FOSTER, G. R. et al. Conversion of the universal soilloss equation to SI units. Journal of Soil and Water Conservation, v. 36, p. 355-359, 1981.

FOURNIER, F. Climat et erosion. Paris: Press Universitaries de France, 1960.

FRANCESCONI, W. et al. Using the soil and water assessment tool (SWAT) to model ecosystem services: a systematic review. Journal of Hydrology, v. 535, p. 625-636, 2016.

FREIRE, O. et al. Solos da bacia do Broa. São Paulo: Universidade Federal de São Carlos, 1978.

FUKUNAGA, D. C. et al. Application of the SWAT hydrologic model to a tropical watershed at Brazil. Catena, v. 125, p. 206-213, 2015.

GALVÁN, L. et al. Application of the SWAT model to an AMD-affected river (Meca River, SW Spain). Estimation of transported pollutant load. Journal of Hydrology, v. 377, n. 3-4, p 445-454, 2009.

GASSMAN, P. W. et al. The soil and water assessment tool: historical development, applications, and future research directions Invited Review Series. Transactions of the ASABE, v. 50, n. 4, p. 1211$1250,2007$.

GITAU, M. W.; CHAUBEY, I. Regionalization of SWAT model parameters for use in ungauged watersheds. Water, v. 2, n. 4, p. 849-871, 2010.

GREEN, C. H.; VAN GRIENSVEN, A. Autocalibration in hydrologic modeling: Using SWAT2005 in small-scale watersheds. Environmental Modelling \& Software, v. 23, n. 4, p. 422-434, 2008.

GRIFFIN, M. L.; BARFIELD, B. J.; WARNER, R. C. Laboratory studies of dead storage in sediment ponds. Transactions of the ASAE, v. 28, n. 3, p. 799-804, 1985.

GUIMARÃES, R. Z. et al. Espacialização da perda de solo por erosão laminar na microbacia do Rio Campinas, Joinville. SC. Raega - o espaço geográfico em análise, v. 23, p. 534-554, 2011.

GUO, X. C. et al. A Novel LS-SVMs hyper-parameter selection based on particle swarm optimization. Neurocomputing, v. 71, n. 16-18, p. 3211-3215, 2008.

GUPTA, H. V.; WAGENER, T.; LIU, Y. Reconciling theory with observations: elements of a diagnostic approach to model evaluation. Hydrological Processes, v. 22, n. 18, p. 3802-3813, 2008.

HAITH, D. A.; SHOEMAKER, L. L. Generalized watershed loading functions for stream flow nutrients. Water Resources Bulletin, v. 23, n. 3, p. 471-478, 1987.

HAITH, D. A.; MANDEL, R.; WU, R. S. Generalized watershed loading functions version 2.0 user's manual. Ithaca: Cornell University, 1992.

HAWKINS, R. H. et al. Runoff probability, storm depth, and curve numbers. Journal of Irrigation and Drainage Engineering, v. 111, n. 4, p. 330-340, 1985.

HIPÓLITO, J. N. A Água no solo. In: QUINTELA, A. C. Hidrologia e Recursos hídricos. Associação de Estudantes do Instituto Superior Técnico, 1996.

p. $8.1-8.24$. 
HIPÓLITO, J. R.; VAZ, A. C. Hidrologia e recursos hídricos. Lisboa: IST-PRESS, 2011. v.1.

HJELMFELT, A. T. J.; KRAMER, K. A.; BURWELL, R. E. Curve numbers as random variables. In: INTERNATIONAL SYMPOSIUM ON RAINFALL-RUNOFF MODELLING, 1982. Proceedings... Littleton: Water Resources Publication, 1982. p. 365-373.

HORTON, R. E. The Role of infiltration in the hydrological cycle. Transactions American Geophysical, v.14, p- 446-460, 1933.

HUANG, J.; HONG, H. Comparative study of two models to simulate diffuse nitrogen and phosphorus pollution in a medium-sized watershed, southeast China. Estuarine. Coastal and Shelf Science, v. 86, n. 3, p. 387-394, 2010.

HUBER, W. C.; DICKINSON, R. E. Storm water management model, version 4: User's manual. Athens: Cooperative Agreement; U.S. Environmental Protection Agency, 1988.

HYDROLOGIC ENGINEERING CENTER. HEC-1 flood hydrograph package, user's manual. Davis: U.S. Army Corps of Engineers, 1968.

HYDROLOGY. In: NATIONAL engineering handbook. Washington: USDA; Michigan: Natural Resources Conservation Service, 1972. Seção 4, Chap.10, p.10.5-10.6.

INSTITUTO DE PESQUISAS TECNOLÓGICAS DO ESTADO DE SÃO PAULO. Mapa geomorfológico do estado de São Paulo; escala 1:1.000.000. São Paulo: IPT, 1981.

Avaliação da vulnerabilidade e risco de contaminação das águas subterrâneas no estado de São Paulo. São Paulo: IPT, 2011. (Relatório Técnico, nº 122.645-205).

KALERIS, V.; LANGOUSIS, A. Comparison of two rainfall-runoff models: effects of conceptualization on water budget components. Hydrological Sciences Journal, v. 62, n. 5, p. 729 $748,2016$.

KHANBILVARDI, R. M.; ROGOWSKI, A. S. Quantitative evaluation of sediment delivery ratios. JAWRA Journal of the American Water Resources Association, v. 20, n. 6, p. 865-874, 1984.

KIM, H.; PARAJULI, P. B. Impacts of reservoir outflow estimation methods in SWAT model calibration. Transactions of the ASABE, v. 57, n. 4, p. 1029-1042, 2014.

KINNELL, P. I. A. Sediment delivery ratios: a misaligned approach to determining sediment delivery from hillslopes. Hydrological Processes, v. 18, n. 16, p. 3191-3194, 2004.

KIRSCH, K.; KIRSCH, A.; ARNOLD, J. G. Predicting sediment and phosphorus loads in the rock river basin using SWAT. Transactions of the ASAE, v. 45, n. 6, p. 1757, 2002.

KISI, Ö.; OZKAN, C.; AKAY, B. Modeling discharge-sediment relationship using neural networks with artificial bee colony algorithm. Journal of Hydrology, v. 428, p. 94-103, 2012.

KOULI, M.; SOUPIOS, P.; VALLIANATOS, F. Soil erosion prediction using the revised universal soil loss equation (RUSLE) in a GIS framework, Chania, Northwestern Crete, Greece. Environmental Geology, v. 57, n. 3, p. 483-497, 2009.

KRAUSE, P.; BOYLE, D. P.; BÃSE, F. Comparison of different efficiency criteria for hydrological model assessment. Advances in Geosciences, v. 5, p. 89-97, 2005. 
KUHNLE, R. A. et al. Effect of land use changes on sediment transport in Goodwin Creek. Water Resources Research, v. 32, n. 10, p. 3189-3196, 1996.

JONES, C. RUSLE applications on Arizona rangelands. Arizona Ranchers' Management guide. Rangeland Management, p. 73-78, 2001.

LAPOLA, D. M. et al. Pervasive transition of the Brazilian land-use system. Nature Climate Change, v. 4, p. 27-35, 2014.

LEE, K.Y. et al. Modeling the hydrochemistry ofthe Choptank River basin using GWLF and GIS. Biogeochemistry, v. 49, p. 143-173, 2000.

LEITE, M. A. Variação espacial e temporal da taxa de sedimentação no reservatório de Salto Grande (Americana-SP) e sua influência sobre as características limnológicas do sistema. 1998. 164p. Dissertação (Mestrado) - Escola de Engenharia de São Carlos, Universidade de São Paulo, São Carlos, 1998.

LENHART. K.; ECKHARDT, N.; FOHRER, F. H. G. Comparison of two different approaches of sensitivity analysis. Physics and Chemistry of the Earth, v. 27, p. 645-654, 2002.

LEPRUN, J.C. A Erosão, a conservação e o manejo do solo do nordeste brasileiro: balanço diagnóstico e novas linhasde pesquisa. Recife: SUDENE/ORSTOM, 1981.

LI, X.; WELLER, D. E.; JORDAN, T. E. Watershed model calibration using multi-objective optimization and multi-site averaging. Journal of Hydrology, v. 380, n. 3, p. 277-288, 2010.

LIM, K. J. et al. GIS-based sediment assessment tool. Catena, v. 64, n. 1, p. 61-80, 2005.

LIMA, J. M. et al. Dispersão do material de solo em água para avaliação indireta da erodibilidade de latossolos. Revista Brasileira de Ciência do Solo, v. 14, n. 1, p.85-90, 1990.

LIU, Z. J.; WELLER, D.E. A Stream network model for integrated watershed modeling.

Environmental Modelling \& Assessment, v. 13, n. 2, p. 291-303, 2007.

LOMBARDI NETO, F. Erodibilidade de solos do estado de São Paulo avaliada por atributos físicos e químicos. In: REUNIÃO BRASILEIRA DE MANEJO E CONSERVAÇÃO DO SOLO E DA ÁGUA, 10., 1994, Florianópolis. Anais... Florianópolis: Universidade Federal de Santa Catarina, 1994.

LOMBARDI NETO, F.; BERTOLINI, J. Erodibilidade de solos paulistas. Campinas: Instituto Agronômico de Campinas, 1975. (Boletim Técnico, $\mathrm{n}^{\circ} 28$ ).

LOMBARDI-NETO, F.; BERTOLINI, J. Tolerância de perdas de terra para solos do estado de São Paulo. Campinas: IAC, 1975. (IAC Boletim Técnico, 28).

LOMBARDI NETO, F.; MOLDENHAUER, W.C. Erosividade da chuva - sua distribuição e relação com perdas de solo em Campinas, SP. In: ENCONTRO NACIONAL DE PESQUISA SOBRE SOLO, 3., 1980, Recife. Anais... Recife: UFRPE, 1980.

LOMBARDI NETO, F. et al. Nova abordagem para cálculo de espaçamento entre terraços. In: SIMPÓSIO SOBRE TERRACEAMENTO AGRÍCOLA, Campinas, 1988. Anais... Campinas, Fundação Cargill, 1989. p. 99-124.

LUBITZ, E.; PINHEIRO, A.; KAUFMANN, V. Simulação do transporte de sedimentos, nitrogênio e fósforo na bacia do Ribeirão Concórdia, SC. RBRH: revista brasileira de recursos hídricos, v. 18, n. 2 , p. 39-54, 2013. 
MACHADO, R. E. Simulação de escoamento e de produção de sedimentos em uma microbacia hidrográfica utilizando técnicas de modelagem e geoprocessamento. 2002. 166p. Tese (Doutorado) - Ecola Superior de Agricultura “ Luiz de Queiroz”, Universidade de São Paulo, São Paulo, 2002.

MACHADO, R. E.; VETTORAZZI, C. A. Simulação da produção de sedimentos para a microbacia hidrográfica do Ribeirão dos Marins (SP). Revista Brasileira de Ciência do Solo, v. 27, n. 4, 2003.

MADSEN, H. Automatic calibration of a conceptual rainfall-runoff model using multiple objectives. Journal of Hydrology, v. 235, p. 3-4, p. 276-288, 2000.

MALAGÓ, A. et al. Modelling water and nutrient fluxes in the Danube River Basin with SWAT. Science of the Total Environment, v. 603, p. 196-218, 2017.

MANNIGEL, A. R. et al. Fator erodibilidade e tolerância de perda dos solos do Estado de São Paulo. Acta Scientiarum. Agronomy, v. 24, p. 1335-1340, 2002.

MAPA geológico do estado de São Paulo: folha campinas. Escala 1:250.000. São Paulo:

Departamento de Águas e Energia Elétrica do Estado de São Paulo; Universidade Estadual Paulista, 1982.

MARCOMIN, F. E. Análise ambiental da bacia hidrográfica do Rio Pinheiros (Municípios de Orleans e São Rudgero, SC) com base na caracterização e diagnóstico dos elementos da paisagem e da perda de solo por erosão laminar. 2002. 174p. Tese (Doutorado) - Programa de Pós-Graduação em Ecologia e Recursos Naturais, Universidade Federal de São Carlos, 2002.

MCCARTHY, G. T. The Unit hydrograph and flood routing. In: CONFERENCE OF THE NORTH ATLANTIC DIVISION, 1938. Proceedings... New London: U.S. Engineer Department, 1938.

McCOOL, D. K.; FOSTER, G. R.; WEESIES, G. A. Slope length and steepness factor. In: PREDICTING soil erosion by water - a guide to conservation planning with Revised Universal Soil Loss Equation (RUSLE). Washington: US Government Printing Officie, 1997. (Agriculture Handbook, n.703).

ME, W.; ABELL, J. M.; HAMILTON, D. P. Effects of hydrologic conditions on SWAT model performance and parameter sensitivity for a small, mixed land use catchment in New Zealand. Hydrology and Earth System Sciences, v. 19, n. 10, p. 4127, 2015.

MELONE, F. et al. Review and selection of hydrological models - integration of hydrological models and meteorological inputs. Italy: Gennaio, 2005. (Contract $n^{\circ} 12$ ).

MEMARIAN, H. et al. SWAT-based hydrological modelling of tropical land-use scenarios. Hydrological Sciences Journal, v. 59, n. 10, p. 1808-1829, 2014.

MENESES, B. M. et al. Land use and land cover changes in Zêzere watershed (Portugal) -water quality implications. Science of the Total Environment, v. 527, p. 439-447, 2015.

MERTEN, G. H.; MINELLA, J. P. Qualidade da água em bacias hidrográficas rurais: um desafio atual para a sobrevivência futura. Agroecologia e Desenvolvimento Rural Sustentável, v. 3, n. 4, p. 33-38, 2002.

METCALF; EDDY, Inc. University of Florida, and Water Resources Engineers, Inc. Storm water management model. Washington: EPA, 1971. v. 1—Final report. (EPA Report n ${ }^{\circ} 11024 D O C 07 / 71$ - NITS PB-203289). 
MICHAUD, J.; SOROOSHIAN, S. Comparison of simple versus complex distributed runoff models on a midsized semiarid watershed. Water Resources Research, v. 30, n. 3, p. 593-605, 1994.

MIDDLETON, H. E. Properties of soils which influence soil erosion. Washington: D. C. USDA, 1930. (Technical Bulletin, 178)

MINELLA, J. P.; MERTEN, G. H.; RUHOFF, A. L. Utilização de métodos de representação espacial para cálculo do fator topográfico na equação universal de perda de solo revisada em bacias hidrográficas. Revista Brasileira de Ciência do Solo, v. 34, n. 4, p. 1455-1462, 2010.

MINELLA, J. P. et al. Identificação e implicações para a conservação do solo das fontes de sedimentos em bacias hidrográficas. Revista Brasileira de Ciência do Solo, v. 31, n.6, p. 1637-1646, 2007.

MISHRA, A.; KAR, S.; SINGH, V. P. Prioritizing structural management by quantifying the effect of land use and land cover on watershed runoff and sediment yield. Water Resources Management, v. 21, n. 11, p. 1899-1913, 2007.

MOCKUS, V. Land use and treatment classes. In: PART 630 hydrology national engineering handbook. Washington: United States Department of Agriculture; Natural Resources Conservation Service, 2002. Cap.8, p.8.1-8.5.

MOCKUS V. Hydrologic soil groups. In: PART 630 hydrology national engineering handbook. Washington: United States Department of Agriculture; Natural Resources Conservation Service, 1964. Cap.7, p.7.1-7.5.

MOCKUS V. Estimation of direct runoff from storm rainfall. In: PART 630 hydrology national engineering handbook. Washington: United States Department of Agriculture; Natural Resources Conservation Service, 1972. Cap.10, p.10.1-10.17.

MOORE, I. D.; BURCH G. J. Physical basis of the length-slope factor in the Universal Soil Loss Equation. Soil Science Society of America Journal, v. 50, p. 1294-1298, 1986.

MOORE, I. D.; NIEBER, J. L. Landscape assessment of soil erosion and nonpoint source pollution. Journal of the Minnesota Academy of Science, v. 55, n. 1, p. 18-25, 1989.

MOORE, I. D.; GRAYSON, R. B.; LADSON. A. R. Digital terrain modelling: a review of hydrological, geomorphological, and biological applications. Hydrological processes, v.5, p. 3-30, 1991.

MORAIS, L. F. B. et al. Índice EI30 e sua relação como coeficiente de chuva do sudoeste do Mato Grosso. Revista Brasileira de Ciência do Solo, v. 15, p. 339-344, 1991.

MORGAN, R. P. C. Soil erosion and conservation. London: Longman Scientific and Technical, 1995.

MORGAN, R. P. C. et al. The European Soil Erosion Model (EUROSEM): a dynamic approach for predicting sediment transport from fields and small catchments. Earth Surface Processes and Landforms, v. 23, n. 6, p. 527-544, 1998.

MORIASI, D. N. et al. Model evaluation guidelines for systematic quantification of accuracy in watershed simulations. Transactions of the ASABE, v. 50, n. 3, p. 885-900, 2007. 
MULETA, M. K. Improving model performance using season-based evaluation. Journal of Hydrologic Engineering, v. 191, p. 191-200, 2012.

NAEF, F. Can we model the rainfall-runoff process today? / Peut-on actuellement mettre en modèle le processus pluie-écoulement?. Hydrological Sciences Journal, v. 26, n. 3, p. 281-289, 1981.

NASH, J. E.; SUTCLIFFE, J. V. River flow forecasting through conceptual models part I-A discussion of principles. Journal of Hydrology, v. 10, n. 3, p. 282-290, 1970.

NATIONAL engineering handbook. Washington: USDA; Michigan: Natural Resources Conservation Service, 1972. p.101-1023.

NEITSCH, S. L. et al. Soil and water assessment tool, theoretical documentation: version 2000. Temple: Blackland Research Center, Texas Agricultural Experiment Station, 2001.

Soil and water assessment tool user's manual: version 2000. Texas: Texas Water Resources Instititue, College Station, 2002. (GSWRL Report 02-02, BRC Report 02-06, TR-192).

Soil and water assessment tool theoretical documentation. Temple: Soil and Water Research Laboratory, 2005.

Soil and water assessment tool theoretical documentation: version 2009. Texas: Texas Water Resources Institute, 2009.

NEJADHASHEMI, A. P.; WARDYNSKI, B. J.; MUNOZ, J. D. Large-scale hydrologic modeling of the michigan and wisconsin agricultural regions to study impacts of land use changes. Transactions of the ASABE, v. 55, p. 821-838, 2012.

NIRAULA, R. et al. Identifying critical source areas of nonpoint source pollution with SWAT and GWLF. Ecological Modelling, v. 268, p. 123-133, 2013.

NOVO, A. L. et al. Dairy production and beef in Brazil: Competing claims on land use in São Paulo State. Journal of Peasant Studies, v. 37, p. 769-792, 2010.

OLIVEIRA, J. B., PRADO, H. Levantamento pedológico semidetalhado do estado de São Paulo: memorial descritivo. Campinas: IAC, 1984.

OLIVEIRA JUNIOR, R. C. A Erosividade das chuvas na parte leste do estado do Pará. 1988. 52p. Dissertação (Mestrado) - Faculdade de Ciências Agrárias do Pará, Belém, 1988.

OLIVEIRA JUNIOR, R. C.; MEDINA, B. F. A Erosividade daschuvas em Manaus (AM). Revista Brasileira de Ciência do Solo, v. 14, p. 235-239, 1990.

OUYANG, B.; BARTHOLIC, J. Predicting sediment delivery ratio in saginaw bay watershed. In: ANNUAL CONFERENCE OF THE NATIONAL ASSOCIATION OF ENVIRONMENTAL PROFESSIONALS CONFERENCE: held in conjunction with the ERE'97, environmental resources expo, 22., 1997, Orlando. Proceedings...Washington: FAEP; NAEP, 1997. p. 659-671.

PIKOUNIS, M. et al. Application of the SWAT model in the Pinios river basin under different landuse scenarios. Global Nest: international journal, v. 5, n. 2, p. 71-79, 2003.

PONCE, V. M. Engineering hydrology, principles and practices. Englewood Cliffs: Prentice Hall, 1989. 
PONCE, V. M.; HAWKINS, R. H. Runoff curve number: Has it reached maturity? Journal of Hydrologic Engineering, v. 1, n. 1, p. 11-19, 1996.

QUYEN, N. T. N.; LIEM, N. D.; LOI, N. K. Effect of land use change on water discharge in Srepok watershed, Central Highland, Viet Nam. International Soil and Water Conservation Research, v. 2, n. 3, p. 74-86, 2014.

RABELO, J. L.; WENDLAND, E. Assessment of groundwater recharge and water fluxes of the Guarani Aquifer System, Brazil. Hydrogeology Journal, v. 17, n. 7, p. 1733, 2009.

RALLISON, J. M. Note on the time-dependent deformation of a viscous drop which is almost spherical. Journal of Fluid Mechanics, v. 98, n. 3, p. 625-633, 1980.

RANDALL, M.; MULETA, M. Modeling erosion and sedimentation processes in the chorro creek subwatershed to evaluate and develop effective watershed management approaches. In: BEIGHLEY II, R.E.; KILLGORE, M.W. (Ed.). World environmental and water resources congress 2011: bearing knowledge for sustainability. Reston: ASCE, 2011. p. 2881-2889.

RENARD, K. G. et al. RUSLE: revised universal soil loss equation. Journal of Soil and Water Conservation, v. 46, n. 1, p. 30-33, 1991.

RENFRO, W. G. Use of erosion equation and sediment delivery ratios for predicting sediment yield. In: PRESENT AND PROSPECTIVE TECNOLOGY FOR PREDICTING SEDIMENT YIELDS AND SOURCES, 1975, Washington. Proceedings... Washington: US Department of Agriculture, Agricultural Research Service, 1975. p. 33-45. (ARS-S-40).

RIDGWAY, R.L.; LLOYD, E.P.; CROSS, W.H. (Ed.). Cotton insect management with special reference to the boll weevil. Washington: US Department of Agriculture, 1978. p. 534. (Agriculture Handbook, n.589).

RODRIGUES, E. L. et al. Impact of changes in land use in the flow of the Pará River Basin, MG. Revista Brasileira de Engenharia Agrícola e Ambiental, v. 19, n. 1, p. 70-76, 2015.

RODRÍGUEZ-BLANCO, M. L. et al. Sediment yield at catchment scale using the SWAT (Soil and Water Assessment Tool) model. Soil Science, v. 181, n. 7, p. 326-334, 2016.

RODRÍGUEZ-BLANCO, M. L.; TABOADA-CASTRO, M. M.; TABOADA-CASTRO, M. T. Linking the field to the stream: Soil erosion and sediment yield in a rural catchment, NW Spain. Catena, v. 102, p. 74-81, 2013.

ROEHL, J.E. Sediment source areas, and delivery ratios influencing morphological factors. International Association Hydrological Science, v. 59, p. 202-213, 1962.

ROLOFF, G.; DENARDIN, J.E. Estimativa simplificada da erodibilidade do solo. In. REUNIÃO BRASILEIRA DE MANEJO E CONSERVAÇÃ̃O DO SOLO E DA ÁGUA, 10., 1994, Florianópolis. Anais... Florianópolis: Sociedade Brasileira de Ciência do Solo, 1994. p. 150-151.

RUDORFF., B. F. T. et al. Studies on the rapid expansion of sugarcane for ethanol production in São Paulo State (Brazil) using Landsat Data. Remote Sensing, v. 2, n. 4, p. 1057-1076, 2010.

RUFINO, R. L.; BISCAIA, R. C. M.; MERTEN, G. H. Determinação do potencial erosivo da chuva do Estado do Paraná através de pluviometria: Terceira aproximação. Revista Brasileira de Ciência do Solo, v. 17, p. 439-444, 1993. 
SADEGHI, S. H. R. et al. Is MUSLE apt to small steeply reforested watershed? Journal of Forest Research, v. 12, n. 4, p. 270-277, 2007.

SANTOS, C. C. et al. Assessing the effects of land cover and future climate conditions on the provision of hydrological services in a medium-sized watershed of Portugal. Hydrological Processes, v. 30, n. 5, p. 720-738, 2016.

SANTOS, F. M.; OLIVEIRA; R. P. O.; MAUAD; F. M. Lumped versus distributed hydrological modeling of the Jacaré-Guaçu Basin, Brazil. Journal of Environmental Engineering, v. 144, n. 8 , p. 04018056, 2018.

SANTOS, G. G.; GRIEBELER, N. P.; OLIVEIRA, L. F. C. Chuvas intensas relacionadas à erosão hídrica. Revista Brasileira de Engenharia Agrícola e Ambiental, v. 14, n. 2, p. 115-123, 2010.

SANTOS, M. et al. A Dinâmica fluvial da bacia hidrográfica do Córrego Cachoeirinha no município de Cáceres MT- Brasil. Enciclopédia Biosfera, v. 9, n. 17, 2013.

SARTOR, J. D.; BOYD, G. B. Water pollution aspects of street surface contaminants. Washington DC: U.S. Environmental Protection Agency, 1972.

SAXTON, K. E.; RAWLS, W. J. Soil water characteristic estimates by texture and organic matter for hydrologic solutions. Soil science society of America Journal, v. 70, n. 5, p. 1569-1578, 2006.

SCHNEIDERMAN, E. M., et al. Modeling the hydrochemistry of the Cannonsville watershed with Generalized Watershed Loading Functions (GWLF). JAWRA Journal of the American Water Resources Association, v. 38, n. 5, p. 1323-1347, 2002.

SCHNEIDERMAN, E. M. et al. Incorporating variable source area hydrology into a curve-numberbased watershed model. Hydrological Processes, v. 21, n. 25, p. 3420-3430, 2007.

SHARPLEY, A. N.; SYERS, J. K. Phosphorus inputs into a stream draining an agricultural watershed. Water, Air, and Soil Pollution, v. 11, n. 4, p. 417-428, 1979.

SHERMAN, I. K. Streamflow from rainfall by the unit hydrograph method. Engineering News Record, v. 106, p. 501505, 1932.

SHI, Z. H. et al. Soil conservation planning at the small watershed level using RUSLE with GIS: a case study in the Three Gorge Area of China. Catena, v. 55, n. 1, p. 33-48, 2004.

SHRESTHA, S.; KAZAMA, F. Assessment of surface water quality using multivariate statistical techniques: a case study of the Fuji river basin, Japan. Environmental Modelling \& Software, v. 22, n. 4, p. 464-475, 2007.

SISTEMA INTEGRADO DE GERENCIAMENTO DE RECURSOS HÍDRICOS. Situação de recursos hídricos do estado de São Paulo: 2015. 6.ed. São Paulo: Governo do Estado de São Paulo; Secretaria de Saneamento e Recursos Hídricos; Coordenadoria de Recursos Hídricos, 2017.

SILVA, A. M.; SCHULZ, H. E.; CAMARGO, P. B. Erosão e hidrossedimentação em bacias hidrográficas. São Carlos: RiMa, 2003.

SILVA, J. B. Erosão e escoamento pluvial superficial: Uma experiencia na bacia hidrográfica da glória em Uberlândia-MG. Brazilian Geographical Journal: geosciences and humanities research medium, v. 3, n. 2, 2012. 
SIMMS, A. D.; WOODROFFE, C. D.; JONES, B. G. Application of RUSLE for erosion management in a coastal catchment, southern NSW. In: MODSIM 2003: international congress on modelling and simulation, 2., 2003, Townsville. Proceedings... Townsville: Integrative Modelling of Biophysical, Social and Economic Systems for Resource Management Solutions, 2003. p. 678-683.

SINGH, K. P.; MALIK, A.; SINHA, S. Water quality assessment and apportionment of pollution sources of Gomti river (India) using multivariate statistical techniques - a case study. Analytica Chimica Acta, v. 538, n. 1, p. 355-374, 2005.

SINGH, V. P.; WOOLHISER, D. A. Mathematical modeling of watershed hydrology. Journal of Hydrologic Engineering, v. 7, n. 4, p. 270-292, 2002.

SLOAN, P. G. et al. Modeling surface and subsurface stormflow on steeply-sloping forested watersheds. Lexington: University Kentucky, 1983. (Water Resources Institute Report, 142).

SOUTO, A. R. Análise espacial e temporal da produção de sedimentos em uma microbacia rural com o modelo AGNPS e técnicas de SIG. 1998. 111p. Dissertação (Mestrado) - Escola de Engenharia de São Carlos, Universidade de São Paulo, São Carlos, 1998.

SPRUILL, C. A.; WORKMAN, S.R.; TARABA, J.L. Simulation of daily and monthly stream discharge from small watersheds using the SWAT model. Transactions of the ASAE, v. 43, n. 6 , p. 1431-1439, 2000.

SUGUIO, K. Introdução à sedimentologia. São Paulo: Edgard Blucher, 1973.

SWANEY, D. P.; SHERMAN, D.; HOWARTH, R.W. Modeling water, sediment and organic carbon discharges in the Hudson-Mohawk basin. Estuaries, v. 19, n. 4, p. 833-847, 1996.

THORNTHWAITE, C. W. An Approach toward a rational classification of climate. Geographical Review, v. 38, n. 1, p. 55-94, 1948.

THORNTHWAITE, C. W.; MATTER, J. R. The Water balance. New Jersey: Drexel Institute of Thecnology - Laboratory of Climatology, 1955. (Publications in Climatology, v.III, n.1).

THORNTHWAITE, C. W.; MATHER, J. R. Instructions and tables for computing potential evapotranspiration and the water balance. New Jersey: Drexel Institute of Thecnology Laboratory of Climatology, 1957. (Publications in Climatology, v.X, n.3).

TODINI, E. Hydrological catchment modelling: past, present and future. Hydrologyand Earth System Sciences, v. 11, n. 1, p. 468-482, 2007.

TU, J. Combined impact of climate and land use changes on stream- flow and water quality in eastern Massachusetts, USA. Journal Hydrology, v. 379, n. 3-4, p. 268-283, 2009.

TUCCI, C.E.M. Modelos hidrológicos. Porto Alegre:, Ed.UFRGS, 1998.

TUCCI, C. E. M. et al. Drenagem urbana. Porto Alegre: Ed.UFRGS; ABRH, 1995.

TUNDISI, J.G. Local community involvement in environmental planning and management: focus on river basin management - The Horto/ Itaqueri-Broa reservoir case study. Expert group on Environmental Planning and Management for Local Regional Development: focus on training aspects derived from studies of inland water management. Otsu e Nagoya, Japan, November, 1986. [S.1.:s.n.], 1986. p.10-21. 
UNIDADE HIDROGRÁFICA DE GERENCIAMENTO DE RECURSOS - 5 -

Piracicaba/Capivari/Jundiaí (PCJ). Mapeamento de uso e cobertura da terra. Disponível em: $<$ http://www2.ambiente.sp.gov.br/cpla/mapa-de-uso-e-ocupacao-da-terra-ugrhi-5-pcj/>. Acesso em: 22 mar. 2018.

USACE - U. S. ARMY CORPS OF ENGINEERS HYDROLOGIC ENGINEERING CENTER.

STORM: storage, treatment, overflow runoff model. program users manual. Davis, 1977.

USDA Soil Conservation Service, 1972. National Engineering Handbook. US Government Printing Gtlice, Washington, DC, Hydrology Section 4, Chapters 4-10.

USDA Soil Conservation Service, 1983. National Engineering Handbook. US Government Printing Office, Washington, DC, Hydrology Section 4, Chapter 19.

VAL, L.A. et al. Erosividade das chuvas em Lavras. Ciência Prática., v. 10, p. 187-98, 1986.

VAN GRIENSVEN, A. et al. A Global sensitivity analysis tool for the parameters of multi-variable catchment models. Journal of Hydrology, v. 324, p. 10-23, 2006.

VAN ROMPAEY, A. J. et al. Modelling mean annual sediment yield using a distributed approach. Earth Surface Processes and Landforms, v. 26, n. 11, p. 1221-1236, 2001.

VANONI, V. A. Sedimentation engineering. New York: American Society of Civil Engineers, 1975. (Manual and Report, $n^{\circ} 54$ ).

VANZELA, L.; HERNANDEZ, F. B.; FRANCO, R. A. Influência do uso e ocupação do solo nos recursos hídricos do Córrego Três Barras, Marinópolis. Revista Brasileira de Engenharia Agricola e Ambiental-Agriambi, v. 14, n.1, 2010.

WANG, X. Integrating water-quality management and land-use planning in a watershed context. Journal of Environmental Management, v. 61, n. 1, p. 25-36, 2001.

WILLIAMS, J. R. Sediment routing for agricultural watersheds. Water Resource Bulletin, v.11, n.5, p. $965-974,1975$.

WILLIAMS, J. R.; HAROLD, D. B. Sediment yield computed with universal equation. Journal of the Hydraulics Division, v. 98, n. 12, p. 2087-2098, 1972.

WILLIAMS, J. R.; SHARPLEY, A. N. (Eds.), EPIC - erosion/productivity impact calculator: 1 model documentation. Washington: USDA, 1989. (Technical Bulletin, $\mathrm{n}^{\circ} 1768$ ).

WISCHMEIER, W. H.; SMITH, D. D. Rainfall energy and its relationship to soil loss. Transactions of the American Geophysical Union, v. 39, n. 2, p. 285-291, 1958.

Rainfall-erosion losses from cropland east of the Rocky Mountains, guide for selection of practices for soil and water conservation. Washington: US Department of Agriculture, 1965. (Agriculture Handbook, n.282).

Predicting rainfall erosion losses: a guide to conservation planning. Washington: US Department of Agriculture, 1978. (Agriculture Handbook, n.537).

WISCHMEIER, W. H.; JOHNSON, C. B.; CROSS, B. V. Soil erodibility nomograph for farmland and construction sites. Journal of Soil and Water Conservation, v. 26, p. 189-193, 1971. 
WOLDESENBET, T. A.; ELAGIB, N. A.; RIBBE, L.; HEINRICH, J. Hydrological responses to land use/cover changes in the source region of the Upper Blue Nile Basin, Ethiopia. Science of the Total Environment, v. 575, p. 724-741, 2017.

WORLD METEOROLOGICAL ORGANIZATION. Intercomparison of conceptual models used in operational hydrological forecasting. Geneva, 1975. (Oper. Hydrol. Rep. 7, WMO nº429).

WU, R. S.; HAITH, D. A. GWLF, generalized watershed loading functions user's manual. Ithaca: Deptment of Agricultural \& Biological Engineering, Cornell University, 1989.

WU, W.; HALL, C. A. S.; SCETENA, F. N. Modeling the impact of recent landuse changes on the stream flows in northeastern Puerto Rico. Hydrology Processes, v. 21, p. 2944-2956, 2007.

XAVIER, A. C.; KING, C. W.; SCANLON, B. R. Daily gridded meteorological variables in Brazil (1980-2013). International Journal of Climatology, v. 36, n. 6, p. 2644-2659, 2016.

XU, C. Y.; SINGH, V. P. A Review on monthly water balance models for water resources investigations. Water Resources Management, v. 12, n. 1, p. 20-50, 1998.

YAPO, P. O.; GUPTA, H. V.; SOROOSHIAN, S. Automatic calibration of conceptual rainfall-runoff models: sensitivity to calibration data. Journal of Hydrology, v. 181, n. 1-4, p. 23-48, 1996.

YOUNG, P.C.; PARKINSON, S.; LEES, M. Simplicity out of complexity in environmental modelling: occam's razor revisited. Journal of Applied Statistics, v. 23, n. 2-3, p. 165-210, 1996.

YOUNG. R. A. et al. AgNPS: agricultural non-point-source pollution model: a watershed analysis tool. Washington: USDA-ARS, 1987. (Conservation Research Report, 35).

ZEVENBERGEN, L. W.; THORNE, C. R. Quantitative analysis of land surface topography. Earth Surface Processes and Landforms, v. 12, p. 47-56, 1987.

ZIMMERMANN, C. M.; GUIMARÃES, O. M.; PERALTA-ZAMORA, P. G. Avaliação da qualidade do corpo hídrico do rio Tibagi na região de Ponta Grossa utilizando análise de componentes principais (PCA). Química Nova, v.31, n.7, p. 1727-1732, 2008. 